\title{
DISTRIBUIÇÃO E DINÂMICA DA VARIABILIDADE GENÉTICA EM POPULAÇÕES NATURAIS DE PALMITEIRO (Euterpe edulis MARTIUS)
}

\author{
MAURICIO SEDREZ DOS REIS \\ Engenheiro Agrônomo
}

Orientador: Prof. Dr. PAULO YOSHIO KAGEYAMA

Tese apresentada à Escola Superior de Agricultura "Luiz de Queiroz", da Universidade de São Paulo, para obtenção do título de Doutor em Agronomia, Área de Concentração: Genética e Melhoramento de Plantas.

\section{PIRACICABA}

Estado de São Paulo - Brasil

Fevereiro 1996 
Reis, Mauricio Sedrez dos

Distribuição e dinâmica da variabilidade genética em populaçōes naturais de palmiteiro (Euterpe edulis Martius) / Mauricio Sedrez dos Reis. - Piracicaba, 1996. 210p. : il.

Tese (Doutorado) - Escola Superior de Agricultura Luiz de Queiroz, 1996. Bibliografia.

1. Palmito - Melhoramento 2. Palmito - Variação genética I. Titulo 


\title{
DISTRIBUIÇÃO E DINÂMICA DA VARIABILIDADE GENÉTICA EM POPULAÇÕES NATURAIS DE PALMITEIRO (Euterpe edulis MARTIUS)
}

\author{
MAURÍCIO SEDREZ DOS REIS
}

Aprovada em:

Comissão julgadora :

Prof. Dr. Paulo Yoshio Kageyama

ESALQ/USP

Prof. Dr. Roland Vencovsky

ESALQ/USP

Prof. Dr. Paulo Sodero Martins

ESALQ/USP

Prof. Dr. Rubens Onofre Nodari

CCA/UFSC

Prof. Dr. Aldo Melender de Araujo

CCB/UFRGS

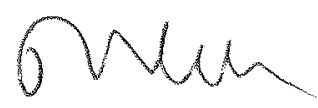

Prof. Dr. Paulo Yoshio Kageyama Orientador 
TOS ESPÍRTOS DR FLORESTA 


\section{AGRADECIMENTOS}

Agradeço a todos que, de alguma forma auxiliaram na realização deste trabalho e que contribuíram para esta importante etapa da minha formação. Em especial,

Ao Prof. Dr. Paulo Yoshio Kageyama pela orientação e oportunidade de realização do meu treinamento;

Ao Prof. Dr. Roland Vencovsky pelas valiosas sugestões e discussões, que muito contribuíram para a minha formação;

Ao Departamento de Fitotecnia da Universidade Federal de Santa Catarina e ao Curso de Pós-Graduação em Genética e Melhoramento de Plantas do Departamento de Genética da ESALQ/USP pela oportunidade de realização do treinamento; Ao Departamento de Engenharia Florestal da ESALQ/USP e IPEF pela cessão da área para produção de parte das plântulas utilizadas;

À Fundação Florestal / Fazenda Intervales, especialmente ao Escritório de Registro, pela permissão e colaboração na coleta e produção de parte das plântulas utilizadas e à Florestal RH / Fazenda Faxinal pela permissão para coleta;

À Financiadora de Estudos e Projetos (FINEP), ao CNPq, à FAO e à FAPEU / UFSC pelo apoio financeiro;

À CAPES / PICD pela concessão da bolsa;

Ao Núcleo de Pesquisas em Florestas Tropicais da UFSC pela cooperação e apoio.

Além disso, estiveram presentes neste trabalho :

Adelar Mantovani, Ademir Reis, Alfredo C. Fantini, Breno Burigo, Édio Sgrot, Elza Guimarães, Elza M. Ferraz, Flávio B. Gandara, Gabriela P. de Oliveira, Joanir Odorizzi, Mey Li M. O. Lima, Miguel P. Guerra, Nadja L. da Cuna, Raquel N. dos Anjos, Ricardo Lang, Rogério G. Franchini, Rubens O. Nodari. 
SUMÁRIO

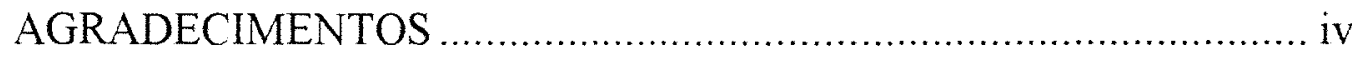

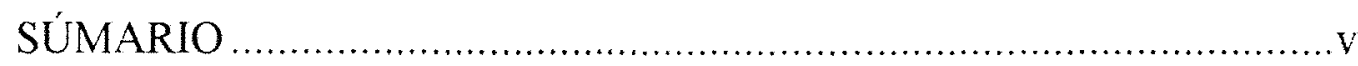

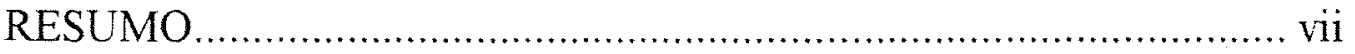

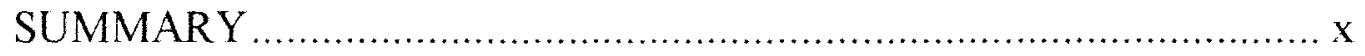

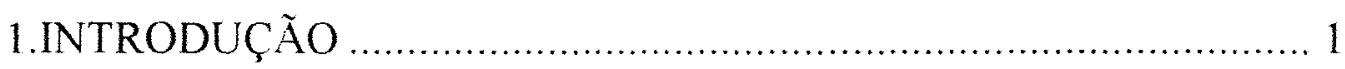

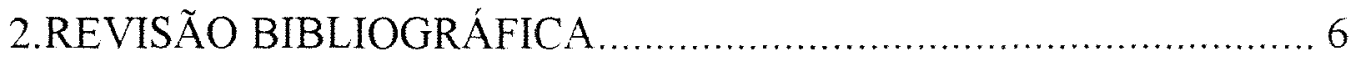

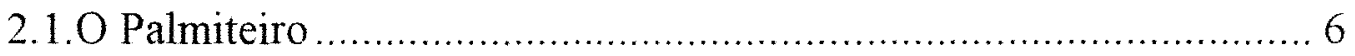

2.2.Diversidade Genética ............................................................ 12

2.3.Estrutura Genética em Populações Naturais................................... 18

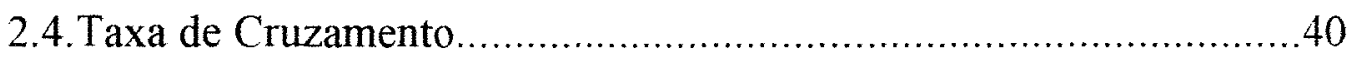

2.5.Fluxo Gênico e Tamanho de Vizinhança .......................................47

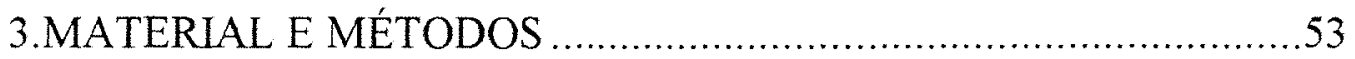

3.1. Características das Áreas de Coleta de Amostras Foliares e Sementes 53

3.1.1.Região do Médio Vale do Itajaí Açu..........................................53

3.1.2. Região do Vale do Rio Ribeira do Iguape .................................56

3.2. Caracterizaçăo Genética das Populações em Estudo .........................58

3.2.1. Tecidos para Eletroforese de Alozimas .....................................58

3.2.2.Procedimentos de Extração de Enzimas e Carregamento do Gel...59

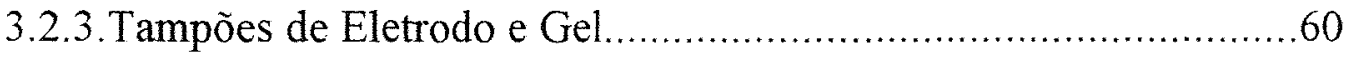

3.2.4. Sistemas Enzimáticos Testados e Procedimentos para Coloração 60

3.2.5.Interpretação dos Zimogramas ....................................................63

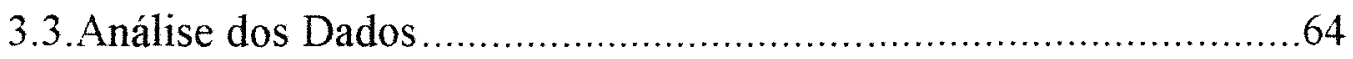

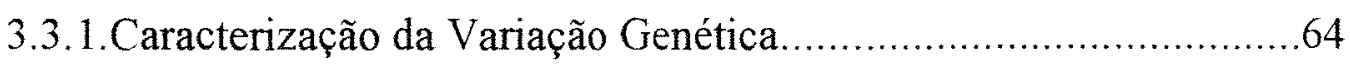

3.3.1.1.Estimativas das Freqüências Alélicas......................................64

3.3.1.2. Estimativas dos Índices de Diversidade ...................................65

3.3.2. Caracterização da Estrutura Genética das Populações..................67

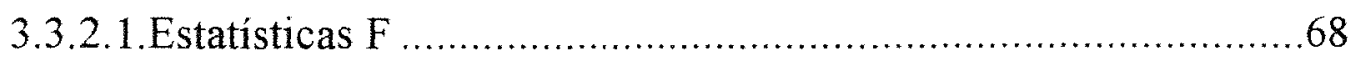

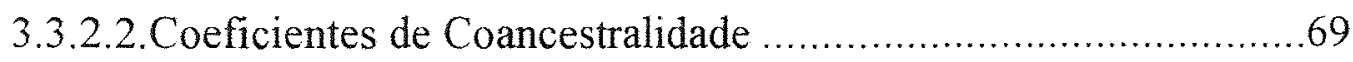


3.3.2.3.Análise da Diversidade em Populações Subdivididas.................80

3.3.3. Caracterização do Sistema Reprodutivo......................................81

3.3.3.1.Teste de Aderência ao Equilíbrio de Panmixia e Endogamia......82

3.3.3.2.Estimativas da Taxa de Cruzamento ........................................82

3.3.3.2.1. Taxa de Cruzamento Aparente ............................................83

3.3.3.2.2.Taxa de Cruzamento Multilocos ...........................................83

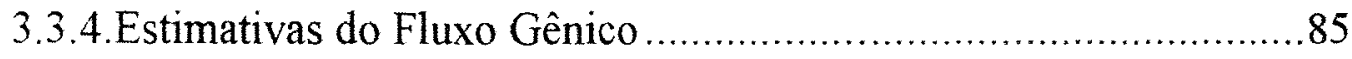

3.3.5. Caracterização da Variação Geográfica .......................................86

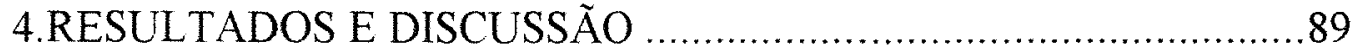

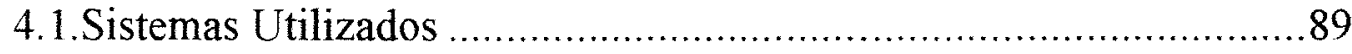

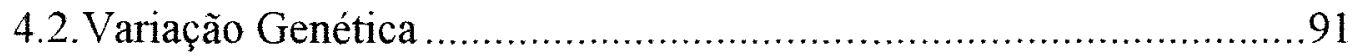

4.3. Organização da Variação Genética Entre e Dentro de Populações 106

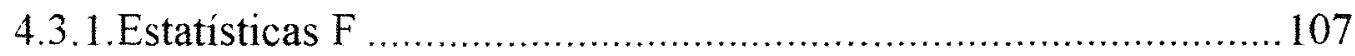

4.3.2. Análise da Diversidade em Populações Subdivididas.................. 111

4.3.3.Estimativas dos Coeficientes de Coancestralidade ..................... 114

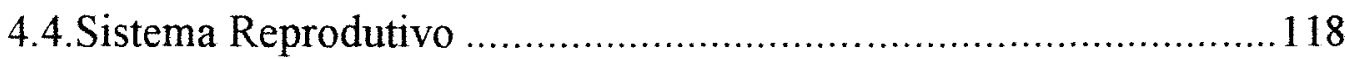

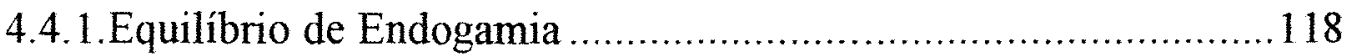

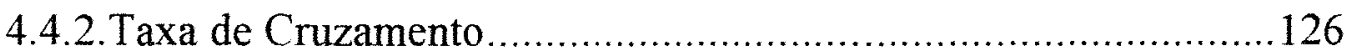

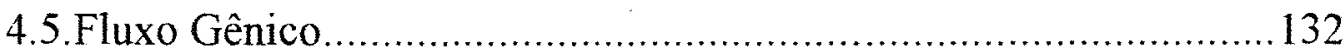

4.6.Associação da Variação Genética com a Distribuição Geográfica.. 136

4.7.Implicações para o Manejo e Conservação de Populações Naturais 147

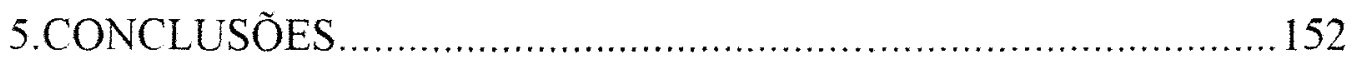

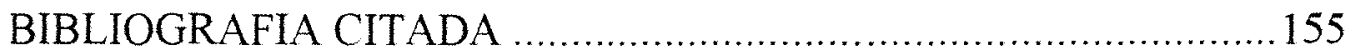

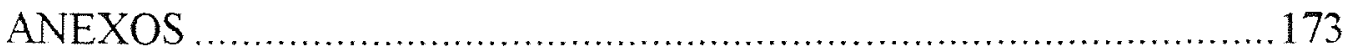


DISTRIBUIÇÃO E DINÂMICA DA VARIAÇÃO GENÉTICA EM POPULAÇÕES NATURAIS DE PALMITEIRO (Euterpe edulis MARTIUS)

Autor : Maurício Sedrez dos Reis
Orientador : Prof. Doutor Paulo Yoshio Kageyama

RESUMO

O palmiteiro (Euterpe edulis Martius) é uma palmeira do sub-bosque da Floresta Tropical Atlântica cujas populações naturais se encontram degradadas pelo extrativismo. Entretanto, apresenta características que indicam ser uma espécie estratégica para a conservação deste ecossistema e adequada para o manejo sustentado de suas populações naturais.

Assim, este trabalho visou gerar informações relativas à distribuição e dinâmica dos alelos em populações naturais da espécie, caracterizando, através de marcadores alozímicos, os niveis e a distribuição da variabilidade genética, a estrutura genética de suas populações, o sistema reprodutivo e o fluxo gênico da mesma. Além disso, procurou avaliar a adequação de diferentes sistemáticas de análise e, principalmente, discutir as perspectivas de utilização dos resultados obtidos. Para tanto, foram coletadas amostras foliares e sementes (progênies) de indivíduos procedentes de regiǒes distintas (Santa Catarina - Município de Blumenau, Vale do Rio Itajaí Açu; São Paulo - Município de Sete Barras, Vale do Rio Ribeira do Iguape). Em São Paulo as coletas foram realizadas na Fazenda Intervales em dois locais; no primeiro - Saibadela - as amostras foram obtidas em três níveis altitudinais $(100,250$ e $350 \mathrm{~m})$, constituindo três populações contíguas; no segundo - Limão - em dois níveis altitudinais $(350$ e $700 \mathrm{~m})$, constituindo duas populações contíguas. Em Santa Catarina, a amostragem foi realizada em apenas um 
local, em três níveis de altitude (450, 550 e $650 \mathrm{~m})$, constituindo três populações contíguas.

A caracterização genética foi realizada empregando-se marcadores alozímicos, revelados a partir de eletroforese em gel de amido (penetrose 30 à 13\%), com tampão Citrato/Morfolina (eletrodo: Ác. Cítrico 7,7 g/l - titular com Morfolina até pH 6,1; gel: diluição 1:20). Foram utilizados os sistemas enzimáticos Peroxidase (4 locos: PRX2 3 alelos; PRX3 5 alelos; PRX4 4 alelos; PRX5 3 alelos), Fosfoglucoisomerase (PGI2 4 alelos), Fosfoglucomutase (PGM1 5 alelos) e Glucose 6 fosfato Desidrogenase (G6P1 3 alelos).

Os resultados obtidos revelaram níveis elevados de heterozigosidade ( $\hat{H} e$ - esperada, Ho observada), tanto a partir das progênies $(\hat{H} e=0,436$ e Ho $=$ 0,403 com 3,9 alelos por loco ), quanto a partir de indivíduos adultos ( $\hat{H} e=0,452 \mathrm{e}$ Ho $=0,467$ com 3,4 alelos por loco). Esta alta diversidade obtida para a espécie apresenta especial relevância, pois as gerações posteriores poderão sempre apresentar novos recombinantes ou mais recombinantes, permitindo adaptação a microambientes e a manutenção da dinâmica populacional.

A estrutura genética foi caracterizada a partir das estimativas das estatísticas $F$ de Wright, dos coeficientes de coancestralidade $(\theta)$ de Cockerham e da análise de populações subdivididas de Nei. Os resultados indicaram menor divergência entre populações contíguas. Estes resultados sugerem a existência de efeitos de deriva e/ou de seleção entre regiões e locais, sendo os mesmos de menor efeito ou contrapostos pelo fluxo gênico entre as populações contíguas. Assim, é razoável considerar o modelo de isolamento por distância, reforçado pelo gradiente altitudinal em escala ampla, que intensifica os efeitos de deriva em decorrência de variações fenológicas, como a forma básica de organização da variabilidade genética na espécie. Além disso, a sistemática de análise empregada para obtenção das estimativas dos coeficientes de coancestralidade, ainda que mais trabalhosa, apresenta a melhor correção dos vieses existentes e, portanto, é recomendável para qualquer tamanho de amostra; adicionalmente, é mais versátil, permitindo estimar a divergência em diferentes níveis de hierarquia sem os efeitos dos níveis superiores, sendo, portanto, especialmente adequada para amostragens hierarquizadas.

O sistema reprodutivo foi caracterizado a partir da avaliação da existência de equilíbrio de panmixia e endogamia, bem como a partir da estimativa da taxa de cruzamento. A média da taxa multilocos de cruzamento foi de 0,99 
da taxa de cruzamento. A média da taxa multilocos de cruzamento foi de 0,99 (variando de 0,94 à 1,04, entre as populações estudadas). Contudo, a inexistência de equilíbrio de endogamia nas progênies indica a ocorrência de eventos adicionais envolvidos no sistema reprodutivo. Os resultados obtidos evidenciam a ocorrência de cruzamentos não aleatórios, associados à amplitude do período de florescimento e à protandria acentuada existente na espécie. Assim, é razoável considerar que a cada ciclo reprodutivo predominam cruzamentos não aleatórios entre os indivíduos, produzindo progênies que não apresentam equilíbrio de panmixia ou endogamia, mesmo quando os indivíduos adultos estão em equilíbrio de panmixia.

O fluxo gênico estimado foi elevado (10,7 indivíduos por geração) e coerente com os mecanismos de dispersão de sementes e polinização descritos para a espécie. A estimativa do tamanho de vizinhança, em termos médios, foi de 67 indivíduos. Adicionalmente, estimativas preliminares da área de vizinhança ficaram entre 18.199 e $8.090 \mathrm{~m}^{2}$, levando à recomendação da manutenção de ao menos 60 indivíduos reprodutivos por hectare nas populações sob manejo.

A coerência dos resultados obtidos e a estratégia de amostragem empregada, com uma cobertura ampla da área e situações de ocorrência, possibilitou a formação de um referencial, em relação aos níveis e distribuição da variação genética, para a coleta de germoplasma, a produção de sementes e o melhoramento da espécie, bem como para o monitoramento das populações naturais sob manejo sustentado. 
Author: Maurício Sedrez dos Reis Adviser: Prof. Dr. Paulo Yoshio Kageyama

SUMMARY

The heart-of-palm tree (Euterpe edulis Martius) is an Atlantic Tropical Forest understory palm tree whose natural populations are degraded by exploitation. However, its features indicate it is a strategic species in the conservation of this ecosystem and suited for a sustainable management of its natural populations.

Thus, the aim of this work was to generate information regarding allele distribution and dynamics in natural populations of the species while characterizing the levels and distribution of the genetic variability, the genetic structure of its populations, the mating system, and its gene flow by means of allozyme markers. Furthermore, it attempted to appraise the adequacy of different analysis methods and mainly discuss the perspectives of use of the results achieved. For such, leaf samples and seeds (progenies) of individuals from distinct regions (Blumenau, Vale do Rio Itajaí Açu - Santa Catarina; Sete Barras, Vale do Rio Ribeira do Iguape - São Paulo) were collected. In São Paulo collecting was accomplished at Intervales Farm at two sites; at the first - Saibadela - samples were obtained at three altitude levels (100, 250 and $350 \mathrm{~m}$ ) constituting three neighboring populations; at the second - Limão at two altitude levels $(350$ and $700 \mathrm{~m})$ constituting two neighboring populations. Sampling in Santa Catarina was done at only one site, at three altitude levels (450, 550 and $650 \mathrm{~m}$ ) constituting three neighboring populations. 
The genetical characterization was performed through allozymic markers revealed from starch gel electrophoresis (Penetrose 30 at 13\%) with Citrate/Morfoline buffer (electrode: Citric Acid $7.7 \mathrm{~g} / 1$ - with Morfolina until $\mathrm{pH}$ 6.1; gel: 1:20 dilution). The Peroxidase (4 loci; PRX2 3 alleles; PRX3 5 alleles; PRX4 4 alleles; PRX5 3 alleles), Phosphoglucomutase (PGM1 5 alleles), Phosphoglucoisomerase (PGI2 4 alleles), and Glucose 6-Phosphate Dehydrogenase (G6P1 3 alleles) enzymatic systems were used.

The results revealed high levels of heterozygosity ( $\hat{H} e$ - expected, Ho observed) both from progenies ( $\hat{H} e=0.436$ and $H_{0}=0.403$, with 3.9 alleles per locus) and from adult individuals ( $\hat{H} e=0.452$ and $\mathrm{Ho}=0.467$, with 3.4 alleles per locus). This high diversity found for the species is specially relevant since succeeding generations will always be able to present new recombinants or more recombinants thus allowing the adaptation to microevironments and maintenance of populations dynamics.

The genetical structure was characterized by Wright's F-statistics estimates, by Cockerham's coancestry coefficients $(\theta)$, and by Nei's subdivided population analysis. The results indicated lower divergence between neighboring populations. In addition, they indicate the existence of significant genetic drift and/or natural selection effects between regions and sites, with lesser effect or opposed gene flow between neighboring populations. Thus, it is reasonable to consider the isolation by distance model reinforced by the wide altitude gradient which intensifies the genetic drift effects as a result of phenological variations such as the basic form of genetic variability organization within the species. Furthermore, the analysis method employed to obtain coancestry coefficient estimates, although labor intensive, reveles the best bias correction ant therefore is recommended for any sample size; moreover, it is more versatile and allows the estimate of divergence at different hierarchy levels without superior level effects, and it is therefore specially suitable for hierarchised samplings.

The mating system was characterized by the evaluation of the existence of panmixy and inbreeding equilibrium as well as from the estimate of outcrossing rate. The average multiloci outcrossing rate was 0.99 (varying from 0.94 to 1.04 between the studied populations). However, the absence of inbreeding equilibrium in progenies indicates the occurrence of additional events involved in the mating system. The results show evidence of non-random mating associated to 
the scope of the blooming period and to the stressed protandry of the species. Thus, it is reasonable to consider that non-random mating between individuals prevail at each mating cycle thus producing progenies failing to present panmixy or inbreeding equilibrium, even when adult individuals are at panmixy equilibrium.

The estimated gene flow was high (10.7 individuals per generation) and coherent with the seed dispersion and pollination events described for the species. The neighborhood size estimate, in average terms, was of 67 individuals. Further, preliminary estimates of the neighborhood area ranged 18,199 to $8,090 \mathrm{~m}^{2}$, pointing to the recommendation of maintenance of at least 60 reproductive individuals per hectare in the populations under management.

The coherence of the results obtained and the sampling strategy employed, with a wide range of the area and occurrence situations made possible the formation of a referential regarding the genetic variation levels and characteristics for germplasm collecting, seed production, and genetic improvement of the species as well as for the monitoring of natural populations under sustainable management. 


\section{INTRODUÇÃO}

O palmiteiro (Euterpe edulis Martius), também conhecido por juçara ou içara, é uma palmeira nativa do domínio da Floresta Tropical Atlântica do Brasil; sua área de ocorrência se estende desde o Sul da Bahia $\left(15^{\circ} \mathrm{S}\right)$ até o Norte do Rio Grande do Sul $\left(30^{\circ} \mathrm{S}\right)$ no litoral, adentrando, no Sul, até o Leste do Paraguai e Norte da Argentina $\left(57^{\circ} \mathrm{W}\right)$.

A espécie apresenta um grande valor econômico por ser a principal produtora do palmito, iguaria consumida especialmente nas regiões Sul e Sudeste do pais. Esse valor econômico fez com que a mesma fosse alvo de uma intensa exploração predatória desde o final da década de 60; o que deixou as suas populações naturais profundamente depauperadas.

Atualmente a exploração continua em áreas relictuais, de forma clandestina e ilegal na grande maioria das situações. No entanto, apesar de predatória, a exploração é a principal fonte de renda para várias comunidades, especialmente na região do Vale do Ribeira no Estado de São Paulo e litoral Norte do Estado de Santa Catarina, garantindo o sustento de várias familias de baixa renda.

Nesse contexto, as possibilidades de utilização da espécie, como fonte adicional de renda, para proprietários rurais têm sido ressaltadas em vários trabalhos (PEDROSA MACEDO et al., s.d.; 1973; YAMAZOE, 1973; LEÃO e CARDOSO, 
1974; CARDOSO e LEÃO, 1974; REITZ et al., 1978, 1983; KLEIN, 1968, 19791980; NEGREIROS, 1982; GUERRA et al., 1984; BOVI et al., 1987a; NODARI et al., 1987; FLORIANO et al., 1987; REIS,A. et al., 1988, 1991, 1992a, b; REIS et al., 1994a, 1996; RIBEIRO et al., 1994; PEREIRA, 1994); evidenciando, assim, a necessidade de aprofundamento no conhecimento da espécie, especialmente em relação ao comportamento de suas populações naturais, devido ao emprego do extrativismo como forma quase exclusiva de exploração da mesma.

O produto obtido, palmito, é facilmente comercializado, sendo integralmente absorvido pela grande demanda existente no mercado interno, mais exigente quanto à qualidade. O mercado externo também apresenta uma razoável demanda, contudo, o palmito destinado à exportação é procedente, na sua quase totalidade, da região Amazônica, obtido a partir de Euterpe oleracea.

Apesar do caráter predatório da exploração contribuir para a degradação da Floresta Tropical Atlântica, E. edulis apresenta um grande potencial para utilização como modelo para manejo de suas populações naturais de forma sustentável. Tal aspecto se deve à sua grande abundância no sub-bosque de toda área coberta pelo domínio da Floresta Tropical Atlântica, grande capacidade de regeneração natural em suas populações naturais, fácil comercialização e intensa interação com a fauna.

Além disso, a intensa interação com a fauna - funcionando como nutridora de grande quantidade de animais (REIS,A., 1995) -, indica ser esta uma espécie estratégica para a manutenção da dinâmica do ecossistema, bem como para a retomada da dinâmica em áreas de formação secundária, como discutem REIS,A. et al. (1992a). 
O elevado valor comercial, o ciclo relativamente curto e a grande abundância de indivíduos dentro das florestas são fatores que favorecem a utilização de um sistema de manejo sustentável para as populações naturais desta espécie, como demonstram REIS et al. (1991, 1996), REIS,A. et al. $(1991,1992 b)$ e RIBEIRO et al. (1994). Neste sentido, os resultados obtidos até o momento, especialmente em RIBEIRO et al. (1994) e REIS et al. (1994a, 1996), permitiram a reestruturação da legislação visando à exploração sustentada das populações naturais do palmiteiro no Estado de São Paulo (Resolução SMA de 16 de junho de 1994 /DPRN-SMA SP, normatizando o Decreto lei 750 de 10 de fevereiro de 1993).

A utilização sustentada das populações naturais da espécie, como proposto por FANTINI et al. (1992a) e discutida nos trabalhos mencionados nos dois parágrafos anteriores, implica numa perspectiva conservacionista, pois pressupõe a manutenção da dinâmica demográfica e estrutura genética das populações naturais, bem como suas interações com as demais espécies do ecossistema, como discutem REIS et al. (1994b).

A proposição de manejo de rendimento sustentado mencionada no parágrafo anterior prevê a retirada de um número de indivíduos, a cada ciclo de corte, que possa ser reposto pelo próprio dinamismo da espécie. Assim, implica no aproveitamento da regeneração natural da mesma, a partir do desenvolvimento dos indivíduos remanescentes e da contínua reposição de propágulos para manutenção do banco de plântulas. Logo, é dependente da permanência de indivíduos reprodutivos nas áreas sob manejo. Ou seja, há necessidade de que um certo número de indivíduos, já em fase reprodutiva, permaneçam para que ocorra a ressemeadura natural. Neste contexto, a manutenção da dinâmica demográfica da espécie é de extrema importância, para que as expectativas de rendimento, a cada ciclo, se 
mantenham; assim, os níveis de variabilidade nas plantas reprodutivas remanescentes e, portanto, a garantia de continuidade do processo será dada pelas possibilidades de ocorrência de recombinantes nas gerações subseqüentes .

Dessa forma, a caracterização dos níveis de variabilidade $\mathrm{e}$ estruturação genética , bem como o entendimento da dinâmica de movimentação dos alelos nas populações naturais da espécie, trarão subsídios para a maximização de estratégias e monitoramento do processo de exploração em regime de rendimento sustentado para o palmiteiro.

Além disso, considera-se que a conservação dos ecossistemas tropicais, e portanto de sua diversidade, definida como a riqueza de espécies e a variabilidade genética dentro de cada espécie, está associada à existência de alternativas que coadunem este aspecto à obtenção de renda para os proprietários da terra.

O papel ecológico da espécie e sua grande abundância no estrato médio da Floresta Tropical Atlântica colocam a mesma numa posição estratégica para conservação deste ecossistema. Tal aspecto tem sido discutido em REIS,A. et al. (1992a) e, especialmente por REIS et al. (1994b). Também KAGEYAMA e GANDARA (1994), discutem a importância da utilização do palmiteiro como um possível referencial de espécie comum, para a definição de estratégias para conservação e manejo de ecossistemas tropicais.

Entretanto, seja para manejo de suas populações naturais em regime de rendimento sustentado, seja para subsidiar estratégias de conservação de ecossistemas naturais, estudos relativos à autoecologia da espécie se fazem necessários. Em especial os estudos relativos à dinâmica demográfica e à 
movimentação dos alelos em populações naturais, como discutem OYAMA (1993) e REIS et al. (1994b).

Nesta perspectiva, e considerando a escassez de informações relativas à distribuição e dinâmica dos alelos em populações naturais de Euterpe edulis, este trabalho tem por objetivos :

1. Quantificar os níveis de variabilidade genética em populações naturais da espécie;

2. Avaliar a distribuição desta variabilidade em nível local e regional;

3. Caracterizar os níveis de estruturação associados à distribuição da variabilidade.

E, numa perspectiva mais dinâmica:

4. Determinar a taxa de cruzamento nas populações naturais;

5. Determinar os níveis de fluxo gênico entre as populações; bem como definir o tamanho de vizinhança nas populações naturais da espécie.

Além disso, a diversidade de abordagens de análises visando o alcance dos objetivos mencionados acima, especialmente no que se refere à caracterização da estrutura genética, sugere a necessidade de :

6. Discutir e avaliar a adequação de diferentes alternativas de análises relativas à caracterização dos níveis de estruturação genética de populações naturais. 


\section{REVISÃO BIBLIOGRÁFICA}

\subsection{O Palmiteiro}

Como mencionado na Introdução, o palmiteiro (Euterpe edulis Martius) apresenta sua distribuição por toda a área de abrangência do domínio da Floresta Tropical Atlântica (Figura 1), assumindo sempre elevados índices de abundância e freqüência no estrato médio das formações florestais deste ecossistema.

A grande abundância do palmiteiro na floresta foi inicialmente caracterizada nos trabalhos de VELOSO e KLEIN (1957, 1959), e decorre de ser esta a espécie de maior ocorrência no extrato médio da Floresta Ombrófila Densa. Em seus levantamentos, estes autores observaram até 1000 indivíduos por hectare com altura superior a $1,5 \mathrm{~m}$., sendo sempre a espécie com maior freqüência e abundância no estrato médio (sub-bosque). Tais dados têm sido confirmados em estudos mais recentes que apresentam dados relativos à demografia da espécie (NEGREIROS, 1982; NODARI et al., 1987; REIS et al., 1991,1994a; FANTINI et al., 1993; REIS,A., 1995), mesmo em formações secundárias ou pequenos relictos (SILVA, 1991; ALVES, 1994; REIS et al., 1996). 


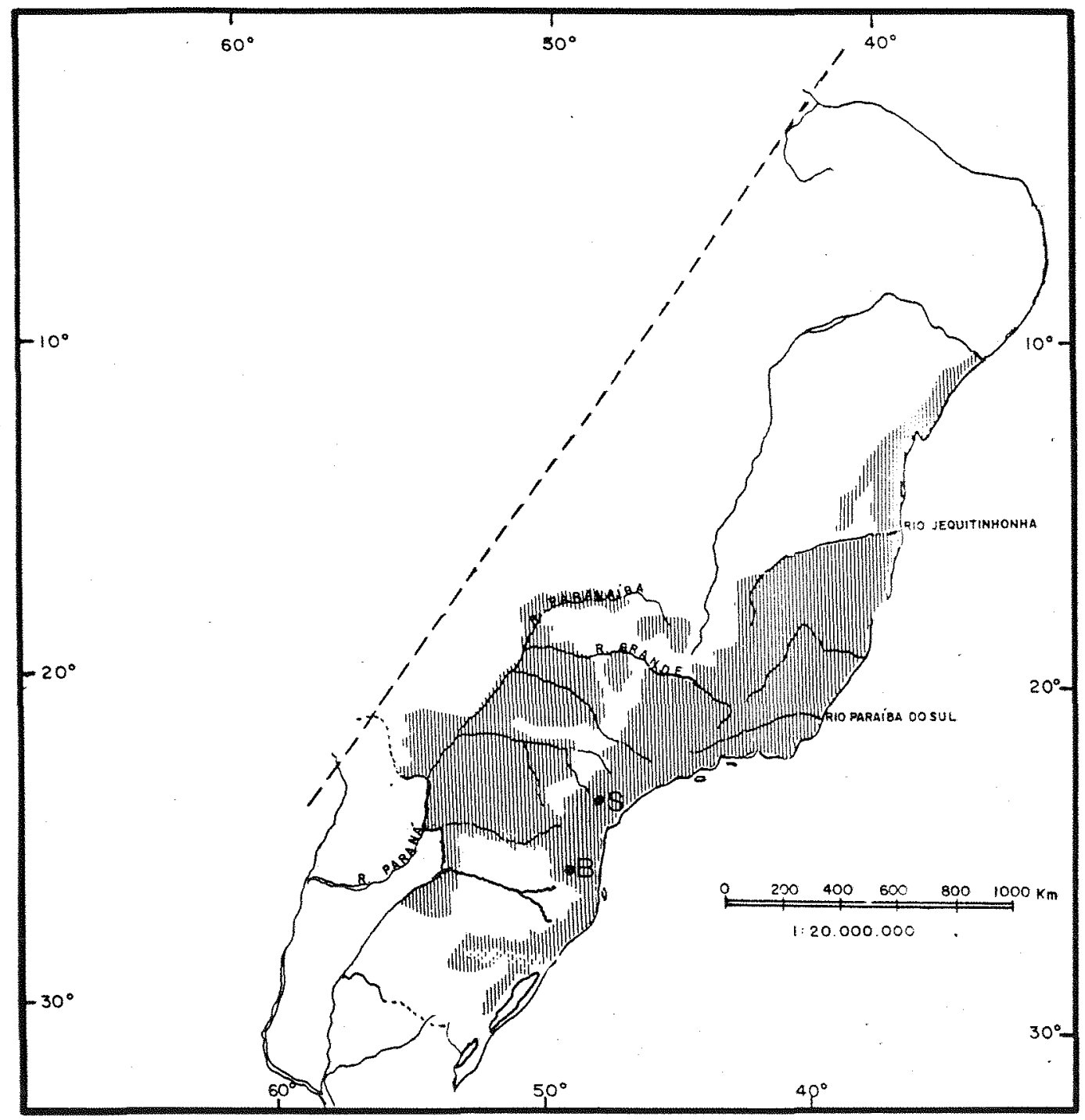

Figura 1. Área de ocorrência natural do palmiteiro (Euterpe edulis Martius), abrangendo o domínio da Floresta Tropical Atlântica (adaptado de REIS et al., 1996), e indicação dos locais de coleta das emostras empregas neste trabalho (BBlumenau / Santa Catarina; S- Sete Barras / São Paulo). Piracicaba-SP, ESALQ/USP, 1996. 
A espécie apresenta, conforme descrito por REITZ (1974), inflorescências em forma de panícula, com ráquilas que apresentam dezenas de tríades florais, compostas de duas flores masculinas e uma flor feminina. A abertura das flores se dá com uma forte dicogamia protândrica na inflorescência, conforme mencionam REIS et al. (1993). Somente após o encerramento da florada masculina é que se inicia a abertura das flores femininas, implicando em garantia de fecundação cruzada, exceto para os casos em que se desenvolvem duas ou mais inflorescências por planta, evento de freqüência reduzida dentro da Floresta $(6,4 \%$ das plantas, REIS et al.,1993), e há coincidência das floradas masculina e feminina entre as inflorescências, conforme discutem os autores.

Além disso, os resultados obtidos por REIS et al. (1988, 1994a, 1996) e REIS,A. (1995) indicam ser o palmiteiro uma espécie com estratégia de formação de banco de plântulas (Figura 2), apresentando em média 12.000 plântulas (altura da inserção inferior a $10 \mathrm{~cm}$.) por hectare (REIS et al., 1996).

A abundante produção de frutos e o amplo período de fornecimento destes apresentam especial relevância na manutenção da fauna, pois grande diversidade de animais, como aves e mamíferos de médio e grande porte, utilizam estes frutos na sua dieta básica (REIS,A., 1995). Por sua vez, a fauna é responsável pela dispersão dos frutos, implicando numa contribuição imprescindível para a manutenção da dinâmica demográfica e do fluxo gênico da espécie (REIS, et al. 1994b). Tal aspecto apresenta especial relevância na retomada da dinâmica de formações secundárias, pois a atração de vetores de dispersão de sementes (fauna) implicará na vinda de novas sementes, aumentando a diversidade nestas áreas e dando continuidade ao processo de sucessão (REIS,A. et al., 1992a; REIS,A., 1993). 


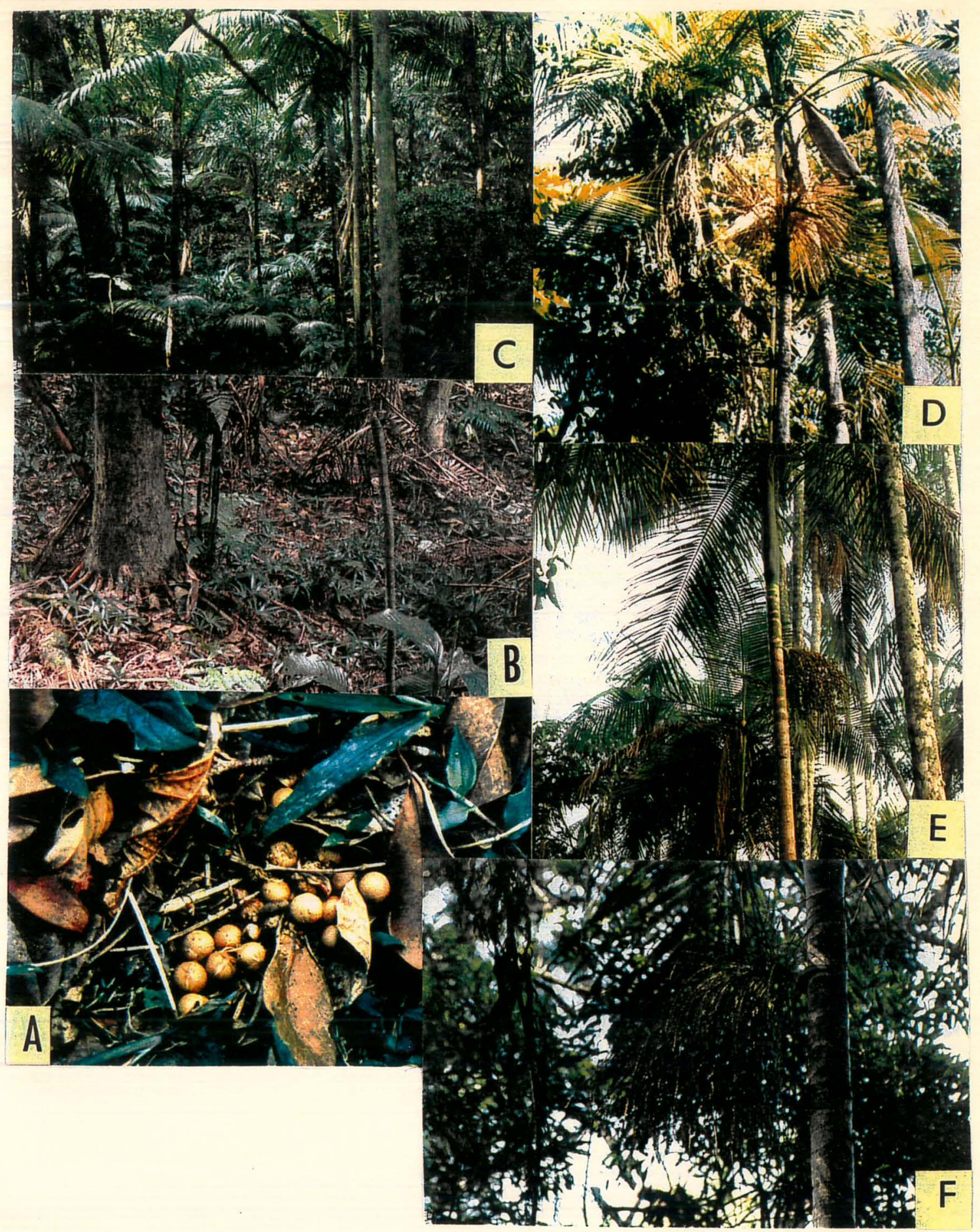

Figura 2. Aspectos da dinâmica demográfica do palmiteiro (Euterpe edulis Martius): a)frutos, despolpados pelos dispersores, no solo; b) banco de plântulas; c) plantas jovens em processo de recrutamento; d) planta reprodutiva (adulta) em floração (florada masculina);e) planta reprodutiva com frutos verdes; f) planta reprodutiva com frutos maduros. Piracicaba-SP, ESALQ/USP, 1996. (fotos: a,d - P.Y. Kageyama, 1992; b,c - A.F. Reis, 1993; e,f - M.S. Reis, 1994) 
Além disso, o pólen produzido em abundância, os exsudados e as próprias partes da inflorescência (Figura 2) são recursos alimentares procurados por grande diversidade de insetos, que visitam intensamente as inflorescências de Euterpe edulis durante o seu amplo período de florescimento (REIS et al.,1993).

Desta forma a espécie apresenta, além de valor econômico e importância social, um grande valor ecológico, se aproximando do conceito de "keystone" de TERBORGH (1986).

A utilização do palmiteiro em regime de rendimento sustentado, como discutida na Introdução, traz efeitos ambientais benéficos, uma vez que a própria característica da espécie - desenvolver-se no estrato médio, à sombra das espécies que ocupam o dossel - implica na necessidade de manejá-la dentro da floresta original, ou em áreas já perturbadas, mas que ainda tenham uma cobertura arbórea. Isto significa que se deva conservar a floresta para que possa haver produção de palmito (FLORIANO et al., 1987; FANTINI et al., 1992a;. REIS et al., 1994a, b, 1996; REIS,A. et al., 1994).

Aspectos genéticos de E. edulis têm sido estudados, principalmente, caracterizando a variabilidade em fases iniciais de desenvolvimento de plântulas em ensaios de procedência e progênie, como em NODARI et al. (1993) e REIS et al. (1992), ou estabelecendo bases para programas de seleção através da caracterização de correlações entre plantas jovens e adultas (BOVI e GODOY JR., 1991).

NODARI et al. (1993) avaliaram características de desenvolvimento de plantas em progênies de três procedências distintas do Estado de Santa Catarina, até os seis anos. Os resultados revelaram herdabilidades reduzidas em todas as situações analisadas; além disso, os autores (NODARI e REIS, 1995) sugerem modificações na sistemática de utilização destes testes para estudos com espécies formadoras de 
banco de plântulas. Por sua vez, REIS et al. (1992) avaliaram as variações no período germinativo de propágulos de 25 matrizes, caracterizando comportamentos distintos entre matrizes, com um período de germinação superior a um ano, em alguns casos. Os resultados, apesar de envolverem efeitos maternais, revelaram uma estratégia adaptativa importante, pois indicam a possibilidade de formação de um banco efêmero de sementes, o que permite a entrada gradual dos indivíduos, a cada geração, no banco de plântulas.

O trabalho de BOVI e GODOY JR. (1991) avalia os ganhos esperados com seleção precoce, a partir do acompanhamento de 177 indivíduos por 10 anos. Os resultados indicaram que o número de folhas e o diâmetro do caule são as características de maior relação com a produção e apresentam estimativas expressivas de ganho por seleção a partir do terceiro ano.

Outros trabalhos, como REIS,A. et al. (1987), BOVI et al. (1991) e FANTINI et al. (1992b), procuram caracterizar as relações entre diversas características das plantas e o rendimento, visando seleção indireta e/ou manejo e comercialização da espécie. Tais trabalhos indicaram as maiores associações entre o diâmetro das plantas, o número de folhas $\mathrm{e}$ as variáveis relativas à cabeça do palmito, com o rendimento.

Alguns trabalhos têm sido realizados no sentido de adequar a espécie ou híbridos interespecíficos ( E. oleraceae $\mathrm{x}$ E. edulis) a plantios comerciais em associação com outras espécies (BOVI et al., 1987a, b; CAMPOS et al., 1991), especialmente na sua fase inicial de desenvolvimento; pois a espécie, em condições naturais, se desenvolve no sub-bosque, portanto, à sombra das demais, sendo, assim, tipicamente esciófila, como caracterizam KLEN (1974) e REITZ et al. (1978) . Contudo, os resultados indicam que o híbrido apresenta variações para algumas 
características de interesse, como o afilhamento (BOVI et al., 1987b). Por sua vez, os plantios comerciais podem apresentar bons resultados, mas não prescindem de uma cultura para produzir um sombreamento inicial e necessitam de regeneração artificial a cada ciclo de corte.

\subsection{Diversidade Genética}

$O$ conceito de diversidade tem sido empregado em dois sentidos distintos e complementares. O primeiro se refere a riqueza de espécies existente em um ecossistema, como discutido em WOLDA (1981) e LUDWIG e REYNOLDS (1988). O segundo, proposto por NEI (1973), se refere ao nível de heterozigosidade de uma população obtido a partir das freqüências alélicas desta. Este valor é o complemento da identidade genética, ou a probabilidade de não identidade, e equivale à quantidade de heterozigotos esperada (heterozigosidade) em uma população de cruzamentos ao acaso (panmítica). Assim, independente de efeitos de migração, seleção, mutação ou sistema reprodutivo, este valor permite uma idéia do nível de variação genética em uma população de uma determinada espécie. $O$ sentido genético, a nível populacional, conforme proposto por NEI (1973), será o significado dado à diversidade neste trabalho.

WEIR (1990a) considera a freqüência de heterozigotos como um importante indicador da diversidade genética, uma vez que cada heterozigoto carrega alelos diferentes e, portanto, representa melhor a variação existente. Contudo, o autor considera que a heterozigosidade esperada, ou diversidade gênica, como 
proposto por NEI (1973), uma medida mais apropriada por representar a variação tanto em populações de espécies autógamas, como em alógamas.

Além da heterozigosidade, têm sido empregados também a percentagem de locos polimórficos e o número médio de alelos por loco como índices de diversidade em população naturais, no sentido de caracterizar e comparar os níveis de variação genética nestas populações.

A diversidade genética em populações naturais tem sido estimada a partir de levantamentos ou amostragens genéticos, empregando-se como marcadores locos alozímicos, pressupondo representatividade da amostra de locos utilizada (BROWN, 1978). Segundo o mesmo autor, as inferências com dados obtidos a partir de locos alozímicos se aplicam mais aos segmentos marcados por aquele loco do que aos marcadores em si.

Tais marcadores apresentam como características : neutralidade e codominância. Apesar destes pressupostos, algumas evidências no sentido do valor adaptativo dos alelos destes locos têm sido obtidas, como discutem HAMRICK (1982) e, em revisão recente, TORGLER (1994).

SIMON e ARCHIE (1985) discutem algumas restrições ao emprego das estimativas de diversidade a partir de locos alozímicos, especialmente no que se refere a comparação entre espécies diferentes. Segundo os autores, a escolha dos locos afeta as estimativas obtidas, pois o comportamento especifico destes locos (distintas taxas de mutação e número de alelos) decorre do tamanho e da forma da enzima, portanto, as comparações entre taxa devem ser tomadas com cautela, especialmente se envolvem poucos e diferentes (diferentes enzimas) locos. Além disso, pequenas variações na interpretação e resolução das enzimas se refletem nas estimativas e podem comprometer a representatividade. 
Outro aspecto importante é a inclusão ou não dos locos monomórficos nas estimativas de diversidade. Na medida em que um determinado número de locos, tomados ao acaso, revela uma certa quantidade de monomórficos há maior possibilidade de representatividade com a inclusão dos mesmos. Caso contrário (locos não tomados ao acaso), os mesmos (locos monomórficos) podem produzir um viés expressivo, pois a inclusão destes produz efeitos de grande magnitude nas estimativas. SIMON e ARCHIE (1985) sugerem que as comparações entre diferentes taxa sejam realizadas a partir de locos provenientes de um mesmo grupo de sistemas enzimáticos.

Por outro lado, a neutralidade dos locos alozímicos apresenta como vantagem a possibilidade do emprego de modelos que não envolvem a seleção, fator de difícil caracterização, especialmente em populações naturais. Contudo, o pressuposto de inexistência de valor adaptativo para tais locos implica na possibilidade de um comportamento diferenciado entre os locos cujos alelos estão sob o efeito da seleção natural e os locos neutros (MUONA, 1990). Esta possibilidade associa um viés no pressuposto de representatividade do genoma, pois implica em efeitos e comportamentos que podem ser distintos dos locos sujeitos à seleção .

A utilização de marcadores alozímicos, pela sua neutralidade, ou quase neutralidade, apresenta como principal vantagem a possibilidade de caracterização das forças evolutivas (eventos determinantes da organização da variabilidade genética), sem a influência da seleção, permitindo uma maior compreensão do comportamento das populações naturais.

Assim, apesar da existência de restrições à utilização destes marcadores como base para obtenção de estimativas de diversidade, os mesmos são 
adequados para a caracterização de fenômenos como a deriva genética, o fluxo gênico e a endogamia, devido a suas características de neutralidade e codominância. Dessa forma, os marcadores alozimáticos mostram-se bastante eficientes para caracterização da dinâmica da movimentação de alelos em populações naturais.

HAMRICK e GODT (1990) analisam 653 estudos com alozímas, incluindo 449 espécies vegetais de 165 gêneros, visando associar os níveis de diversidade a aspectos da história de vida e ecologia de espécies vegetais. Os autores incluem nestes trabalhos apenas dados provenientes de levantamentos em que os locos monomórficos estavam presentes nas estimativas da diversidade genética, pressupondo amostragem ao acaso dos locos. Os autores concluem que, para espécies vegetais, em média, $50,5 \%$ dos locos são polimórficos e a heterozigosidade média é de 0,149 . Dentro de populações, em média, $34,2 \%$ dos locos são polimórficos e a heterozigosidade média é de 0,113 . Nesta análise, os autores concluem que o sistema reprodutivo e a distribuição geográfica das espécies foram os fatores que mais contribuem para a variação dos dados. Os maiores índices de diversidade, tanto ao nível de espécie, quanto a nível de população foram registrados para Alseis blackiana (uma espécie arbórea tropical que ocupa o dossel nas florestas da América Central) e os menores para Pinus resinosa ( ao nível de espécie) e Pinus longaeva (a nível de população). Em geral os maiores índices estão associados a espécies perenes, de final de sucessão e polinizadas pelo vento; sendo as gimnospermas o grupo com os maiores valores médios. Em relação às espécies tropicais, os valores médios obtidos não diferem das demais (temperadas $\mathrm{e}$ tropical/temperada), exceto em relação às espécies boreais (com valores significativamente superiores); contudo, este grupo (boreais) encontra-se inflacionado pela grande proporção de gimnospermas incluídas . 
Em espécies tropicais, a variabilidade genética nas populações naturais também tem sido caracterizada a partir de levantamentos alozímicos (Tabela 1, Anexo 1). Os resultados obtidos revelam variações expressivas nos níveis de diversidade genética, bem como no que se refere à percentagem de locos polimórficos e número de alelos por loco; contudo, as comparações entre espécies ficam comprometidas pois nem todos os trabalhos incluem os locos monomórficos ou são realizados com grande número de locos. Em termos médios (Tabela 1), os valores de diversidade para as 82 espécies tropicais mencionadas no Anexo $\mathrm{I},\left(\mathrm{H}_{\mathrm{T}}=\right.$ $0,146)$ se mostram similares aos obtidos para as espécies vegetais em geral, e confirmam os valores médios obtidos por HAMRICK e GODT (1990), mesmo quando se considera apenas as espécies tropicais arbóreas e arbustivas (76 espécies, $\left.\mathrm{H}_{\mathrm{T}}=0,150\right)$.

Além disso, pode-se observar valores bastante variados para a diversidade em espécies arbóreas e arbustivas, desde 0,0 em Piper jacmontianum (arbusto de formações secundárias; HEYWOOD e FLEMING, 1986) e em Faramea occidentalis (arbórea de sub-bosque; HAMRICK e LOVELESS, 1986), até 0,375 para Acrocomea aculeata (LOPES et al., 1992) e 0,436 para Phoenix dactylifera (BENNACER et al., 1991) (considerando-se levantamentos com ao menos 10 locos). A diversidade média obtida para as palmeiras ( 3 espécies, Tabela 1) foi de 0,321 . Enquanto que para outros agrupamentos os valores ficaram sempre próximos da média geral: 0,174 (29 espécies arbóreas de dossel; não considerando as raras do trabalho de HAMRICK e MURAWSKI, 1991); 0,131 (16 espécies arbóreas de sub-bosque); 0,167 (8 espécies colonizadoras); 0,136 (38 espécies comuns, exceto colonizadoras); 0,157 (20 espécies raras). 
Tabela 1. Valores médios de diversidade genética $\left(\mathrm{H}_{\mathrm{T}}\right)$ para espécies tropicais agrupadas de acordo com diferentes aspectos ecofisiologicos. Piracicaba-SP, ESALQ/USP, 1996

$\begin{array}{lll}\text { Grupo } & \mathrm{H}_{\mathrm{T}} & \mathrm{H}_{\mathrm{v}}{ }^{*} \quad \text { Número de }\end{array}$

Espécies

Espécies Tropicais

Arbóreas e arbustivas

Espécies de dossel (1)

Espécies de sub-bosque

Espécies colonizadoras

Espécies comuns

Espécies raras

Palmeiras
0,146

0,150

0,174

0,131

0,167

0,136

0,157
82

76

24

16

8

38

20

* Diversidade genética considerando apenas locos polimórficos

** 18 espécies

(1) exceto as espécies raras mencionadas em MURAWSKY e HAMRICK (1991)

A penúltima coluna da Tabela 1 (e do Anexo I) apresenta a diversidade genética apenas dos locos polimórficos $\left(\mathrm{H}_{\mathrm{p}}\right)$, nos trabalhos onde tal valor é apresentado ou pode ser calculado. Este valor, ainda que apresente algumas das restrições mencionadas por SIMON e ARCHIE (1985), permite uma comparação em bases similares e expressa de forma mais adequada a variabilidade potencial nos diferentes taxa. A maior adequação desta estimativa em relação à variabilidade potencial se fundamenta no fato de que os locos alozímicos polimórficos, ainda que possam ser questionados em relação à sua representatividade, refletem, como já 
mencionado, a maioria dos eventos associados a produção, manutenção, ampliação e organização da variabilidade; a saber : sistema reprodutivo, deriva genética, mutação e fluxo gênico. O valor médio obtido para as 18 espécies onde tal estimativa foi possível, alcançou 0,413; variando, para espécies arbóreas, de 0,288 em Cedrela fissilis (GANDARA, 1995), até 0,518 em Joanesia princeps (HERRIT, 1991).

\subsection{Estrutura Genética em populações naturais}

A distribuição da variabilidade genética entre e dentro de populações naturais tem sido referenciada como estrutura genética (BROWN, 1978). Contudo, a organização interna das populações também tem sido referenciada como tal, como pode ser observado em HAMRICK (1982); no entanto, tal aspecto não será alvo deste trabalho.

A formação de estrutura é decorrente de fatores como sistema reprodutivo, níveis de endogamia, seleção natural, fluxo gênico e deriva genética entre e dentro das populações.

Tomando-se como referência o teorema de Hardy e Weinberg, as principais forças microevolutivas podem ser tomadas como desvios deste equilíbrio.

Segundo WRIGHT (1931), uma alteração na freqüência alélica entre gerações $(\Delta q)$ pode ser dada por :

$$
\Delta q=v(1-q)-u q-m\left(q-q_{m}\right)+s_{q}(1-q)
$$

onde:

v e $u=$ taxas de mutação (e reversão) para um mesmo alelo 


$$
\begin{aligned}
& \mathrm{m}=\text { taxa de migração do alelo } 1 \\
& \mathrm{qm}_{\mathrm{m}}=\text { freqüência do alelo } 1 \text { na população vizinha } \\
& \mathrm{S}_{\mathrm{q}}=\text { vantagem seletiva do alelo } 1
\end{aligned}
$$

Além disso, a freqüência na próxima geração será, também, influenciada pelo tamanho da população que efetivamente trocará alelos, especialmente em populações pequenas, devido a efeitos de amostragem, ou seja, a deriva genética.

Também o cruzamento entre aparentados e a autofecundação, ou a proximidade de genótipos similares decorrente de dispersão de pólen ou sementes a curta distância, tende a ampliar a quantidade de homozigotos, a partir da redução dos heterozigotos, em nível local.

Da mesma forma, a maior probabilidade de cruzamento entre indivíduos mais próximos tende a formar grupos ou subdivisões internas (demes panmíticas), reduzindo a proporção total de heterozigotos na população (efeito Wahlund), como descreve WRIGHT (1931).

A redução de heterozigose pode ser quantificada através de um índice de fixação ou coeficiente de endogamia ( $\mathrm{F}$ de endogamia), a partir do teorema de Hardy-Weinberg (Tabela 2).

Nesse contexto, não apenas a quantificação da estrutura, mas também a caracterização dos eventos determinantes desta, apresentam relevância para 0 entendimento da dinâmica destas populações. Assim, a caracterização dos efeitos de deriva genética, sistema reprodutivo, fluxo gênico e dos níveis de endogamia, permitem o entendimento do comportamento dos alelos nas populações naturais, bem como subsidiam estratégias de manejo e conservação das mesmas. 
Em populações naturais, o emprego de marcadores alozímicos tem permitido grandes avanços na quantificação dos eventos determinantes da estrutura genética, pois permitem a avaliação da movimentação dos alelos nas populações, sem efeitos de seleção. Assim, a quantificação do grau de estrutura permite estabelecer os níveis de endogamia produzidos pela deriva genética ou pelo sistema reprodutivo, bem como o fluxo gênico.

Tabela 2. Freqüências genotípicas esperadas no equilíbrio de panmixia (HardyWeinberg) e equilíbrio de Endogamia (Wright), para o caso de locos com 3 ou mais alelos (adaptado de WRIGHT, 1951, p.324). Piracicaba-SP, ESALQ/USP, 1996

Genótipo

Freqüência Esperada

Panmixia

A1A1

A1A2

A2A2

$\mathrm{A} 1 \mathrm{~A} 3$

$\mathrm{A} 2 \mathrm{~A} 3$

A 3 A 3

AlAn

A2An

A3An

AnAn $\mathrm{p}_{1}{ }^{2}$

$2\left(\mathrm{p}_{1} \mathrm{p}_{2}\right)$

$\mathrm{p}_{2}{ }^{2}$

$2\left(\mathrm{p}_{1} \mathrm{p}_{3}\right)$

$2\left(\mathrm{p}_{2} \mathrm{p}_{3}\right)$

$\mathrm{p}_{3}^{2}$

$2\left(p_{1} p_{n}\right)$

$2\left(\mathrm{p}_{2} \mathrm{p}_{\mathrm{n}}\right)$

$2\left(\mathrm{p}_{3} \mathrm{p}_{\mathrm{n}}\right)$

$p^{2}$
Freqüência Esperada

Endogamia

$p_{1}^{2}+F p_{1}\left(1-p_{1}\right)$

$2\left(\mathrm{p}_{1} \mathrm{p}_{2}\right)(1-\mathrm{F})$

$\mathrm{p}_{2}{ }^{2}+\mathrm{F} \mathrm{p}_{2}\left(1-\mathrm{p}_{2}\right)$

$2\left(\mathrm{p}_{\mathrm{l}} \mathrm{p}_{3}\right)(1-\mathrm{F})$

$2\left(\mathrm{p}_{2} \mathrm{p}_{3}\right)(1-\mathrm{F})$

$\mathrm{p}_{3^{2}}+\mathrm{F} \mathrm{p}_{3}\left(1-\mathrm{p}_{3}\right)$

$2\left(\mathrm{p}_{\mathrm{l}} \mathrm{p}_{\mathrm{n}}\right)(1-\mathrm{F})$

$2\left(\mathrm{p}_{2} \mathrm{p}_{\mathrm{n}}\right)(1-\mathrm{F})$

$2\left(\mathrm{p}_{3} \mathrm{p}_{\mathrm{n}}\right)(1-\mathrm{F})$

$\mathrm{p}_{\mathrm{n}}^{2}+\mathrm{F} \mathrm{p}_{\mathrm{n}}\left(1-\mathrm{p}_{\mathrm{n}}\right)$

$p_{n}=$ frequência do alelo $n$ na população 
WRIGHT (1951) considera o coeficiente F (tabela 2) como a medida do grau de desvio do equilíbrio de Hardy-Weinberg nas populações, no sentido da fixação. $\mathrm{O}$ autor considera a existência de diferentes situações, onde o valor de $\mathrm{F}$ pode significar aspectos distintos e, portanto, faz-se necessário mais que um valor de F para caracterizar a estrutura da população.

Segundo WRIGHT (1943), a freqüência alélica (q) de um dado grupo ou deme tende a variar em torno de um certo ponto de equilíbrio ( $\mathrm{q}^{\prime}$ ), com uma curva de distribuição, determinada pela taxa de alteração da freqüência alélica entre gerações devido à mutação, migração e seleção $(\Delta q)$, em conjunto com os efeitos cumulativos de amostragem : desvios casuais, $\delta_{q}$; com variância por geração $\sigma_{\delta q^{*}}^{2}$ Estes efeitos podem ser caracterizados, em uma população com cruzamentos aleatórios como sendo:

$$
\sigma_{\delta q}^{2}=q(1-q) / 2 N
$$

onde:

$$
\mathrm{N}=\text { tamanho da população ou grupo panmítico }
$$

Assim, considerando a distribuição em torno de q', um valor mais acurado para a população pode ser obtido com $\sigma^{2}{ }_{q}$, a partir dos desvios em torno de q'. Considerando que os efeitos de $\Delta \mathrm{q}^{2}$ são de ordem desprezível (ou considerando ausência de seleção, como mencionado em WRIGHT, 1951):

$$
\sigma_{\mathrm{q}}^{2}=\mathrm{q}^{\prime}\left(1-\mathrm{q}^{\prime}\right) /(4 \mathrm{Nm}+1)
$$

ou, no balanço entre os efeitos de migração e amostragem 


$$
\sigma_{\mathrm{q}}^{2}=\mathrm{q}^{\prime}\left(1-\mathrm{q}^{\prime}\right) /\left[2 \mathrm{~N}-(2 \mathrm{~N}-1)(1-\mathrm{m})^{2}\right]
$$

Neste contexto, o coeficiente de endogamia pode ser decorrência de cruzamentos entre aparentados ou de subdivisões da população em grupos, cada qual com cruzamentos aleatórios internamente, ou de ambos (WRIGHT, 1943). Assim, considerando que a quantidade de heterozigotos $(\mathrm{Y})$ na geração seguinte será:

$$
Y=2 q^{\prime}\left(1-q^{\prime}\right)-2 \sigma_{q}^{2}
$$

de onde pode-se deduzir que

$$
\sigma_{q}^{2}=q^{\prime}\left(1-q^{\prime}\right) F
$$

Esta relação conecta duas maneiras diferentes de abordar a estrutura de populações naturais, conforme WRIGHT (1951), e dá um significado adicional ao valor de $F$ : uma medida da variância da frequiência de alelos neutros entre grupos, relativa ao valor limite $\mathrm{q}(1-\mathrm{q})$, quando da completa fixação do mesmo alelo.

Assumindo que uma população se apresente dividida em $n$ demes com cruzamentos ao acaso e com frequiências alélicas variáveis $q_{d}$, a heterozigosidade em cada deme será:

$$
H_{d}=2 q_{d}\left(1-q_{d}\right)
$$

Sendo a variância das freqüências alélicas entre as demes dada por: 


$$
\sigma_{\mathrm{q}(\mathrm{DT})}^{2}=(1 / \mathrm{n}) \Sigma\left(\mathrm{q}_{\mathrm{d}}-\mathrm{q}\right)^{2}
$$

assim,

$$
H=2\left[q(1-q)-\sigma_{q(D T)}^{2}\right] \text { (efeito Wahlund) }
$$

nesse caso, quando não há endogamia dentro das demes,

$$
\sigma_{\mathrm{q}(\mathrm{DT})}^{2}=\mathrm{q}(1-\mathrm{q}) \mathrm{F}_{\mathrm{IT}}
$$

onde:

$$
F_{I T}=\text { coeficiente de endogamia em relação ao total (WRIGHT, 1943) }
$$
ou endogamia devida ao efeito de subdivisão

Considerando a ocorrência de endogamia dentro das divisões, então:

$$
H_{d}=2 q_{d}\left(1-q_{d}\right)\left(1-F_{I S}\right)
$$

onde

$$
F_{\text {IS }}=\text { coeficiente de endogamia a nível de grupo (WRIGHT, 1943), }
$$
equivalente à média dos índices de fixação entre os grupos

assim,

$$
\sigma_{\mathrm{q}(\mathrm{ST})}{ }^{2}=\mathrm{q}(1-\mathrm{q})\left(\mathrm{F}_{\mathrm{IT}}-\mathrm{F}_{\mathrm{IS}}\right) /\left(1-\mathrm{F}_{\mathrm{IS}}\right)(\mathrm{WRIGHT}, 1943 ; \mathrm{p} .126)
$$


ou

$$
\sigma_{\mathrm{q}(\mathrm{ST})}^{2}=\mathrm{q}(1-\mathrm{q}) \mathrm{F}_{\mathrm{ST}}
$$

ou

$$
\mathrm{F}_{\mathrm{ST}}=\left(\mathrm{F}_{\mathrm{IT}}-\mathrm{F}_{\mathrm{IS}}\right) /\left(1-\mathrm{F}_{\mathrm{IS}}\right)
$$

sendo, na definição de WRIGHT (1965),

$\mathrm{F}_{\mathrm{IT}}=$ correlação entre gametas que se unem para produzir indivíduos em relação aos gametas de toda a população

$\mathrm{F}_{\mathrm{IS}}=$ média das correlações entre gametas que se unem de cada subdivisão em relação ao total de cada subdivisão

$\mathrm{F}_{\mathrm{ST}}=$ correlação entre gametas tomados ao acaso dentro das subdivisões em relação aos gametas de toda a população

sendo:

$$
\left(1-\mathrm{F}_{\mathrm{IT}}\right)=\left(1-\mathrm{F}_{\mathrm{IS}}\right)\left(1-\mathrm{F}_{\mathrm{ST}}\right)
$$

NEI (1977) demonstra que os valores das estatísticas $F$ podem ser também definidos a partir das heterozigosidades observadas e esperadas; assim, os estimadores das estatísticas $\mathrm{F}$ podem ser dados por:

$$
\begin{aligned}
& \hat{F}_{I T}=1-H_{o r} / \hat{H}_{e t} \\
& \hat{F}_{I S}=1-H_{o r} / \hat{H}_{e i} \\
& \hat{F}_{S T}=1-\hat{H}_{e i} / \hat{H}_{e t}
\end{aligned}
$$

onde:

$$
H_{o r}=1-\Sigma \Sigma \mathrm{X}_{\mathrm{li}} / \mathrm{ls}
$$




$$
\begin{aligned}
& \hat{H}_{e i}=1-\left(\Sigma_{\mathrm{i}} \Sigma_{\mathrm{l}} \Sigma_{\mathrm{k}} \mathrm{x}_{\mathrm{ilk}}^{2}\right) / 1 \mathrm{~s} \\
& \hat{H}_{e t}=1-\left[\left(\Sigma_{\mathrm{l}} \Sigma_{\mathrm{k}} \mathrm{x}_{\mathrm{lk}}\right) / \mathrm{s}\right]^{2} / 1
\end{aligned}
$$

sendo:

$$
\begin{aligned}
& \hat{H}_{e t}=\text { heterozigosidade esperada total (todas as populações) } \\
& H_{o t}=\text { heterozigosidade observada total } \\
& \hat{H}_{e i}=\text { heterozigosidade esperada média nas populações } \\
& \mathrm{X}_{\mathrm{il}}=\text { frequência de heterozigotos do loco } 1 \text { na população } \mathrm{i} \\
& \mathrm{X}_{\mathrm{ilk}}=\text { freqüência do alelo } \mathrm{k} \text { do loco I na população } \mathrm{i} \\
& \mathrm{S}=\text { número de populações } \\
& 1=\text { número de locos }
\end{aligned}
$$

As estatísticas $\mathrm{F}$ podem ainda ser interpretadas como probabilidade de identidade por origem, conforme WRIGHT (1965, p. 400); contudo, como os valores de $F_{I S}$ e $F_{I T}$ podem variar de $-1,0$ até $+1,0$, o autor considera a interpretação destes coeficientes como correlações de aplicação mais ampla.

Adicionalmente, além da interpretação como índices de fixação (desvios de heterozigosidade esperada), correlações e probabilidades, os valores de $\mathrm{F}$ podem ser interpretados como partições de variância das freqüências alélicas. Desta forma, WRIGHT (1965, p.402), diz que :

" $F_{\text {IT }}$ dá a quantidade de variância das freqüências alélicas das subdivisões de cruzamento aleatório (se isto ocorre), com o máximo de q (1-q)...

$\ldots F_{I S}$ dá a média desta quantidade entre as subdivisões... 
....F ST é a quantidade de variância das frequêencias alélicas das subdivisões, em relação ao seu valor limite, sendo necessariamente positivo. $F_{I S}$ é geralmente positivo, sendo negativo se ocorrer um escape sistemático dos cruzamentos consangüíneos dentro das subdivisões. $F_{I T}$ é positivo se houver divisões sistemáticas em demes $\left(\mathrm{F}_{\mathrm{IS}}=0, \mathrm{~F}_{\mathrm{IT}}=\mathrm{F}_{\mathrm{ST}}\right)$ ou em grupos endogâmicos, mas pode ser negativo se não houver divisões sistemáticas e uma predominância de escape aos cruzamentos consangüineos."

A existência dessa redução dos heterozigotos e formação de grupos, ou estrutura, decorre principalmente das limitações físicas no sentido de todos os indivíduos se cruzarem entre si, ou da ocorrência em maior probabilidade de indivíduos próximos (FUTUYMA, 1992), formando demes panmíticas. Isso produz uma tendência localizada no sentido da fixação de certos alelos (aumento de freqüência de alguns e diminuição de outros), pois apenas uma amostra da população estará trocando alelos ao acaso. Também a autofecundação ou o cruzamento entre aparentados tenderá a alterar a freqüência de certos alelos em relação ao total da população.

Assim, por deriva genética ou endogamia haverá a formação de diferentes grupos, formando-se "populações divergentes". Essa tendência será contraposta pelo fluxo gênico, ou seja, pela quantidade de migrantes de populações vizinhas, que introduzirão alelos no sentido de manter as freqüências alélicas próximas à média, como discutido por WRIGHT (1931).

Adicionalmente, os efeitos de seleção irão favorecer alelos com maior valor adaptativo local, ampliando ou reduzindo a divergência em funçăo das variações ambientais existentes. 
A estrutura genética tem sido caracterizada a partir dos níveis de endogamia (entre e dentro de populações), estimada diretamente a partir das estatísticas F de WRIGHT (1951), ou de seus estimadores, como descrito em NEI $(1977,1987)$, ou através dos coeficientes de coancestralidade ( $\theta$ 's) de COCKERHAM (1969), ou através dos níveis de heterozigosidade nas subdivisões das populações, conforme NEI (1973).

COCKERHAM (1969) aborda a estruturação em populações através das covariâncias entre pares de alelos estimadas a partir de coeficientes de coancestralidade entre indivíduos e/ou grupos $\left(\theta^{\star} \mathrm{s}\right.$, correlaçǒes intraclasse), sendo estes obtidos a partir da decomposição de variâncias da análise de variância das frequiências alélicas. Assim, $\theta$ representa, conforme COCKERHAM (1969),

“...a correlação entre a freqüência de uma alelo ao acaso de um indivíduo com aquela de um alelo ao acaso de outro ."

Segundo o autor a variância entre as freqüências alélicas de grupos de indivíduos, para alelos neutros, depende da endogamia e do grau de parentesco entre os indivíduos no grupo, tanto quanto do número de indivíduos (deriva). Assim, em um grupo, a coancestralidade é determinada pelo parentesco entre os indivíduos, exceto quando o número de indivíduos é muito pequeno, de forma que num grupo de indivíduos sem endogamia:

$$
\sigma_{p}^{2}=p(1-p) / 2 N
$$

onde:

$$
p=\text { freqüência do alelo no grupo }
$$


se há efeitos de endogamia, então:

$$
\sigma_{p}^{2}=(1+F) p(1-p) / 2 N
$$

Desta forma, considerando um modelo linear como:

$$
\mathrm{x}_{\mathrm{kij}}=\mathrm{p}+\mathrm{a}_{\mathrm{k}}+\mathrm{b}_{\mathrm{ki}}+\mathrm{w}_{\mathrm{kij}}
$$

onde a, b e w são os efeitos para grupos (k), indivíduos (i) e alelos (j) dentro de indivíduos, respectivamente, com variâncias $\sigma_{a}^{2}, \sigma_{b}^{2}$ e $\sigma_{w}^{2}$, respectivamente, então, as esperanças dos quadrados médios em relação a diferentes classes de pares de alelos são dadas, conforme COCKERHAM (1969), por:

$$
\begin{aligned}
& E\left[x_{k i j} x_{k} i_{i j}^{\prime}\right]= \\
& \mathrm{p}^{2}+\sigma^{2} \quad \text { se } \mathrm{k}=\mathrm{k}^{\prime}, \mathrm{i}=\mathrm{i}^{\prime}, \mathrm{j}=\mathrm{j}^{\prime} \\
& p^{2}+\operatorname{cov}_{a b} \quad \text { se } k=k^{\prime}, i=i^{\prime}, j \neq j^{\prime} \\
& p^{2}+\operatorname{cov}_{a} \quad \text { se } k=k^{\prime}, i \neq i^{\prime} \\
& \mathrm{p}^{2}+\operatorname{cov}_{\mathrm{g}} \quad \text { se } \mathrm{k} \neq \mathrm{k}^{\prime}
\end{aligned}
$$

para grupos não correlacionados $\operatorname{cov}_{\mathrm{g}}=0$, e, parametricamente,

$$
\begin{aligned}
& \sigma^{2}=p(1-p) \\
& \operatorname{cov}_{a b}=\rho_{a b} p(1-p) \\
& \operatorname{cov}_{a}=\rho_{a} p(1-p)
\end{aligned}
$$


Assim, as correlações $\rho_{a b}$ e $\rho_{a}$ se relacionam com os componentes de variância da seguinte forma :

$$
\begin{aligned}
& \left(1-\rho_{a b}\right) p(1-p)=\sigma^{2}{ }_{w} \\
& \left(\rho_{a b}-\rho_{a}\right) p(1-p)=\sigma_{b}^{2} \\
& \rho_{a} p(1-p)=\sigma_{a}^{2}
\end{aligned}
$$

$\mathrm{e}$

$$
\sigma^{2}=\sigma_{\mathrm{w}}^{2}+\sigma_{\mathrm{b}}^{2}+\sigma_{\mathrm{a}}^{2}
$$

"Dessa forma, as correlações intraclasse, as covariâncias e os componentes de variância são formas diferentes da mesma parametrização, e são medidas que acomodam os fatores que causam diferenças entre as freqüências alélicas. Considerando que as variações são inteiramente devidas a efeitos de deriva e decorrentes do sistema de cruzamento, então estas medidas podem ser sumarizadas em termos de F e $\theta$." (COCKERHAM, 1969, p.74)

Assim,

$$
\rho_{\mathrm{a}}=\sigma_{\mathrm{a}}^{2} /\left(\sigma_{\mathrm{w}}^{2}+\sigma_{\mathrm{b}}^{2}+\sigma_{\mathrm{a}}^{2}\right)=\theta
$$

representa a correlação entre frequêencias de alelos de diferentes indivíduos do mesmo grupo;

$$
\rho_{\mathrm{ab}}=\left(\sigma_{\mathrm{b}}^{2}+\sigma_{\mathrm{a}}^{2}\right) /\left(\sigma_{\mathrm{w}}^{2}+\sigma_{\mathrm{b}}^{2}+\sigma_{\mathrm{a}}^{2}\right)=\mathrm{F}
$$

representa a correlação de alelos dentro de indivíduos de diferentes grupos;

$$
\rho_{\mathrm{a}}=\sigma_{\mathrm{b}}^{2} /\left(\sigma_{\mathrm{w}}^{2}+\sigma_{\mathrm{b}}^{2}\right)=(\mathrm{F}-\theta) /(1-\theta)=\mathbf{f}
$$


representa a correlação dos alelos dentro de indivíduos dentro de grupos.

Desta forma, o autor demonstra, por identificação, que:

$$
\begin{aligned}
& \mathrm{F}=\mathrm{F}_{\mathrm{IT}} \\
& \theta=\mathrm{F}_{\mathrm{ST}} \\
& \mathrm{f}=\mathrm{F}_{\mathrm{IS}}
\end{aligned}
$$

Sendo que os dois conjuntos de parâmetros podem ser tomados como o mesmo, sempre que " $\theta=$ F $_{S T}$ " (COCKERHAM, 1969; WEIR e COCKERHAM, 1984).

WEIR e COCKERHAM (1984) e WEIR (1990a) discutem a utilização de estimativas para este conjunto de parâmetros, incluindo ponderações relativas à amostragem (número de alelos por loco, número de indivíduos por população e número de populações), e apresentam estimativas para os parâmetros mencionados. Os autores consideram que estimativas adequadas da estrutura das populações necessitam levar em conta aspectos relativos ao tamanho finito das amostras e ressaltam que vários trabalhos têm desconsiderado este aspecto na caracterização da estrutura genética de populações. Em trabalho posterior os mesmos autores discutem os vieses e discrepâncias da utilização inadequada de estimativas de F $_{\text {ST }}$ (COCKERHAM e WEIR, 1993).

VENCOVSKY (1992) apresenta a sistemática de obtenção das estimativas para os coeficientes de coancestralidade a partir de progênies de meiosirmãos e agrega um estimador para o nível de parentesco entre indivíduos dentro de famílias, $\theta_{1}$, equivalente ao nível de variação aditiva para famílias de meios-irmãos.

Nesse contexto, qualquer combinação hierárquica entre grupos pode ser estabelecida, como indicado em WEIR (1990a) e VENCOVSKY (1992), sendo esta uma das vantagens desta sistemática. Os diferentes níveis hierárquicos que 
podem ser estabelecidos, como indivíduos dentro de grupos, dentro de populações, dentro de vales, dentro de regiões, dentro de ecossistemas, e assim por diante, conforme a estratégia de amostragem empregada, possibilitam a decomposição de variâncias específicas (covariâncias) para cada situação. Isto implica na possibilidade de interpretações específicas em cada nível hierárquico e, portanto, em um entendimento mais completo em relação à distribuição da variabilidade genética e dinâmica da movimentação de alelos em populações naturais. Apesar da abordagem de WRIGHT $(1951,1965)$ também permitir a acomodação de diferentes níveis hierárquicos, a decomposição das variâncias prevista na metodologia proposta por WEIR e COCKERHAM (1984), WEIR (1990a) e VENCOVSKY (1992), permite uma exploração mais completa dos dados, pois permite a obtenção de estimativas livres dos efeitos dos níveis hierárquicos superiores.

Por outro lado, NEI (1973) propõe um método baseado na identidade de alelos tomados ao acaso entre indivíduos de uma população, que pode ser estendido a uma estrutura hierárquica de subdivisões desta população, independentemente do número de alelos por loco, do número de demes existentes, ou das forças evolutivas envolvidas (incluindo seleção).

Assim, dado que a identidade genética de uma população é dada por: $\mathrm{J}=\Sigma_{\mathrm{k}} \mathrm{X}_{\mathrm{k}}^{2}$

onde:

$$
\mathrm{x}=\text { freqüência do alelo } \mathrm{k} \text { na população }
$$

e a probabilidade de não identidade, usualmente heterozigosidade, ou diversidade genética é dada por: 


$$
H=1-J
$$

ao nível de subpopulação, a identidade é dada por:

$$
\mathrm{J}_{\mathrm{i}}=\Sigma_{\mathrm{k}} \mathrm{x}_{\mathrm{ik}}
$$

e ao nível populacional:

$$
\mathrm{J}_{\mathrm{T}}=\sum_{\mathrm{k}} \mathrm{x}^{2} \cdot \mathrm{k}
$$

onde:

$$
\mathrm{X}_{\mathrm{k}}=\text { média ponderada da freqüência do alelo } \mathrm{k} \text { entre as subpopulações }
$$

Desta forma, considerando s subpopulações, $\mathrm{J}_{\mathrm{T}}$ pode ser escrito como:

$$
\mathrm{J}_{\mathrm{T}}=\left(\sum \mathrm{J}_{\mathrm{i}}+\sum_{\mathrm{i \neq j}} \mathrm{J}_{\mathrm{ij}}\right) / \mathrm{s}^{2}
$$

onde:

$$
\mathrm{J}_{\mathrm{ij}}=\Sigma_{\mathrm{k}} \mathbf{x}_{\mathrm{ik}} \mathbf{x}_{\mathrm{jk}}
$$

sendo:

$\mathrm{x}_{\mathrm{ik}} \mathrm{x}_{\mathrm{jk}}=$ freqüência do alelo $\mathrm{k}$ nas populações I e $\mathrm{j}$, respectivamente

Assim, a diversidade mínima entre populações (equivalente à denominada distância genética mínima, conforme NEI, 1987) pode ser dada por:

$$
D_{i j}=H_{i j}-\left(H_{i}+H_{j}\right) / 2
$$


onde :

$$
H_{i j}=1-J_{i j}
$$

Desta forma $J_{T}$ pode ser escrito como:

$$
J_{\mathrm{T}}=\left(\Sigma \mathrm{J}_{\mathrm{i}}\right) / \mathrm{s}-\left(\Sigma_{\mathrm{i}} \Sigma_{\mathrm{j}} \mathrm{D}_{\mathrm{ij}}\right) / \mathrm{s}^{2}
$$

ou

$$
\mathrm{J}_{\mathrm{T}}=\mathrm{J}_{\mathrm{S}}-\mathrm{D}_{\mathrm{ST}}
$$

e, considerando

$$
\mathrm{H}_{\mathrm{T}}=1-\mathrm{J}_{\mathrm{T}} \quad \text { e } \quad \mathrm{H}_{\mathrm{S}}=1-\mathrm{J}_{\mathrm{S}}
$$

então,

$$
\mathrm{H}_{\mathrm{T}}=\mathrm{H}_{\mathrm{S}}+\mathrm{D}_{\mathrm{ST}}
$$

sendo a relação entre a heterozigosidade total e a heterozigosidade entre populações definida como $\mathrm{G}_{\mathrm{ST}}$ :

$$
\mathrm{G}_{\mathrm{ST}}=\mathrm{D}_{\mathrm{ST}} / \mathrm{H}_{\mathrm{T}}
$$

Para locos com dois alelos, pode ser demonstrado, segundo NEI (1973, p. 3322), que:

$$
\mathrm{H}_{\mathrm{T}}=2 \mathrm{x}(1-\mathrm{x})
$$

e 


$$
\mathrm{D}_{\mathrm{ST}}=2 \sigma_{\mathrm{x}}^{2}
$$

assim,

$$
\mathrm{G}_{\mathrm{ST}}=\sigma_{\mathrm{x}}^{2} /[\mathrm{x}(1-\mathrm{x})]
$$

portanto, por definição, $\mathrm{G}_{\mathrm{ST}}$ equivale a $\mathrm{F}_{\mathrm{ST}}$. Mesmo para alelos múltiplos, conforme S. Wright (citado em NEI, 1973), G ST $_{\text {equivale a }}$ F $_{S T}$ ponderado para todos os alelos. Essa equivalência foi demonstrada posteriormente em NEI (1977).

Os estimadores para $H_{T}, H_{S}$ e $D_{S T}$ são descritos em NEI (1987), como:

$$
\begin{aligned}
& \hat{H}_{S}=2 \mathrm{n}\left(1-\sum_{i} x_{i}^{2}\right) /(2 \mathrm{n}-1) \\
& \hat{H}_{T}=1-\sum \mathbf{i ~ x}^{2}+\hat{H}_{S} /(2 \mathrm{~ns})
\end{aligned}
$$

onde

$\mathrm{n}$ = número de indivíduos amostrados

$\mathrm{S}=$ número de subpopulações

$\mathrm{x}_{\mathrm{i}}=$ média ponderada da freqüência do alelo $\mathrm{k}$ entre as subpopulações

$\Sigma_{i} x^{2}{ }_{i}=$ média do somatório da freqüência alélica quadrada entre as subpopulações

Contudo, COCKERHAM e WEIR (1993, p. 863) não consideram GST como estimador de FST. Os autores mencionados (1984 e 1993), discutem a 
utilização de diferentes modalidades de obtenção do $\mathrm{F}_{\mathrm{ST}}$, chamando a atenção para as diferenças no uso de $\mathrm{F}_{\mathrm{ST}}$, $\mathrm{G}_{\mathrm{ST}}$ e $\theta$ como parâmetros ou estatísticas. Segundo os mesmos, grande parte dos trabalhos desconsidera o processo amostral associado à obtenção das informações, implicando na introdução de vieses desnecessários às estimativas. WEIR e COCKERHAM (1984, p. 1362) mencionam que vários autores se preocupam com a remoção dos vieses em suas estimativas, contudo, empregam apenas correções envolvendo termos que subtraem o recíproco do tamanho amostral, como o proposto em WORKMAN e NISWANDER (1970); essa abordagem, segundo os autores, é insuficiente para reduzir os vieses do processo amostral em amostras pequenas. Assim, os mesmos recomendam o emprego das estimativas propostas para os coeficientes de coancestralidade, pois estas consideram de forma mais adequada o processo amostral, gerando valores com menor viés, como indicam as simulações realizadas em WEIR e COCKERHAM (1984) e COCKERHAM e WEIR (1993).

Nos casos em que a amostragem é grande, ou seja, quando $1 / \mathrm{n}$ (com n igual ao número de indivíduos amostrados) pode ser ignorado, as estimativas de $\theta, F$ e f, não diferem daquelas discutidas em NEI (1977) para $F_{S T}, F_{I T}$ e $F_{I S}$, conforme WEIR e COCKERHAM (1984), e, por extensão, de $G_{S T}$ a partir das estimativas năo viesadas das identidades genéticas de NEI $(1978,1987)$.

Assim, parece razoável a utilização da abordagem proposta por WEIR e COCKERHAM (1984), WEIR (1990a) e VENCOVSKY (1992) em qualquer situação, ficando o emprego das estimativas de $\mathrm{G}_{\mathrm{ST}}$ restrito às situações com amostras grandes. 
Apesar da controvérsia, estimativas de divergência via $G_{S T}$ têm sido largamente empregadas, bem como a equivalência entre $\mathrm{G}_{S T}$ e $F_{S T}$ ou $\theta$ e $F_{S T}$, especialmente em populações naturais.

HAMRICK e GODT (1990) analisam vários estudos com plantas, utilizando a abordagem de NEI (1973), uma vez que esta tem sido a mais empregada; os resultados mostraram como valores médios: $\mathrm{H}_{\mathrm{T}}=0,31 ; \mathrm{H}_{\mathrm{S}}=0,23 \mathrm{e}$ $\mathrm{G}_{\mathrm{ST}}=0,224$. Em média, por espécie, foram analisadas 12,7 populações com 16,5 locos. As análise indicam, como em estudos anteriores (HAMRICK et al., 1979; LEVELESS e HAMRICK, 1984), que espécies perenes de vida longa, com fecundação cruzada e de fase final de sucessão polinizadas pelo vento, apresentam maior variação dentro e menor entre populações, do que espécies com outras combinações de categorias. Neste estudo, as 41 espécies tropicais analisadas apresentaram valores médios de $\mathrm{H}_{\mathrm{T}}$ e $\mathrm{H}_{\mathrm{S}}(0,28$ e 0,23 ; respectivamente) similares às demais (temperadas, boreais e temperada/tropicais); entretanto, apresentam $\mathrm{G}_{\mathrm{ST}}$ $(0,17)$ superior às boreais, não diferindo das demais categorias.

Uma análise mais detalhada pode ser feita, para 32 espécies tropicais já estudadas, separando as abordagens $\mathrm{G}_{\mathrm{ST}}, \mathrm{F}_{\mathrm{ST}}$ e $\theta$, como nas Tabelas 3 e 4 .

Os estudos realizados empregando a abordagem de NEI $(1973,1987)$ (Tabela 3) revelam um valor médio para $\mathrm{G}_{\mathrm{ST}}$ de 0,187 (20 espécies), ou 0,124 (17 espécies arbóreas ou arbustivas). Uma tendência de reduzida divergência entre populações fica ressaltada, quando se retira Lisianthius skineri $\left(\mathrm{G}_{\mathrm{ST}}=0,903\right.$; SYSTMA e SCHAAL, 1985) da estimativa da média entre espécies arbóreas e arbustivas, ficando $\mathrm{G}_{\mathrm{ST}} \mathrm{em} 0,075$. 
Tabela 3 Estrutura genética, abordagem pela análise de populações subdivididas de NEI (1973), em populações naturais de espécies tropicais. Piracicaba-SP, ESALQ/USP, 1996

\begin{tabular}{lllllll} 
Espécie & N.p $*^{*}$ & $\mathrm{H}_{\mathrm{T}}$ & $\mathrm{H}_{\mathrm{S}}$ & $\mathrm{G}_{\mathrm{ST}}$ & $\mathrm{Nm}$ & Referência \\
\hline Aghatis borneensis & 5 & 0.122 & 0.106 & 0.140 & 1.26 & Bornéo / KITAMURA e \\
& & & & & & RAHMAN (1992) \\
\hline
\end{tabular}

$\begin{array}{lllllll}\text { Bertholletia excelsa } & 2 & 0,190 & 0,183 & 0,037 & 3.35 & \text { Amazonnia / BUCKLEY et }\end{array}$
al. (1988)

\begin{tabular}{|c|c|c|c|c|c|c|}
\hline Stemonoporus obtusifolius & 4 & 0,342 & 0.298 & 0,163 & 1.96 & $\begin{array}{l}\text { Sri Lanka / MURAWSKI e } \\
\text { BAWA (1994) }\end{array}$ \\
\hline Carapa guianensis & 9 & 0,328 & 0,313 & 0.046 & +.1 & $\begin{array}{l}\text { Costa Rica / HALL et al. } \\
\text { (1994) }\end{array}$ \\
\hline Phoenix dactvlifera & 4 & 0,436 & 0,393 & 0.067 & & $\begin{array}{l}\text { Argélia / BENNACER et } \\
\text { al. (1991) }\end{array}$ \\
\hline Hemionitis palmata & 9 & 0,049 & - & 0,698 & 0.102 & $\begin{array}{l}\text { Amér. Central / RANKER } \\
(1992)\end{array}$ \\
\hline Lisianthius skinneri & 7 & 0.526 & 0.052 & 0.903 & 0.01 & $\begin{array}{l}\text { Panamá / SYSTMA £ } \\
\text { SCHAAL (1985) }\end{array}$ \\
\hline Aechemea magdalenae & 9 & 0,363 & 0,258 & 0,356 & 0,43 & $\begin{array}{l}\text { Panamá / MURAWSKY e } \\
\text { HAMRICK (1990) }\end{array}$ \\
\hline Acacia mangium. & 11 & 0.025 & - & 0.311 & & $\begin{array}{l}\text { Austrália / MORAN et al } \\
\text { (1989) }\end{array}$ \\
\hline
\end{tabular}


Tabela 3 (continuação)

\begin{tabular}{|c|c|c|c|c|c|c|}
\hline Espécie & N.p. & $\mathrm{H}_{\mathrm{T}}$ & $\mathrm{H}_{\mathrm{S}}$ & $\mathrm{G}_{\mathrm{ST}}$ & $\mathrm{Nm}$ & Referência \\
\hline Muracrodruom urundewa & 2 & 0.452 & 0.436 & 0.036 & 3.351 & Brasil / MORAES (1992) \\
\hline Hevea brasiliensis & 2 & 0,336 & 0,335 & .0003 & 416.1 & $\begin{array}{l}\text { Brasil / PAIVA et al. } \\
(1994 a)\end{array}$ \\
\hline Eichornia paniculata & 10 & 0,15 & 0,09 & 0,57 & & $\begin{array}{l}\text { Brasil / GLOVER } \\
\text { BARRET (1987) }\end{array}$ \\
\hline Quaribea asterolepis & 3 & 0,374 & 0,365 & 0.021 & 5,18 & Panamá \\
\hline Alseis blackiana & 3 & 0,423 & 0.412 & 0,043 & 2.47 & LOVELESS e HAMRICK \\
\hline Acalypha diversifolia & 3 & 0,378 & 0,344 & 0,094 & 1.07 & $(1987)$ \\
\hline Sorocea afinis & 3 & 0,323 & 0,307 & 0,047 & 2,25 & \\
\hline Swartzia simplex & 3 & 0,358 & 0,337 & 0,035 & 3,02 & \\
\hline Psychotria horizontalis & 3 & 0,290 & 0,277 & 0,039 & 2,74 & \\
\hline Hybanthus prunifolius & 3 & 0,351 & 0,335 & 0,041 & 2,30 & \\
\hline Rinorea sv/vatica & 3 & 0,318 & 0.236 & 0.083 & 1.22 & \\
\hline
\end{tabular}

*Np = número de populações estudadas 
Tabela 4 Estrutura genética, abordagem pelas estatísticas F de WRIGHT (1951). em populações naturais de espécies tropicais. Piracicaba-SP. ESALQ/USP. 1996

\begin{tabular}{ccccccc} 
Espécie & $\mathrm{Np}^{* *}$ & $\mathrm{~F}_{\mathrm{IS}}$ & $\mathrm{F}_{\mathrm{IT}}$ & $\mathrm{F}_{\mathrm{ST}}$ & $\mathrm{Nm}$ & Referência \\
\hline \multirow{2}{*}{$\begin{array}{c}\text { Astrocarium mexicanum } \\
\text { Adultos }\end{array}$} & 4 & -0.42 & -0.036 & 0.039 & 3.41 & al. (1992) \\
Progênies & 4 & -0.19 & -0.12 & 0.009 & & \\
\hline
\end{tabular}

$\begin{array}{llllll}\text { Piper amalago* } & 5 & 0.242 & 0.319 & 0.103 & \text { Costa Rica / HEYWOOD }\end{array}$

e FLEMING (1986)

\begin{tabular}{|c|c|c|c|c|c|c|}
\hline Psychotria faxlucens & & & & & & México / PÉREZ- \\
\hline Adultos & 2 & 0.133 & 0.160 & 0.031 & & NASSER et al. (1993) \\
\hline Progênies & 2 & 0.115 & 0.138 & 0.026 & & \\
\hline Tillandsia recurvata & 7 & 1,00 & 1.00 & 0,907 & & México / SOLTIS et al. \\
\hline T. ionantha & 3 & 0,056 & 0.097 & 0.043 & & $(1987)$ \\
\hline Cariniana legalis * & 2 & -0.11 & -0.05 & 0,053 & 1.13 & Brasil / HERRIT (1991) \\
\hline Cordia trichotoma* & 2 & 0.006 & 0.007 & .0004 & 312.4 & \\
\hline Joanesia princeps ${ }^{*}$ & 2 & -0.02 & 0.058 & 0.069 & 1.68 & \\
\hline \multirow[t]{2}{*}{ Cecropia obtusifolia } & 8 & 0.034 & 0.061 & 0.029 & 24,9 & Méx./ALVAREZ- \\
\hline & & & & & & $\begin{array}{l}\text { BUYLLA e GARAY } \\
(1994)\end{array}$ \\
\hline Echornia paniculata* & 10 & 0,088 & 0.384 & 0,324 & & $\begin{array}{l}\text { Brasil / GLOVER } \\
\text { BARRET }(1987) \\
\end{array}$ \\
\hline Hevea brasiliensis* & 2 & 0,336 & 0,335 & 0,03 & & $\begin{array}{l}\text { Brasil / PAIVA et al. } \\
(1994 \mathrm{~b})\end{array}$ \\
\hline Myracrodruom urundeuva* & 2 & 0.495 & 0.520 & 0.049 & & Brasil / MORAES (1992) \\
\hline
\end{tabular}

* empregando os estimadores de WEIR e COCKERHAM (1984)

**Np = número de populaçǒes estudadas 
Para as espécies tropicais onde os estudos empregaram estimativas de

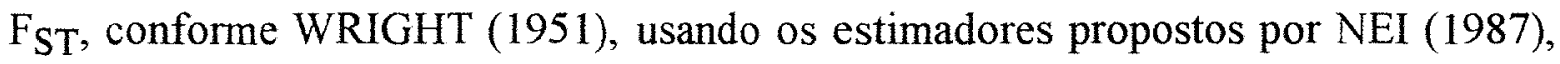
ou com base em WEIR e COCKERHAM (1984), mencionadas na Tabela 4, os valores médios foram de 0,137 (considerando as 12 espécies), ou 0,042 (9 espécies arbóreas ou arbustivas). Novamente fica ressaltada a reduzida divergência entre populações para a maioria das situações.

\subsection{Taxa de Cruzamento}

O sistema reprodutivo afeta diretamente a estrutura e dinâmica das populações naturais (BROWN, 1978; RITLAND e JAIN, 1981) e mostra-se entre os fatores mais importantes na determinação da variação existente entre espécies em relação à estrutura genética, como demonstraram as análises realizadas por HAMRICK et al, 1979 e HAMRICK e GODT (1990). Assim, sua caracterização e,

especialmente, a da taxa de cruzamento (t), faz-se necessária para o estudo da dinâmica dos alelos em populações naturais ou artificiais, tanto em programas de melhoramento, quanto para definição de estratégias de manejo e conservação.

A taxa de cruzamento, bem como o fluxo gênico, trazem uma perspectiva dinâmica aos estudos de estrutura genética em populações naturais.

As estimativas da taxa de cruzamento têm sido obtidas a partir da relação

$$
t=(1-f) /(1+f)
$$


dada por WRIGHT (1921), sendo "f" a estimativa da endogamia existente ao nível de indivíduo. Esta estimativa pode ser obtida a partir do índice de fixação, estimado loco a loco, obtendo-se uma média da taxa de cruzamento aparente (VENCOVSKY, 1992), como em MARCON (1988), MORAES (1992) e PAIVA et al. (1994b).

Contudo, o emprego de modelos multilocos permitem a obtenção de estimativas mais adequadas da taxa de cruzamento, pois levam em consideração as combinações genotípicas envolvendo todos os locos. Assim, BROWN e ALLARD (1970) apresentam um modelo multilocos para obtenção da taxa de cruzamento; bem como, posteriormente, outros autores, como CLEG et al (1978), SHAW et al. (1980) e RITLAND e JAIN (1981). Destes, o modelo proposto por RITLAND e JAIN (1981) vem sendo o mais empregado pelos trabalhos recentes. O modelo está disponível no programa MLT (RITLAND, 1990), o qual agrega a estimativa de genótipos maternos, quando estes não são fornecidos, empregando o método proposto em BROWN e ALLARD (1970).

O modelo multilocos de RITLAND e JAIN (1981) se fundamenta em que as progênies de um genótipo materno representam um conjunto de genótipos derivados de óvulos, que se cruzam numa probabilidade $t$, com um conjunto de pólens com freqüências alélicas $p$ e, se autofecundam, numa probabilidade (1-t). Pressupondo, conforme RITLAND e JAIN (1981, p. 38), a inexistência de: mutação, seleção após fertilização, ligação entre os locos analisados, cruzamentos preferenciais e variação nas freqüências alélicas do conjunto de pólens. Assim, implica na necessidade do fornecimento dos genótipos maternos, além das progênies. Quando os genótipos maternos não são fornecidos diretamente, os mesmos são estimados conforme mencionado anteriormente. 
O processo de obtenção das estimativas tem implícito um equilíbrio de endogamia (RITLAND e JAIN, 1981; RITLAND e EL-KASSABY, 1985), equivalente ao equilibrio de Wright, com $\mathrm{f}$ dependente de $\mathrm{t}$, envolvendo um processo matricial:

$$
P=(1-t) S+t T
$$

onde:

$$
\begin{aligned}
& \mathrm{P}=\text { matriz de probabilidades de genótipos multilocos nas progênies } \\
& \mathrm{S}=\text { matriz de probabilidades nas progênies, por autofecundação } \\
& \mathrm{T}=\text { matriz de probabilidades nas progênies, por cruzamento }
\end{aligned}
$$

Conforme RITLAND e JAIN (1981), a matriz de genótipos multilocos nas progênies (observada) é estabelecida inicialmente $(\mathrm{P})$ e, posteriormente, esta matriz de genótipos multilocos é maximizada através de uma função log de máxima verossimilhança, onde $\mathrm{P}$ é função de $\mathrm{t}$ e $\mathrm{p}$. O processo permite a obtenção da freqüência de alelos em óvulos e pólens, pela maximização da matriz T. Em geral várias interações são necessárias para convergência, na medida do número de locos empregados. Ocasionalmente não há convergência, especialmente quando há quebra nos pressupostos (principalmente por seleção ou cruzamentos preferenciais).

As simulações realizadas pelos autores mostram que o viés, com seleção ou cruzamentos preferências, é reduzido quando são empregados 4 ou mais locos. Também a variância da estimativa de " $\mathrm{t}$ " fica reduzida com o aumento no número de indivíduos por progênies (mais que 10 indivíduos, segundo RITLAND e EL-KASSABY, 1985) e emprego de 4 a 5 locos, para situações em que a taxa de 
indivíduos (em termos totais) e o fornecimento dos genótipos maternos, para obtenção de estimativas mais consistentes.

Além disso, a comparação entre a média das estimativas de locos simples $\left(\hat{t}_{s}\right)$ e a estimativa multilocos $\left(\hat{t}_{m}\right)$ permite avaliar a ocorrência de cruzamentos entre aparentados, possibilitando a caracterização de ocorrência de endogamia através dessa via, conforme discutem RITLAND e JAN (1981) e RITLAND e EL KASSABY (1985).

Para espécies tropicais, vários trabalhos recentes têm apresentado estimativas da taxa de cruzamento (Tabela 5). Os valores, em geral, se mostram elevados (não diferentes de 1,0), como em Astrocarium mexicanum (EGUIARTE et al., 1992) e Psychotria faxlucens (PEREZ-NASSER et al., 1993), entre outras.

Valores intermediários têm sido obtidos em poucas espécies, como Cavanillesia platanifolia, uma espécie que ocorre em baixa densidade, (MURAWSKY et al., 1990) e Ceiba pentandra (MURAWSKY e HAMRICK, 1992a). Também para Hevea brasiliensis (PAIVA et al.,1994b), Myracrodruon urundeuva (MORAES, 1992) e Stylosantes humilis (herbácea, colonizadora; MARCON, 1988), foram obtidos valores intermediários; contudo, estes autores não empregaram estimativas multilocos, o que em geral produz valores subestimados, pois as estimativas da taxa de cruzamento aparente não consideram as combinações genotípicas. 
Tabela 5. Taxa de Cruzamento em populações naturais de espécies tropicais. Piracicaba-SP, ESALQ/USP, 1996

\begin{tabular}{|c|c|c|c|c|c|c|c|}
\hline Espécie & local & ano & $\mathrm{ts}^{*}$ & $\mathrm{tm}$ & St & $\mathrm{n}$ & Referência \\
\hline Bertholletia excelsa & & & 0.799 & 0,849 & 0.03 & 2 & $\begin{array}{l}\text { O'MALLEY et al. } \\
(1988)\end{array}$ \\
\hline Astrocarium & LT-B & 1985 & 0,956 & 0,933 & 0.174 & 2 & EGUIARTE et al. \\
\hline \multirow[t]{5}{*}{ mexicanum } & LT-A & 1987 & 1,077 & 1,050 & 0.066 & 5 & (1992) \\
\hline & LT-B & 1987 & 1.078 & 0.992 & 0.039 & 5 & \\
\hline & LT-C & 1987 & 1.070 & 1,018 & 0,063 & 5 & \\
\hline & LTC & 1987 & 1,068 & 0,985 & 0.065 & 5 & \\
\hline & LT-B & 1988 & 1.045 & 1.007 & 0.053 & 5 & \\
\hline \multirow[t]{2}{*}{ Psychotria faxlucens } & LTI & 1987 & 0,996 & 1.008 & 0,122 & 6 & PEREZ-NASSER \\
\hline & LT2 & 1987 & 0.959 & 1.025 & 0.106 & 6 & al. (1993) \\
\hline Piper amalago (a) & . & 1983 & 0,578 & & & 1 & $\begin{array}{l}\text { HEYWOOD } \\
\text { FLEMING (1986) }\end{array}$ \\
\hline $\begin{array}{l}\text { Stemonoperus } \\
\text { oblongifolius }\end{array}$ & & 1991 & 0.889 & 0.844 & 0.021 & 6 & $\begin{array}{l}\text { MURAWSKY } \\
\text { BAWA (1994) }\end{array}$ \\
\hline Carapa guianensis & $\begin{array}{l}\text { LS } \\
\text { GF }\end{array}$ & $\begin{array}{r}1992 \\
1991 \\
\end{array}$ & $\begin{array}{r}0,932 \\
1.000 \\
\end{array}$ & $\begin{array}{l}0.967 \\
0.986 \\
\end{array}$ & $\begin{array}{l}0.022 \\
0.028 \\
\end{array}$ & $\begin{array}{l}5 \\
5 \\
\end{array}$ & HALL et al. (1994) \\
\hline $\begin{array}{l}\text { Pithecellobium } \\
\text { pedicelare }\end{array}$ & LS & & 0,937 & 0.951 & 0.021 & 4 & $\begin{array}{l}\text { O'MALLEY } \\
\text { BAWA (1987) }\end{array}$ \\
\hline
\end{tabular}


Tabela 5 (continuação)

\begin{tabular}{|c|c|c|c|c|c|c|c|}
\hline Espécie & local & ano & $\mathrm{ts}^{*}$ & $\mathrm{tm}$ & St & $\mathrm{n}$ & Referência \\
\hline Cavanillesia & $\mathrm{BCI}$ & 1987 & 0,524 & 0,569 & 0.024 & + & MURAWSKY et al., \\
\hline \multirow[t]{3}{*}{ platanifolia } & $\mathrm{BCI}$ & 1988 & 0.440 & 0.347 & 0.025 & 5 & 1990 \\
\hline & $\mathrm{BCI}$ & 1989 & 0,195 & 0.213 & 0.052 & 5 & \\
\hline & Darie & 1990 & 0.608 & 0.661 & 0.074 & & \\
\hline Quaribea astrelopsis & $\mathrm{BCl}$ & 1987 & 0.97 & 1,008 & 0.01 & 5 & $\begin{array}{l}\text { MURAWSKY et al. } \\
1990\end{array}$ \\
\hline Ceiba pentandra & $\mathrm{BCI}$ & 1989 & 0.659 & 0,689 & 0.03 & 6 & $\begin{array}{l}\text { MURAWSKY } \\
\text { HAMRICK. 1992a }\end{array}$ \\
\hline \multirow[t]{2}{*}{ Platypodium elegans } & BCI L & 1988 & & 0,924 & 0,043 & 10 & \multirow{3}{*}{$\begin{array}{l}\text { MURAWSKI } \\
\text { HAMRICK (1991) }\end{array}$} \\
\hline & $\mathrm{BCIH}$ & 1989 & & 0,898 & 0,043 & 10 & \\
\hline Tachigali versicolor & $\mathrm{BCl}$ & & & 0.937 & 0.044 & 2 & \\
\hline \multicolumn{8}{|l|}{ Beilschmedia } \\
\hline pendula & $\mathrm{BCl}$ & & & 0.918 & 0,058 & 3 & \\
\hline Trichilia tuberculata & $\mathrm{BCI}$ & & & 1,077 & 0.028 & 3 & \\
\hline Brosimum alicastrum & $\mathrm{BCl}$ & & & 0,875 & 0.035 & 7 & \\
\hline \multirow[t]{2}{*}{ Sorocea affinis } & BCIL & & & 1.089 & 0,045 & 5 & \\
\hline & $\mathrm{BCIH}$ & & & 0,969 & 0,020 & 5 & \\
\hline Diptervx oleifera & $\mathrm{BCl}$ & & & 0.074 & 0,07 & & \\
\hline
\end{tabular}


Tabela 5 (continuação)

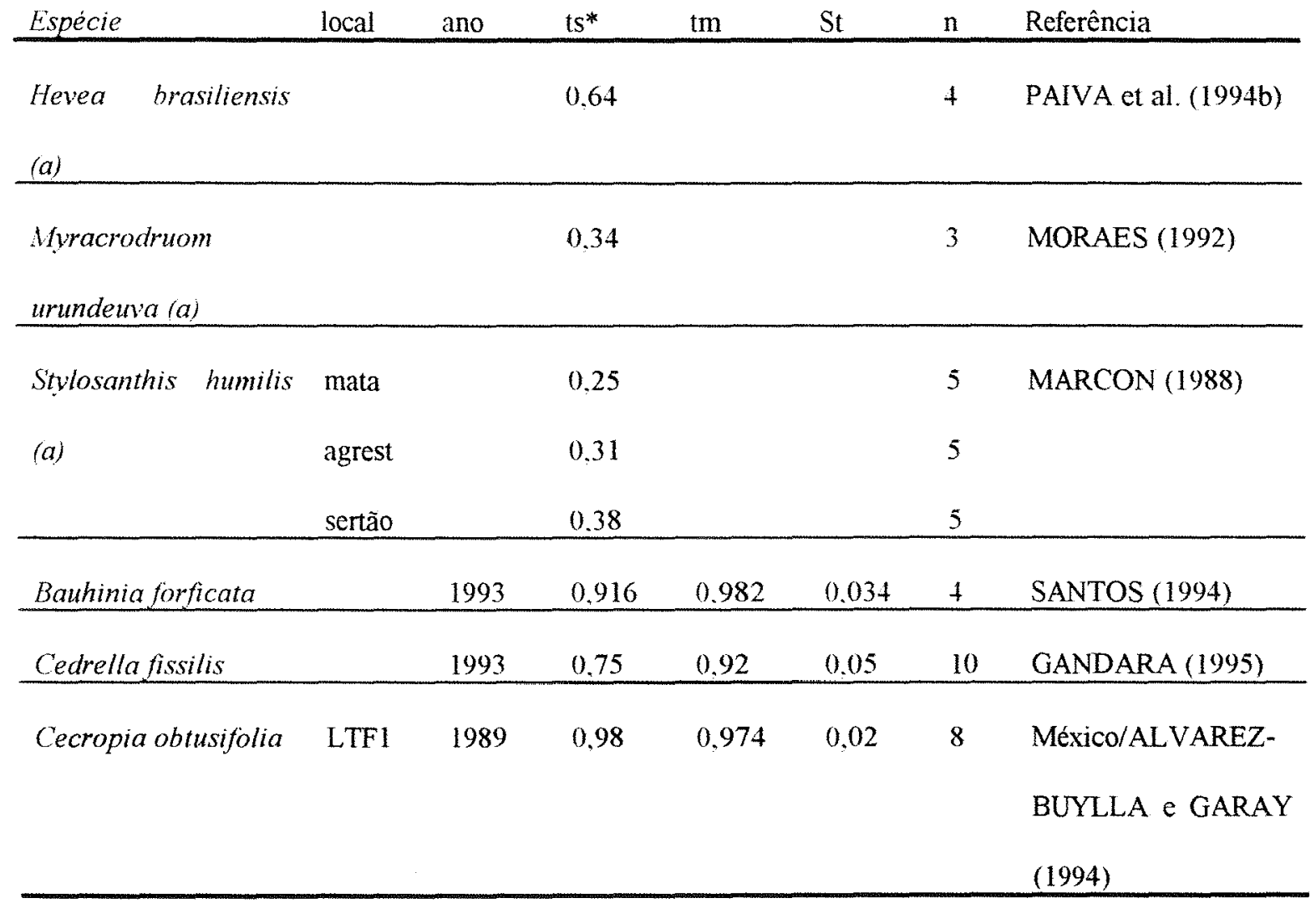

(a) taxa de cruzamento aparente

$*_{\text {ts }}=$ média dos locos individuais, empregando estimador de RITLAD e JAIN (1981)

$\mathrm{tm}=$ taxa de cruzamento multilocos, empregando estimador de RITLAD e JAIN (1981)

$\mathrm{St}=$ desvio padrão da estimativa multilocos

$\mathrm{nl}=$ número de locos empregados 
Especial ênfase tem sido dada à caracterização das variações existentes, associadas com variações de ambiente (anos, locais) e com a densidade de floração. Assim, em Astrocarium mexicanum, EGUIARTE et al. (1992) caracterizaram pequenas diferenças entre os locais (parcelas) e anos de amostragem. Resultado similar foi obtido por PEREZ-NASSER et al. (1993) para Psychotria faxlucens, e por HALL et al. (1994) para Carapa guianesis. Para Cavanillesia plantanifolia, contudo, as variações foram mais expressivas (Tabela 5), e mostraramse associadas às densidades de floração, revelando uma relação direta (MURAWSKY et al.,1990).

A associação entre densidade de floração e taxa de cruzamento também foi discutida, considerando diferentes espécies, por MURAWSKY e HAMRICK (1991). Os resultados indicaram contribuições heterogêneas de freqüências alélicas em grãos de pólen, sugerindo a ocorrência de cruzamentos não aleatórios como principal consequência desta associação.

Além disso, diversos trabalhos (MURAWSKI et al., 1990; MURAWSKI e HAMRICK, 1991, 1992a,b; GANDARA, 1995) tèm revelado heterogeneidade de freqüências alélicas entre pólen e óvulo, indicando que a ocorrência de cruzamentos não aleatórios é um evento relativamente comum em espécies tropicais.

2.5. Fluxo Gênico e Tamanho de Vizinhança

"Fluxo gênico é um termo coletivo que inclui todos os mecanismos que resultam no movimento de alelos de uma população para outra..." (SLATKIN, 1985). 
Neste sentido, o fluxo gênico está entre os eventos que melhor caracterizam a dinâmica da movimentação de alelos em populações naturais, pois implica na quantificação deste movimento entre populações, bem como na caracterização dos mecanismos envolvidos.

FUTUYMA (1992) descreve quatro modelos básicos de fluxo gênico: a) continente-ilha, onde o movimento é uniderecional de uma população grande para outra menor e/ou isolada ou para colonização; b) ilhas, onde a migração ocorre ao acaso entre um grupo de pequenas populações bem definidas; c) alpondras (ou "stepping-stone") onde as populações trocam migrantes entre populações vizinhas; d) isolamento por distância, onde o fluxo ocorre entre grupos vizinhos, (eventualmente sobrepostos), em uma população contínua.

As implicações e efeitos do fluxo gênico têm sido discutida no âmbito das suas consequências evolutivas por EHLICH e RAVEN (1969) e GRANT (1980). Os autores discutem a importância relativa da migração e seleção como forças de coesão e/ou disrupção entre as populações, ficando ressaltada a importância dos eventos casuais no processo.

LEVIN e KESTER (1974) e SLATKIN (1985) apresentam resultados de vários trabalhos com diferentes espécies e discutem metodologias que vêm sendo empregadas para obtenção de estimativas do fluxo gênico. As metodologias empregadas envolvem medidas diretas e indiretas da movimentação dos alelos.

Medidas diretas da distância de transporte dos grãos de pólen e das sementes, empregando a relação proposta por LEVIN e KESTER $(1969,1971)$ :

$$
\mathrm{Ne}=12,6\left(\mathrm{t} \sigma_{\mathrm{p}}^{2} / 2+\sigma_{\mathrm{s}}^{2} / 2\right) \mathrm{d}
$$


onde:

$\mathrm{Ne}=$ tamanho de vizinhança

$\mathrm{t}=$ taxa de cruzamento

$\sigma_{\mathrm{p}}^{2}=$ variância das distâncias de dispersão do pólen

$\sigma_{\mathrm{s}}^{2}=$ variância das distâncias de dispersão de sementes

$\mathrm{d}=$ densidade demográfica (número de indivíduos por unidade de área)

com eventuais adaptações, como discutido em RICHARDS (1986).

A relação mencionada se fundamenta na discussão de WRIGHT (1943, 1946), onde o autor propõe que o tamanho de vizinhança $(\mathrm{N})$ é o número de indivíduos num círculo cujo raio é igual a duas vezes o desvio padrão da dispersão de alelos $\left(\sigma_{a}\right)$ por geração por população. Assim,

$$
\mathrm{N}=\pi+\sigma_{\mathrm{a}}^{2}=12,6 \sigma_{\mathrm{a}}^{2}
$$

As medidas indiretas se fundamentam na relação entre a taxa de migração (m) e a divergência entre populações, indicando uma relação inversa entre a divergência e a migração, considerando um modelo de ilhas:

$$
\sigma_{q}^{2} / q(1-q)=1 /(4 N m+1) \text { WRIGHT (1931) }
$$

A disponibilidade de marcadores genéticos, como as alozimas, permitiu a aplicação do proposto por WRIGHT (1951); assim, como:

$$
\mathrm{F}_{\mathrm{ST}}=\sigma_{q}^{2} / \mathrm{q}(1-\mathrm{q})
$$


então,

$$
\mathrm{F}_{\mathrm{ST}}=1 /(4 \mathrm{Nm}+1)
$$

CROW e AOKI (1984), empregando $\mathrm{G}_{\mathrm{ST}}$ e pressupondo uma taxa de mutação desprezível em relação a taxa de migrantes, agregam o número de populações envolvidas na estimativa de divergência para obtenção de uma estimativa mais adequada do fluxo gênico:

$$
\mathrm{G}_{\mathrm{ST}}=1 /(4 \mathrm{Nm} \alpha+1)
$$

onde :

$$
\alpha=[\mathrm{n} /(\mathrm{n}-1)]^{2}
$$

sendo n o número de populações amostradas.

Desta forma, é possivel empregar $\mathrm{G}_{\mathrm{ST}}$, em lugar de $\mathrm{F}_{\mathrm{ST}}$, conforme CROW e AOKI (1984) e SLATKIN e BURTON (1989).

A relação mencionada tem sido intensamente utilizada para obtenção de estimativas dos níveis de fluxo gênico entre populações naturais de várias espécies vegetais (GOVINDARAJU, 1988), ou exclusivamente em arbóreas (GOVINDARAJU, 1989).

SLATKIN e BARTON (1989) discutem a utilização de três métodos distintos para obtenção de estimativas de fluxo gênico. $O$ primeiro, a) a partir de estimativas da divergência genética entre populações; o segundo, b) com base na freqüência de alelos raros (BARTON e SLATKIN, 1986); e o terceiro, c) 
empregando estimadores de máxima verossimilhança. Os autores concluem que a utilização de estimativas da divergência genética para caracterização dos níveis de fluxo gênico é um método tão eficiente quanto os demais; sendo robusto suficiente para obtenção de estimativas razoáveis mesmo quando em situações onde o modelo de fluxo gênico é contínuo, como o isolamento por distância, ou quando existem efeitos de seleção. SLATKIN e BARTON (1989) discutem ainda a utilização de diferentes medidas de divergência, como o $\mathrm{G}_{\mathrm{ST}}(\mathrm{NEI}, 1973)$ e os coeficientes de coancestralidade (WEIR e COCKERHAM, 1984), concluindo, a partir de simulações, que ambos apresentam resultados similares. Entretanto, COCKERHAM e WEIR (1993) apontam equívocos nas simulações realizadas por SLATKIN e BARTON (1989) e demonstram a maior adequação dos coeficientes de coancestralidade para obtenção destas estimativas, pois estes estimadores ponderam aspectos do processo amostral, como número de populações e número de indivíduos por população, reduzindo eventuais vieses decorrentes deste processo.

SLATKIN e BARTON (1989) e EGUIARTE et al. (1993) chamam atenção para a maior adequação, no sentido biológico, da utilização do conceito de tamanho de vizinhança na discussão relativa ao fluxo gênico em espécies onde as populações se organizam em modelos contínuos (isolamento por distância). Segundo SLATKIN E BARTON (1989)

"Uma das maneiras de quantificar o fluxo gênico é com parâmetros que descrevem o movimento de gametas ou indivíduos, independentemente do tamanho da população. Nos modelos de ilha e alpondras, este parâmetro é $\mathrm{m}$, a probabilidade de cada gameta ser um migrante. Em modelos como látice ou contínuos (isolamento por distância), este parâmetro é $\sigma$, o desvio padrão da distância de movimento de cada gameta em qualquer direção. 
Outra maneira de quantificar o fluxo gênico é através da do número de gametas ou individuos que se movem. No modelo de ilhas, este número é dado por $\mathrm{Nm}$, enquanto que em modelos contínuos, este número é o tamanho de vizinhança $\mathrm{Nb}$. "

Os autores demonstram que a relação entre $\mathrm{Nb}$ e $\mathrm{Nm}$ pode ser dada por:

$$
\mathrm{Nb}=2 \pi \mathrm{Nm}
$$

Em espécies tropicais, os valores obtidos para Nm (Tabelas 3 e 4) têm se mostrado, em geral, superiores a 1,0. Segundo WRIGHT (1951), quando $\mathrm{Nm} \geq$ 1,0 ; ou seja, quando um ou mais indivíduos migram por geração, os efeitos da migração são suficientes para contrapor os efeitos da deriva, e, portanto, impedem a divergência entre populações por essa via. 


\section{MATERIAL E MÉTODOS}

3.1. Características das áreas de coleta de amostras foliares e sementes

O presente trabalho foi conduzido a partir da amostragem de plantas localizadas em duas regiões geográficas distintas. A primeira localizada no Médio Vale do Rio Itajaí-Açu (Município de Blumenau, Estado de Santa Catarina) e a segunda no Vale do Rio Ribeira do Iguape (Município de Sete Barras, Estado de São Paulo). Em ambas as regiões foram estabelecidas áreas de coleta de amostras foliares e de sementes, em gradientes altitudinais, visando detectar a existência de variações associadas a este fator. Assim, cada área amostrada ficou definida como uma população de trabalho, de forma que o termo população será empregado para definir o grupo de plantas, representado pelas amostras foliares ou de sementes, de uma determinada altitude em cada um dos locais de coleta.

\subsubsection{Região do Médio Vale do Itajaí-Açu}

Na região do Médio Vale do Itajaí-Açu as amostras foliares e sementes foram obtidas na Fazenda Faxinal, localizada no Município de Blumenau - Santa Catarina, junto às nascentes do Rio Garcia (afluente do Rio Itajaí-Açu), situada entre 
os paralelos $27^{\circ} 04^{\prime}$, e $27^{\circ} 05^{\prime}$, Sul e os meridianos $49^{\circ} 05^{\prime}$, e $49^{\circ} 10^{\prime}$, a Oeste de Greenwich (Figura 1 - B).

O clima da região é do tipo Cfa - mesotérmico úmido com verão quente (IDE et al. 1980), com precipitação anual entre 1600 e $1800 \mathrm{~mm}$, bem distribuídos, apresentando entre 120 e 140 dias de chuva durante o ano e umidade relativa entre 75 e $80 \%$, segundo ORSELLI (1986). De acordo com o mesmo autor, a região do Vale do Itajaí apresenta uma temperatura média anual entre 16 e $18^{\circ} \mathrm{C}$, tendo a temperatura média do mês de janeiro (mês mais quente) uma variação entre 20 e $22^{\circ} \mathrm{C}$ e a média do mês de julho (mês mais frio) entre 12 e $14^{\circ} \mathrm{C}$.

O solo da região é um Cambissolo Álico (MOSER et al., 1986). A topografia local pode ser classificada como ondulada a fortemente ondulada, com as altitudes dentro da Fazenda Faxinal variando entre 400 e 900 metros. A área específica de amostragem apresenta uma variação entre 450 e 690 metros acima do nível do mar.

A vegetação local, segundo KLEIN et al. (1986) e VELOSO et al. (1991), se caracteriza como sendo de Floresta Ómbrófila Densa Montana.

Dentro da Fazenda Faxinal foi escolhido um local com cobertura florestal natural (original), não submetida a exploração de madeira e de palmito. Neste local foram estabelecidas três áreas de coleta contíguas, num mesmo vale (Ribeirão Jacutinga, afluente do Rio Garcia), com altitudes médias de 450, 550 e $650 \mathrm{~m}$, denominados de SC450 (Santa Catarina 450), SC550 e SC650, respectivamente.

$\mathrm{Na}$ área localizada a 650 metros de altitude, a amostragem ficou circunscrita aos 5,44 hectares $(160 \times 340 \mathrm{~m})$ demarcados por REIS, A. (1995). 
Nas três áreas estabelecidas (três populações) foram coletadas amostras foliares e sementes (progênies) de indivíduos adultos tomados aleatoriamente, conforme Tabela 6 . A aleatoriedade foi estabelecida sem critérios de distância mínima, assim, podiam compor a amostra indivíduos próximos (vizinhos) ou não, desde que fossem reprodutivos.

Tabela 6. Características das populações de Euterpe edulis amostradas. PiracicabaSP, ESALQ/USP, 1996

\begin{tabular}{rrrrrrr}
\hline População & $\begin{array}{c}\text { Área da * } \\
\text { amostra }\end{array}$ & $\begin{array}{r}\text { Densidade } \\
\text { reprod. } * *\end{array}$ & $\begin{array}{r}\text { Número } \\
\text { Fem.*** }\end{array}$ & $\begin{array}{r}\text { Número } \\
\text { Masc.*** }\end{array}$ & $\begin{array}{r}\text { Amostra } \\
\text { Adultos }\end{array}$ & $\begin{array}{c}\text { Amostra } \\
\text { Progennies }\end{array}$ \\
\hline SC650 & 6 & 54 & 324 & 443 & 23 & 17 \\
SC550 & 8 & 54 & 432 & 680 & 27 & 11 \\
SC450 & 10 & 54 & 540 & 745 & 23 & 12 \\
SPS250 & 2 & 262 & 524 & 996 & 26 & 16 \\
SPS100 & 5 & 113 & 565 & 791 & 26 & 11 \\
SPS350 & 5 & 113 & 565 & 791 & 26 & 18 \\
SPL650 & 4 & 200 & 800 & 1200 & 22 & 22 \\
SPL350 & 5 & 113 & 565 & 791 & 25 & - \\
\hline
\end{tabular}

*área aproximada de abrangència da amostra (ha)

** número de indivíduos reprodutivos por hectare. a partir de REIS. A. (1995), para Blumenau. e de FANTINI et al (1993) e RIBEIRO et al (1994) para Saibadela e Limão

***Total de indivíduos reprodutivos estimados para a área de coleta (receptores de pólen - Fem) e total de indivíduos reprodutivos que poderiam contribuir com gametas masculinos (Masc - doadores de pólen) (área de abrangência Masc = aproximadamente uma faixa de $50 \mathrm{~m}$ em torno da área da coleta) 


\subsubsection{Região do Vale do Rio Ribeira do Iguape}

Na Região do Vale do Rio Ribeira do Iguape as coletas foram realizadas na Fazenda Intervales da Fundação para a Conservação e Produção Florestal do Estado de São Paulo da Secretaria de Meio Ambiente do Estado de São Paulo, localizada no Município de Sete Barras (SP). O local de coleta fica situado entre os paralelos $2413^{\prime}$ e $2414^{\prime}$ Sul, e entre 48 04' e 48 06' a Oeste de Greenwich (Figura 1 - S). A Fazenda Intervales possui 38.354 ha e está interligada a outras três unidades de conservação (Parque Estadual de Carlos Botelho, Estação Ecológica do Xitué e Parque Estadual Turístico do Alto Ribeira).

O clima da região é do tipo Cfa - mesotérmico úmido de verão quente, com temperatura média do mês mais quente superior a $22^{\circ} \mathrm{C}$ e do mês mais frio entre 3 e $18^{\circ} \mathrm{C}$; apresentando mais de $30 \mathrm{~mm}$ de chuvas no mês mais seco e uma precipitação média em torno de $2000 \mathrm{~mm}$, sem estiagem (BRASIL, 1979).

O solo na região é classificado como Podzólico Vermelho Amarelo (BRASIL, 1979), com relevo ondulado e forte ondulado; e as altitudes dentro da Fazenda Intervales variando entre 100 e 900 m (GUIX et al. ,1992).

A cobertura vegetal é característica da Floresta Ombrófila Densa (Floresta Tropical Atlântica), sob condições primárias, com histórico de pouca ou nenhuma perturbação antrópica.

Dentro da Fazenda Intervales foram estabelecidos dois locais de estudo. O primeiro, denominado Saibadela, localizado na Bacia do Rio Saibadela (afluente do Rio Ribeira do Iguape), onde foram estabelecidas três áreas de coleta contíguas, em altitudes médias de 100, 250 e 350 m, denominadas SPS100 (São Paulo/Saibadela 100), SPS250 e SPS350, respectivamente. O segundo local, 
denominado Limão, foi estabelecido no Vale do Rio São Pedro, distando aproximadamente $9 \mathrm{~km}$ do primeiro local, onde foram definidas duas áreas de coleta, a 350 e $700 \mathrm{~m}$ de altitude média, denominadas SPL350 (São Paulo/Limão 350) e SPL700 respectivamente. Entre os locais havia cobertura florestal contínua.

$\mathrm{Na}$ área localizada a $250 \mathrm{~m}$ na Bacia do Rio Saibadela, a amostragem ficou restrita à área de produção de sementes $(1,8$ ha) da Fazenda Intervales, descrita em FANTINI et al. (1993)

Nas cinco áreas (cinco populações) estabelecidas foram coletadas amostras foliares e sementes (progênies) de indivíduos adultos tomados aleatoriamente, conforme Tabela 6 .

O estabelecimento da estratégia de amostragem nas duas regiões, com locais distintos, em uma delas, e com populações contíguas em cada local, permite caracterizar a estrutura e avaliar os níveis de fluxo gênico em diferentes situações. Assim, as populações contíguas (três em Blumenau e três em Saibadela) permitem avaliar divergências relativas a pequenas distâncias; os dois locais (Limão e Saibadela) amostrados na Fazenda Intervales, sob cobertura florestal contínua, permitem avaliar divergências e fluxo a maiores distâncias, sem isolamento geográfico; enquanto que a comparação entre as duas regiōes, permite caracterizar a divergência em populações isoladas geograficamente ou por distâncias muito grandes (mais de $500 \mathrm{~km}$ ). Em todas as situações o modelo básico pressuposto é o de isolamento por distância, pois, originalmente o palmiteiro aparecia no sub-bosque de quase toda a área coberta pela Floresta Tropical Atlântica em grande abundância (VELOSO e KLEIN, 1957, 1959; PEDROSA MACEDO et al., s.d.), e o tempo ocorrido desde o inicio da devastação da Floresta Tropical Atlântica, com conseqüente fragmentação das populações (últimos 50 anos), não deve ter permitido 
a passagem de mais do que uma geração, especialmente nas áreas em que foram realizadas as coletas.

3.2. Caracterização Genética das Populações em Estudo

A caracterização genética foi realizada empregando-se marcadores alozímicos, revelados a partir de eletroforese em gel de amido, seguindo as recomendações de KEPHART (1990), ALFENAS et al. (1991) e FERRAZ et al. (1994).

\subsubsection{Tecidos para Eletroforese de Alozimas}

As análises de eletroforese de alozimas foram realizadas utilizando-se tecidos foliares de plântulas e de indivíduos adultos. A sistemática de coleta, transporte e armazenagem dos folíolos foi determinada a partir de avaliações preliminares, procurando-se estabelecer uma metodologia que não alterasse os padrões de atividade enzimática dos tecidos empregados.

Para as análises das progênies foram coletados folíolos de plantas com aproximadamente 12 meses após a semeadura em areia, cultivadas sob telado, com cobertura de sombrite $(50 \%)$. Os folíolos coletados eram imediatamente submetidos a extração, ou armazenados em geladeira $\left(5\right.$ a $\left.10^{\circ} \mathrm{C}\right)$ por até 3 semanas.

Nas plantas adultas, amostradas nas áreas de coleta, foram obtidos folíolos, os quais eram acondicionados em sacos plásticos e estes em recipientes 
com gelo para transporte até o laboratório. Uma vez no laboratório eram mantidos em geladeira $\left(5\right.$ a $\left.10^{\circ} \mathrm{C}\right)$ até sua utilização (até aproximadamente 4 semanas).

\subsubsection{Procedimentos de Extração de Enzimas e Carregamento do Gel}

Para extração das enzimas foram empregadas amostras de aproximadamente $20 \mathrm{mg}$ de tecido do limbo foliar, maceradas com aproximadamente $7 \mathrm{mg}$ de Polivinil Polipirrolidona, $10 \mathrm{mg}$ de areia lavada (48 horas em água corrente, 24 horas em ácido nítrico concentrado, seguido de 48 horas em água corrente) e 100 microlitros da solução de extração número 1 de ALFENAS et al. (1991, p 41), modificada pela ausência de 2-Mercaptoetanol (Anexo II).

Os tecidos foram macerados com auxílio de um bastão de vidro, sobre placas de porcelana resfriadas, mantidas sobre barras de gelo durante o processo de extração.

Os extratos de cada amostra eram absorvidos em pedaços de papel filtro (Whatman $\mathrm{n}^{\circ}$ 3), com dimensões de $6 \times 10 \mathrm{~mm}$. Após absorção dos extratos, os pedaços de papel eram inseridos no gel lado a lado (até 20 amostras). Nas duas extremidades do gel, eram ainda adicionados pedaços de papel filtro embebidos em solução de azul de bromofenol à $0,1 \%$, para marcação da linha de frente durante a migração. 


\subsubsection{Tampões de Eletrodo e Gel}

O meio suporte utilizado para a eletroforese foi o gel de amido de milho (penetrose 30), à $13 \%$, sendo testados os quatro sistemas de tampão eletrodo/gel, discriminados na Tabela 7 .

Durante a migração os géis eram mantidos à temperatura de aproximadamente $5^{\circ} \mathrm{C}$ (sob condições de geladeira, adicionando-se uma placa de gelo sobre o gel), com corrente constante $(20 \mathrm{~mA}$ durante os primeiros 20 a 30 minutos e $40 \mathrm{~mA}$ após), com voltagem inicialmente de 100 a 150 volts e 300 a 350 volts após passagem da corrente para $40 \mathrm{~mA}$. Os papéis filtro com as amostras eram retirados 20 a 30 minutos após o início da migração. O tempo de corrida era de aproximadamente 7 horas, quando o marcador de bromofenol atingia de 8 a $9 \mathrm{~cm}$ de migração.

Após o término da migração, os géis eram cortados em 6 fatias de aproximadamente $1,5 \mathrm{~mm}$ de espessura, sendo empregadas as quatro fatias intermediárias para coloração.

3.2.4. Sistemas Enzimáticos Testados e Procedimentos para Coloração

Foram testados 18 sistemas enzimáticos (Tabela 8) nas diferentes camadas do gel, empregando-se as receitas descritas em ALFENAS et al. (1991, p. 133 a 160$)$. 
Tabela 7. Sistemas de Tampão eletrodo/gel para eletroforese de enzimas, testados em Euterpe edulis. Piracicaba-SP, ESALQ/USP, 1996

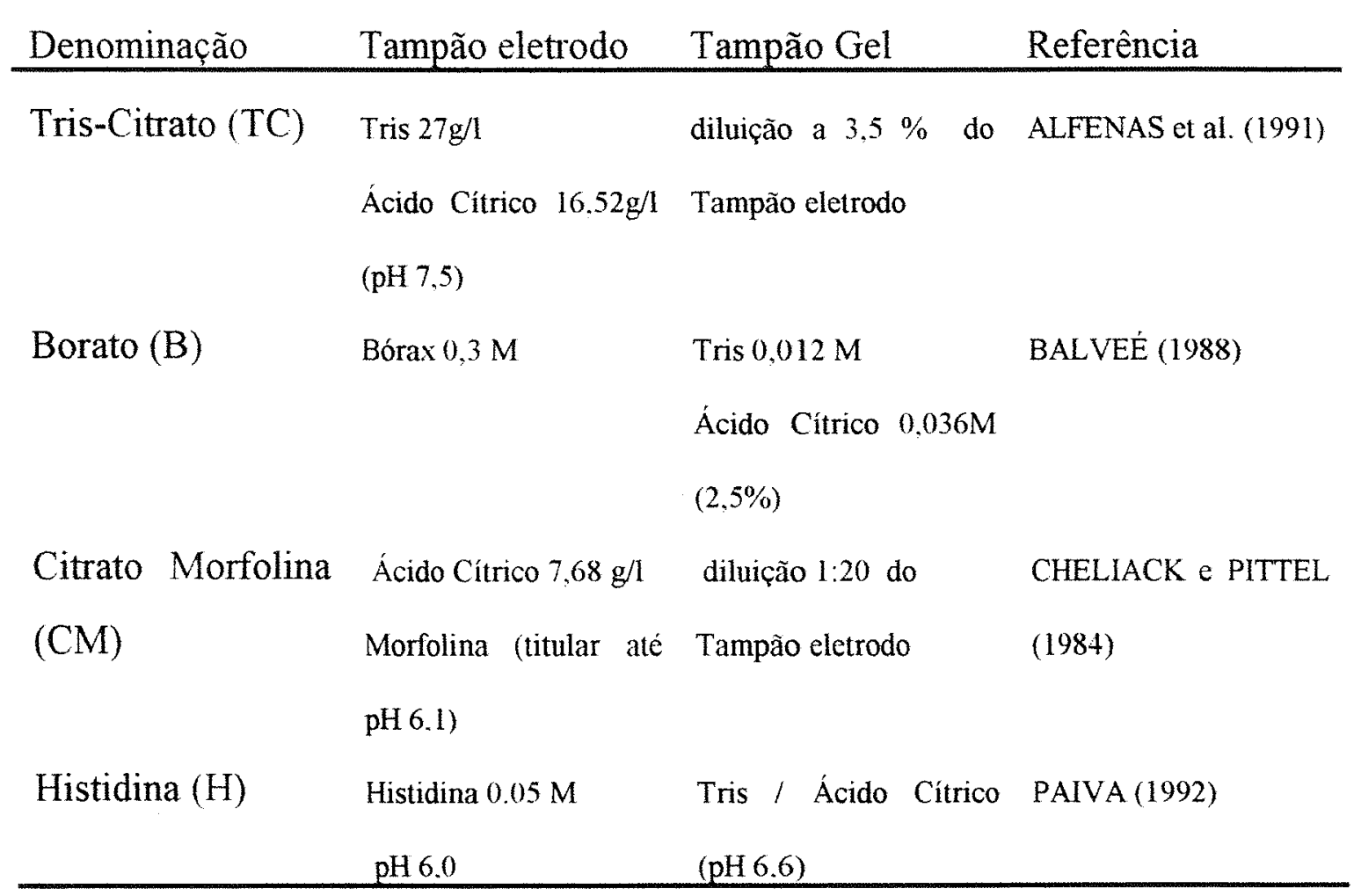

O resultado das combinações entre tampões de eletrodo/gel, sistemas enzimáticos e camadas do gel, em termos de resolução, número de locos aparentes e presença de polimorfismos foram os critérios empregados na definição do protocolo para a espécie. Procurou-se a maior nitidez na definição das bandas, considerando-se as quatro camadas disponíveis, de modo a se obter o maior número de locos aparentes numa corrida. 
Tabela 8. Sistemas enzimáticos testados em Euterpe edulis. Piracicaba-SP, ESALQ/USP, 1996

\begin{tabular}{lll}
\hline Enzima & Código & Sigla \\
\hline Alfa-Esterase & Alfa-EST- E.C.3.1.1.1 & $\alpha$-EST \\
Beta-Esterase & Beta-EST- E.C.3.1.1.1 & $\beta$-EST \\
Glutamato Desidrogenase & GDH - E.C.1.4.1.3 & GDH \\
Leucina Aminopeptidase & LAP - E.C.3.4.11.1 & LAP \\
Shiquimato Desidrogenase & SKDH - E.C.1.1.1.25 & SK \\
Malato Desidrogenase & MDH - E.C.1.1.1.37 & MDH \\
Isocitrato Desidrogenase & IDH - E.C.1.1.1.42 & IDH \\
Fosfatase Ácida & ACP - 3.1.3.2 & ACP \\
Fosfatase Alcalina & ALP - E.C.3.1.3.1 & APS \\
Álcool Desidrogenase & ADH - E.C.1.1.1.1 & ADH \\
Peroxidase & PO - E.C.1.11.1.7 & PRX \\
Fosfoglucomutase & PGM - E.C.2.7.5.1 & PGM \\
Fosfoglucose Isomerase & PGI- E.C.5.3.1.9 & PGI \\
6-Fosfogliconato Desidrogenase & 6PGD - E.C.1.1.1.44 & 6 PG \\
Glucose-6-Fosfato Desidrogenase & G6PDH E.C.1.1.1.49 & G6P \\
Glutamato-Oxalacetato Transaminase & GOT - E.C.2.6.1.1 & GOT \\
Glicerato-2 Desidrogenase & G2DH - E.C.1.1.1.29 & G2D \\
Catalase & CAT - E.C.1.11.1.6 & CAT \\
\hline
\end{tabular}


Por loco aparente entende-se cada regiăo do zimograma que apresenta um comportamento aparentemente independente das demais e pode ser interpretada geneticamente ou, que apresenta uma segregação mendeliana aparente, tomando-se em conta a possível estrutura quaternária de cada enzima em questão. A coerência entre genitor feminino (receptor de pólen) e progênie proporciona consistência a essa interpretação.

\subsubsection{Interpretação dos Zimogramas}

A leitura dos zimogramas era realizada logo após a revelação das isoenzimas, quando as bandas eram desenhadas em filme plástico, mantendo-se as dimensões originais, para mensuração das distâncias de migração. Eram também desenhadas as posições do marcador de bromofenol, para comparações entre géis e obtenção dos valores de Rf, conforme citado por ALFENAS et al. (1991), onde :

$$
\mathrm{Rf}=\mathrm{di} / \mathrm{db}
$$

sendo

$$
\begin{aligned}
& \mathrm{di}=\text { distância da origem à banda em questão } \\
& \mathrm{db}=\text { distância da origem até a posição média do marcador de }
\end{aligned}
$$

bromofenol

Foi também estimado o RM (migração relativa), conforme CHELIAK e PITTEL (1984), onde :

$$
\mathrm{RM}=\mathrm{di} / \mathrm{df}
$$


sendo:

df = distância da origem até a posição da banda mais freqüente.

Logo após desenhados os géis eram fotografados, permitindo assim a disponibilidade de reproduções fiéis dos zimogramas, para eventuais releituras.

3.3. Análise dos Dados

3.3.1. Caracterização da Variação Genética

A variação genética foi caracterizada a partir das estimativas das freqüências alélicas e dos índices de diversidade (heterozigosidade, percentagem de locos polimórficos e número médio de alelos por loco), para cada população individualmente. Além disso, foram comparadas as freqüências alélicas entre populações e gerações.

3.3.1.1.Estimativas das Freqüências Alélicas

A partir da interpretação dos zimogramas e conseqüente definição dos genótipos de cada individuo estudado, para os marcadores empregados, foram estabelecidas as freqüências alélicas para cada população pré-definida, tanto para os indivíduos adultos quanto para as progênies, onde:

$$
\hat{p}_{i j}=\mathrm{n}_{\mathrm{ij}} / \mathrm{n}_{\mathrm{j}}
$$


sendo :

$$
\begin{aligned}
& \hat{p}_{i j}=\text { freqüência do alelo } \mathrm{i} \text { na população } \mathrm{j} \\
& \mathrm{n}_{\mathrm{ij}}=\text { número de ocorrências do alelo } \mathrm{i} \text { na população } \mathrm{j} \\
& \mathrm{n}_{\mathrm{j}}=\text { número total de alelos amostrados na população } \mathrm{j}
\end{aligned}
$$

Para a obtenção destas estimativas empregou-se o programa BIOSYS-1 (SWOFFORD e SELANDER, 1989).

As frequiências alélicas foram comparadas entre populações, tanto para adultos quanto para progênies, e entre gerações, através de testes de contingência, conforme proposto por WORKMAN e NISWANDER (1970), empregando-se também o programa BIOSYS-1. Tais comparações visaram caracterizar eventuais divergências entre as populações e/ou entre gerações, as quais possibilitaram testar a hipótese de existência ou não de divergência entre as populações (ho : $F_{\mathrm{ST}}=0$ ), conforme discutem LI e HORWITZ (1953) e WORKMAN e NISWANDER (1970). Nas situações em que uma classe de freqüência esperada apresentou valor inferior a um (1) esta era somada a classe de menor freqüência entre as demais, para obtenção do valor de $\chi^{2}$, conforme recomendações de GOMES (1990).

\subsubsection{Estimativas dos Índices de Diversidade}

Foram feitas estimativas da porcentagem de locos polimórficos $(\mathrm{P})$, do número médio de alelos por loco $(\mathrm{A})$, das heterozigosidades médias observada $(\mathrm{Ho})$ e esperada $(\mathrm{He})$ e dos índices de fixação $(F)$ para as oito populações estudadas, tanto para indivíduos adultos quanto para progênies. Tais índices foram também estimados 
agrupando-se as populações por local e os locais por região. As estimativas $\mathrm{P}, \mathrm{A}, \mathrm{Ho}$ e He foram obtidas empregando-se o programa BIOSYS-1 (SWOFFORD e SELANDER, 1989).

A porcentagem de locos polimórficos foi estimada considerando o número de locos que apresentavam o alelo mais freqüente com ocorrência inferior a $95 \%$, em relação ao número total de locos.

O número médio de alelos por loco foi estimado a partir da média aritmética do número de alelos de cada loco, em cada população, para cada loco, fazendo-se a média aritmética entre locos.

A heterozigosidade média observada (Ho) foi obtida pela média aritmética das proporções do número total de heterozigotos em relação ao número total de indivíduos entre os locos analisados. Enquanto que a heterozigosidade esperada $(\mathrm{He})$ foi obtida por :

$$
\hat{H} e=2 n\left(1-\sum \hat{p}_{i}^{2}\right) /(2 n-1)(\mathrm{NEI}, 1978)
$$

onde :

$$
\mathrm{n} \text { = número de indivíduos amostrados }
$$

fazendo-se a média aritmética entre os locos estudados.

Os índices de fixação foram estimados como desvios da heterozigosidade esperada, assim :

$$
\hat{F}=(H o-\hat{H} e) / \hat{H} e
$$




\subsubsection{Caracterização da Estrutura Genética das Populações}

A caracterização da estrutura genética entre populações foi realizada a partir de três abordagens: estatísticas F de Wright (WRIGHT, 1951, 1965), coeficientes de coancestralidade de Cockerham (COCKERHAM, 1969; WEIR, 1990a; VENCOVSKY, 1992) e análise da diversidade genética em populações subdivididas de Nei (NEI, 1973, 1977, 1987).

Ainda que com bases genéticas similares, as três abordagens são complementares no sentido do significado biológico das estimativas obtidas. Assim, as estatísticas $F$ permitem não apenas caracterizar como está distribuída a variabilidade genética entre as populações $\left(\mathrm{F}_{\mathrm{ST}}\right)$, mas também produz informações sobre os níveis médios de endogamia a nível de população $\left(F_{I S}\right)$ e a nível de espécie $\left(\mathrm{F}_{\mathrm{IT}}\right)$. Os coeficientes de coancestralidade $(\theta)$ possibilitam a avaliação da divergência em diferentes níveis de hierarquia, além de possibilitar a obtenção de estimativas dos níveis de endogamia a partir de uma base não viesada. A análise da diversidade genética em populações subdivididas permite a comparação dos níveis de heterozigosidade entre e dentro das populações e a obtenção de uma estimativa de divergência a partir de uma base diferente daquela que fundamentam as estimativas de $F_{\text {ST }}$ e $\theta$.

Adicionalmente, a comparação dos valores obtidos para as estimativas de $G_{S T}, F_{S T}$ e $\theta$, permitirá uma discussão sobre a adequação das três abordagens em relação a caracterização da estrutura genética em populações naturais, bem como à obtenção de estimativas do fluxo gênico. 


\subsubsection{Estatísticas $F$}

A estatísticas $F\left(F_{I T}, F_{I S}\right.$ e $\left.F_{S T}\right)$ foram estimadas a partir do proposto por WRIGHT $(1951,1965)$, empregando-se o programa BIOSYS-1 (SWOFFORD e SELANDER, 1989). Assim, conforme NEI (1977):

$$
\begin{aligned}
& \hat{F}_{I T}=1-H_{o t} / \hat{H}_{e t} \\
& \hat{F}_{I S}=1-H_{o t} / \hat{H}_{e i} \\
& \hat{F}_{S T}=1-\hat{H}_{e i} / \hat{H}_{e r}
\end{aligned}
$$

onde:

$$
\begin{aligned}
& H_{o t}=1-\sum \sum \mathrm{X}_{\mathrm{li}} / \mathrm{s} \\
& \hat{H}_{e i}=1-\left(\sum_{\mathrm{i}} \Sigma_{\mathrm{l}} \Sigma_{\mathrm{k}} \mathrm{X}^{2}{ }_{\mathrm{ilk}}\right) / 1 \mathrm{~s} \\
& \hat{H}_{e t}=1-\left[\left(\Sigma_{\mathrm{l}} \Sigma_{\mathrm{k}} \mathrm{X}_{\mathrm{lk}}\right) / \mathrm{s}\right]^{2} / 1
\end{aligned}
$$

sendo:

$\hat{H}_{e r}=$ heterozigosidade esperada total (todas as populações)

$H_{o t}=$ heterozigosidade observada total

$\hat{H}_{e i}=$ heterozigosidade esperada média entre as populações

$\mathrm{X}_{\mathrm{il}}=$ freqüência de heterozigotos do locos 1 na população $\mathrm{i}$

$\mathrm{x}_{\mathrm{ilk}}=$ freqüência do alelo $\mathrm{k}$ do locos 1 na população $\mathrm{i}$

$\mathrm{s}=$ número de populações

1 = número de locos 


\subsubsection{Coeficientes de Coancestralidade}

Os coeficientes de coancestralidade foram obtidos a partir da decomposição dos componentes de variação da análise da variância das freqüências alélicas individuais, conforme COCKERHAM (1969). Assim, empregou-se um modelo hierárquico, desbalanceado, a partir do descrito por WEIR (1990a) e VENCOVSKY (1992), para adultos e progênies.

Para adultos foi estruturado um modelo com quatro níveis de hierarquia, a saber:

$$
\mathrm{Y}_{\text {hijkl }}=\mu+\mathrm{r}_{\mathrm{h}}+\mathrm{l}_{\mathrm{i(h)}}+\mathrm{p}_{\mathrm{j}(\mathrm{hi})}+\mathrm{a}_{\mathrm{k}(\mathrm{hij})}+\mathrm{g}_{\mathrm{l}(\mathrm{hijk})}
$$

onde:

$$
\begin{aligned}
& \mathrm{Y}_{\text {hijkl }}=\text { freqüência do alelo } 1 \text {, dentro do indivíduo } \mathrm{k} \text {, da população } \mathrm{j} \text {, do local } \mathrm{i} \text {, } \\
& \mu=\text { média geral; } \\
& \mathrm{r}_{\mathrm{h}}=\text { efeito da região } \mathrm{h}, \mathrm{com} \mathrm{h}=1, \mathrm{n}_{1} \text {; } \\
& \mathrm{l}_{\mathrm{i}(\mathrm{h})}=\text { efeito do local } \mathrm{i} \text {, dentro da região } \mathrm{h}, \mathrm{com} \mathrm{i}=1, \ldots, \mathrm{n}_{2 \mathrm{~h}} \text {; } \\
& \mathrm{p}_{\mathrm{j}(\mathrm{hi})}=\text { efeito da população } \mathrm{j} \text {, dentro do local } \mathrm{i} \text {, dentro da região } \mathrm{h} \text {, com } \mathrm{j}= \\
& 1, \ldots, \underline{n} 3 h_{i}
\end{aligned}
$$


$\mathrm{a}_{\mathrm{k}(\mathrm{hij})}=$ efeito do indivíduo $\mathrm{k}$, dentro da população $\mathrm{j}$, dentro do local $\mathrm{i}$, dentro da regiäo $h$, com $k=1, \ldots, n_{4}$ hij;

$\mathrm{g}_{\mathrm{l}(\mathrm{hijk})}=$ efeito do gene 1 , dentro do indivíduo $\mathrm{k}$, dentro da população $\mathrm{j}$, dentro do local i, dentro da região $h, \operatorname{com} 1=1, \ldots, n_{6 h i j k}$;

sendo:

$$
\begin{aligned}
& \mathrm{n}_{1}=\text { número de regiões } \\
& \mathrm{n}_{2 \mathrm{~h}}=\text { número de locais em cada região } \\
& \mathrm{n}_{3 \mathrm{hi}}=\text { número de populações em cada local de cada região } \\
& \mathrm{n}_{4 \mathrm{hij}}=\text { número de indivíduos em cada população de cada local de cada }
\end{aligned}
$$

região

$\mathrm{n}_{6 \text { hịk }}=$ número de alelos em cada indivíduo dentro de cada população de cada local de cada região ( 1 ou 2)

Para progênies foi estruturado um modelo com cinco níveis de hierarquia, a saber:

$$
Y_{\text {hijkIm }}=\mu+r_{h}+l_{i(h)}+p_{j(h i)}+f_{k(h i j)}+a_{1(h i j k)}+g_{m(h i j k l)}
$$

onde:

$$
\begin{aligned}
& Y_{\text {hijklm }}=\text { freqüência do alelo } \mathrm{m} \text {, dentro do indivíduo } 1 \text {, da família } \mathrm{k} \text {, da } \\
& \quad \text { população } \mathrm{j} \text {, do local } \mathrm{i} \text {, da região } \mathrm{h} \text {; } \\
& \mu=\text { média geral; }
\end{aligned}
$$


$\mathrm{r}_{\mathrm{h}}=$ efeito da região $\mathrm{h}, \mathrm{com} \mathrm{h}=1, \mathrm{n}_{1}$;

$\mathrm{I}_{\mathrm{i}(\mathrm{h})}=$ efeito do local $\mathrm{i}$, dentro da região $\mathrm{h}, \operatorname{com} \mathrm{i}=1, \ldots, \mathrm{n}_{2 \mathrm{~h}}$;

$p_{j(h i)}=$ efeito da população $j$, dentro do local $i$, dentro da região $h$, com $j=$ $1, \ldots, \mathrm{n}_{3 \mathrm{hi}}$

$\mathrm{f}_{\mathrm{k}(\text { hij })}=$ efeito da família $\mathrm{k}$, dentro da população $\mathrm{j}$, dentro do local $\mathrm{i}$, dentro da região $h, \operatorname{com~} k=1, \ldots, n_{4 h i j}$;

$a_{1(h j k)}=$ efeito do indivíduo 1 , dentro da família $\mathrm{k}$, dentro da população $\mathrm{j}$, dentro do local i, dentro da região $h$, com $l=1, \ldots, n_{5}$ hijk;

$\mathrm{g}_{\mathrm{m}(\mathrm{hijk})}=$ efeito do gene $\mathrm{m}$, dentro do indivíduo 1, dentro da família $\mathrm{k}$, dentro da população $j$, dentro do local $i$, dentro da região $h, \operatorname{com~} m=1, \ldots, n_{6 h i j k l}$.

sendo:

$$
\begin{aligned}
& \mathrm{n}_{1}=\text { número de regiões } \\
& \mathrm{n}_{2 \mathrm{~h}}=\text { número de locais em cada região } \\
& \mathrm{n}_{3 \mathrm{hi}}=\text { número de populações em cada local de cada região } \\
& \mathrm{n}_{4 \mathrm{hij}}=\text { número de famílias em cada população de cada local de cada }
\end{aligned}
$$

região

$$
\mathrm{n}_{5 \mathrm{hijk}}=\text { número de indivíduos dentro de cada família em cada }
$$
população de cada local de cada região 
$\mathrm{n}_{6 \text { hijk }}=$ número de alelos em cada indivíduo de cada família dentro de cada população de cada local de cada região ( 1 ou 2 )

A estrutura de análise de variância para indivíduos adultos é apresentada na Tabela 9 e para progênies na Tabela 10.

As estimativas dos componentes de variância para indivíduos adultos, podem ser obtidas a partir das esperanças dos quadrados médios demonstradas na Tabela 9, assim:

$$
\begin{aligned}
& \hat{\sigma}_{G}^{2}=\mathrm{QMG} \\
& \hat{\sigma}_{I}^{2}=(\mathrm{QMI}-\mathrm{QMG}) / 2 \\
& \hat{\sigma}_{P}^{2}=[(\mathrm{QMP}-\mathrm{QMI})] / \mathrm{k}_{1} \\
& \hat{\sigma}_{L}^{2}=\left[(\mathrm{QML}-\mathrm{QMI})-\mathrm{k}_{2} \hat{\sigma}_{P}^{2}\right] / \mathrm{k}_{3} \\
& \hat{\sigma}_{R}^{2}=\left[(\mathrm{QMR}-\mathrm{QMI})-\mathrm{k}_{4} \hat{\sigma}_{P}^{2}-\mathrm{k}_{5} \hat{\sigma}_{L}^{2}\right] / \mathrm{k}_{6} \\
& \hat{\sigma}_{T}^{2}=\hat{\sigma}_{G}^{2}+\hat{\sigma}_{I}^{2}+\hat{\sigma}_{P}^{2}+\hat{\sigma}_{L}^{2}+\hat{\sigma}_{R}^{2}
\end{aligned}
$$

sendo os valores de $\mathrm{k}$ obtidos conforme ANDERSON e BANCROFT (1952). 
Tabela 9 .Análise da variância de frequiências alélicas com modelo hierárquico desbalanceado para indivíduos adultos de Euterpe edulis. Piracicaba-SP, ESALQ/USP, 1996

Fontes de variação Graus de liberdade Quadrados Esperanças (QM)

médios (QM)

Regiões

$n_{1}-1$

QMR

$\sigma_{G}^{2}+2 \sigma_{I}^{2}+k_{4} \sigma_{P}^{2}+k_{5} \sigma_{L}^{2}+k_{6} \sigma_{R}^{2}$

Locais/regiões

$$
\sum_{h=1}^{n_{1}} n_{2 h}-n_{1}
$$

QML

$$
\sigma_{G}^{2}+2 \sigma_{I}^{2}+k_{2} \sigma_{P}^{2}+k_{3} \sigma_{L}^{2}
$$

Populações/locais/

regiōes

$\sum_{h=1}^{n_{1}} \sum_{i=1}^{n_{2}} n_{3 h i}-\sum_{h=1}^{n_{1}} n_{2 h}$

QMP

$\sigma_{G}^{2}+2 \sigma_{I}^{2}+k_{1} \sigma_{P}^{2}$

Indivíduos/

populações/locais/

regiões

$\sum_{h=1}^{n} \sum_{i=1}^{n_{2}} \sum_{j=1}^{n^{n}}{ }_{S h i j}-\sum_{h=1}^{n} \sum_{i=1}^{n_{2}} n_{3 h i}$

QMI

$$
\sigma_{G}^{2}+2 \sigma_{I}^{2}
$$

Genes/Individuos/

populações/locais/

regiões

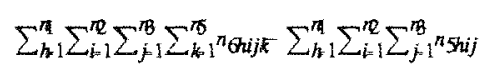

QMG

$\sigma_{G}^{2}$ 


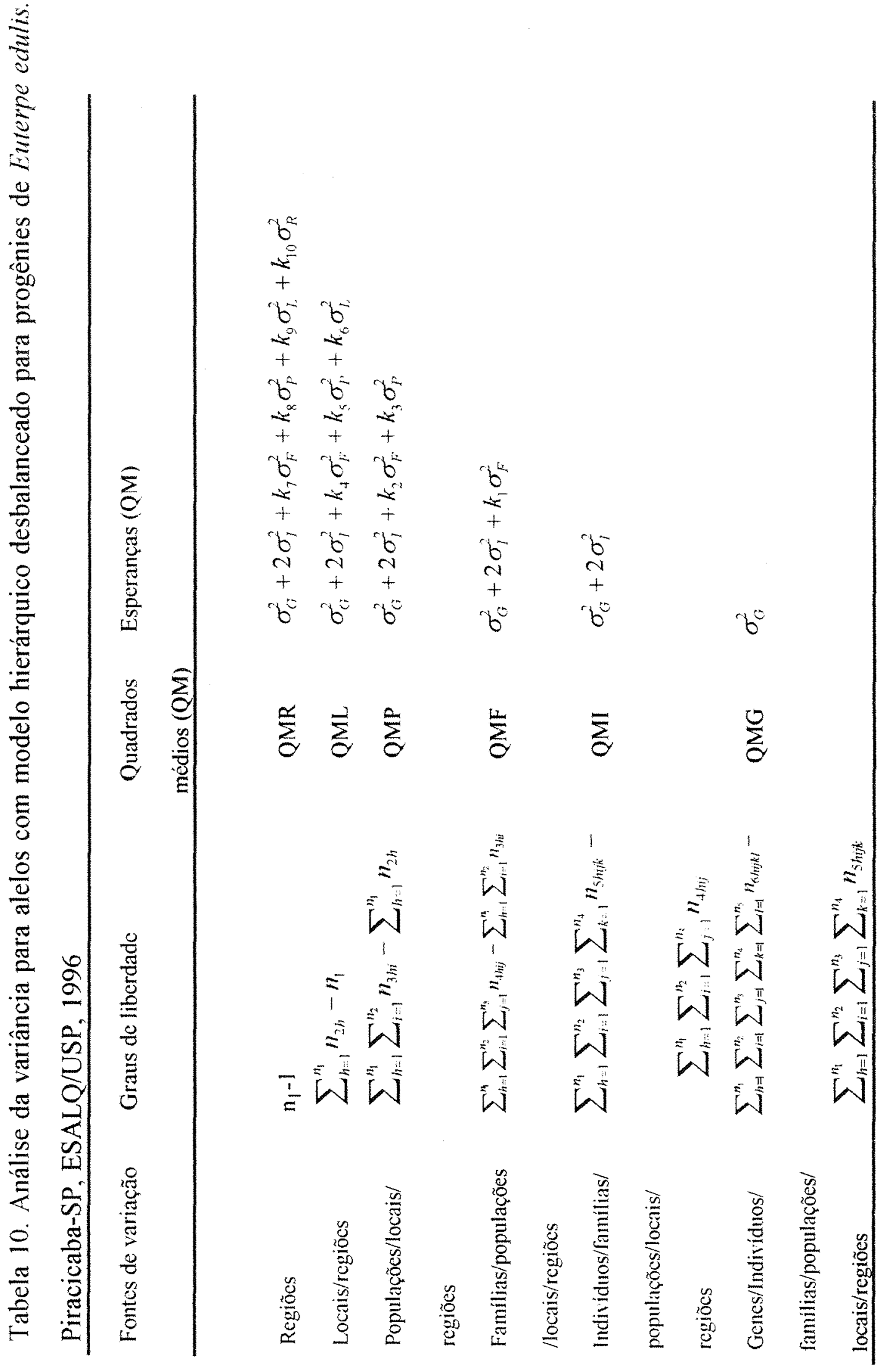


O significado genético destes componentes, estimados a partir de cada alelo pode ser definido em termos das correlações intraclasse, ou coeficientes de coancestralidade, nos diferentes níveis de hierarquia. Assim, baseado em COCKERHAM (1969) e WEIR (1990a), tem-se que :

$$
\begin{aligned}
& \sigma_{T}^{2}=p(1-p) \\
& \sigma_{R}^{2}=p(1-p) \theta_{R} \\
& \sigma_{L}^{2}=p(1-p)\left(\theta_{L}-\theta_{R}\right) \\
& \sigma_{P}^{2}=p(1-p)\left(\theta_{P}-\theta_{L}\right) \\
& \sigma_{L}^{2}=p(1-p)\left(F-\theta_{P}\right) \\
& \sigma_{G}^{2}=p(1-p)(1-F)
\end{aligned}
$$

onde :

$$
\theta_{R}=\text { correlação entre freqüências alélicas de diferentes locais dentro }
$$

de regiões

$$
\theta_{\mathrm{L}}=\text { correlação entre freqüências alélicas de diferentes populações do }
$$
mesmo local de diferentes regiões

$$
\theta_{\mathrm{P}}=\text { correlações entre freqüências alélicas de diferentes indivíduos da }
$$
mesma população de diferentes locais de diferentes regiões 
$\mathrm{F}=$ correlação entre alelos dentro de indivíduos de diferentes populações de diferentes locais de diferentes regiões

$\mathrm{f}=$ correlação entre alelos dentro de indivíduos dentro de populações

Desta forma, estimativas dos coeficientes de coancestralidade podem ser obtidas a partir dos componentes de variância :

$$
\begin{aligned}
& \hat{\theta}_{R}=\hat{\sigma}_{R}^{2} / \hat{\sigma}_{T}^{2} \\
& \hat{\theta}_{L}=\hat{\sigma}_{L}^{2} / \hat{\sigma}_{T}^{2}+\hat{\theta}_{R}=\left(\hat{\sigma}_{L}^{2}+\hat{\sigma}_{R}^{2}\right) / \hat{\sigma}_{T}^{2} \\
& \hat{\theta}_{P}=\hat{\sigma}_{P}^{2} / \hat{\sigma}_{T}^{2}+\hat{\theta}_{L}=\left(\hat{\sigma}_{P}^{2}+\hat{\sigma}_{L}^{2}+\hat{\sigma}_{R}^{2}\right) / \hat{\sigma}_{T}^{2} \\
& \hat{F}=\hat{\sigma}_{I}^{2} / \hat{\sigma}_{T}^{2}+\hat{\theta}_{P}=\left(\hat{\sigma}_{I}^{2}+\hat{\sigma}_{P}^{2}+\hat{\sigma}_{L}^{2}+\hat{\sigma}_{R}^{2}\right) / \hat{\sigma}_{T}^{2} \\
& \hat{f}=\hat{\sigma}_{I}^{2} /\left(\hat{\sigma}_{G}^{2}+\hat{\sigma}_{I}^{2}\right)\left(\text { por definição, como }\left[\sigma_{b}^{2} /\left(\sigma_{\mathrm{w}}^{2}+\sigma_{b}^{2}\right)\right] \mathrm{em}\right.
\end{aligned}
$$

COCKERHAM, 1969, p.74)

assim,

$$
\hat{f}=\left(\hat{F}-\hat{\theta}_{P}\right) /\left(1-\hat{\theta}_{p}\right)
$$

As estimativas dos componentes de variância para progênies foram obtidas a partir das esperanças dos quadrados médios da Tabela 10, assim: 


$$
\begin{aligned}
& \hat{\sigma}_{G}^{2}=\mathrm{QMG} \\
& \hat{\sigma}_{I}^{2}=(\mathrm{QMI}-\mathrm{QMG}) / 2 \\
& \hat{\sigma}_{F}^{2}=(\mathrm{QMF}-\mathrm{QMI}) / \mathrm{k}_{1} \\
& \hat{\sigma}_{P}^{2}=\left[(\mathrm{QMP}-\mathrm{QMI})-\mathrm{k}_{2} \hat{\sigma}_{F}^{2}\right] / \mathrm{k}_{3} \\
& \hat{\sigma}_{L}^{2}=\left[(\mathrm{QML}-\mathrm{QMI})-\mathrm{k}_{4} \hat{\sigma}_{F}^{2}-\mathrm{k}_{5} \hat{\sigma}_{P}^{2}\right] / \mathrm{k}_{6} \\
& \hat{\sigma}_{R}^{2}=\left[(\mathrm{QMR}-\mathrm{QMI})-\mathrm{k}_{7} \hat{\sigma}_{F}^{2}-\mathrm{k}_{8} \hat{\sigma}_{P}^{2}-\mathrm{k}_{9} \hat{\sigma}_{L}^{2}\right] / \mathrm{k}_{10} \\
& \hat{\sigma}_{T}^{2}=\hat{\sigma}_{G}^{2}+\hat{\sigma}_{I}^{2}+\hat{\sigma}_{F}^{2}+\hat{\sigma}_{P}^{2}+\hat{\sigma}_{L}^{2}+\hat{\sigma}_{R}^{2}
\end{aligned}
$$

sendo os valores de $\mathrm{k}$ obtidos conforme ANDERSON e BANCROFT (1952).

O significado genético destes componentes, estimados a partir de cada alelo pode ser definido em termos das correlações intraclasse, ou coeficientes de coancestralidade, nos diferentes níveis de hierarquia. Assim, baseado em COCKERHAM (1969), WEIR (1990a) e VENCOVSKY (1992), tem-se que :

$$
\begin{aligned}
& \sigma_{\mathrm{T}}^{2}=p(1-p) \\
& \sigma_{\mathrm{R}}^{2}=p(1-p) \theta_{\mathrm{R}} \\
& \sigma_{\mathrm{L}}^{2}=p(1-p)\left(\theta_{\mathrm{L}}-\theta_{\mathrm{R}}\right)
\end{aligned}
$$




$$
\begin{aligned}
& \sigma_{\mathrm{P}}^{2}=p(1-p)\left(\theta_{\mathrm{P}}-\theta_{\mathrm{L}}\right) \\
& \sigma_{\mathrm{F}}^{2}=p(1-p)\left(\theta_{\mathrm{F}}-\theta_{\mathrm{P}}\right) \\
& \sigma_{\mathrm{I}}^{2}=p(1-p)\left(F-\theta_{\mathrm{F}}\right) \\
& \sigma_{\mathrm{G}}^{2}=p(1-p)(1-F)
\end{aligned}
$$

onde :

$\theta_{\mathrm{R}}=$ correlação entre freqüências alélicas de diferentes locais dentro de regiões

$$
\theta_{\mathfrak{L}}=\text { correlação entre freqüências alélicas de diferentes populações do }
$$
mesmo local de diferentes regiões

$\theta_{\mathrm{P}}=$ correlações entre freqüências alélicas de diferentes famílias da mesma população de diferentes locais de diferentes regiões

$\theta_{\mathrm{F}}=$ correlação entre freqüências alélicas entre indivíduos dentro de famílias de diferentes populações de diferentes locais de diferentes regiǒes

$\mathrm{F}=$ correlação entre alelos dentro de indivíduos de diferentes famílias de diferentes populações de diferentes locais de diferentes regiões

$\mathrm{f}=$ correlação entre alelos dentro de indivíduos dentro de populações

Desta forma, estimativas dos coeficientes de coancestralidade podem ser obtidas a partir dos componentes de variância :

$$
\hat{\theta}_{R}=\hat{\sigma}_{R}^{2} / \hat{\sigma}_{T}^{2}
$$




$$
\begin{aligned}
& \hat{\theta}_{L}=\hat{\sigma}_{L}^{2} / \hat{\sigma}_{T}^{2}+\hat{\theta}_{R}=\left(\hat{\sigma}_{L}^{2}+\hat{\sigma}_{R}^{2}\right) / \hat{\sigma}_{T}^{2} \\
& \hat{\theta}_{P}=\hat{\sigma}_{P}^{2} / \hat{\sigma}_{T}^{2}+\hat{\theta}_{L}=\left(\hat{\sigma}_{P}^{2}+\hat{\sigma}_{L}^{2}+\hat{\sigma}_{R}^{2}\right) / \hat{\sigma}_{T}^{2} \\
& \hat{\theta}_{F}=\hat{\sigma}_{F}^{2} / \sigma_{T}^{2}+\hat{\theta}_{P}=\left(\hat{\sigma}_{I}^{2}+\hat{\sigma}_{F}^{2}+\hat{\sigma}_{P}^{2}+\hat{\sigma}_{L}^{2}+\hat{\sigma}_{R}^{2}\right) / \hat{\sigma}_{T}^{2} \\
& \hat{F}=\hat{\sigma}_{I}^{2} / \hat{\sigma}_{T}^{2}+\hat{\theta}_{P}=\left(\hat{\sigma}_{I}^{2}+\hat{\sigma}_{F}^{2}+\hat{\sigma}_{P}^{2}+\hat{\sigma}_{L}^{2}+\hat{\sigma}_{R}^{2}\right) / \hat{\sigma}_{T}^{2} \\
& \hat{f}=\left(\hat{\sigma}_{I}^{2}+\hat{\sigma}_{F}^{2}\right) /\left(\hat{\sigma}_{G}^{2}+\hat{\sigma}_{I}^{2}+\hat{\sigma}_{F}^{2}\right) \text { (por definição, como }\left[\sigma_{\mathrm{b}}^{2} /\left(\sigma_{\mathrm{w}}^{2}+\sigma_{\mathrm{b}}^{2}\right)\right]
\end{aligned}
$$

em COCKERHAM, 1969, p.74)

assim,

$$
\hat{f}=\left(\hat{F}-\hat{\theta}_{p}\right) /\left(1-\hat{\theta}_{p}\right)
$$

Da mesma forma, $\theta_{F}$ pode ser definido a nível populacional (VENCOVSKY, comunicação pessoal), ou seja, desconsiderando-se os efeitos das diferenças entre populações, locais e/ou regiões como :

$$
\hat{\theta}_{F}=\left(\hat{\theta}_{F}-\hat{\theta}_{P}\right) /\left(1-\hat{\theta}_{F}\right)
$$

sendo 0,125 para pragênies de meios-irmãos, em populações panmíticas.

A análise conjunta para todos os alelos em todos os locos foi realizada somando-se as somas de quadrados e graus de liberdade, obtendo-se daí um quadrado médio único para todos os alelos ou um quadrado médio para cada loco. 
Este último permite a obtenção das médias aritméticas entre os locos. Os quadrados médios obtidos foram decompostos nos componentes de variância correspondentes, e estes processados para obtenção das estimativas dos coeficientes de coancestralidade.

WEIR (1990a) recomenda a realização da análise conjunta a partir do quadrado médio obtido com o somatório das somas de quadrado e graus de liberdade de todos os alelos, contudo, foi também realizada a análise a partir da média entre locos, uma vez que os alelos não são independentes dentro de cada loco.

As análises da variância, com modelos hierarquizados e desbalanceados foram realizadas empregando-se o procedimento NESTED do programa estatístico SAS (SAS Institute, 1985), conforme recomenda WEIR (1990b).

3.3.2.3. Análise da Diversidade em Populações Subdivididas

A análise da diversidade em populações subdivididas, conforme NEI (1973), se fundamenta na distribuição da heterozigosidade ou diversidade genética total $\left(\mathrm{H}_{\mathrm{T}}\right)$ entre $\left(\mathrm{D}_{\mathrm{ST}}\right)$ e dentro $\left(\mathrm{H}_{\mathrm{S}}\right)$ das subpopulações.

Os estimadores para $\mathrm{H}_{\mathrm{T}}, \mathrm{H}_{\mathrm{S}}$ e $\mathrm{D}_{\mathrm{ST}}$ são descritos em NEI (1987), como:

$$
\begin{aligned}
& \hat{H}_{s}=2 \mathrm{n}\left(1-\sum_{k} x_{k}^{2}\right) /(2 \mathrm{n}-1) \\
& \hat{H}_{T}=1-\sum_{\mathrm{i} x^{2}}{ }_{\mathrm{i}}+\hat{H}_{s} /(2 \mathrm{~ns})
\end{aligned}
$$


onde :

$\mathrm{n}$ = número de indivíduos amostrados

$\mathrm{s}=$ número de subpopulações

$\mathrm{x}_{\mathrm{i}}=$ média ponderada da freqüência do alelo $\mathrm{k}$ nas subpopulações

$\Sigma_{i} x^{2}=$ média do somatório da freqüência alélica quadrada entre as subpopulações

sendo:

$$
\hat{H}_{T}=\hat{H}_{S}-\hat{D}_{S T}
$$

$\mathrm{e}$

$$
\hat{G}_{S T}=\hat{D}_{S T} / \hat{H}_{T}
$$

\subsubsection{Caracterização do Sistema Reprodutivo}

A endogamia existente em uma espécie apresenta-se estreitamente relacionada ao sistema reprodutivo desta. Dessa forma, a taxa de cruzamento ou percentual da alogamia, pode ser estimada a partir dos níveis de endogamia existentes. Portanto, o primeiro aspecto a ser observado é a existência de desvios do equilíbrio de panmixia. Assim, inicialmente foi testada a aderência das freqüências genotípicas aos equilíbrios de panmixia e endogamia e posteriormente estimada a taxa de cruzamento. 
3.3.3.1. Teste de Aderência ao Equilíbrio de Panmixia e Equilibrio de Endogamia

A aderência ao equilíbrio de panmixia foi testada comparando-se as freqüências genotípicas observadas e esperadas, conforme a extensão do teorema de Hardy-Weinberg para o número correspondente de alelos para cada loco (Tabela 2), e agrupando-se os genótipos em três classes: homozigotos para o alelo mais freqüente; heterozigotos entre o alelo mais freqüente e os demais; e todos os demais genótipos. Neste último caso o $\chi^{2}$ é testado com um grau de liberdade. Nas situações em que uma classe de freqüência esperada apresentou valor inferior a um (1) esta era somada a classe de menor freqüência entre as demais, para obtenção do valor de $\chi^{2}$, conforme recomendações de GOMES (1990).

$\mathrm{O}$ teste de aderência ao equilibrio de endogamia ou equilibrio de Wright foi realizado também comparando-se as freqüências genotípicas observadas e esperadas, estabelecendo-se, contudo, os valores esperados a partir de uma extensão do teorema de Hardy-Weinberg que agrega o índice de fixação (F) (WRIGHT, 1951), conforme explicitado na Tabela 2. Neste caso o $\chi^{2}$ é testado com um grau de liberdade a menos e, portanto, só pode ser empregado quando há três ou mais alelos por loco.

\subsubsection{Estimativas da Taxa de Cruzamento}

Neste trabalho empregaram-se duas estratégias distintas para avaliação da taxa de cruzamento. Inicialmente foram estimadas as taxas aparentes de cruzamento, a partir das estimativas de endogamia obtidas. Adicionalmente 
caracterizou-se a taxa de cruzamento empregando estimadores de máxima verossimilhança multilocos.

\subsection{Taxa de Cruzamento Aparente}

A taxa de cruzamento aparente foi obtida a partir das estimativas do coeficiente de endogamia (índice de fixação) estimado diretamente para cada população, como descrito no item 3.3.1.2. $\left(\hat{l}_{a 1}\right)$, a partir da estimativa de $\mathrm{F}_{\mathrm{IS}}$ (como descrito no item 3.3.2.1.) $\left(\hat{t}_{a 2}\right)$ e a partir do valor $\hat{f}$ na abordagem da análise de variância (como descrito no item 3.3.2.2.) $\left(\hat{t}_{a 3}\right)$.

Nas três situações empregou-se a relação proposta por WRIGHT (1921) entre a taxa de cruzamento e a endogamia, sendo pressuposta a existência de equilíbrio de endogamia:

$$
\mathbf{f}=(1-\mathrm{t}) /(1+\mathrm{t})
$$

ou

$$
t=(1-f) /(1+f)
$$

\subsection{Taxa de Cruzamento Multilocos}

A estimativa multilocos da taxa de cruzamento $\left(\hat{t}_{m}\right)$ foi obtida a partir do modelo proposto por RITLAND e JAIN (1981), empregando-se o programa MLT (RITLAND, 1990), para cada população pré-estabelecida individualmente, 
eliminando-se as famílias que produziam estimativas $\hat{t}_{m}=2,0$, como sugerem RITLAND e EL KASSABY (1986). Adicionalmente, foram obtidas as estimativas para cada loco individual $\left(\hat{t}_{s}\right)$, empregando-se o mesmo estimador, bem como testada a adequação das estimativas ao modelo multilocos, através de um $\chi^{2}$ de contingência.

Em todas as análises realizadas o erro padrão das estimativas de $t$ foi obtido empregando-se 100 "bootstraps", conforme sugerem RITLAND e EL KASSABY (1985).

Além disso, o modelo em questão possibilita a obtenção das estimativas separadas das freqüências alélicas de pólen e de óvulo, permitindo uma avaliação da heterogeneidade destas frequêencias através de um teste $\chi^{2}$, conforme propõem WORKMAN e NISWANDER (1970) :

$$
\chi^{2}=\mathrm{NF}_{\mathrm{ST}}(\mathrm{a}-1)
$$

onde:

$\mathrm{N}=$ número total de gametas

$F_{\mathrm{ST}}=$ divergência genética entre população de gametas masculinos e população de gametas femininos, calculada com base em:

$$
\mathrm{F}_{\mathrm{ST}}=\sigma_{\mathrm{p}}^{2} /[\mathrm{p}(1-\mathrm{p})]
$$

sendo:

$$
p=\text { frequiência de um determinado alelo }
$$


$\mathrm{a}=$ número de alelos por loco

\subsubsection{Estimativas do Fluxo Gênico}

As estimativas de fluxo gênico foram realizadas a partir da relação proposta por WRIGHT $(1951$, p. 331), entre a quantidade de migrantes $(\hat{N m})$ e a divergência entre populações $\left(\hat{F}_{S T}\right)$ :

$$
\hat{F}_{S T}=1 /(1+4 \hat{N m})
$$

ou

$$
\hat{N m}=(1 / 4)\left(1 / \hat{F}_{S T}-1\right)
$$

onde:

$\mathrm{N}=$ número de indivíduos da população

$\mathrm{m}=$ taxa de migração ou percentual de migrantes

Ou, mais adequadamente, conforme WEIR e COCKERHAM (1984) e COCKERHAM e WEIR (1993), empregando $\theta$ em lugar de $\mathrm{F}_{\mathrm{ST}}$.

Adicionalmente, foi feita a estimativa do tamanho de vizinhança $(\mathrm{Nb}$ número de indivíduos numa área de vizinhança ou área onde ocorre panmixia, 
conforme WRIGHT, 1931), como sugerem SLATKIN e BARTON (1989) para modelos contínuos, como o isolamento por distância.

Assim,

$$
\dot{N b}=2 \pi \dot{N m}
$$

Desta forma, considerando-se a densidade de indivíduos reprodutivos por área (D), pode-se definir a área de vizinhança (A) como :

$$
\mathrm{A}=\mathrm{D} \dot{\mathrm{Nb}}
$$

\subsubsection{Caracterização da Variação Geográfica}

A variaçào geográfica foi analisada comparando-se a variabilidade genética entre regiões (variação em latitude) e locais, bem como considerando os gradientes altitudinais existentes. Assim, foram empregadas duas abordagens, a análise gráfica das variações nas freqüências alélicas e os agrupamentos formados a partir das estimativas das distâncias genéticas não viesadas de Nei.

A análise gráfica foi realizada a partir da plotagem das freqüências alélicas, para cada alelo, em relação aos gradientes altitudinais em cada uma das regiōes. Além disso, foram também plotadas as diferenças acumuladas das freqüências alélicas (considerando que os efeitos da deriva podem ser tomados sempre a partir da situação imediatamente anterior) em relação ao gradiente 
altitudinal. A comparação entre as duas situações pode revelar tendências adaptativas ou apenas efeitos de deriva.

Tais análise foram realizadas apenas para as freqüências alélicas dos indivíduos adultos, uma vez que, caso existisse a tendência de formação de uma clina, esta ficaria mais evidenciada nos adultos; os quais são produtos dos efeitos adaptativos, ou seja, já passaram por pressões seletivas no seu desenvolvimento.

As distâncias genéticas, conforme proposto por NEI (1972, 1973, 1978), foram estimadas entre as populações estudadas, tanto para adultos como para progênies. Empregou-se o programa BIOSYS-1 (SWOFFORD e SELANDER, 1989) para o cálculo, estimando-se a Distância Genética não viesada (NEI, 1978) como:

$$
\begin{aligned}
& \hat{D}=-\ln \hat{I} \\
& \hat{I}=\hat{J}_{x v} / \sqrt{\hat{J}_{x} \hat{J}_{v}}
\end{aligned}
$$

onde :

$$
\begin{aligned}
& \hat{J}_{x v}=\left(\sum_{1}^{r} \sum x_{i} y_{i}\right) / r \\
& \hat{J}_{x}=\left[\sum_{1}^{r}\left(2 n_{x} \sum x_{i}-1\right) /\left(2 n_{x}-1\right] / r\right. \\
& \hat{J}_{v}=\left[\sum_{1}^{r}\left(2 n_{v} \sum y_{i}-1\right) /\left(2 n_{v}-1\right] / r\right.
\end{aligned}
$$

sendo :

$\hat{I}$ = identidade genética não viesada

$\mathrm{x}_{\mathrm{i}}=$ freqüência do alelo i na população $\mathrm{x}$

$\mathrm{y}_{\mathrm{i}}=$ freqüência do alelo i na população $\mathrm{y}$

$\mathrm{r}=$ número de locos 
Os valores obtidos foram utilizados para a construção dos dendrogramas, empregando-se o método UPGMA de agrupamento, conforme descrito em SNEATH e SOKAL (1973). 


\section{RESULTADOS E DISCUSSÃO}

\subsection{Sistemas Utilizados}

Os resultados obtidos com os 18 sistemas testados nos quatro diferentes tampões de eletrodo e gel encontram-se inseridos na Tabela 11. Pode-se observar, na referida Tabela, que o maior número de sistemas com boa resolução foi obtido com a utilização do tampão CM. Dos sistemas testados, PRX, G6P, PGI, PGM, MDH, IDH, G2D, 6PG e LAP apresentaram melhor resolução e possibilidade de interpretação genética.

O emprego de amostras constituídas de progênies maternais e grupos de indivíduos adultos possibilitou a seleção de sistemas que apresentaram polimorfismos em ao menos uma região (loco aparente), devido à segregação nas progênies. Além disso, a avaliação da resolução diferencial nas distintas fatias do el permitiu compor um grupo de sistemas que maximizassem o emprego das amostras por gel ou corrida. 
Tabela 11. Resultados obtidos com os sistemas (tampões e enzimas) testados para eletroforese de isoenzimas em populações naturais de Euterpe edulis. Piracicaba-SP, ESALQ/USP. 1996

\begin{tabular}{|c|c|c|c|c|}
\hline Enzima & $B(1)$ & $\mathrm{H}(2)$ & $\mathrm{TC}(3)$ & $\mathrm{CM}(4)$ \\
\hline$\alpha-\mathrm{EST}$ & 1 & F D & B & $I^{*}$ \\
\hline$\beta$-EST & 1 & F D & B & 1 \\
\hline $\mathrm{GDH}$ & $\mathrm{nt}$ & I & I & $\mathrm{F}$ \\
\hline LAP & $\mathrm{nt}$ & $\mathrm{nt}$ & $F$ & F \\
\hline SK & $\mathrm{nt}$ & $I$ & I & $\mathrm{nt}$ \\
\hline MDH & $\mathrm{nt}$ & $\mathrm{nt}$ & $\mathrm{nt}$ & B \\
\hline IDH & $\mathrm{nt}$ & nt & $\mathrm{F}$ & $B$ \\
\hline $\mathrm{ACP}$ & $\mathrm{nt}$ & $\mathrm{nt}$ & $\mathrm{nt}$ & F D \\
\hline APS & I & $\mathrm{F}$ & B & $\mathrm{nt}$ \\
\hline $\mathrm{ADH}$ & F D & $\mathrm{F}$ & F D & I \\
\hline PRX & $\mathrm{nt}$ & $\mathrm{D}$ & B & B \\
\hline PGM & nt & $\mathrm{nt}$ & D & B \\
\hline PGI & $\mathrm{F}$ & I & $\mathrm{F}$ & $\mathrm{B}$ \\
\hline $6 \mathrm{PG}$ & $\mathrm{nt}$ & nt & $\mathrm{B}$ & $\mathrm{nt}$ \\
\hline G6P & $\mathrm{nt}$ & $\mathrm{D}$ & B & B \\
\hline GOT & I & nt & F D & $\mathrm{nt}$ \\
\hline G2D & $\mathrm{nt}$ & $\mathrm{nt}$ & $\mathrm{nt}$ & B \\
\hline CAT & $\mathrm{nt}$ & $\mathrm{nt}$ & 1 & $\mathrm{nt}$ \\
\hline $\mathrm{ME}$ & I & $\mathrm{nt}$ & $\mathrm{nt}$ & $\mathrm{nt}$ \\
\hline $\mathrm{SDH}$ & $\mathrm{nt}$ & $\mathrm{F}$ & nt & I \\
\hline
\end{tabular}

(1) Tampão eletrodo $=$ bórax $0.3 \mathrm{M}$

Tampão gel= Tris 0.012M+ Ác.Cit.0.036M (2.5\%) (BALVEÉ. 1988)

(2) Tampão eletrodo $=$ Tris + Ác. Cítr. (pH 6.6)

Tampão gel $=$ Histidina 0.05 M. pH 6.0 (PAIVA. 1992)

(3) Tampão eletrodo $=$ Tris $27 \mathrm{~g} / 1+$ Ác. Cítr. $16.52 \mathrm{~g} / \mathrm{l}(\mathrm{pH} 7.5)$

Tampão gel $=$ diluição a $3.5 \% \mathrm{~T}$. eletrodo (ALFENAS et al.,1991)

(4) Tampão eletrodo = Ác. Cítr. $7,68 \mathrm{~g} / \mathrm{l}+$ Morfolina (titular até pH 6.1)

Tampão gel = diluição 1:20 T. eletrodo (ALFENAS et al..1991)

*B,F,D,I e nt = resolução das bandas Boa, Fraca, Difusa. Inexistente e não testado. respectivamente 
Assim, considerando-se os sistemas de melhor resolução em uma composição única de tampão de eletrodo e gel, a existência de polimorfismos e a possibilidade de maximizar o esforço laboratorial, com a realização de apenas uma corrida por progênie e com o aproveitamento de quatro fatias por gel; foi escolhido o tampão CM para eletrodo e gel, bem como os seguintes sistemas : PGI ( $2^{\mathrm{a}}$ fatia), $\operatorname{PRX}\left(3^{\mathrm{a}}\right.$ fatia), PGM ( $4^{\mathrm{a}}$ fatia) e G6P ( $5^{\mathrm{a}}$ fatia).

Os zimogramas obtidos com os 4 sistemas sugerem a existência de 9 locos aparentes: PGI - 2 locos, PRX - 5 locos, PGM - 1 loco e G6P - 1 loco (Figura 3). Contudo, o loco mais anódico de PGI e o loco mais anódico de PRX não apresentaram resolução que permitisse uma interpretação clara. Assim, 7 locos foram interpretados e empregados nas análises (Figura 4): PRX2 (monomérica, com 3 alelos), PRX3 (monomérica, com 5 alelos - um dos quais nulo), PRX4 (monomérica, com 4 alelos - um dos quais nulo), PRX5 (monomérica, com 3 alelos), PGI2 (dimérica, com 4 alelos - um dos quais nulo), PGM1 (monomérica, com 5 alelos) e G6P1 (dimérica com 3 alelos).

\subsection{Variação Genética}

As freqüencias alélicas obtidas para os sete locos analisados nas progênies e nos indivíduos adultos das populações estudadas encontram-se expostas nas Tabelas 12 e 13 .

Os valores obtidos variaram desde a completa fixação, no caso do alelo 1 da PRX5 na população SC550 nos indivíduos adultos, até freqüências muito reduzidas, como no alelo 5 da PRX3 em algumas populações, nas progênies. 


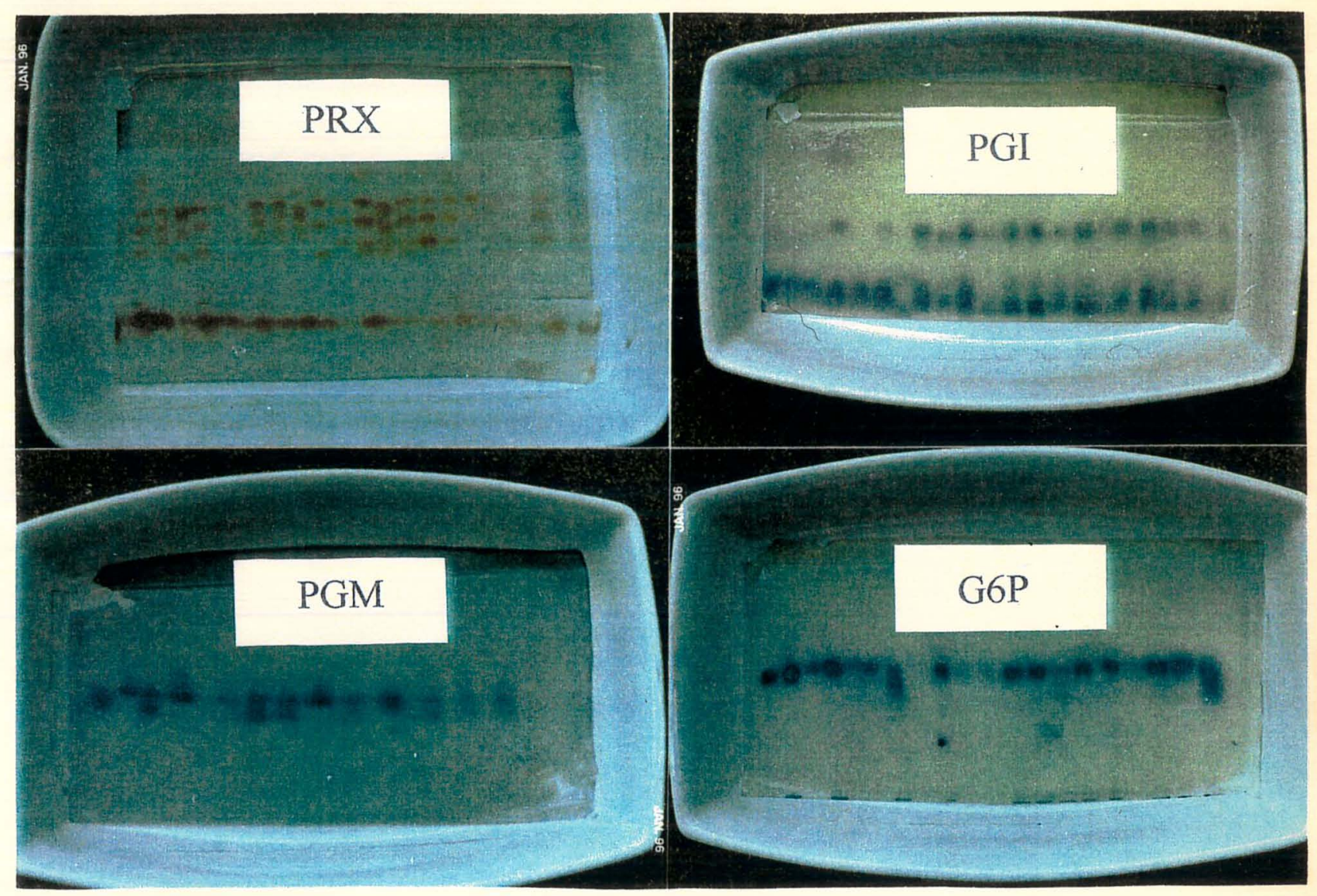

Figura 3. Zimogramas, ainda em gel, para os quatro sistemas enzimáticos (Peroxidase - PRX; Fosfoglucomutase - PGM; Fosfoglucose Isomerase - PGI; Glucose 6 Fosfato Desidrogenase - G6P) empregados em Euterpe edulis. PiracicabaSP, ESALQ/USP, 1996 (Fotos: M.S. Reis, 1994) 

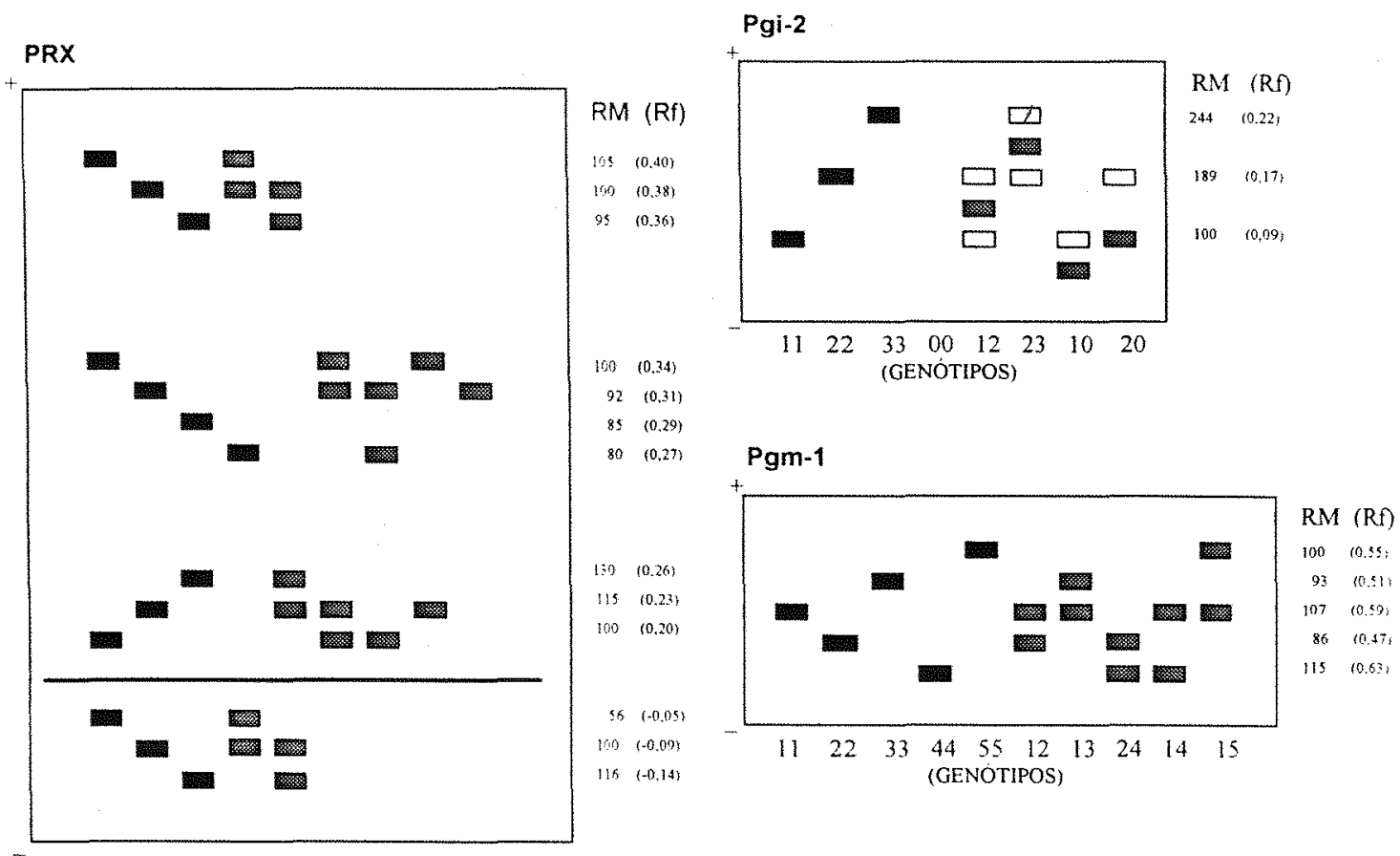

$\begin{array}{llllll}\operatorname{Prx}-2 & 33 & 11 & 22 & 13 & 12\end{array}$

$\begin{array}{lllllllllll}\text { Prx-3 } & 11 & 22 & 44 & 33 & 00 & 12 & 23 & 10 & 20\end{array}$

$\begin{array}{llllllllll}\text { Prx-4 } & 11 & 22 & 33 & 00 & 23 & 12 & 10 & 20\end{array}$

$\begin{array}{llllll}\text { Prx-5 } & 33 & 11 & 22 & 13 & 12\end{array}$

(GENÓTIPOS)

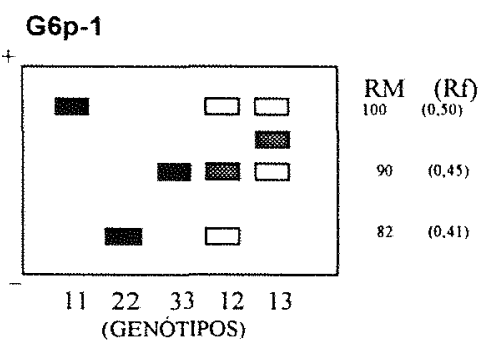

Fígura 4. Esquema dos Zimogramas apresentando fenótipos dos locos PRX2, PRX3, PRX4, PRX5, PGI2, PGMl e G6P1 obtidos para Euterpe edulis, com seus respectivos genótipos e valores de RM e Rf. Piracicaba-SP, ESALQ/USP, 1996 
Tabela 12. Freqüências alélicas para sete locos alozímicos em progênies de sete populações naturais de Palmiteiro (Euterpe echulis), procedentes de Santa Catarina (SC) e de São Paulo (SPS e SPL). Piracicaba-SP, ESALQ/USP. 1996

\begin{tabular}{|c|c|c|c|c|c|c|c|}
\hline Loco / alelo & SC450 & SC550 & SC650 & SPS100 & SPS250 & SPS350 & SPL 700 \\
\hline $\mathrm{PRX} 2 / \mathrm{N}^{*}$ & 164 & 160 & 246 & 216 & 312 & 353 & 429 \\
\hline 1 &, 780 & .678 & .730 & .787 & .827 &, 763 & .719 \\
\hline 2 & .107 & .206 & .232 &, 093 & .131 &, 169 & .254 \\
\hline 3 & .113 & .116 & .039 & .120 & .042 & .068 & .027 \\
\hline PRX $3 / N$ & 163 & 159 & 246 & 216 & 309 & 350 & 429 \\
\hline 1 &, 644 & .613 & .610 &, 556 & .604 & 464 & .603 \\
\hline 2 & .153 & .230 & .161 & .174 &, 160 & .249 & .090 \\
\hline 3 &, 101 & .069 & .124 & .069 & .087 & 071 & .143 \\
\hline 4 & .101 & .088 & .106 & .201 & .147 & .214 & .164 \\
\hline 5 & .000 & .000 & .000 & .000 &, 002 & .001 & .000 \\
\hline $\mathrm{PRX}+/ \mathrm{N}$ & 160 & 155 & 243 & 216 & 312 & 352 & 429 \\
\hline 1 & .169 & .071 & .130 & .171 & .189 & .114 & .293 \\
\hline 2 & .366 & .229 & .364 & .178 & .107 & .126 & .159 \\
\hline 3 & .050 & .132 & .111 & .025 & .038 & .075 & .041 \\
\hline 4 &.+16 & .568 & .395 & .625 & .665 & .685 & .508 \\
\hline PRX $5 / N$ & 164 & 161 & 248 & 218 & 312 & 354 & 430 \\
\hline 1 & .936 & .876 & .956 &, 975 &, 910 &, 938 & .953 \\
\hline 2 &, 055 & 124 & .030 & .025 & .090 &, 059 & .044 \\
\hline 3 & .009 & .000 & .014 & .000 &, 000 & .003 & .002 \\
\hline PGI $2 / \mathrm{N}$ & 163 & 161 & 249 & 218 & 307 & 352 & 436 \\
\hline 1 & .629 & .609 & .598 & .573 & .453 & 460 & .630 \\
\hline 2 & 362 & 391 & .396 &, 401 &, 493 &, 491 &, 338 \\
\hline 3 &, 009 & .000 & .006 & .005 &, 020 & .011 & .009 \\
\hline+ & .000 & .000 & .000 & .021 & .034 & .037 & .023 \\
\hline PGM $1 / N$ & 158 & 159 & 248 & 213 & 295 & 344 & 408 \\
\hline 1 & .089 & .182 & .171 & 124 & .334 & .365 &, 411 \\
\hline 2 &, 320 & .289 & .202 & .279 & .251 & .273 & .219 \\
\hline 3 & .566 & .487 & .512 & .566 & .398 & .326 & .314 \\
\hline 4 & .000 & .022 & .085 & .026 & .014 & (029 & .048 \\
\hline 5 & .025 & .019 & .030 & .005 & .003 & .007 & .009 \\
\hline G6P I / N & 162 & 158 & 248 & 213 & 306 & 339 & 429 \\
\hline 1 & .926 & .930 & .863 &, 923 & .938 &, 951 &, 953 \\
\hline 2 & .074 & .070 & .129 & .073 & .056 & .037 & .044 \\
\hline 3 & .000 & .000 & .008 & .005 & .007 & .012 & .002 \\
\hline
\end{tabular}

$* \mathrm{~N}=$ número de indivíduos analisados 
Tabela 13. Frequeências alélicas para sete locos alozímicos em indivíduos adultos de oito populações naturais de Palmiteiro (Euterpe edulis), procedentes de Santa Catarina (SC) e São Paulo (SPS e SPL). Piracicaba-SP, ESQLQ/USP, 1996

\begin{tabular}{|c|c|c|c|c|c|c|c|c|}
\hline Loco / alelo & $\mathrm{SC} 450$ & SC550 & SC650 & SPS100 & SPS250 & SPS350 & SPL350 & SPL700 \\
\hline $\mathrm{PRX} 2 / \mathrm{N}$ & 23 & 27 & 23 & 26 & 26 & 25 & 25 & 22 \\
\hline 1 &, 739 & .833 & .783 & .769 & .712 &, 660 &, 840 & .659 \\
\hline 2 & .152 & .111 & .217 & .154 &, 192 & .260 & 100 & .295 \\
\hline 3 & .109 & .056 &, 000 & .077 & .096 & .080 &, 060 & .045 \\
\hline $\operatorname{PRX} 3 / \mathrm{N}$ & 23 & 27 & 23 & 26 & 26 & 25 & 25 & 22 \\
\hline 1 &, 565 & .593 & .565 & .558 & .596 & .520 &, 580 & .636 \\
\hline 2 & .217 & .222 & .196 &, 327 &, 192 & 240 &, 140 & .023 \\
\hline 3 &, 065 & .037 & .065 & .058 & .058 &, 020 &, 080 & .114 \\
\hline 4 & .152 & .148 & .174 & .058 & .154 & .220 & .200 & .227 \\
\hline $\mathrm{PRX}+/ \mathrm{N}$ & 23 & 27 & 23 & 26 & 26 & 26 & 24 & 22 \\
\hline 1 & .174 & .185 & .130 &, 288 & .231 & .192 &, 396 & .409 \\
\hline 2 & .239 & .241 & .348 & .154 &, 135 & .173 & 167 & .091 \\
\hline 3 &, 000 & .074 & .065 & .077 & .019 &, 096 & 104 & .023 \\
\hline 4 & .587 & .500 & .457 & .481 & .615 & .538 & .333 & .477 \\
\hline $\mathrm{PRX} 5 / \mathrm{N}$ & 23 & 27 & 22 & 26 & 26 & 25 & 25 & 22 \\
\hline 1 & .978 & 1.000 & 977 & 1,000 & .885 &, 940 & 880 &, 977 \\
\hline 2 &, 022 & .000 & .000 &, 000 & .115 & .040 &, 120 & .023 \\
\hline 3 & .000 & .000 & .023 &, 000 & .000 & .020 & .000 &, 000 \\
\hline PGI $2 / N$ & 23 & 27 & 23 & 24 & 26 & 26 & 25 & 22 \\
\hline 1 &, 522 & .556 & .587 &, 583 & .519 & 423 & 640 & 614 \\
\hline 2 & .478 & 444 & 413 &, 417 & 462 &, 500 &, 340 &, 364 \\
\hline 3 &, 000 & .000 & .000 &, 000 & .019 & .058 & .000 & .000 \\
\hline 4 & .000 & .000 & .000 & .000 & .000 & .019 & .020 & .023 \\
\hline PGM I / N & 23 & 27 & 23 & 25 & 24 & 26 & 25 & 22 \\
\hline 1 & .174 & .204 & .239 & 360 & 375 & .423 & 400 & .386 \\
\hline 2 & .457 & .259 & .217 & .260 & .250 & .308 &, 380 & .250 \\
\hline 3 & 370 & .537 & .522 & .320 & .354 & .231 & .080 & .273 \\
\hline 4 &, 000 & .000 & .022 & .060 & .021 & .038 & .140 & .091 \\
\hline G6P 1/N & 23 & 27 & 23 & 22 & 23 & 26 & 25 & 22 \\
\hline 1 & .913 & 907 & .804 & .795 & 804 & 827 & 960 & 955 \\
\hline 2 &, 087 & .093 & .196 & .205 & .196 & .173 & .040 & .045 \\
\hline
\end{tabular}

* $N=$ número de indivíduos analisados 
A existência de alelos exclusivos foi detectada em algumas populações. Nas progênies, os alelos 3 da PRX5 e G6P1 e o alelo 5 da PRX3 não estão presentes em todas as populações. Em especial o alelo 4 de PGI2, que ocorre nas populações de São Paulo (freqüência entre 2,1 e 3,7 \%) e não foi detectado nos indivíduos procedentes de Santa Catarina, e o alelo 5 da PRX3 que ocorre apenas em duas populações de São Paulo.

Nos indivíduos adultos os alelos 3 e 4 da PGI2 só aparecem nas populações de São Paulo, e os alelos 4 da PGM1 e 3 da PRX5 não aparecem em todas as populações. Adicionalmente, os alelos 5 da PRX3 e PGM1 e 3 da G6P1, detectados nas progênies, não aparecem nos indivíduos adultos.

Além disso, os alelos 1,2,3 e 4 da PRX3 e PGM1 para progênies e 2,3 e 4 da PRX2 e 1,2,3 e 4 da PRX3 e PGM1 para adultos, apresentam freqüências bastante distintas entre as populações (Tabelas 12 e 13 ).

Tais resultados sugerem a existência de diferenças entre as populações em relação às freqüências alélicas e níveis de diversidade, indicando uma divergência incipiente entre as mesmas, especialmente entre as duas regiões estudadas. Além disso, a ocorrência de alelos nas progênies que não foram detectados nos adultos sugere uma amostragem insuficiente nestes, ou a ocorrência de fluxo gênico a partir de populações não amostradas.

A amostragem genética foi avaliada a partir da caracterização do tamanho efetivo da amostra $(\mathrm{Ne})$ nas progênies, considerando-se que as populações amostradas não apresentam desvios do equilíbrio de panmixia $(\alpha=f=0)$. Assim, conforme VENCOVSKY (comunicação pessoal), baseado em KIMURA e CROW (1963):

$$
\mathrm{Ne}=\Sigma \mathrm{k} /\left[\left(\mathrm{s}_{\mathrm{k}}^{2} / \mathrm{k}_{\mathrm{mi}}\right)+1\right]
$$


onde :

$\mathrm{k}=$ número total de gametas na amostra

$\mathrm{s}_{\mathrm{k}}^{2}=\mathrm{Vk}_{\mathrm{m}}+\mathrm{Vk}_{\mathrm{f}}$

$\mathrm{Vk}_{\mathrm{m}}=$ variância no número de alelos entre genitores masculinos (considerada aproximadamente número médio de gametas masculinos na amostra em relação ao total de genitores masculinos possiveis, numa aproximação pela distribuição de Poisson)

$\mathrm{Vk}_{\mathrm{f}}=$ variância no número de alelos entre genitores femininos

$\mathrm{k}_{\mathrm{mff}}=$ número médio de gametas (masculinos e femininos) em relação ao total de genitores possíveis na população

Os resultados obtidos (Tabela 14) indicam que a representatividade genética nas progênies foi sempre superior a dos adultos, variando entre 35 e 77 indivíduos. Tal resultado pode explicar, parcialmente, as diferenças nas freqüências alélicas entre progênies e adultos (Tabelas 12 e 13), especialmente no que se refere aos alelos presentes nas progênies e ausentes entre os adultos.

Em relação aos índices de diversidade, os resultados obtidos estão expostos nas Tabelas 15 e 16. O número médio de alelos por loco fícou entre 3,4 e 4,0 nas progênies (Tabela 15), não diferindo entre as populações. Vale ressaltar que estes valores se encontram entre os mais elevados quando comparados a outras espécies arbóreas tropicais (Tabela 1, Anexo I). Nos indivíduos adultos, este índice variou de 2,7 a 3,1 (Tabela 16), também não diferindo entre as populações. Os valores inferiores encontrados nos indivíduos adultos refletem, possivelmente, a menor intensidade amostral neste grupo (Tabela 14), como já mencionado anteriormente. 
Tabela 14. Representatividade genética da amostragem realizada nas populações naturais de palmiteiro ( Euterpe edulis Martius) coletadas em Santa Catarina e São Paulo, sob condições de Floresta Ombrófila Densa. Piracicba-SP,ESALQ/USP, 1996

\begin{tabular}{lllllll} 
População & $\begin{array}{c}\text { Adultos * } \\
\text { amostrados }\end{array}$ & $\begin{array}{c}\text { Progênies * } \\
\text { amostradas }\end{array}$ & $\begin{array}{c}\text { genitores } \\
\text { possiveis** }\end{array}$ & $\begin{array}{c}\text { média de } \\
\text { gametas } \\
\text { femininos }\end{array}$ & $\mathrm{Ne}^{1}$ & $\begin{array}{c}\text { Ne por } \\
\text { progênie }\end{array}$ \\
\hline SC650 & 23 & 17 & 443 & 14,7 & 54,6 & 3,2 \\
SC550 & 27 & 11 & 610 & 14,7 & 35,2 & 3,2 \\
SC450 & 23 & 12 & 745 & 13,7 & 35,2 & 2,9 \\
SPS250 & 26 & 16 & 996 & 19,8 & 56,3 & 3,5 \\
SPS100 & 26 & 11 & 791 & 19,8 & 42,4 & 3,8 \\
SPS350 & 26 & 18 & 791 & 19,7 & 63,6 & 3,5 \\
SPL700 & 22 & 22 & 1200 & 19,8 & 77,6 & 3,5 \\
\hline
\end{tabular}

${ }^{1} \mathrm{Ne}=$ tamanho efetivo da população amostrada

* número de indivíduos

** ver Tabela 2 (material e métodos) 
Tabela 15. Índices de diversidade para sete populações naturais de Euterpe edulis procedentes de Santa Catarina (3) e São Paulo (4), obtidos a partir da análise de sete locos alozímicos em 107 progênies. Piracicaba-SP, ESALQ/USP, 1996

\begin{tabular}{|c|c|c|c|c|c|c|}
\hline \multirow[b]{2}{*}{ População } & \multirow[b]{2}{*}{$\begin{array}{l}\text { tamanho médio } \\
\text { da mostra } \\
\text { por locos }\end{array}$} & \multirow[b]{2}{*}{$\begin{array}{c}\text { número. } \\
\text { médio de } \\
\text { alelos/loco }\end{array}$} & \multirow[b]{2}{*}{$\begin{array}{l}\text { Percentagem } \\
\text { locos } \\
\text { polimórficos }\end{array}$} & \multicolumn{3}{|c|}{ Heterozigosidade média } \\
\hline & & & & $\begin{array}{cc}\text { contagem } & - \text { Esper } \\
\text { direta } & (\mathrm{H}\end{array}$ & rado & $\begin{array}{l}\text { Indice de } \\
\text { fixação } \\
\text { (F) }\end{array}$ \\
\hline $\mathrm{SC} 450$ & $\begin{array}{l}162,0 \\
(0,8)\end{array}$ & $\begin{array}{c}3,3 \\
(0,3)\end{array}$ & 100,0 & $\begin{array}{c}0,409 \\
(0,075)\end{array}$ & $\begin{array}{l}0,411 \\
(0,080)\end{array}$ & 0,005 \\
\hline SC550 & $\begin{array}{l}159,0 \\
(0,8)\end{array}$ & $\begin{array}{l}3,1 \\
(0,5)\end{array}$ & 100,0 & $\begin{array}{l}0,437 \\
(0,072)\end{array}$ & $\begin{array}{l}0,446 \\
(0,074)\end{array}$ & 0,020 \\
\hline SC650 & $\begin{array}{l}246,9 \\
(0,8)\end{array}$ & $\begin{array}{l}3,6 \\
(0,3)\end{array}$ & 85,7 & $\begin{array}{l}0,421 \\
(0,072)\end{array}$ & $\begin{array}{l}0,449 \\
(0,084)\end{array}$ & 0,062 \\
\hline SPS100 & $\begin{array}{l}215,7 \\
(0,8)\end{array}$ & $\begin{array}{l}3,6 \\
(0,4)\end{array}$ & 85,7 & $\begin{array}{l}0,395 \quad 0 \\
(0,085)\end{array}$ & $\begin{array}{l}0,402 \\
(0,085)\end{array}$ & 0,017 \\
\hline SPS250 & $\begin{array}{r}307,6 \\
(2,3)\end{array}$ & $\begin{array}{l}3,7 \\
(0,4)\end{array}$ & 100,0 & $\begin{array}{c}0,397 \quad 0 \\
(0,072)\end{array}$ & $\begin{array}{l}0,413 \\
(0,082)\end{array}$ & 0,039 \\
\hline SPS350 & $\begin{array}{l}349,1 \\
(2,1)\end{array}$ & $\begin{array}{c}3,9 \\
(0,3)\end{array}$ & 85,7 & $\begin{array}{ll}0,378 & 0 \\
(0,079) & (\end{array}$ & $\begin{array}{l}0,428 \\
(0,092)\end{array}$ & 0,117 \\
\hline SPL700 & $\begin{array}{l}427,1 \\
(3,3)\end{array}$ & $\begin{array}{c}3,7 \\
(0,3)\end{array}$ & 71,4 & $\begin{array}{c}0,406 \\
(0,089)\end{array}$ & $\begin{array}{c}0,426 \\
(0,093)\end{array}$ & 0,047 \\
\hline $\begin{array}{l}\text { Santa Catarina } \\
(1,2 \text { e } 3)\end{array}$ & $\begin{array}{r}567,9 \\
(2,0)\end{array}$ & $\begin{array}{l}3,6 \\
(0,3)\end{array}$ & 100,0 & $\begin{array}{l}0,422 \\
(0,072)\end{array}$ & $\begin{array}{l}0,441 \\
(0,080)\end{array}$ & 0.043 \\
\hline $\begin{array}{l}\text { São Paulo } \\
(4,5,6 \text { e } 7)\end{array}$ & $\begin{array}{r}1299,6 \\
(7,4)\end{array}$ & $\begin{array}{l}3,9 \\
(0,3)\end{array}$ & 100,0 & $\begin{array}{l}0,395 \\
(0,080)\end{array}$ & $\begin{array}{l}0,427 \\
(0,090)\end{array}$ & 0,075 \\
\hline $\begin{array}{l}\text { SP-Saibadela } \\
\quad(4,5 \text { e } 6)\end{array}$ & $\begin{array}{r}863,4 \\
(4,7)\end{array}$ & $\begin{array}{l}3,9 \\
(0,3)\end{array}$ & 100,0 & $\begin{array}{l}0,390 \\
(0,077)\end{array}$ & $\begin{array}{l}0,421 \\
(0,088)\end{array}$ & 0,074 \\
\hline Total & $\begin{array}{r}1867,4 \\
(8,3) \\
\end{array}$ & $\begin{array}{l}3,9 \\
(0,3)\end{array}$ & 100,0 & $\begin{array}{l}0,403 \\
(0,077)\end{array}$ & $\begin{array}{l}0,436 \\
(0,088)\end{array}$ & 0,076 \\
\hline
\end{tabular}

* estimativa não viesada de NEI (1978) 
Tabela 16. Índices de diversidade para oito populações naturais de Euterpe edulis procedentes de Santa Catarina (3) e São Paulo (5), obtidos a partir da análise de sete locos alozímicos em 198 indivíduos adultos. Piracicaba-SP, ESALQ/USP, 1996

\begin{tabular}{|c|c|c|c|c|c|c|}
\hline População & $\begin{array}{l}\text { tamanho } \\
\text { média da } \\
\text { mostra/locos }\end{array}$ & $\begin{array}{c}\text { número } \\
\text { médio de } \\
\text { alelos/loco } \\
\end{array}$ & $\begin{array}{l}\text { Percentagem } \\
\text { de locos } \\
\text { polimórficos } \\
\end{array}$ & $\begin{array}{l}\text { Heterozigosidade } \\
\begin{array}{l}\text { contagem- esper } \\
\text { direta }\end{array} \\
\end{array}$ & $\begin{array}{l}\text { de média } \\
\text { Wado } \\
\text { W) }\end{array}$ & $\begin{array}{l}\text { Índice de } \\
\text { fixação } \\
\text { (F) }\end{array}$ \\
\hline $\mathrm{SC} 450$ & $\begin{array}{l}23,0 \\
(0,0)\end{array}$ & $\begin{array}{l}2,7 \\
(0,3)\end{array}$ & 85,7 & $\begin{array}{l}0,391 \quad 0,42 \\
(0,083)\end{array}$ & $\begin{array}{l}26 \\
(0,089)\end{array}$ & 0,082 \\
\hline SC550 & $\begin{array}{l}27,0 \\
(0,0)\end{array}$ & $\begin{array}{l}2,7 \\
(0,4)\end{array}$ & 85,7 & $\begin{array}{l}0,407 \quad 0,40 \\
(0,105)\end{array}$ & $\begin{array}{l}405 \\
0,096)\end{array}$ & $-0,005$ \\
\hline SC650 & $\begin{array}{l}22,9 \\
\quad(0,1)\end{array}$ & $\begin{array}{l}2,9 \\
(0,4)\end{array}$ & 85,7 & $\begin{array}{l}0,454 \quad 0,44 \\
(0,080)\end{array}$ & $\begin{array}{l}447 \\
0,085)\end{array}$ & $-0,016$ \\
\hline SPS100 & $\begin{array}{c}25,0 \\
(0,6)\end{array}$ & $\begin{array}{l}2,9 \\
(0,5)\end{array}$ & 85,7 & $\begin{array}{ll}0,507 & 0 \\
(0,107) & (c\end{array}$ & $\begin{array}{l}, 455 \\
0,092)\end{array}$ & $-0,114$ \\
\hline SPS250 & $\begin{array}{r}25,3 \\
(0,5)\end{array}$ & $\begin{array}{l}3,1 \\
(0,3)\end{array}$ & 100,0 & $\begin{array}{l}0,570 \quad 0,4 \\
(0,074) \quad(0\end{array}$ & $\begin{array}{l}479 \\
0,062)\end{array}$ & $-0,190$ \\
\hline SPS350 & $\begin{array}{l}25,6 \\
(0,2)\end{array}$ & $\begin{array}{l}3,4 \\
(0,3)\end{array}$ & 100,0 & $\begin{array}{ll}0,524 & 0, \\
(0,098) & (0\end{array}$ & $\begin{array}{l}, 493 \\
0,080)\end{array}$ & $-0,063$ \\
\hline SPL350 & $\begin{array}{c}24,9 \\
(0,1)\end{array}$ & $\begin{array}{c}3,1 \\
(0,3)\end{array}$ & 85,7 & $\begin{array}{cc}0,385 & 0 \\
(0,072) & (0\end{array}$ & $\begin{array}{l}0,438 \\
0,093)\end{array}$ & $-0,121$ \\
\hline SPL700 & $\begin{array}{r}22,0 \\
(0,0)\end{array}$ & $\begin{array}{l}3,1 \\
(0,3)\end{array}$ & 71,4 & $\begin{array}{ll}0,494 & 0 \\
(0,112) & (\end{array}$ & $\begin{array}{l}0,428 \\
(0,098)\end{array}$ & $-0,154$ \\
\hline $\begin{array}{l}\text { - Santa Catarina } \\
(1,2 \text { e } 3)\end{array}$ & $\begin{array}{l}72,9 \\
(0,1)\end{array}$ & $\begin{array}{l}3,1 \\
(0,3)\end{array}$ & 87,7 & $\begin{array}{l}0,417 \\
(0,088)\end{array}$ & $\begin{array}{l}0,424 \\
(0,089)\end{array}$ & 0,017 \\
\hline $\begin{array}{l}\text { São Paulo } \\
(4,5,6,7 \text { e } 8)\end{array}$ & $\begin{array}{l}122,7 \\
(0,8)\end{array}$ & $\begin{array}{l}3,4 \\
(0,3)\end{array}$ & 100,0 & $\begin{array}{c}0,496 \\
(0,085)\end{array}$ & $\begin{array}{l}0,463 \\
(0,082)\end{array}$ & $-0,071$ \\
\hline $\begin{array}{l}\text { SP-Saibadela } \\
\qquad(4,5 \text { e } 6)\end{array}$ & $\begin{array}{r}74,9 \\
(0,9)\end{array}$ & $\begin{array}{l}3,4 \\
(0,3)\end{array}$ & 100,0 & $\begin{array}{c}0,537 \\
(0,088)\end{array}$ & $\begin{array}{l}0,474 \\
(0,076)\end{array}$ & $-0,133$ \\
\hline $\begin{array}{l}\text { SP-Limão } \\
\quad(7 \text { e } 8)\end{array}$ & $\begin{array}{l}46,9 \\
(0,1)\end{array}$ & $\begin{array}{c}3,1 \\
(0,3)\end{array}$ & 85,7 & $\begin{array}{r}0,436 \\
(0,086)\end{array}$ & $\begin{array}{l}0,436 \\
(0,093)\end{array}$ & 0,000 \\
\hline Total & $\begin{array}{l}195,6 \\
(0,8)\end{array}$ & $\begin{array}{l}3,4 \\
(0,3)\end{array}$ & 85,7 & $\begin{array}{l}0,476 \\
(0,084)\end{array}$ & $\begin{array}{l}0,452 \\
(0,086)\end{array}$ & $-0,033$ \\
\hline
\end{tabular}

* estimativa não viesada de NEI (1978) 
A percentagem de locos polimórficos variou entre 66,7 a $100,0 \%$ (alelo mais freqüente com freqüência igual ou inferior a $95 \%$ ) entre as populações, na avaliação das progênies (Tabela 15). Os valores elevados obtidos eram esperados uma vez que procurou-se trabalhar exclusivamente com locos polimórficos. Cabe ressaltar, contudo, que os índices inferiores a 100,0\% estavam sempre associados aos locos PRX5 e G6P1, que apresentaram, em geral, menor grau de polimorfismo. Entretanto, utilizando-se como critério uma freqüência de até $99 \%$ para o alelo mais comum, como sugere NEI (1987) para amostras superiores a 50 indivíduos, todos os locos mostram-se polimórficos em todas as populações (Tabela 12). Nos indivíduos adultos, os valores ficaram entre 71,4 e $100,0 \%$ (Tabela 16), estando os valores menores que $100,0 \%$ igualmente associados aos locos PRX5 e G6P1.

Os valores de heterozigosidade observada (Ho) e esperada ( $\hat{H} e)$ (Tabela 15) nas progênies das 7 populações estudadas indicaram um alto grau de diversidade para a espécie, considerando os marcadores empregados. A heterozigosidade observada variou de 0,378 a 0,437 e a esperada variou de 0,402 a 0,449 sendo, esta última, sempre numericamente superior à primeira. Os valores obtidos, contudo, não diferem entre si na comparação entre populações, nem na comparação entre esperado e observado.

Em relação aos indivíduos adultos, a heterozigosidade observada variou de 0,385 a 0,570 e a esperada ficou entre 0,405 e 0,493 (Tabela 16), sendo a observada superior a esperada para a maior parte das populações (exceto em SPL350 e SC450).

Este excesso de heterozigotos observado na maioria das populações para os adultos decorre, possivelmente, de efeitos de seleção em favor dos mesmos existentes na espécie. Tal afirmação se fundamenta também no diferencial existente 
entre progênies e adultos em relação à quantidade de heterozigotos, refletindo em índices de fixação/endogamia relativamente reduzidos, mas consistentes, nas progênies e índices de fixação negativos, em sua maioria, para os indivíduos adultos.

$\mathrm{O}$ excesso de heterozigotos tem sido descrito também para outras espécies tropicais como Pithecellobium pedicelare (O'MALEY et al., 1987), Bertholetia excelsa (O'MALEY et al., 1988), Ceiba pentandra (MURAWSKY e HAMRICK, 1992a), Psychotria faxlucens (PEREZ-NASSER et al, 1993), Astrocarium mexicanum (EGUIARTE et al., 1993) e Cecropia obtusifolia (ALVAREZ-BUYLLA e GARAY, 1994). Entretanto, a maioria delas não apresenta um padrão definido de aumento de heterozigotos nos adultos em relação às progênies; como P. faxlucens, que não mostra uma tendência clara, e $P$. pedicelare, onde tanto adultos quanto progênies apresentam um excesso de heterozigotos, mas não diferem entre si. Por sua vez, $A$. mexicanum, uma palmeira do sub-bosque das florestas tropicais da América Central, mostra excesso de heterozigotos nas progênies $(F=-0,186)$ e nos adultos $(F=-0,411)$, contudo, o expressivo aumento de heterozigosidade nos adultos sugere uma sobrevivência ou recrutamento preferencial dos heterozigotos, segundo os autores.

Fenômeno similar pode estar ocorrendo em E. edulis, especialmente se considerarmos a redução que ocorre entre o número de propágulos produzidos, estimado em 377.101 por hectare, por ano (REIS, A.,1995), na área da população SC650 e o número de indivíduos que chegam a fase reprodutiva (61, Figura 5 ). 


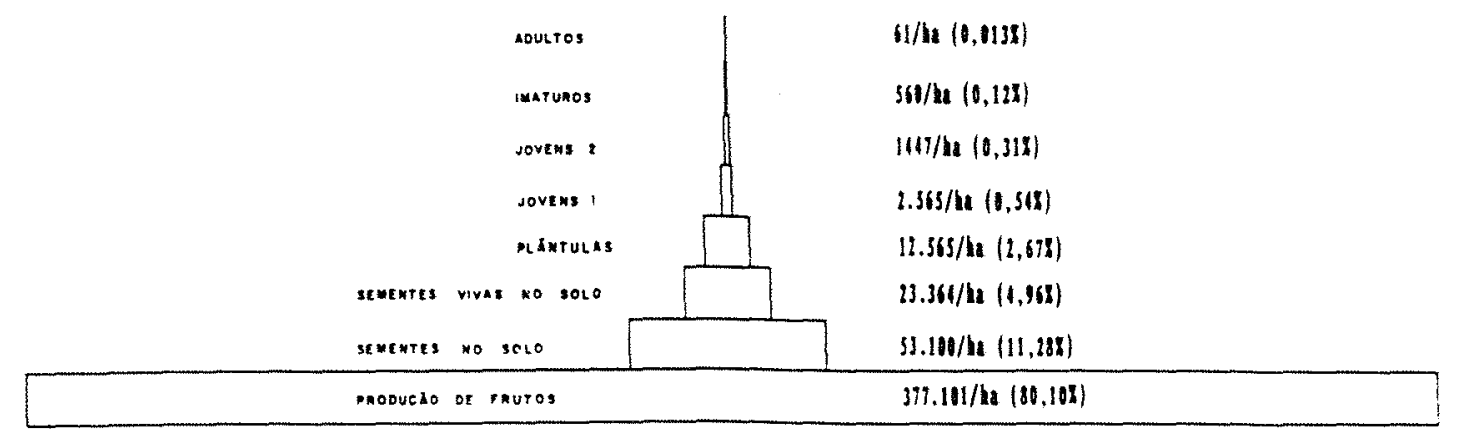

Figura 5 - Pirâmide demográfica da população SC650, representando as proporções entre os propágulos e os distintos estádios de tamanho de plantas de Euterpe edulis, conforme REIS, A. et al. (1995). Piracicaba-SP, ESALQ/USP, 1996 
É razoável considerar que grande parte dos propágulos são predados ou sofrem ação de microorganismos e não conseguem produzir uma plântula $(80,1 \%$, segundo REIS, A., 1995); além disso, grande parte das plântulas produzidas (12.565/ ha, Figura 5) são predadas. Nestes fenômenos, o valor adaptativo dos indivíduos deve ter influência reduzida, apresentando maior importância na distribuição espacial dos indivíduos das coortes subseqüentes, juntamente com os dispersores (ação, presença ou ausência destes), como discutido em OYAMA (1993) e demonstrado por REIS, A. (1995) para E. edulis. Ou seja, a redução da população de propágulos deve ter um efeito aleatório predominante na variabilidade genética, até este ponto. Contudo, o desenvolvimento diferencial e recrutamento destas plântulas, redução de 12.565 plântulas por hectare à 560 palmeiras $(3,3 \%)$ com mais de $1,3 \mathrm{~m}$ de estipe, bem como a passagem para a fase reprodutiva $(0,3 \%$; Figura 5$)$, devem apresentar um forte componente seletivo, aparentemente favorecendo heterozigotos.

Comparando-se com os dados existentes para outras espécies arbóreas tropicais (Tabela 1, Anexo I), a heterozigosidade esperada para a espécie se encontra entre os valores mais elevados, ressaltando a alta diversidade genética para a mesma. Contudo, considerando-se que foram empregados somente locos polimórficos para este estudo, a comparação com outras espécies deve ser realizada tomando em conta somente os locos polimórficos. Tal comparação coloca o palmiteiro, ainda, entre as espécies tropicais estudadas de maior diversidade.

De uma maneira geral, os índices de diversidade obtidos, heterozigosidade, número de alelos por loco e percentagem de locos polimórficos, foram todos elevados, sempre similares ou superiores à maioria dos valores obtidos para outras espécies tropicais. Especialmente a comparação com outras espécies tropicais comuns do sub-bosque reflete esta superioridade (Tabela 1, Anexo I). A 
comparação com outras palmeiras indica valores similares, principalmente a comparação específica com Astrocarium mexicanum (EGUIARTE et al., 1992), outra palmeira de sub-bosque.

A alta diversidade obtida para a espécie apresenta especial relevância, pois a geração posterior poderá sempre apresentar novos recombinantes ou mais recombinantes, permitindo adaptação a microambientes e a manutenção da dinâmica populacional, como demonstrado por MARTINS e JAIN (1977) e JAIN e MARTINS (1979) para Trifolium hirtum (leguminosa colonizadora), e discutido em BARRETT e KOHN (1991). Conforme OYAMA (1993), a variação genética dentro de indivíduos é tão importante quanto a variação entre; e, se o tamanho das populações naturais em espécies tropicais, onde os níveis de diversidade elevados são comuns, se reduz, também ficará reduzido o potencial de ocupação de novos microambientes ou alterações naturais destes. Assim, considerando que características associadas ao vigor das sementes e/ou desenvolvimento inicial das plantas apresentam variação genética, como evidenciado por REIS et al. (1992) e NODARI et al. (1993) para E. edulis, a alteração dos níveis de recombinação e heterozigosidade com o avançar das gerações comprometerá o estabelecimento, desenvolvimento e recrutamento de novos individuos. Tal aspecto tem implicações diretas no dinamismo demográfico e no manejo de populações naturais com fins comerciais.

Os índices de fixação (endogamia) variaram de 0,005 a 0,117 nas progênies (Tabela 15), indicando a existência de endogamia em níveis relativamente reduzidos para a maior parte das populações. Em relação aos indivíduos adultos, os indices de fixação foram, em sua maioria, negativos (Tabela 16), refletindo o excesso de heterozigotos existente, como já mencionado anteriormente. 
O agrupamento das populações, por regiões ou locais, produz índices similares de diversidade, tanto nas progênies quanto nos indivíduos adultos (Tabelas 15 e 16). As variâncias obtidas para estes indices demostram que os mesmos não diferem entre si e tampouco diferem daqueles obtidos para as população individualmente. Este aspecto indica que, apesar da aparente divergência entre as populações, discutida a partir das diferenças entre as frequiências alélicas, as populações apresentam um padrão de diversidade similar.

\subsection{Organização da Variação Genética Entre e Dentro de Populações}

A caracterização da distribuição da variabilidade genética entre e dentro de populações foi realizada considerando três abordagens. Inicialmente foram estimados os valores de $F_{I S}, F_{I T}$ e $F_{S T}$, conforme WRIGHT (1951) e NEI (1977), considerando as populações individualmente ou agrupando por locais e regiões, tanto para progênies quanto para individuos adultos. Adicionalmente, foi analisada a diversidade considerando a subdivisão das populações, conforme propõe NEI (1973, 1978), obtendo-se as estimativas das heterozigosidades totais e por subdivisão, bem como a diferenciação relativa entre as subpopulações $\left(G_{S T}\right)$. Finalmente, foram estimados os coeficientes de coancestralidade entre regiões, locais, populações e famílias, bem como o valor de F, conforme COCHERAN (1969), empregando-se a metodologia proposta por WEIR (1990a) e VENCOVSKY (1992); hierarquizando indivíduos dentro de progênies dentro de populações dentro de locais dentro de regiões, na análise das progênies, ou indivíduos dentro de populações dentro de locais dentro de regiões, para os indivíduos adultos. 
Este conjunto de análises visa não somente a caracterização da estruturação das populações naturais da espécie, mas também avaliar a adequação das diferentes abordagens ao tipo de estudo em questão.

\subsubsection{Estatísticas $F$}

Os valores médios obtidos (Tabela 17 e 18) mostram uma endogamia total reduzida para progênies e negativa para indivíduos adultos, conforme já indicado pelos índices de fixação (Tabelas 15 e 16).

Os valores de $\hat{F}_{I T}$ foram negativos nos adultos, refletindo o excesso de heterozigotos já mencionado. Além disso, os valores de $\hat{F}_{l s}$ foram também negativos, indicando um comportamento similar nas populações individualmente.

Os valores de $\hat{F}_{S T}$ obtidos indicaram uma reduzida divergência entre as populações estudadas, tanto para progênies quanto para indivíduos adultos. $\mathrm{O}$ agrupamento por locais e regiões mostrou um comportamento similar.

A magnitude dos valores obtidos é similar àquela obtida para a maioria das espécies tropicais já estudadas (Tabela 4 ).

Apesar de reduzidos, os valores obtidos são significativamente diferentes de zero, como indicam os testes de heterogeneidade realizados a partir da comparação das freqüências alélicas entre as populações, através de testes de contingência, conforme WORKMAN e NISWANDER (1970). Inicialmente as comparações foram feitas entre todas as populações, posteriormente entre locais e entre populações dentro de locais, para progênies e adultos, conforme Tabelas $17 \mathrm{e}$ 18 (Anexos III e IV). 
Tabela 17. Estimativas de $F_{I S} F_{I T}$ e $F_{S T}$ para sete populações naturais de Euterpe edulis, avaliação a partir de progênies, baseadas em sete locos alozímicos, agrupadas de diferentes modos. Piracicaba-SP, ESALQ/USP, 1996

\begin{tabular}{llll}
\hline Populações & $\hat{F}_{I S}$ & $\hat{F}_{I T}$ & $\hat{F}_{S T}$ \\
\hline 7 populações & 0,042 & 0,068 & $0,026^{* *}$ \\
$\operatorname{SC}^{1} x S x L(3)^{2}$ & 0,053 & 0,072 & $0,019^{* *}$ \\
$\operatorname{SCxSP}(2)$ & 0,058 & 0,070 & $0,012^{* *}$ \\
$\operatorname{SCxS}(2)$ & 0,059 & 0,072 & $0,014^{* *}$ \\
$\operatorname{SCxS}(6)$ & 0,042 & 0,065 & $0,024^{* *}$ \\
$\operatorname{SCxL}(2)$ & 0,044 & 0,060 & $0,017^{* *}$ \\
$\operatorname{SCxL}(4)$ & 0,032 & 0,052 & $0,021^{* *}$ \\
$\operatorname{SxL}(2)$ & 0,060 & 0,072 & $0,013^{* *}$ \\
$\operatorname{SxL}(4)$ & 0,054 & 0,073 & $0,020^{* *}$ \\
$\operatorname{SC~(3)}$ & 0,028 & 0,038 & $0,011^{* *}$ \\
$\operatorname{S~}(3)$ & 0,057 & 0,070 & $0,014^{* *}$ \\
\hline
\end{tabular}

'SC, S e L correspondem a Santa Catarina, SP-Saibadela e SP-Limão, respectivamente

${ }^{2}()$ número de "grupos" na comparação

** significativo à $1 \%$ pelo teste de contingência $-\chi^{2}$ 
Tabela 18. Estimativas de $\mathrm{F}_{\mathrm{IS}} \mathrm{F}_{\mathrm{IT}}$ e $\mathrm{F}_{\mathrm{ST}}$ para oito populações naturais de Euterpe edulis, avaliação a partir de indivíduos adultos, baseadas em sete locos alozímicos, agrupadas de diferentes modos. Piracicaba-SP, ESALQ/USP, 1996

\begin{tabular}{llll}
\hline Populações & $\hat{F}_{I S}$ & $\hat{F}_{I T}$ & $\hat{F}_{S T}$ \\
\hline 8 populações & $-0,067$ & -0.033 & $0,031^{* *}$ \\
SC1 xSxL (3) $)^{2}$ & $-0,051$ & $-0,029$ & $0,021^{* *}$ \\
SCxSP (2) & $-0,036$ & $-0,025$ & $0,011^{* *}$ \\
SCxS (2) & $-0,065$ & $-0,056$ & $0,009^{* *}$ \\
SCxS (6) & $-0,076$ & $-0,055$ & $0,020^{* *}$ \\
SCxL (2) & $-0,001$ & $-0,023$ & $0,024^{* *}$ \\
SCxL (5) & $-0,015$ & $-0,022$ & $0,037^{* *}$ \\
SxL (2) & $-0,076$ & $-0,060$ & $0,014^{* *}$ \\
SxL (5) & $-0,104$ & $-0,075$ & $0,026^{* *}$ \\
SC (3) & $-0,000$ & $-0,012$ & 0,013 \\
S (3) & $-0,145$ & $-0,133$ & 0,010 \\
L (2) & $-0,037$ & $-0,020$ & 0,017 \\
\hline
\end{tabular}

'SC, S e L correspondem a Santa Catarina, SP-Saibadela e SP-Limão, respectivamente ${ }^{2}()$ número de "grupos" na comparação

** significativo à $1 \%$ pelo teste de contingência $-\chi^{2}$

Os resultados indicaram a existência de heterogeneidade entre as populações em todas as comparações realizadas, exceto para os indivíduos adultos nas populações contíguas (Tabela 18). As maiores contribuições para o valor calculado de $\chi^{2}$ foram associadas às populações SPL350 e SPL700 e SC650 para adultos, e SPL700, SC450, SC550, SC650 e SPS100 para progênies. Entre os locos, 
PRX2 e PGM1 apresentaram maior heterogeneidade entre as populações (Anexo III).

Estes resultados reforçam a idéia discutida no item anterior, em relação aos alelos exclusivos, pois evidenciam uma tendência de divergência entre as populações amostradas.

As estimativas obtidas para os grupos de populações contínuas (Santa Catarina: SC450, SC550 e SC650; São Paulo-Saibadela: SPS100, SPS250 e SPS350; São Paulo-Limão: SPL700 e SPL350), indicaram divergências reduzidas para progênies $(0,11$ e 0,14$)$ e praticamente nulas $\left(\hat{F}_{S T}\right.$ não significativo) para adultos (Tabelas 17 e 18). Por sua vez, as comparações envolvendo populações de diferentes locais e/ou regiões (Santa Catarina x São Paulo-Saibadela e SP-Saibadela x SPLimão) revelaram divergências de magnitudes similares (Tabela 17 e 18) e superiores às populações contínuas .

As divergências caracterizadas (Tabelas 17 e 18) sugerem a existência de efeitos de deriva e/ou de seleção entre regiões e locais. Contudo a inexistência de divergências entre as populações contíguas, para adultos, indicam que os efeitos de deriva e/ou seleção são de menor expressão nestas situação, quanto comparados à variação geográfica de maior amplitude; ou que os efeitos de seleção são expressivos, mas similares nas populações contínuas. A seleção em favor dos heterozigotos corrobora com esta última hipótese.

Estes resultados sugerem o modelo de isolamento por distância para a espécie, pois indicam uma tendência de maior diferenciação com distâncias maiores. Além disso, a distribuição contínua e abundante da espécie, originalmente, em toda a área do domínio da Floresta Tropical Atlântica produz uma expectativa que dá suporte a este modelo. 
O agrupamento de populações por local e/ou regiăo produziu tendências similares às mencionadas anteriormente. Contudo, os valores de $\hat{F}_{S T}$ estimados apresentaram magnitudes sempre inferiores, proporcionalmente à redução no número de grupos (populações, locais ou regiões) comparados. Tal resultado é coerente com que discutem WEIR e COCKERHAM (1984, p.1359) sobre as estimativas para $\mathrm{F}_{\mathrm{ST}}$ como estatística e não como parâmetro, as quais variam conforme o número de populações envolvidas.

Além disso, o agrupamento de populações elimina eventuais divergências associadas à níveis de estrutura de escala geográfica inferior, reduzindo a magnitude da divergência estimada. Assim, quando comparados SC com SPSaibadela considerando-se como dois locais ou como seis populações os resultados são 0,009 e 0,020 para adultos e 0,014 e 0,024 para progênies.

A utilização dessa sistemática para diferentes níveis hierárquicos não permite uma quantificação individualizada da divergência nos diferentes níveis; $\operatorname{logo}$, não permite uma avaliação específica dos fenômenos envolvidos (deriva, fluxo gênico, p.ex.) em cada nível.

4.3.2. Análise da Diversidade em Populações. Subdivididas

A análise da diversidade considerando a subdivisão nas populações revelou resultados, relativos a divergência $\left(\hat{G}_{s T}\right)$, similares aos obtidos com as estimativas das estatísticas $\mathrm{F}$ para progênies (Tabela 19). Em termos médios os resultados mostram valores inferiores aos obtidos para as espécies tropicais em geral (Tabela 3). 
Tabela 19. Estimativas de $\mathrm{H}_{\mathrm{T}}, \mathrm{H}_{\mathrm{S}}$ e $\mathrm{G}_{\mathrm{ST}}$ para sete populações naturais de Euterpe edulis, avaliação a partir de progênies, baseada em sete locos alozímicos, agrupadas de diferentes modos. Piracicaba-SP,ESALQ/USP. 1996

\begin{tabular}{llll}
\hline Populações & $\hat{H}_{\tau}$ & $\hat{H}_{S}$ & $\hat{G}_{S T}$ \\
\hline 8 populações & 0,436 & 0,425 & 0,025 \\
SC'xSxL (3) & 0,436 & 0,429 & 0,016 \\
SCxSP (2) & 0,436 & 0,434 & 0,005 \\
SCxS (2) & 0,435 & 0,431 & 0,009 \\
SCxS (6) & 0,435 & 0,425 & 0,023 \\
SCxL (2) & 0,442 & 0,434 & 0,018 \\
SCxL (5) & 0,442 & 0,433 & 0,020 \\
SxL (2) & 0,427 & 0,424 & 0,007 \\
SxL (5) & 0,427 & 0,417 & 0,023 \\
SC (3) & 0,441 & 0,435 & 0,014 \\
S (3) & 0,421 & 0,414 & 0,017 \\
\hline
\end{tabular}

'SC, S e L correspondem a Santa Catarina, SP-Saibadela e SP-Limão, respectivamente 2( ) número de "grupos" na comparação

Para adultos os resultados mostraram-se em geral inferiores e, em algumas situações, discrepantes, em relação aos valores obtidos para $\hat{F}_{S T}$ (Tabela 20). Sendo inclusive negativos (teoricamente impossível: em termos práticos, não diferentes de zero) para as populações contíguas.

Tais resultados estão possivelmente associadas ao viés existente nas estimativas de $\mathrm{G}_{\mathrm{ST}}$, especialmente para amostras pequenas, como discutem WEIR e COCKERHAM (1984), COCKERHAM e WEIR (1987, 1993). 
Tabela 20. Estimativas de $\mathrm{H}_{\mathrm{T}} \mathrm{H}_{\mathrm{S}}$ e $\mathrm{G}_{\mathrm{ST}}$ para oito populações naturais de Euterpe edulis, avaliaçăo a partir de indivíduos adultos, baseada em sete locos alozímicos, agrupadas de diferentes modos. Piracicaba-SP, ESALQ/USP, 1996

\begin{tabular}{llll}
\hline Populações & $\hat{H}_{T}$ & $\hat{H}_{s}$ & $\hat{G}_{s T}$ \\
\hline 8 populações & 0,452 & 0,446 & 0,013 \\
SC'xSxL (3) & 0,452 & 0,445 & 0,013 \\
SCxSP (2) & 0,452 & 0,444 & 0,018 \\
SCxS (2) & 0,452 & 0,449 & 0,007 \\
SCxS (6) & 0,452 & 0,451 & 0,002 \\
SCxL (2) & 0,437 & 0,430 & 0,016 \\
SCxL (5) & 0,437 & 0,429 & 0,018 \\
SxL (2) & 0,463 & 0,455 & 0,017 \\
SxL (5) & 0,463 & 0,459 & 0,009 \\
SC (3) & 0,424 & 0,426 & $-0,005$ \\
S (3) & 0,474 & 0,476 & $-0,004$ \\
L (2) & 0,436 & 0,433 & $-0,007$ \\
\hline
\end{tabular}

'SC, S e L correspondem a Santa Catarina. SP-Saibadela e SP-Limão, respectivamente ( ) número de "grupos" na comparação

Além disso, os valores foram expressivamente inferiores quando o número de populações comparadas foi reduzido (p. ex. de 6 para 2), possivelmente por eliminar efeitos de variação em menor escala, como já mencionado anteriormente.

Conforme COCKERHAM e WEIR (1993), $\hat{G}_{S T}$ não pode ser considerado como estimador de $\mathrm{F}_{\mathrm{ST}}$, especialmente quando o número de populações 
analisadas e/ou o número de indivíduos amostrados é reduzido, como no caso das avaliações entre populações contíguas de indivíduos adultos.

Assim, a utilização dessa sistemática mostra-se inadequada quando a amostragem é reduzida, além do que não permite individualizar os efeitos das divergências nos diferentes níveis hierárquicos, como mencionado para o $\hat{F}_{S T}$.

\subsubsection{Estimativas dos coeficientes de Coancestralidade}

Os valores dos coeficientes de coancestralidade ( $\theta^{\prime}$ 's) estimados (Tabelas 21 e 22, Anexo V) indicaram uma reduzida divergência entre as populações nos diferentes níveis de hierarquia analisados, tanto para adultos como para progênies.

As estimativas para os coeficientes nos diferentes niveis de hierarquia (regiões $\hat{\theta}_{R}$, locais $\hat{\theta}_{L}$ e populações $\hat{\theta}_{P}$ ) foram similares nas progênies e nos adultos, mostrando um mesmo padrão no sentido de uma reduzida divergência (Tabelas 21 e 22). Além disso, os valores obtidos foram coerentes, inclusive em magnitude, com aqueles obtidos para as estimativas de $\mathrm{F}_{\mathrm{ST}}$ (Tabela 17 e 18).

$\mathrm{O}$ valor de $\hat{\theta}_{F}$ médio foi de 0,14 , aproximando-se do valor esperado para progênies maternais perfeitas, o que sugere a existência de um nível reduzido de endogamia para as populações. Este resultado é coerente com os coeficientes de endogamia obtidos através de diferentes abordagens: F (índices de fixação - Tabelas 15 e 16), $F_{I T}$ (Tabelas 17 e 18) e $f$ (Tabelas 21 e 22 ). 
Tabela 21. Estimativas dos coeficientes de coancestralidade para sete populações naturais de Euterpe edulis, com dados obtidos a partir de progênies de meio-irmãos, empregando-se sete locos alozímicos. Piracicaba-SP, ESALQ/USP, 1996

\begin{tabular}{lllllllll}
\hline loco & $\hat{\theta}_{R}$ & $\hat{\theta}_{L}$ & $\hat{\theta}_{P}$ & $\hat{\theta}_{F}$ & $\hat{\theta}_{F}$ & $\hat{F}$ & $\hat{f}$ & $\hat{t}_{a 3}$ \\
\hline PRX2 & $-0,0162$ & 0,0028 & 0,0077 & 0,1211 & 0,1143 & 0,0743 & 0,0672 & 0,8741 \\
PRX3 & $-0,0051$ & 0,0071 & 0,0081 & 0,1292 & 0,1222 & $-0,0400$ & $-0,0485$ & 1,1019 \\
PRX4 & 0,0289 & 0,0559 & 0,0600 & 0,1912 & 0,1395 & 0,1810 & 0,1287 & 0,7719 \\
PRX5 & 0,0036 & $-0,0082$ & 0,0086 & 0,0745 & 0,0664 & $-0,0324$ & $-0,0414$ & 1,0864 \\
PG12 & $-0,0204$ & 0,0134 & 0,0105 & 0,1336 & 0,1244 & 0,0184 & 0,0080 & 0,9841 \\
PGM1 & 0,0277 & 0,0308 & 0,0403 & 0,2596 & 0,2285 & 0,2173 & 0,1845 & 0,6885 \\
G6P1 & 0,0293 & 0,0091 & 0,0349 & 0,1426 & 0,1116 & 0,0099 & $-0,0259$ & 1,0532 \\
\hline Média & & & & & & & & \\
locos & 0,00531 & 0,0213 & 0,0264 & 0,1631 & 0,1404 & 0,0863 & 0,0615 & 0,8841 \\
alelos & 0,00659 & 0,0225 & 0,0273 & 0,1692 & 0,1459 & 0,0899 & 0,0644 & 0,8789 \\
\hline
\end{tabular}

Nas comparações entre populações contínuas $\left(\hat{\theta}_{P}\right)$ e locais $\left(\hat{\theta}_{L}\right)$ os valores ficaram em torno de $2,3 \%$. Contudo, nas comparações entre regiões, os valores foram extremamente reduzidos $(0,5 \%$ para progênies e $0,2 \%$ para adultos), sugerindo um fluxo gênico superior ao existente nas populações contínuas ou locais. Tais valores, entretanto, devem ser tomados com cautela, pois foram obtidos a partir de variâncias com reduzido número de graus de liberdade e nas situações onde o desbalanceamento entre os níveis (locais) do fator envolvido (regiões) era o mais expressivo (Anexo V). 
Tabela 22. Estimativas dos coeficientes de coancestralidade para oito populações naturais de Euterpe edulis, com dados obtidos a partir de individuos adultos, empregando-se sete locos alozímicos. Piracicaba-SP, ESALQ/USP, 1996

\begin{tabular}{llllll}
\hline loco & $\hat{\theta}_{R}$ & $\hat{\theta}_{L}$ & $\hat{\theta}_{P}$ & $\hat{F}$ & $\hat{f}$ \\
\hline PRX2 & 0,0056 & $-0,0040$ & 0,0101 & $-0,1543$ & $-0,1661$ \\
PRX3 & $-0,0230$ & 0,0034 & $-0,0034$ & $-0,0338$ & $-0,0303$ \\
PRX4 & 0,0001 & 0,0302 & 0,0247 & 0,0970 & 0,0741 \\
PRX5 & 0,0298 & 0,0112 & 0,0484 & $-0,0744$ & $-0,1290$ \\
PGI2 & $-0,0190$ & 0,0041 & $-0,0041$ & $-0,1481$ & $-0,1433$ \\
PGM1 & 0,0574 & 0,0641 & 0,0711 & $-0,0442$ & $-0,1242$ \\
G6P1 & $-0,0733$ & 0,0186 & 0,0137 & $-0,0727$ & $-0,0876$ \\
\hline Média & & & & & \\
locos &,- 0021 & 0,0216 & 0,0224 & $-0,0520$ & $-0,0761$ \\
alelos &, 0022 & 0,0230 & 0,0233 & $-0,0461$ & $-0,0711$ \\
\hline
\end{tabular}

De qualquer forma são indicadores de divergência reduzida entre as regiões, o que pode ser considerado razoável, ou mesmo esperado, para uma espécie de distribuição geográfica ampla e com distribuição originalmente contínua em toda área de ocorrência (Figura 1).

A fragmentação das populações naturais da espécie ocorreu apenas nos últimos 50 anos, tempo insuficiente para que se fixassem eventuais divergências, seja por seleção, seja por deriva, visto ser esta uma espécie perene (ou de ciclo longo), com sobreposição de gerações ocorrendo em suas populações naturais. Além disso, procurou-se estabelecer a amostragem em áreas com reduzida (Fazenda Intervales) ou nenhuma ação antrópica (Blumenau), ou seja, procurou-se trabalhar 
com amostras representativas da situação de ocorrência original da espécie na Floresta Tropical Atlântica.

A sistemática empregada para a obtenção das estimativas dos coeficientes de coancestralidade possibilita outras estimativas, pois implica na decomposição de todos os componentes de variância envolvidas na estrutura hierárquica estabelecida. Assim, como os componentes de variância podem ser interpretados como covariâncias (COCKERHAM, 1969) e, portanto, os coeficientes de coancestralidade são correlações intraclasse, outras correlações intraclasse podem ser estabelecidas.

Desta forma, como o grau de parentesco entre as famílias maternais podem ser melhor estimado por $\hat{\theta}_{F}$ do que por $\hat{\theta}_{F}$ (item 3.3.2.2.), por retirar os efeitos de divergência dos níveis hierárquicos superiores, outros coeficientes também podem ser estimados da mesma forma. Assim,

$$
\hat{\theta}_{L}=\hat{\sigma}_{L}^{2} /\left(\hat{\sigma}_{G}^{2}+\hat{\sigma}_{I}^{2}+\hat{\sigma}_{F}^{2}+\hat{\sigma}_{p}^{2}+\hat{\sigma}_{L}^{2}\right)
$$

$\mathrm{e}$

$$
\hat{\theta}_{p}=\hat{\sigma}_{P}^{2} /\left(\hat{\sigma}_{G}^{2}+\hat{\sigma}_{t}^{2}+\hat{\sigma}_{F}^{2}+\hat{\sigma}_{p}^{2}\right)
$$

Estas estimativas apresentam como vantagem a possibilidade de caracterizar, especificamente em cada nível hierárquico, os efeitos decorrentes da movimentação dos alelos.

Para o palmiteiro os valores estimados foram 0,016 e 0,005 para $\hat{\theta}_{L}$ e $\hat{\theta}_{P}$, a nível de progênies e 0,021 e 0,0003 para $\hat{\theta}_{L}$ e $\hat{\theta}_{P}$, a nível de indivíduos adultos. Estes resultados indicam que as maiores divergências estão associadas aos diferentes locais, independente das regiões; ou que as populações contínuas apresentam 
divergências reduzidas, independente de locais e/ou regiões. Portanto as eventuais limitações de movimentação dos alelos, as quais produzem as subdivisões nas populações estăo relacionadas a uma escala maior do que aquela das populações contínuas.

Por outro lado, é razoável considerar que a metodologia proposta para estimativa dos coeficientes de coancestralidade, além de apresentar menores vieses, por considerar o processo amostral, se mostra mais versátil e eficiente na caracterização da estrutura em populações naturais.

\subsection{Sistema Reprodutivo}

\subsubsection{Equilíbrio de Endogamia}

A avaliação da existência de equilíbrio de panmixia nas populações estudadas pode ser considerada como uma caracterizaçăo inicial do sistema reprodutivo, uma vez que tal equilíbrio implica em cruzamentos ao acaso, ou seja, implica numa taxa de cruzamento de $100 \%$. Assim, foram realizados os testes de aderência ao equilíbrio de panmixia para as populações estudadas, com base na distribuição $\%$ :

Os testes de aderência ao equilíbrio de panmixia (equilíbrio de HardyWeinberg) realizados para as progènies indicaram desvios expressivos (Tabela 23, Anexo VI) na maioria dos locos em todas as populações. O agrupamento de classes para os alelos menos freqüentes (Tabela 23, Anexo VI) produz freqüências genotípicas que também se desviam do equilíbrio de panmixia para boa parte dos 
locos analisados. A análise conjunta de todos os locos em cada população reforça a caracterização dos desvios existentes.

Nos locos com classes genotípicas suficientes, foi testada a aderência ao equilíbrio de endogamia (equilíbrio de Wright) (Tabela 24, Anexo VI). Os resultados indicaram também desvios significativos para este modelo nas progênies.

Assim, as freqüências genotípicas (Anexo VII) nas progênies indicam a ocorrência de endogamia proveniente de fatores năo devidos apenas ao sistema reprodutivo, pois a inexistência de equilíbrio de endogamia sugere a ocorrência de outros fatores envolvidos, como cruzamentos não aleatórios.

A fenologia da espécie é caracterizada por um período bastante amplo de floração: 5 meses em uma população de Euterpe edulis em Floresta Semidecídua, estudada por REIS et al. (1993) e 5 meses na população SC650 (REIS, A., comunicação pessoal). Entretanto, a floração não é sincronizada entre todos os indivíduos, ocorrendo uma tendência a um período inicial com poucas plantas floridas, um aumento gradativo até um máximo e, finalmente, uma redução, como descrito por REIS et al. (1993) e confirmado por REIS, A. (comunicação pessoal) para a população SC650. Além disso, os resultados obtidos por REIS, A. (1995) indicam variação entre anos em relação à quantidade de indivíduos que se reproduzem anualmente (Tabela 25 ). 
Tabela 23. Aderência aos equilíbrio de panmixia para progênies de sete populações naturais de Euterpe edulis. Piracicaba-SP, ESALQ/USP, 1996

\begin{tabular}{lcccccc} 
Populações & GLhw & $\chi^{2}$ hw & Phw & GLp* & $x^{2} \mathrm{p}^{*}$ & $\mathrm{Pp}^{*}$ \\
\hline SC450 & 18 & 33,96 & $<5$ & 6 & 22.89 & $<1$ \\
SC550 & 24 & 132.97 & $<1$ & 4 & 19,48 & $<1$ \\
SC650 & 19 & 97,66 & $<1$ & 7 & 30,98 & $<1$ \\
Santa Catarina (Blu. -3 alt.) & 25 & 253,07 & $<1$ & 7 & 64,31 & $<1$ \\
SPS100 & 18 & 56,12 & $<1$ & 6 & 16,91 & $<1$ \\
SPS250 & 18 & 82.72 & $<1$ & 6 & 32,45 & $<1$ \\
SPS350 & 23 & 170,20 & $<1$ & 7 & 78,38 & $<1$ \\
Saibadela (3 altitudes) & 24 & 289,72 & $<1$ & 7 & 89,31 & $<1$ \\
SPL700 & 19 & 134.23 & $<1$ & 7 & 91,59 & $<1$ \\
São Paulo & 29 & 440,49 & $<1$ & 7 & 134,44 & $<1$ \\
(Saibadela c Limão) & & & & &
\end{tabular}

*agrupando todos os alelos exceto o mais freqüente 
Tabela 24. Aderência ao equilíbrio de endogamia para progênies de sete populações naturais de Euterpe edulis. Piracicaba-SP, ESALQ/USP, 1996

\begin{tabular}{llll} 
Populacão & GL & $\chi^{2}$ & P \\
\hline SC+50 & 11 & 31,434 & $<1$ \\
SC550 & 17 & 123,957 & $<1$ \\
SC650 & 12 & 69,063 & $<1$ \\
Santa Catarina (Blu. 3 alt.) & 18 & 203,757 & $<1$ \\
SPS100 & 11 & 54,320 & $<1$ \\
SPS250 & 11 & 67,671 & $<1$ \\
SPS350 & 16 & 102,459 & $<1$ \\
Saibadela (3 altitudes) & 19 & 220,468 & $<1$ \\
SPL700 & 12 & 120,080 & $<1$ \\
São Paulo & 22 & 341.553 & $<1$ \\
(Saibadela e Limão) & & & \\
\hline
\end{tabular}

Tomando por referência o número de indivíduos que produziram inflorescência (113), a tendência a uma distribuição normal na população para o período de florescimento como um todo, distribuído em 5 meses, e considerando a acentuada protandria da espécie (Figura 6), com tempo de antese e receptividade das flores femininas em uma inflorescência entre 12 e 15 dias não coincidentes (REIS et al, 1993), o número máximo de indivíduos coincidentemente floridos seria de aproximadamente 26 por hectare; ficando entre 10 e 15 individuos por hectare na maior parte do tempo; e chegando a 4 indivíduos por hectare na primeira e última quinzenas. 
Tabela 25. Características reprodutivas da população SC650 de Euterpe edulis, em dois anos de acompanhamento, conforme REIS, A. (1995). Piracicaba-SP, ESALQ/USP, 1996

\begin{tabular}{llll}
\hline Indivíduos / órgãos por hectare & 1992 & 1993 & média \\
\hline Plantas Adultas & 117 & 136 & 127 \\
Plantas com Inflorescências & 115 & 111 & 113 \\
Número de Inflorescências & 189 & 211 & 200 \\
Plantas com Infrutescências & 56 & 96 & 76 \\
Número de Infrutescências & 69 & 160 & 115 \\
Número de Frutos & 228.594 & 531.235 & 379.914 \\
\hline
\end{tabular}

Estes aspectos, aliados às características de microambiente (relevo, vegetação, etc), favorecem a possibilidade de ocorrência de cruzamentos não aleatórios entre os indivíduos, pois nem todos estarão na mesma fase fenológica ou terão possibilidade de serem visitados pelos polinizadores ao mesmo tempo.

Adicionalmente, a existência de estruturação espacial interna nas populações poderia provocar efeitos similares. Contudo, a existência deste tipo de estruturação não pode ser provada neste trabalho, pois não foi realizado um censo nas populações amostradas. Além disso, a dispersão de sementes a longa distância, como caracterizada por REIS, A. (1995) para a espécie, sugere a inexistência deste tipo de estruturação.

Por outro lado, para indivíduos adultos, os resultados indicaram uma aderência da maioria dos locos ao equilíbrio de panmixia (Tabela 26, Anexo VI), exceto na população SPS350. Tal resultado sugere diferenças entre indivíduos adultos e progênies. 

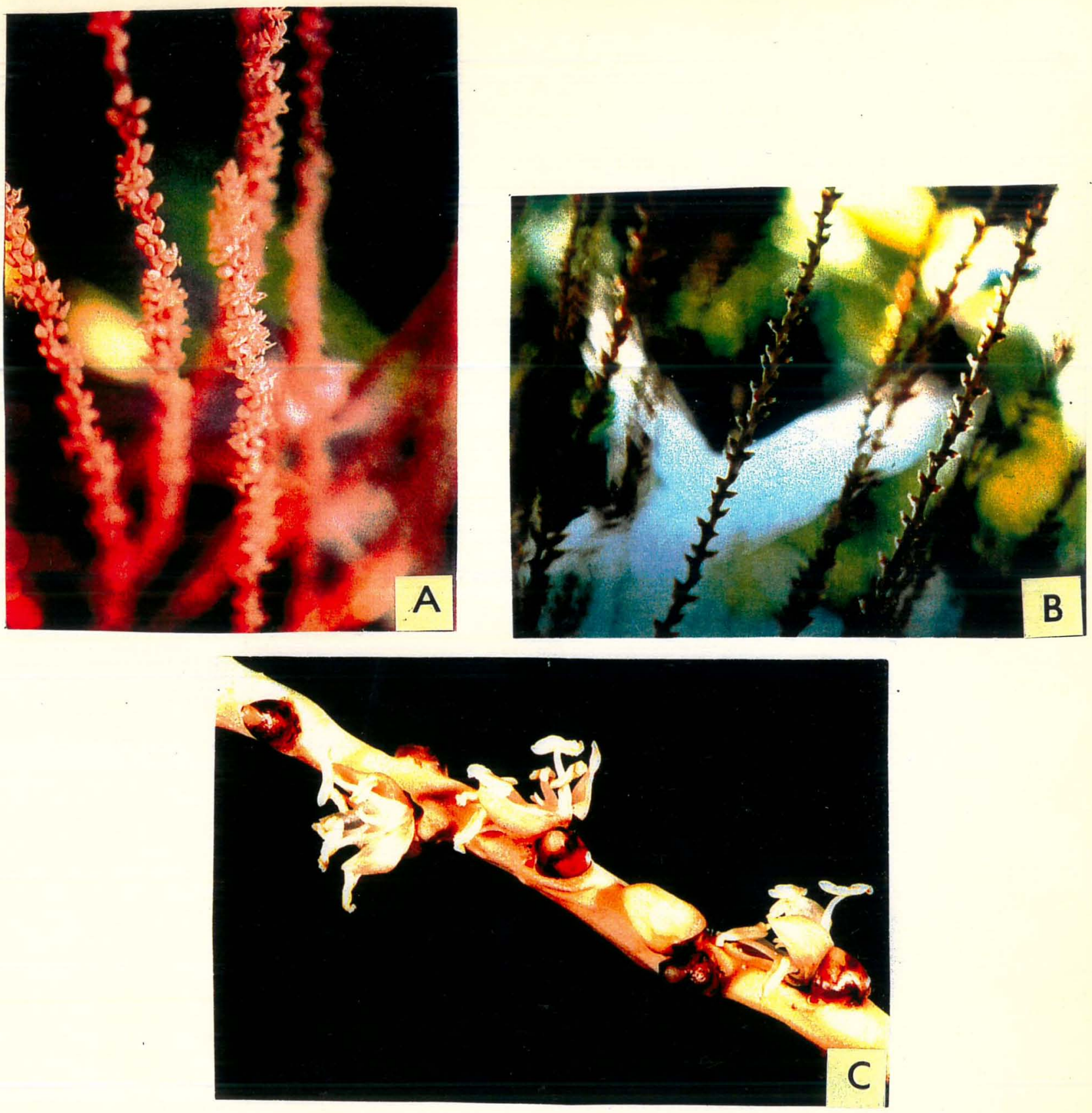

Figura 6. Aspectos da floração em Euterpe edulis: a) florada masculina (antese); b) abertura das flores femininas após queda completa das flores masculinas; c) detalhe da antese e flores feminínas ainda em fase inicial de desenvolvimento. Piracicaba-SP, ESALQ/USP, 1996 (Fotos: a - M.S. Reis, 1993; b - E. Guimarães, 1993; c - R.O. Nodari, 1994) 
Tabela 26. Aderência aos equilíbrio de panmixia em sete locos alozímicos para indivíduos adultos de oito populações naturais de Euterpe edulis. Piracicaba-SP, ESALQ/USP, 1996

\begin{tabular}{|c|c|c|c|c|c|c|}
\hline População & $\mathrm{GL}$ & $x^{2}$ & $\mathrm{P}$ & $\mathrm{GLp}^{*}$ & $z^{2} \mathrm{p}^{*}$ & $\mathrm{Pp}^{*}$ \\
\hline $\mathrm{SC} 450$ & 7 & 1,428 & $>95$ & 4 & 1,210 & $90-75$ \\
\hline $\operatorname{SC} 550$ & 11 & 13,303 & $50-25$ & 4 & 0,948 & $90-95$ \\
\hline SC650 & 10 & 3,585 & $>95$ & 3 & 0,794 & $90-75$ \\
\hline Santa Catarina (Blu. 3 alt.) & 12 & 9.049 & $75-50$ & 5 & 1.365 & $95-90$ \\
\hline SPS100 & 11 & 16.462 & $25-10$ & 4 & 10.128 & $<5$ \\
\hline SPS250 & 11 & 17,989 & $10-5$ & 5 & 12.643 & $<5$ \\
\hline SPS350 & 12 & 23,031 & $<5$ & 6 & 15,922 & $<5$ \\
\hline Saibadela ( 3 altitudes) & 15 & 36,320 & $<1$ & 5 & 1,589 & $95-90$ \\
\hline SPL350 & 11 & 9.313 & $75-50$ & 5 & 7.815 & $25-10$ \\
\hline SPL 700 & 11 & 7,906 & $75-50$ & 5 & 6.465 & $50-25$ \\
\hline Limão (2 altitudes) & 11 & 12,103 & $50-25$ & 6 & 31,042 & $<1$ \\
\hline $\begin{array}{l}\text { São Paulo } \\
\text { (Saibadela e Limão) }\end{array}$ & 15 & 35.745 & $<1$ & 6 & 30.597 & $<1$ \\
\hline
\end{tabular}

*agrupando alelos exceto o mais freqüente

Assim, parece razoável considerar que a cada ciclo reprodutivo predominam cruzamentos não aleatórios entre os indivíduos, produzindo progênies que não apresentam equilíbrio de panmixia ou endogamia, mesmo quando os indivíduos adultos estão em equilíbrio de panmixia. Ou seja, os efeitos de deriva genética decorrente de uma estruturação fenológica das populações produzem progênies em desequilibrio. Possivelmente uma amostragem sistemática, cobrindo todo o período de florescimento/frutificação, traria informações mais completas 
sobre esta estruturação. Além disso, a amostragem de um maior número de progênies poderia diluir estes efeitos.

As freqüências alélicas foram também comparadas entre adultos e progênies, em cada uma das sete populações, empregando a análise de contingência, conforme WORKMAN e NISWANDER (1970). Os resultados (Tabela 27) indicaram a existência de heterogeneidade entre adultos e progênies nas populações SC550, SPS100 e SPS350. Entretanto, a análise conjunta considerando as 7 populações sugeriu a existência de diferenças nas freqüências alélicas entre adultos e progênies. Tal resultado pode estar associado à amostragem com diferentes densidades entre as populações de adultos e de progênies, ou decorre de efeitos relativos a biologia reprodutiva da espécie, como cruzamentos não aleatórios ou a existência de estruturação interna nas populações, como já mencionado

Além disso, a sobreposição de gerações existente na população de indivíduos adultos, bem como a sobrevivência e/ou recrutamento (com efeitos de seleção e/ou deriva), pode ser responsável por grande parte das diferenças existentes, especialmente no que se refere as freqüências alélicas.

Apesar dos indivíduos adultos apresentarem equilíbrio de panmixia, há que se ressaltar a existência de um excesso de heterozigotos, explicitada pelos indices de fixação negativos (Tabela 16). Este contexto sugere a ocorrência de seleção em favor de heterozigotos, como já mencionado. Contudo estudos adicionais devem ser realizados, pois o excesso de heterozigotos não mostrou desvios significativos do equilíbrio de panmixia. Além disso, por definição, os efeitos seletivos só poderiam ficar explícitos em locos alozímicos, se estes últimos estivessem ligados a locos seletivamente ativos, o que não pode ser provado neste estudo. 
Tabela 27. Análise de contingência para freqüências alélicas em sete locos alozímicos entre progênies e adultos em sete populações naturais de Euterpe edulis. Piracicaba-SP, ESALQ/USP, 1996

\begin{tabular}{lccc} 
População & $\begin{array}{l}\text { graus de } \\
\text { liberdade }\end{array}$ & $\chi^{2}$ & P (\%) \\
\hline SC450 & 13 & 22,661 & $<5$ \\
SC550 & 12 & 14,809 & $25-10$ \\
SC650 & 13 & 11,526 & $76-50$ \\
SPS100 & 14 & 53,495 & $<1$ \\
SPS250 & 15 & 21,472 & $25-10$ \\
SPS350 & 15 & 27,754 & $<5$ \\
SPL700 & 15 & 10,340 & $90-75$ \\
\hline Total & 97 & 162,057 & $<1$ \\
\hline
\end{tabular}

O conjunto de resultados sugere um comportamento de alogamia para a espécie. Contudo, a indefinição de um modelo de equilíbrio para as progênies indica a necessidade de análises adicionais visando a obtenção de uma quantificação da taxa de cruzamento.

\subsubsection{Taxa de Cruzamento}

A taxa de cruzamento foi estimada a partir de duas abordagens : a) taxa de cruzamento aparente, a partir dos coeficientes de endogamia obtidos; b) taxa de 
cruzamento multilocos, a partir de um estimador de máxima verossimilhança (RITLAND e JAIN, 1981).

Os valores obtidos para taxa de cruzamento aparente (Tabela 28) são coerentes entre si (em torno de 0,92 ) e sugerindo a existência de endogamia, por autofecundação ou por cruzamento entre aparentados. Por sua vez, as estimativas multilocos (Tabela 29) mostram valores que se aproximam de 1,00 diferindo apenas nas populações SPL700 e SPS350, nestes casos os valores estimados foram de 0,94. Tais resultados demonstram ser Euterpe edulis uma espécie preferencialmente de fecundação cruzada, como já haviam sugerido REIS et al. (1993) a partir do estudo da biologia floral e ecologia da polinização da espécie.

A comparação entre a taxa de cruzamento multilocos e unilocos média, possibilita a caracterização de cruzamento entre aparentados e ou autofecundação, conforme discutem RITLAND e EL-KASSABY (1985), SANTOS (1994) e GANDARA (1995). No caso do palmiteiro essa comparação fica prejudicada pelo erro elevado associado às estimativas unilocos, contudo a diferença entre as duas estimativas aparece na população SPS350. Além disso, a comparação com as estimativas de taxa de cruzamento aparente evidencia a existência de diferenças nas populações SC650, SPS250, SPS350 e SPL700. Tais resultados sugerem a ocorrência de cruzamentos entre aparentados nas populações mencionadas, reforçando a idéia de ocorrência de cruzamentos não aleatórios mencionada anteriormente. 
Tabela 28. Estimativas da taxa de cruzamento aparente para sete populações naturais de Euterpe edulis, obtidas a partir de diferentes coeficientes de endogamia. Piracicaba-SP, ESALQ/USP, 1996

\begin{tabular}{llll}
\hline População & $\hat{t}_{a 1}\left(\mathrm{~F}^{*}\right)$ & $\hat{t}_{a 2}\left(\mathrm{~F}_{\mathrm{IS}}{ }^{*}\right)$ & $\hat{t}_{a 3}\left(\mathrm{f}^{*}\right)$ \\
\hline SC450 & 0,99 & & \\
SC550 & 0,96 & & \\
SC650 & 0,88 & & \\
SPS100 & 0,97 & \\
SPS250 & 0,92 & \\
SPS350 & 0,79 & 0,92 & 0,88 \\
SPL700 & 0,91 & \\
Média (7 pop) & 0,92 & \\
SP-Saibadela & 0,86 & \\
São Paulo & 0,86 & 0,90 & \\
Santa Catarina & 0,92 & 0,89 \\
Locais (3) & & \\
Regiões (2) & &
\end{tabular}

* estimativas obtidas a partir dos índices de fixação (F), do índice médio de endogamia entre populações $\left(F_{I S}\right)$ e da endogamia a nível de indivíduo $(f)$ 
Tabela 29. Taxas de cruzamento para locos individuais e multilocos estimadas para sete populações naturais de palmiteiro. Piracicaba-SP, ESALQ/USP, 1996

\begin{tabular}{|c|c|c|c|c|c|c|c|}
\hline & $\mathrm{SC}$ & & & SPS & & & SPL \\
\hline & 450 & 550 & 650 & 100 & 250 & 350 & 700 \\
\hline Locos & & & Número & Familias & & & \\
\hline & 09 & 04 & 10 & 07 & 07 & 14 & 16 \\
\hline PRX2 & 1,99 & 0,92 & 0,83 & 1,23 & 1,23 & 1,00 & 0,48 \\
\hline PRX3 & 1,02 & $* *$ & 0,96 & 1,23 & 1,28 & 0,81 & 1,21 \\
\hline PRX4 & 1,08 & 0,72 & 0,93 & 1,30 & 0,86 & 0,89 & 0,98 \\
\hline PRX5 & 1,99 & 0,77 & 0,50 & 0,43 & 0,75 & 1,99 & 1,99 \\
\hline PGI2 & 1,20 & 1,43 & 1,26 & 0,93 & 1,50 & 0,77 & 0,96 \\
\hline PGM1 & 1,10 & 0,40 & 0,74 & 1,13 & 0,44 & 0,70 & 0,73 \\
\hline G6P1 & 1.04 & 1,99 & 1,22 & 1,99 & 1,99 & 1,99 & 1,99 \\
\hline$\hat{t}_{s}^{*}$ & 1,09 & 0,85 & 0,92 & 1,04 & 1,01 & 0,84 & 0,87 \\
\hline $\mathrm{S}\left(\hat{t}_{s}\right)$ & 0,02 & 0,37 & 0,26 & 0,33 & 0,33 & 0,03 & 0,29 \\
\hline$\hat{t}_{m}$ & 1,04 & 1,02 & 0,95 & 1,04 & 1,00 & 0,94 & 0,94 \\
\hline $\mathrm{S}\left(\hat{t}_{m}\right)$ & 0,05 & 0,02 & 0,03 & 0,05 & 0,02 & 0,02 & 0,02 \\
\hline$\left(\hat{t}_{m}-\hat{t}_{s}\right)$ & $-0,05$ & 0,17 & 0,03 & 0,04 & $-0,01$ & 0,10 & 0,07 \\
\hline
\end{tabular}

O teste de aderência ao modelo multilocos (Tabela 30 , Anexo VIII) mostra valores significativos para todas as populações estudadas, indicando inadequação do mesmo. RITLAND e EL KASSABY (1985) mencionam que os desvios deste equilibrio não prejudicam a obtenção das estimativas, mas indicam a ocorrência de fatores adicionais ao processo, como cruzamentos preferenciais, 
cruzamentos não aleatórios e/ou cruzamentos biparentais (cruzamentos envolvendo apenas dois genitores).

Um dos fatores mais comuns que leva a ocorrência de desvios significativos do equilíbrio multilocos tem sido a heterogeneidade nas freqüências alélicas entre pólens e óvulos, decorrente da ocorrência de cruzamentos não aleatórios ou biparentais. Tal aspecto tem sido registrado para várias espécies tropicais, como: Canavalesia platanifolia, Quararibea asterolepis (MURAWSKI et al., 1990a), Ceiba pentandra (MURAWSKI e HAMRICK, 1992) e Cedrela fissilis (GANDARA, 1995).

Tabela 30. Aderência ao modelo multilocos para progênies de sete populações naturais de Euterpe edulis. Piracicaba-SP, ESALQ/USP, 1996

\begin{tabular}{lccc}
\hline População & GL & $\chi^{2}$ & $P$ \\
\hline SC450 & 55 & 61,847 & $<1$ \\
SC550 & 30 & 105,614 & $<1$ \\
SC650 & 63 & 128,217 & $<1$ \\
SPS100 & 55 & 89,332 & $<1$ \\
SPS250 & 42 & 150,205 & $<1$ \\
SPS350 & 63 & 253,187 & $<1$ \\
SPL700 & 63 & 256,281 & $<1$ \\
\hline
\end{tabular}

$\mathrm{Na}$ Tabela 31 são apresentados os resultados da avaliação de heterogeneidade nas freqüências alélicas entre pólen e óvulos. Tais resultados demonstram a existência de heterogeneidade nas frequiências alélicas entre os gametas femininos e masculinos, indicando uma contribuição não panmítica do 
conjunto de pólens nas populações em estudo. Estes resultados reforçam as evidências de ocorrência de cruzamentos não aleatórios nas populações naturais de Euterpe edulis mencionados anteriormente.

Tabela 31. Comparação entre as freqüências alélicas em óvulos e pólens, obtidas através do programa MLT (RITLAND, 1990), em sete populações naturais de Euterpe edulis. Piracicaba-SP, ESALQ/USP, 1996

\begin{tabular}{ccc} 
População & Graus de Liberdade & $\chi^{2}$ \\
\hline SC450 & 13 & $694,8^{* *}$ \\
SC550 & 14 & $437,9^{* *}$ \\
SC650 & 11 & $889,4^{* *}$ \\
SPS100 & 13 & $520,7^{* *}$ \\
SPS250 & 12 & $322,9^{* *}$ \\
SPS350 & 14 & $552,1^{* *}$ \\
SPL700 & 14 & $551,9^{* *}$ \\
\hline
\end{tabular}

A caracterização da taxa de cruzamento para o palmiteiro confirma as evidências mencionadas no item anterior, indicando a alogamia como mecanismo básico de reprodução da espécie. Entretanto, os resultados também confirmaram a existências de cruzamentos não aleatórios, como mencionado anteriormente, evidenciando peculiaridades no processo reprodutivo da espécie associadas, possivelmente, à amplitude do período de florescimento. 


\subsection{Fluxo Gênico}

As estimativas de fluxo gênico foram realizadas conforme a relação entre a divergência genética e a quantidade de migrantes $\mathrm{Nm}$.

Os resultados (Tabela 32) apresentaram-se extremamente convergentes, entre as diferentes estimativas de $\theta$ e, especialmente, entre as estimativas obtidas nas diferentes gerações : adultos e progênies.

A abordagem proposta por BURTON e SLATKIN (1989), e empregada por WOLF e SOLTIS (1992) e EGUIARTE et al. (1993), permite uma adaptação da estimativa de Nm proposta por WRIGHT (1931) para o modelo de ilhas, para um modelo que se aproxima do contínuo, como o de isolamento por distância ou o "steping stone". Assim, foi possível estabelecer o tamanho de vizinhança para Euterpe edulis; este valor ficou em 67 individuos, em termos médios (variando entre 57 e 72 ), tanto para as estimativas através de progênies, quanto para estimativas através dos indivíduos adultos.

O resultado obtido indica que as "unidades panmíticas", ou vizinhanças, como sugere WRIGHT (1946), são de 67 indivíduos. Ou seja, os grupos parentais que trocam genes ao acaso estão em torno de 67 indivíduos; assim, numa mesma unidade de área um número menor de indivíduos implicaria em um aumento da divergência entre as vizinhanças em decorrência do aumento interno dos níveis de endogamia. Em outras palavras, a redução nesse número implicaria numa alteração da estrutura genética das populações naturais a médio prazo. Além disso, os efeitos da deriva genética se acentuariam, levando, possivelmente, a perda dos alelos de menor freqüência. Adicionalmente, os níveis de heterozigosidade iriam diminuir, reduzindo a diversidade genética da população. Essa redução na 
diversidade teria consequiências diretas na dinâmica populacional, como discutido anteriormente, implicando na redução do dinamismo das populações naturais da espécie.

Tabela 32. Estimativas de fluxo gênico $(\mathrm{Nm})$ tamanho de vizinhança $(\mathrm{Nb})$ e área de vizinhança* para populações naturais de palmiteiro, a partir de estimadores de divergência genética obtidos de indivíduos adultos e de progênies. Piracicaba-SP, ESALQ/USP, 1996

\begin{tabular}{lllllll}
\hline \multirow{2}{*}{ Estimador } & Divergência & $\hat{N} m$ & $\hat{N} b$ & Área & Área & Área \\
& & & SC. & SP. & Média \\
\hline
\end{tabular}

Progênies

$\begin{array}{llllll}\hat{\theta}_{L} & 0,022 & 11,3 & 71,2 & 11.672 & 4.450\end{array}$

\begin{tabular}{lllllll}
$\hat{\theta}_{P}$ & 0,022 & 10,9 & 68,6 & 11.246 & 4.288 & \\
\hline Média & & 111 & 69,4 & 11.377 & 4.338 & 7.858 \\
\hline
\end{tabular}

\begin{tabular}{lllllll}
\hline \multicolumn{5}{c}{ Adultos } \\
$\hat{\theta}_{L}$ & 0,021 & 11,5 & 72,2 & 11.836 & 4.513 & \\
$\hat{\theta}_{P}$ & 0.026 & 9,2 & 57,9 & 9.492 & 3.619 & \\
\hline Média & & 10,4 & 64,6 & 10.590 & 4.038 & 7.314 \\
\hline Média & & & & & \\
Geral & & 10,7 & 67,0 & 10.948 & 4.188 & 7.586 \\
\hline
\end{tabular}

* em $\mathrm{m}^{2}$, considerando 54 e 160 como densidade média (número de reprodutivos por hectare) para Santa Catarina (SC) e São Paulo (SP), respectivamente

A existência de cruzamentos não aleatórios detectada nas análises anteriores, não invalida a utilização do conceito de demes panmíticas de Wright, pois pode-se considerar que o conjunto de progênies produzidas irá diluir o efeito 
dos desequilibrios individuais ou de grupos de progênies, implicando em que sejam necessários, a cada ciclo, conjuntos de propágulos representativos, ou em equilibrio em cada deme, para manutenção da estrutura existente.

Nesse contexto, passa a ser importante para as perspectivas de manejo das populações naturais da espécie a caracterização da área de vizinhança, ou área ocupada pela vizinhança. Uma estratégia possível é estabelecer a relação direta com os dados da demografia existentes, ou seja, relacionar a área ocupada pelos indivíduos reprodutivos existentes (densidade de reprodutivos por área) com o tamanho de vizinhança. Tais estimativas aparecem na Tabela 32, indicando uma área média de $7.586 \mathrm{~m}^{2}$. Isso significa que seriam necessários 88 indivíduos reprodutivos por hectare para manter a estrutura genética atual nas populações naturais do palmiteiro, em termos médios. Obviamente essa abordagem implica em resultados variáveis em relação à demografia local, para cada situação (Tabela 32).

Contudo, essa abordagem mostra-se frágil em termos de utilização prática, pois sempre indicará que todos os indivíduos reprodutivos existentes sejam necessários para a manutenção da estrutura genética atual. Para obter-se uma estimativa de área de vizinhança que se aproxime do mínimo para a manutenção da estrutura genética existente, valor desejável em termos de utilização para o manejo de populações naturais, torna-se necessário uma estimativa independente e direta da área de vizinhança. Assim, estimativas que envolvem o fluxo de pólen e a dispersão de sementes, como propostas em LEVIN e KESTER (1969) e discutidas em SLATKIN (1985) e RICHARDS (1989) seriam desejáveis nesse contexto.

REIS, A. (1995) estimou em $65 \mathrm{~m}$ a distância de dispersão primária dos propágulos de Euterpe edulis, apresentando uma tendência a dispersão 
leptocúrtica, com variações na forma da distribuição em função do ambiente, mas com tendências similares em termos de distâncias totais.

Em relação ao fluxo de pólen para o palmiteiro não existem informações. Contudo, o principal provável polinizador foi caracterizado em REIS et al. (1993) como Trigona sp, identificado posteriormente como Trigona spinipes; não sendo, entretanto, obtida a informação relativa 'a distância de vôo para a espécie.

Além disso, considerando-se a amplitude do período de floração e uma tendência à normal para o fenômeno, conforme discutido no item 4.4., nos limites do período de floração haveria sucesso reprodutivo com até 4 indivíduos por hectare. Nesta situação a distância média entre plantas reprodutivas, e portanto distância de transporte do pólen, seria de 56 metros.

Desta forma, fazendo uma aproximação do proposto por WRIGHT (1943), onde a área de vizinhança corresponde a $4 \pi \sigma^{2}$, sendo $\sigma$ o desvio padrão da dispersão de alelos, e complementado por LEVIN e KESTER (1969), como:

$$
\mathrm{Av}=4 \pi(\mathrm{Vp} / 2+\mathrm{Vs})
$$

onde:

$$
\begin{aligned}
& \mathrm{Vp}=\text { variância da distância de dispersão de pólen } \\
& \mathrm{Vs}=\text { variância da distância de dispersão de sementes } \\
& \mathrm{Av}=\text { área de vizinhança (área ocupada por aproximadamente } 95 \% \text { dos }
\end{aligned}
$$
indivíduos de uma deme panmítica)

Assim, considerando-se a distância de dispersão obtida por REIS, A. (1995) e a distância provável de dispersão de pólen mencionada (56 m) como 
representando dois desvios padrão em relação ao máximo potencial, a área de vizinhança seria de $18.199 \mathrm{~m}^{2}$. Considerando as distâncias mencionadas como três desvios padrão do máximo potencial, a área de vizinhança seria de $8.090 \mathrm{~m}^{2}$. Estes dois resultados, agregados ao tamanho de vizinhança médio obtido (67 indivíduos) levariam à 37 e 83 indivíduos por hectare, respectivamente, como números mínimos para manutenção da estrutura populacional existente; em termos médios 60 indivíduos por hectare. Contudo, são necessários estudos adicionais para uma melhor caracterização do potencial de distância de fluxo de pólen, bem como as variações existentes entre locais e/ou anos para a distância de dispersão de sementes e a distância de fluxo de pólen.

4.6. Associação da Variação Genética com a Distribuição Geográfica

A avaliação da associação da variação genética com a distribuição geográfica e o gradiente altitudinal foi realizada a partir da análise gráfica das freqüências alélicas, nos indivíduos adultos, relativas ao gradiente altitudinal em dois locais de coleta. Santa Catarina-Blumenau e São Paulo-Saibadela (Figuras 7 a 10). Em ambos os locais os três níveis de altitude permitiram uma avaliação do comportamento das freqüências alélicas considerando-se a possibilidade de associação dos marcadores com caracteres adaptativos (plotagem direta das freqüências alélicas, Figuras 7 e 8) ou a existência exclusiva de deriva genética (plotagem das alterações das freqüências acumuladas, Figuras 9 e 10). 

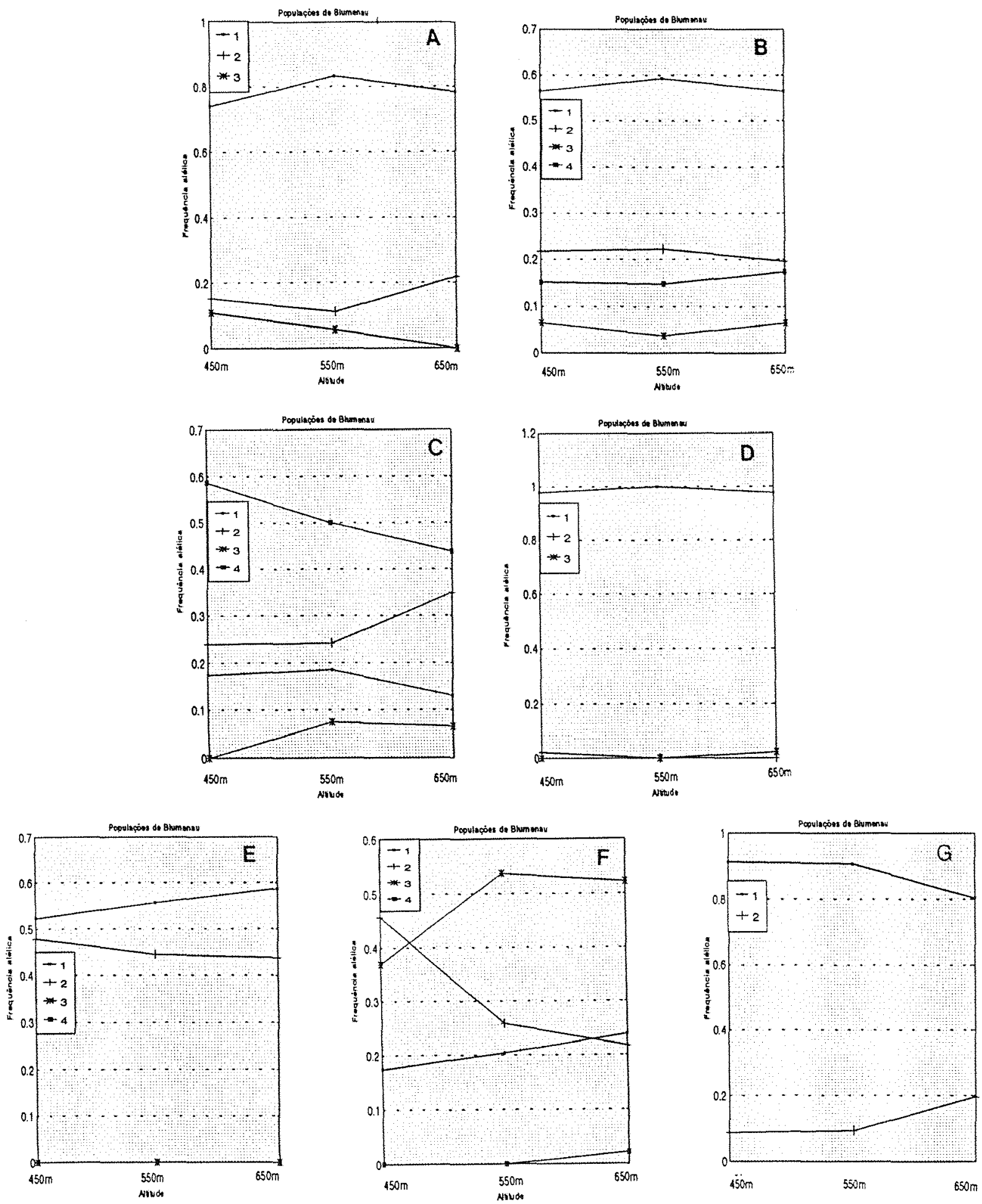

Figura 7. Freqüências alélicas em populações naturais de Euterpe edulis, considerando um gradiente altitudinal em Blumenau - Santa Catarina. a partir de 7 locos alozímicos. Piracicaba-SP, ESALQ/USP, 1996. 

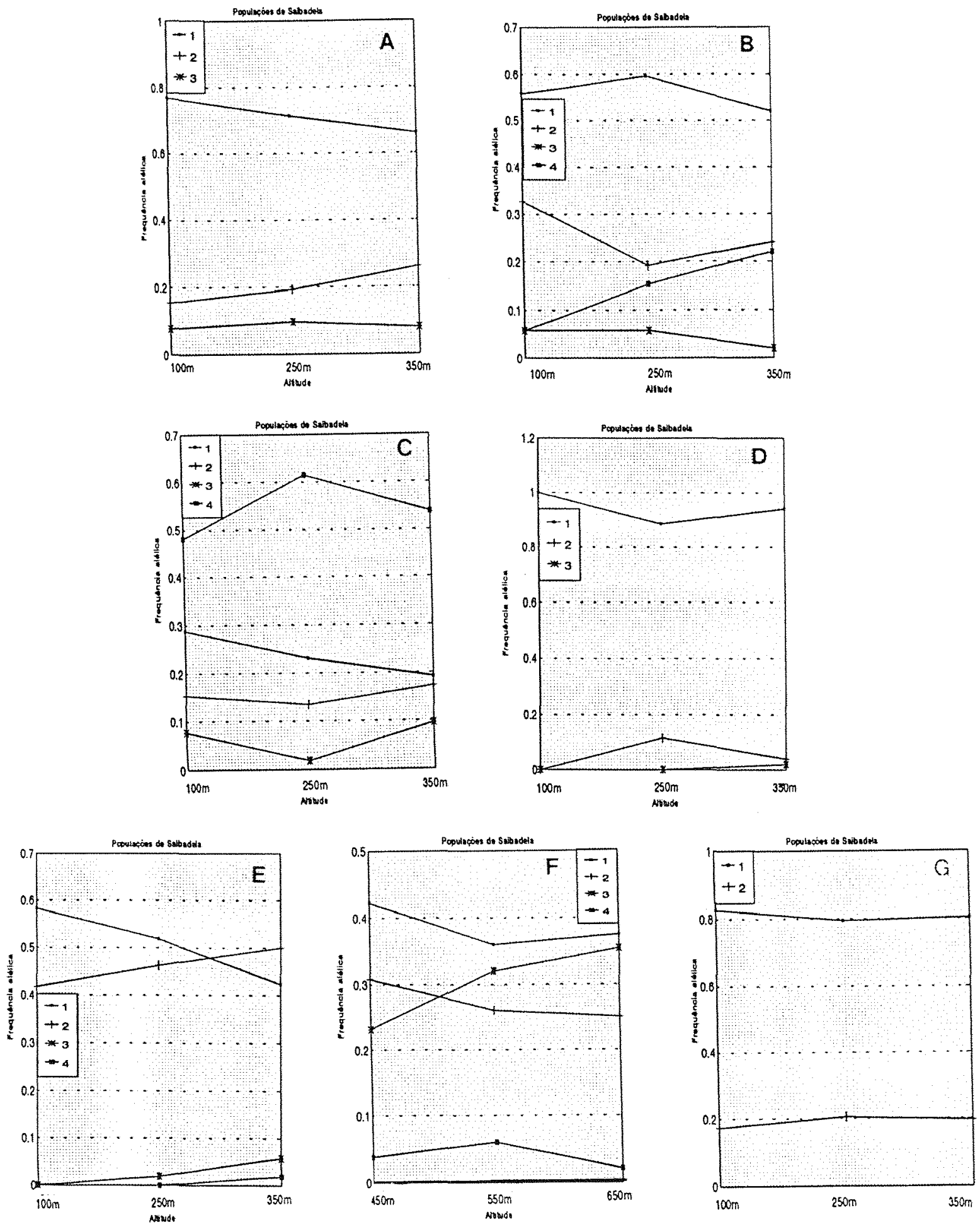

Figura 8. Freqüências alélicas em populações naturais de Euterpe edulis, considerando um gradiente altitudinal em Saibadela - São Paulo. a partir de 7 locos alozimicos. Piracicaba-SP, ESALQ/USP, 1996. 

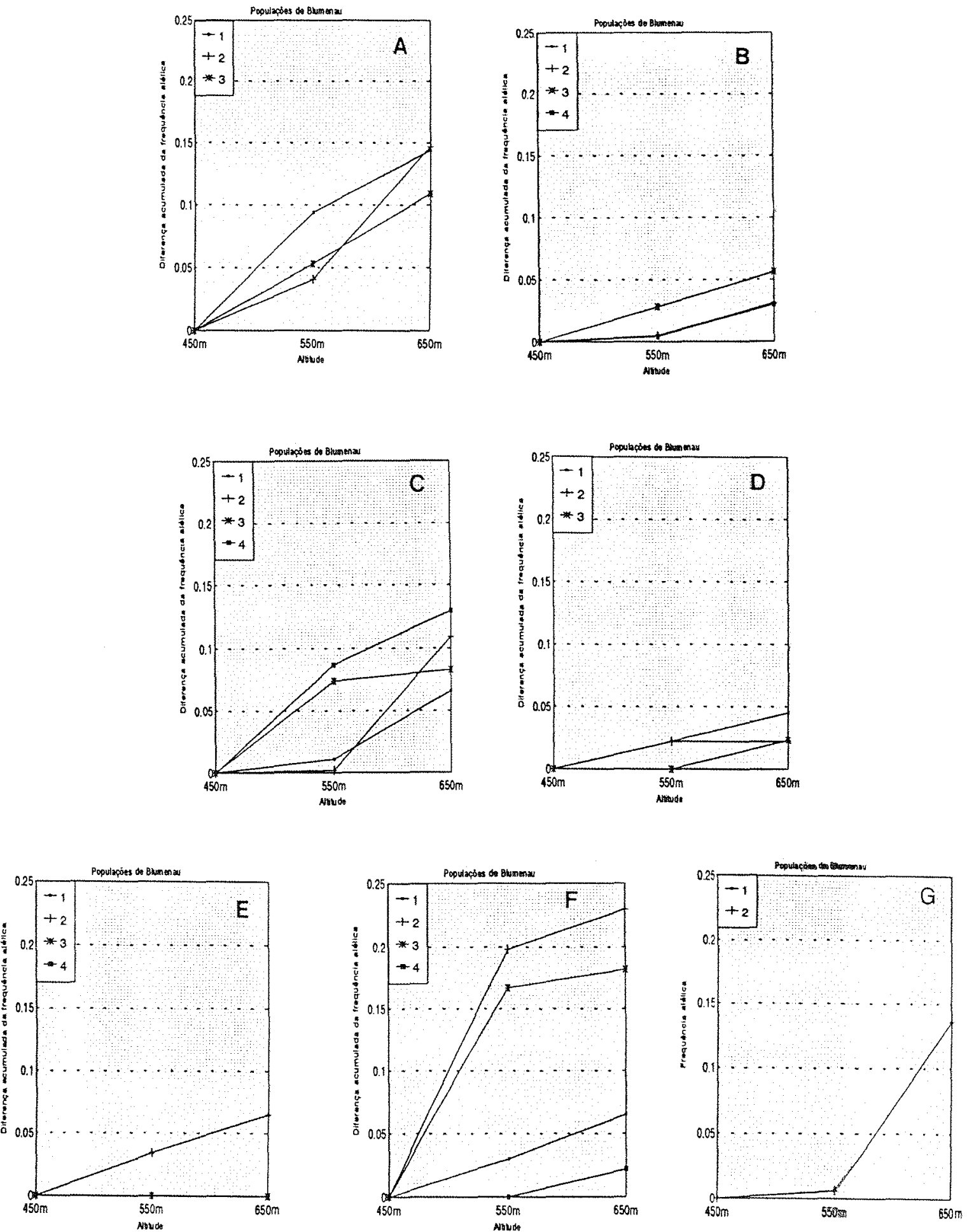

Figura 9. Alterações nas freqüências alélicas acumuladas $\mathrm{em}$ populações naturais de Eututerpe edulis, considerando um gradiente altitudinal em Blumenau - Santa Catarina, a partir de 7 locos alozímicos (A-PRX2: B-PRX3: C-PRX4: D-PRX5: E-PGI2: F-PGM1: G-G6P1). Piracicaba-SP. ESALQ/USP. 1996 

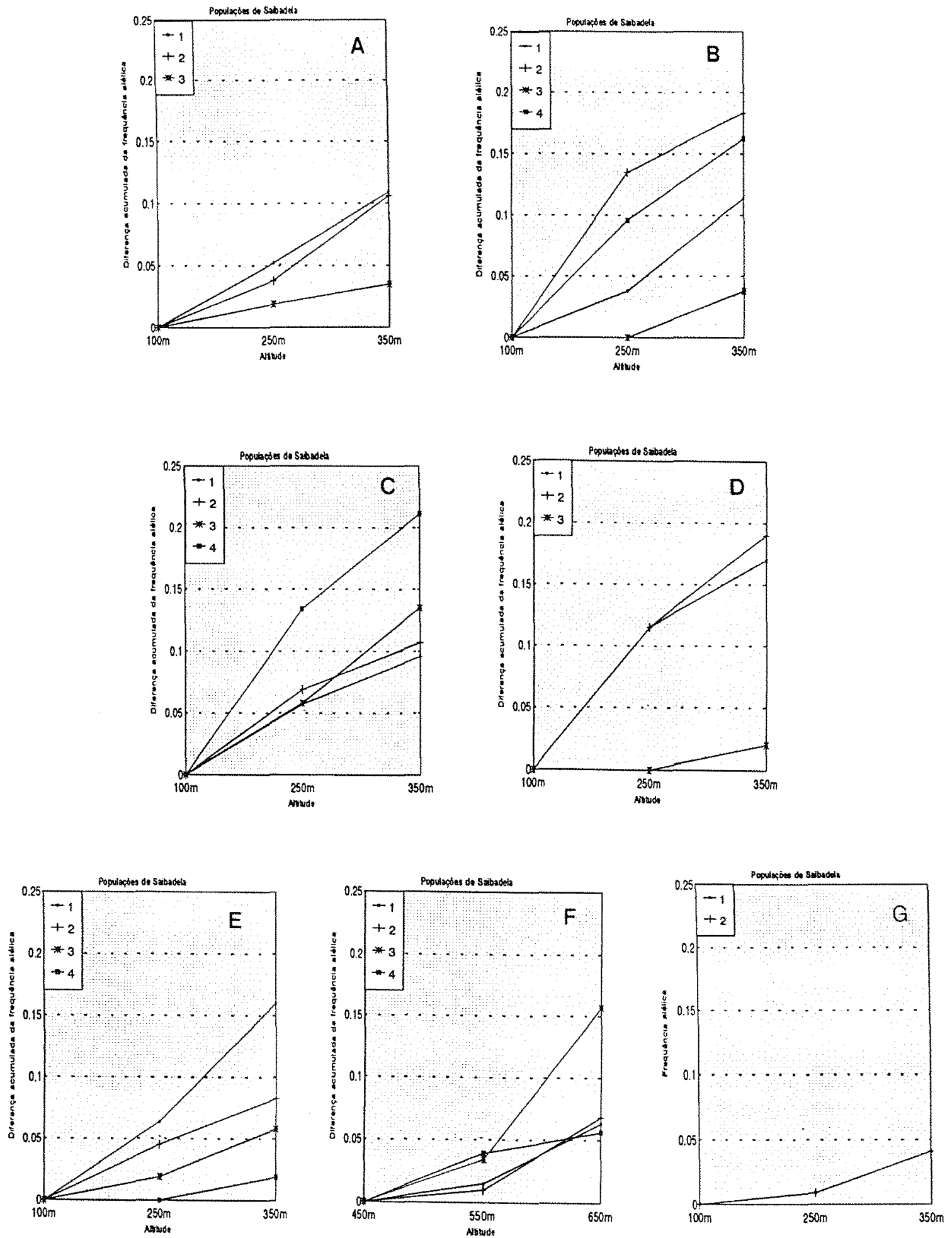

Figura 10 Alterações nas frequências alélicas acumuladas em populações naturais de Eutterpe edulis, considerando um gradiente altitudinal $\mathrm{cm}$ Saibadela - São Paulo. a partir de 7 locos alozimicos (APRX2: B-PRX3: C-PRX4; D-PRX5: E-PGI2: F-PGM1: G-G6P1). Piracicaba-SP. ESALQ/USP, 1996 
Em relação ao locos $\mathrm{PRX} 2$, pode-se observar um comportamento de redução nas freqüências alélicas dos alelos 1 e 3 em ambos os locais, bem como uma tendência de aumento nas freqüências do alelo 2. Em relação às diferenças acumuladas, houve um comportamento similar entre os alelos entre todas as alterações de altitude, sugerindo efeitos de deriva de magnitude similar.

Nos alelos dos locos PRX3, PRX4 e PRX5 não houve um comportamento que permitisse uma associação clara entre as variações nas freqüências alélicas e os gradientes altitudinais, em nenhum dos dois locais. Entretanto, foi possível observar uma menor diferença acumulada nas variações alélicas relacionada ao gradiente altitudinal em Blumenau. Tais resultados sugerem efeitos de deriva menos acentuados em Blumenau, especialmente entre as populações SC550 e SC650.

Em relação ao loco PGI2, houve um comportamento de variação das freqüências alélicas diretamente relacionado aos gradientes altitudinais. No caso de Blumenau houve uma redução expressiva na freqüência do alelo 2, com conseqüente aumento da freqüência do alelo 1 , na medida do aumento do nível altitudinal. Nas populações de Saibadela, as alterações foram no sentido oposto, entre os alelos $1 \mathrm{e}$ 2, havendo, adicionalmente, um incremento das freqüências dos alelos raros ( 3 e 4), associada com o aumento da altitude. Essa associação fica ressaltada na análise das diferenças acumuladas, especialmente no alelo 1 em Saibadela, que apresentou um comportamento de diferença mais acentuada entre 250 e 350 metros.

Para o locos PGM1, houve um comportamento de redução de freqüência alélica para o alelo 1 e incremento para o alelo 3 em ambos os locais. Esse comportamento mostrou-se mais acentuado entre as altitudes de 450 e $550 \mathrm{~m}$ 
em Blumenau e entre 250 e $350 \mathrm{~m}$ em Saibadela, como ressaltam os gráficos relativos às diferenças acumuladas.

O locos G6P1 apresenta apenas dois alelos nos indivíduos adultos, de forma que os comportamentos entre os alelos são complementares e sugerem redução na freqüência do alelo 1 e incremento do alelo 2 , em ambas os locais.

A análise geral indica que, apesar da existência de algumas associações entre as freqüências alélicas e os gradientes altitudinais, o que sugere a existência de forças adaptativas em relação aos gradientes analisados, a maioria dos marcadores não permite a caracterização de um comportamento consistente neste sentido. Assim, aparentemente, as variações existentes são principalmente decorrentes de efeitos de deriva, possivelmente associadas aos processos de polinização e dispersão da espécie, limitando a movimentação dos alelos, bem como devido ao sistema reprodutivo da mesma. Trabalhos clássicos (HAMRICK e ALLARD, 1972; CLEG e ALLARD, 1972) têm mostrado a existência de associações entre fatores de ambiente e as freqüências alélicas de marcadores alozímicos. Em espécies arbóreas Fagus sylvatica (COMPS et al., 1991) também apresenta este tipo de associação; contudo, entre espécies arbóreas tropicais nenhum trabalho similar foi realizado.

A maioria dos trabalhos nesta linha têm mostrado a existência de associações apenas com características quantitativas, como GURIES e LEDIG (1982) e LEGERCRANTZ e RYMAN (1990), não sendo encontradas associações consistentes com marcadores alozímicos .

O comportamento das diferenças acumuladas em relação aos gradientes altitudinais sugere, intuitivamente, uma adequação ao modelo de isolamento por distância, como já sugerido anteriormente, pois demonstra alterações 
de magnitude similar para a maioria dos alelos, em cada um dos locos, entre os níveis altitudinais.

A magnitude das diferenças existente foi estimada a partir da identidade e distância genética não viesada de NEI $(1972,1973,1978)$. Os valores obtidos (Tabelas 33 e 34) refletem uma reduzida divergência entre as populações estudadas, tanto em progênies quanto em adultos .

Os agrupamentos obtidos através da técnica UPGMA, para a distância não viesada de Nei, apresentam uma perfeita coerência com a distribuição geográfica para os indivíduos adultos, mas apenas parcial nas progênies (Figuras 11 e 12), misturando a população SPS100 com as populações de Blumenau. Este resultado reforça a predominância de efeitos de deriva nas progênies, pois não reflete uma tendência adaptativa das populações aos locais de coleta. Por outro lado indica uma tendência oposta em relação aos adultos.

Em ambas as situações as populações do Limão foram as mais divergentes. Cabe ressaltar que as populações do Limão apresentam uma divergência, em relação a Saibadela, de magnitude similar àquela obtida entre Santa Catarina e Saibadela, sendo esperadas diferenças de magnitude intermediária para essa situação. Contudo, a existência de um gradiente fenológico em Euterpe edulis, relacionado ao gradiente altitudinal, foi caracterizada por FANTINI et al. (1992c) para a região em questão. Os autores encontraram uma diferenciação fenológica maior nas populações acima de $600 \mathrm{~m}$, sugerindo o isolamento, em termos de fluxo gênico via pólen para estas populações. Assim, entre as populações do Limão e as de Saibadela o isolamento fenológico deve acentuar os efeitos de deriva entre as populaçōes . 
Tabela 33. Identidades (diagonal superior) e Distâncias Genéticas (diagonal inferior) não viesadas de NEI para progènies de sete populações naturais de Palmiteiro (Euterpe edulis). Piracicaba-SP, ESALQ/USP, 1996

\begin{tabular}{lccccccc}
\hline Populacóes & SC450 & SC550 & SC650 & SPS100 & SPS250 & SPS350 & SPL700 \\
\hline SC450 & $* * *$ & 0,989 & 0,993 & 0,989 & 0,967 & 0,955 & 0,965 \\
SC550 & 0,011 & $* * *$ & 0,988 & 0,990 & 0,982 & 0,979 & 0,975 \\
SC650 & 0,007 & 0,012 & $* * *$ & 0,982 & 0,968 & 0,961 & 0,974 \\
SPS100 & 0,012 & 0,010 & 0,018 & $* * *$ & 0,986 & 0,980 & 0,972 \\
SPS250 & 0,034 & 0,018 & 0,032 & 0,014 & $* * *$ & 0,994 & 0,983 \\
SPS350 & 0,046 & 0,021 & 0,040 & 0,020 & 0,006 & $* * *$ & 0,978 \\
SPL700 & 0,035 & 0,026 & 0,026 & 0,029 & 0,017 & 0,023 & $* * *$ \\
\hline
\end{tabular}

Tabela 34. Identidades (diagonal superior) e Distâncias Genéticas (diagonal inferior) não viesadas de NEI para indivíduos adultos de populações naturais de Palmiteiro (Euterpe edulis). Piracicaba-SP, ESALQ/USP, 1996.

\begin{tabular}{lllllllll}
\hline Populaç̃os & SC450 & SC550 & SC650 & SPS100 & SPS250 & SPS350 & SPL350 & SPL700 \\
\hline SC450 & $* * *$ & 1,000 & 0,995 & 0,994 & 0,999 & 0,996 & 0,969 & 0,979 \\
SC550 & 0,000 & $* * *$ & 1,000 & 0,997 & 0,996 & 0,985 & 0,962 & 0,976 \\
SC650 & 0,005 & 0,000 & $* * *$ & 0,996 & 0,995 & 0,986 & 0,954 & 0,973 \\
SPS100 & 0,006 & 0,003 & 0,004 & $* * *$ & 1,000 & 1,000 & 0,981 & 0,986 \\
SPS250 & 0,001 & 0,004 & 0,005 & 0,000 & $* * *$ & 1,000 & 0,974 & 0,992 \\
SPS350 & 0,004 & 0,015 & 0,014 & 0,000 & 0,000 & $* * *$ & 0,976 & 0,988 \\
SPL350 & 0,031 & 0,039 & 0,047 & 0,019 & 0,027 & 0,025 & $* * *$ & 0,991 \\
SPL700 & 0,021 & 0,025 & 0,027 & 0,014 & 0,008 & 0,012 & 0,009 & $* * *$ \\
\hline
\end{tabular}


Figura 11 - Dendrograma das Distâncias Genéticas não Viesadas de NEI para sete populações naturais de Euterpe edulis, dados obtidos a partir de progênies, empregando-se sete locos alozímicos

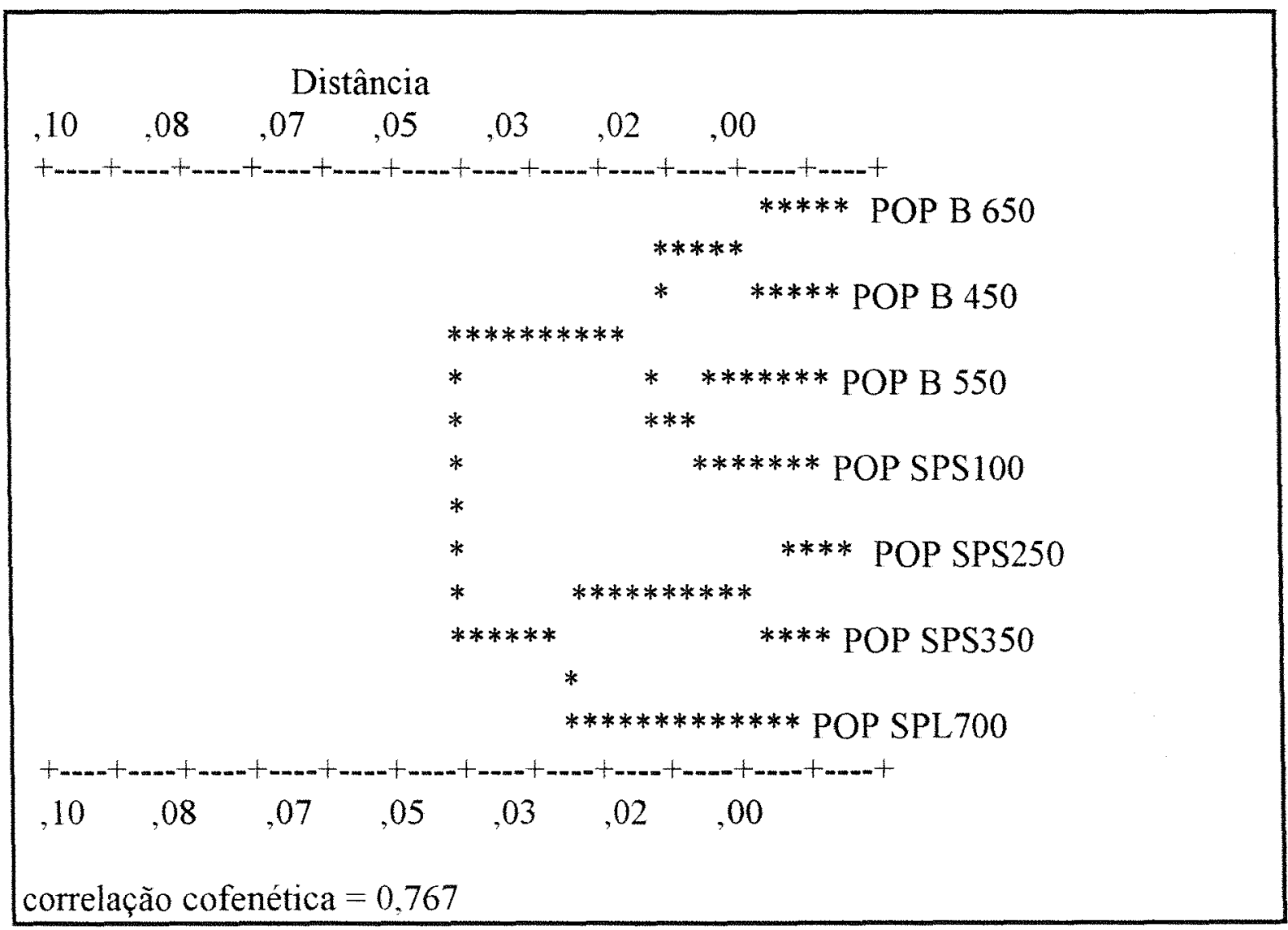

Dessa forma, apesar das divergências não se mostrarem consistentes em relação ao gradiente altitudinal analisado nas populações contíguas, esta tendência fica ressaltada quando comparadas populações separadas, em uma variação altitudinal mais ampla, como o caso da comparação entre Limão e Saibadela, decorrente, possivelmente, de uma variação fenológica associada. 
Figura 12 - Dendrograma das Distâncias Genéticas não Viesadas de NEI para oito populações naturais de Euterpe edulis, dados obtidos a partir de indivíduos adultos, empregando-se sete locos alozímicos

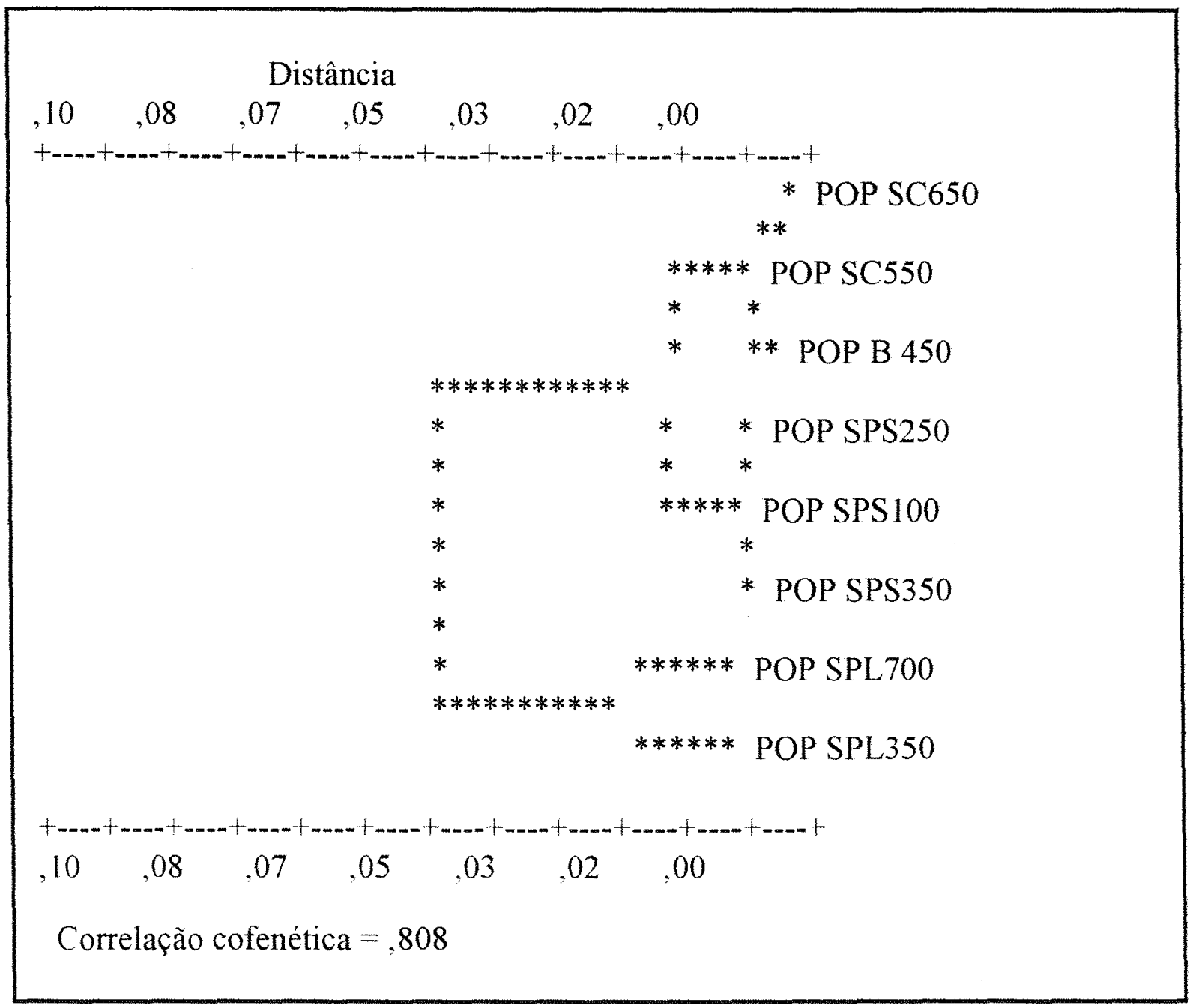

Portanto, parece razoável, considerar o modelo de isolamento por distância, reforçado (intensificando os efeitos de deriva) pelo gradiente altitudinal, em escala ampla, como a forma básica de organização da variabilidade genética na espécie. Cabe ressaltar que, a intensificação dos efeitos de deriva relacionados aos gradientes altitudinais, deve apresentar grande relevância no processo 
coberta por este ecossistema é predominantemente montanhoso, com formação de gradientes altitudinais contínuos em toda a sua extensão. Entretanto, estudos adicionais devem ser realizados nesta linha, com outras espécies, para conclusões mais consistentes.

4.7. Implicações para o Manejo e Conservação de Populações Naturais

Os resultados obtidos demonstraram a existência de uma grande diversidade na espécie, ressaltada pelo elevado número de alelos por loco e pelo alto nível de heterozigosidade; bem como heterogeneidade nas freqüências alélicas entre as populações, com a presença de alelos raros e/ou exclusivos. Contudo, as populações apresentaram uma divergência de magnitude reduzida entre si, seja naquelas tomada de forma contígua, seja quando se considera as duas regiões amostradas; os valores obtidos sugerem uma adequação ao modelo de isolamento por distância. O elevado fluxo gênico e a alta taxa de cruzamento justificam a reduzida divergência.

A inexistência de equilíbrio de endogamia nas progênies e as diferenças existentes entre as frequiências alélicas de adultos e progênies, aliada à informações relativas à fenologia indicam a ocorrência de cruzamentos não aleatórios. Este aspecto fica reforçado pela heterogeneidade entre as frequiências alélicas de pólen e óvulo.

Além disso, estudos da biologia reprodutiva da espécie demonstraram a ocorrência de fecundação cruzada, pela forte dicogamia existente na inflorescência e polinização entomófila (REIS et al.,1993), e dispersão de sementes a longa 
e polinização entomófila (REIS et al.,1993), e dispersão de sementes a longa distância por animais (REIS,A. 1995). Os resultados obtidos são coerentes com estes eventos, pois as estimativas de fluxo gênico indicaram valores elevados.

Estes resultados trazem implicaçǒes importantes para o manejo e conservação das populações naturais da espécie.

No que se refere ao manejo, considera-se aqui a possibilidade de manejo sustentável de acordo com as características demográficas e genéticas das populações naturais da espécie, como proposto para Euterpe edulis em RIBEIRO et al. (1994) e REIS et al. (1994b,1996) e discutido na Introdução. Assim, além de tomar-se em conta a exploração em níveis que possam ser repostos pelo próprio comportamento demográfico da espécie, há que se manter indivíduos reprodutivos que possam repor os estoques (regeneração natural) não só quantitativamente (número de propágulos), mas também qualitativamente (características genéticas das sementes). Desta forma, para que se mantenham os níveis elevados de heterozigosidade e o grande número de alelos por loco, de modo a possibilitar a perpetuação do processo exploratório (premissa básica do manejo sustentável), torna-se necessária a manutenção de um grande número de indivíduos reprodutivos por área.

A necessidade de um número elevado de indivíduos reprodutivos por área também decorre das evidências de existência de cruzamentos não aleatórios predominando a cada ciclo, pois este evento tende a reduzir o número de indivíduos que se cruzam a cada ciclo em cada população e implica na ocorrência de efeitos de endogamia. Assim, um número de indivíduos reprodutivos maior tende a reduzir estes efeitos produzidos por cruzamentos restritos e manter elevados os níveis de heterozigosidade. 
A estimativa obtida de 67 indivíduos formando cada deme panmítica entre 18.199 e $8.090 \mathrm{~m}^{2}$, ou entre 37 e 83 individuos/ha, sugere a necessidade de manutenção de ao menos 60 indivíduos reprodutivos/ha, em termos médios, nas populações sob manejo.

Além disso, a manutenção dos níveis elevados de heterozigosidade também favorece a manutenção da dinâmica populacional e a possibilidade de seleção nas coortes (maior heterozigosidade implicando em maiores níveis de recombinação), levando à uma população de adultos com maior diversidade, a qual poderá gerar novamente progênies com características desejáveis de variabilidade, mantendo, portanto, a dinâmica e estrutura populacional da espécie.

Nesse contexto, a garantia de manutenção destes processos depende da manutenção da fauna como elemento imprescindível na movimentação dos alelos (realização dos cruzamentos, fluxo de pólen, e dispersão dos propágulos ) .

Por outro lado, a manutenção da fauna, no processo de conservação e manejo, necessita de espécies vegetais estratégicas para alimentação e atração dos animais, onde o palmiteiro apresenta também grande importância, tanto pela qualidade quanto pela quantidade de frutos produzidos, bem como pelo amplo período de oferta, conforme menciona REIS, A.(1995). Desta forma, no que se refere à conservação, o palmiteiro e a sua fauna associada, de um modo geral, apresentam uma relação de mútua dependência.

A reduzida divergência entre as populações, o grande número de alelos e a elevada heterozigosidade sugerem, como estratégia de conservação in situ, a estruturação de poucas reservas, mas relativamente grandes. A sugestão de reservas grandes está especialmente relacionada à possibilidade de manutenção da fauna associada em decorrência dos aspectos mencionados no parágrafo anterior; uma vez 
que a alta densidade da espécie implica numa disponibilidade de grande número de indivíduos em áreas relativamente pequenas. Por exemplo, a captura de alelos que ocorrem em freqüências de até $0,1 \%$, como o alelo 5 do loco PRX3 na população SPS350, pode necessitar de 500 indivíduos reprodutivos, o que pode ser obtido numa área de apenas 10 hectares.

Em reação à conservação ex situ, as coletas podem ser realizadas em poucos locais, em decorrência da reduzida divergência observada; com maior intensidade em cada local, devido a alta diversidade existente na espécie. Entretanto, o número de indivíduos necessário pode ser obtido em áreas relativamente pequenas, como discutido no parágrafo anterior. A captura de alelos mais raros (freqüência em torno de $0,1 \%$ ) pode ser feita com coletas de sementes (progênies) em cerca de 160 indivíduos ( $\mathrm{Ne} \cong 500$, tomando por base a amostragem realizada neste trabalho), o que pode ser obtido numa área de até três hectares.

Neste contexto, a região amostrada em São Paulo (fazenda Intervales) pode ser considerada como prioritária, pois apresenta um maior número de alelos e níveis de heterozigosidade similares aos de Santa Catarina.

Outro aspecto relevante é a possibilidade melhoramento e/ou produção de sementes visando o enriquecimento de formações secundárias, especialmente pela possibilidade de retomada da dinâmica sucessional nestas formações, em decorrência da associação do palmiteiro com a fauna, como discutido em REIS, A. (1993, 1995) e REIS et al. (1994b).

A realidade da Floresta Tropical Atlântica, atualmente, é a formação de fragmentos de diferentes tamanhos, em sua grande maioria cobertos com formações secundárias em fase inicial ou intermediária de sucessão. Tal situação implica num valor de uso extremamente reduzido para a maior parte das áreas 
originalmente cobertas por essa formação florestal, principalmente nas situações de maior declividade, onde a vocação de uso é a cobertura permanente. Assim, a reintrodução do palmiteiro nestas áreas implica numa perspectiva de valor econômico, a médio prazo, e retomada ou aceleração da dinâmica sucessional, pela atração da fauna decorrente da produção de frutos do palmiteiro. Assim, a produção de sementes, e estruturação de programas de melhoramento, para enriquecimento possui perspectivas econômicas e conservacionistas expressivas.

Entretanto, a qualidade genética das sementes é um fator definitivo no processo, pois, conforme discutido anteriormente, o dinamismo populacional e a capacidade de adaptação aos microambientes da floresta estão relacionados à manutenção dos níveis elevados de heterozigosidade da espécie. Dessa forma, a estruturação de uma área de coleta de sementes ou de programas de melhoramento devem contemplar, prioritariamente, este aspecto, como discutem REIS et al. (1994b). Iniciativas como a da Fundação Florestal (SMA-SP), contemplando estes aspectos na estruturação de uma área de coleta de sementes na Fazenda Intervales (na área da população SPS250), descrita em FANTINI et al. (1993), apresenta grande relevância e podem ser reeditadas nas reservas ou nas áreas de entorno da maior parte das reservas existentes na Floresta Tropical Atlântica. 


\section{CONCLUSÕES}

A estratégia de coleta/amostragem empregada, abrangendo diferentes regiões, áreas contíguas e separadas, e utilizando indivíduos adultos e progênies, mostrou-se eficiente para a caracterização da distribuição da variação genética, bem como permitiu inferências sobre a dinâmica da movimentação dos alelos em populações naturais do palmiteiro.

Os resultados revelaram um alto nível de diversidade para a espécie, evidenciando uma maior quantidade de heterozigotos nos indivíduos adultos, em relação às progênies. Esta alta diversidade obtida para a espécie apresenta especial relevância, pois as gerações posteriores poderão sempre apresentar novos recombinantes ou mais recombinantes, permitindo adaptação a microambientes e manutenção da dinâmica populacional.

As divergências caracterizadas entre as populações estudadas mostraram-se de maior magnitude entre regiões e locais, sendo de menor expressão entre as populações contínuas. Estes resultados indicam a existência de efeitos de deriva e/ou de seleção entre regiões e locais, sendo estes de menor efeito ou contrapostos pelo fluxo gênico entre as populações contíguas. Assim, é razoável considerar o modelo de isolamento por distância, reforçado pelo gradiente altitudinal em escala ampla, que intensifica os efeitos de deriva em decorrência de variações 
fenológicas. como a forma básica de organização da variabilidade genética na espécie.

A espécie é preferencialmente alógama, com uma taxa de cruzamento média de 0,99 (variando entre 0,94 e 1,04 nas populações estudadas). A inexistência de equilibrio de endogamia nas progênies indica a ocorrência de eventos adicionais envolvidos no sistema reprodutivo. Os resultados obtidos evidenciam a ocorrência de cruzamentos não aleatórios, associados à amplitude do período de florescimento e à protandria acentuada existente na espécie. Assim, é razoável considerar que, a cada ciclo reprodutivo, predominam cruzamentos não aleatórios entre os indivíduos, produzindo progênies que não apresentam equilíbrio de panmixia ou endogamia, mesmo quando os indivíduos adultos estão em equilíbrio de panmixia.

O fluxo gênico obtido foi coerente com a estrutura genética e os mecanismos de dispersão de sementes e polinização descritos para o palmiteiro. Os valores caracterizados (10,7 indivíduos por geração, em média) permitiram a obtenção de estimativas do tamanho de vizinhança para a espécie, em torno de 67 indivíduos. Abordagens preliminares indicam uma área de vizinhança entre $18.199 \mathrm{e}$ $8.090 \mathrm{~m}^{2}$. Tais resultados permitem recomendar a manutenção de em média 60 indivíduos reprodutivos por hectare para populações naturais sob manejo, visando a manutenção da estrutura genética e dinamismo demográfico.

A sistemática de análise empregada neste trabalho mostrou-se redundante em relação às estimativas da taxa de cruzamento e da estrutura genética. Contudo, os resultados obtidos e a análise comparativa da fundamentação teórica dos parâmetros e das estimativas propostos indicam que: 
a) as estimativas multilocos da taxa de cruzamento produzem resultados que se aproximam mais do evento biológico, em relação às estimativas da taxa de cruzamento aparente;

b) parametricamente, $G_{S T}$ e $\theta$ não são diferentes de $F_{S T}$, contudo os estimadores propostos para os três parâmetros produzem resultados distintos, exceto com amostras grandes;

c) as estimativas de divergência a partir de $G_{S T}$ apresentam o maior viés, implicando que sua utilização fique restrita a amostras grandes;

d) a sistemática de análise empregada para obtenção das estimativas dos coefícientes de coancestralidade, ainda que mais trabalhosa, apresenta a melhor correção dos vieses existentes e, portanto, recomendável para qualquer tamanho de amostra; além disso, é mais versátil, permitindo estimar a divergência em diferentes níveis de hierarquia e sem os efeitos dos níveis superiores, sendo, portanto, especialmente adequada para amostragens hierarquizadas .

A coerência dos resultados obtidos e a estratégia de amostragem empregada, com uma cobertura ampla da área e situações de ocorrência, possibilitou a formação de um referencial, em relação aos níveis e distribuição da variação genética, para a coleta de germoplasma, a produção de sementes e o melhoramento da espécie, bem como para o monitoramento das populações naturais sob manejo sustentado. 
BIBLIOGRAFIA CITADA

ALVAREZ-BUYLLA,E.R. e GARAY,A. Population genetic structure of Cecropia obtusifolia, a tropical pioneer species. Evolution, $48(2)$ : 437-53. 1994.

ALFENAS,A.C. ;PETERS,I. ;BRUNE,W; PASSADOR,G.C. Eletroforese de proteinas e isoenzimas de fungos e essências florestais. UFV, Viçosa MG. 1991.242 p.

ALVES, L.F. Competição intraespecifica de padrão espacial em uma população de Euterpe edulis Mart. (Arecaceae). Campinas, SP. 1994. 67 p. (Dissertação de Mestrado, UNICAMP).

ANDERSON, R.L. e BANCROFT, T.A. Statistical theory in research. McGraw-Hill Book Company, Inc., New York. 1952. 399 p.

BALVEÉ, R.M.L. Isoenzimas como marcadores genéticos em palmiteiro (Euterpe spp). Campinas, SP. 1988. 112 p. (Dissertação de Mestrado, UNICAMP).

BARRET,S.C.H. e KOHN, J.R. Genetic and evolutionary consequences of small populations size in plants: implications for conservation. In : FALK, D.A. e HOLSINGER, K.E. (eds.). Genetic and conservation of rare plants. Oxford University Press, N.Y. 1991. p. 3-30. 
BARTON, N.H. e SLATKIN, M. A quasi-equilibrium theory of the distribution of rare alleles in a subdivided population. Heredity, 56: 409-15. 1986.

BENNACER,M.; LANAUD, C.; CHEVALLIER, M.H.; BOUNAGA, N. Genetic diversity of the date palm (Phoenix dactylifera L.) from Algeria reveled by enzyme markers. Plant Breeding, 107: 56-69. 1991.

BOVI, M. L. A.; GODOY JR., G.; SÁES, L.A. Pesquisas com os gêneros Euterpe e Bactris no Instituto Agronômico de Campinas. In : $1^{\circ}$ Encontro Nacional de Pesquisadores em Palmito, Curitiba - PR. Anais, 1987a. p. 1-43.

BOVI, M. L. A.; GODOY JR., G.; SÁES, L.A. Hibridos interespecificos de palmiteiro (Euterpe oleracea $\times$ Euterpe edulis). Bragantia, 46(2): 343-63, $1987 \mathrm{~b}$.

BOVI, M. L. A.; GODOY JR., G.; SÁES, L.A. Correlações fenotípicas entre caracteres da palmeira Euterpe edulis Mart. e produção de palmito. Rev. Bras. Genet., 1f(3): 739-51. 1991.

BOVI, M.L.A. e GODOY JR., G. Juvenile-mature correlations in heart of palm plants. Rev. Bras. Genet., 14(3): 739-51, 1991.

BRASIL. Ministério da Agricultura / SUPLAN. Aptidão agrícola das terras de São Paulo. Estudos Básicos para o Planejamento Agricola, 20.1979. 114 p.

BROWN,A.D.H. Isozymes, plant population genetic structure and genetic conservation. Theor. Appl. Genet., 52:145-57. 1978.

BROWN, A.D.H. e ALLARD,R.W. Estimation of the mating system in open-pollinated maize population using isozyme polymorphisms. Genetics, 66: 133-45. 1970

BUCKLEY, D.P.; O'MALLEY,D.M.; APSIT,U.; PRANCE, G.T.; BAWA, K.S. Genetics of Brazil nut (Bertholletia excelsa Hump. e Bonpl. : Lecythidaceae) 1. Genetic variation in natural populations. Theor. Appl. Genet, 76: 923-8. 1988. 
CAMPOS,S.D.; BOVT, M.L.A.; IADEROZA,M. Caracterização do palmito obtido em algumas combinações hibridas entre açaí e juçara cultivadas sob diferentes condições. I. matéria prima. Pesq. Agropec. Bras., 26(5): 637-46. 1991.

CARDOSO,M. e LEÃO, M. Estudos sobre o cultivo do palmiteiro. O Agronòmico, 26: 118. 1974 .

CHELIAK, W.N. e PITTEL, J.A. Techniques for starch gel electrophoresis ef enzymes from forest tree species. Pataya National Forestry Institute, Canadian Forestry Service Information Report PI-X-42, 1984. 49 p.

CLEG,M.T. e ALLARD, R.W. Patterns of genetic differentiation in the slander wild oat species Avena barbata. Proc. Nat. Acad. Sci. USA, 69(7): 1820-4. 1972.

CLEG,M.T.; KAHLER, A.L; ALLARD,R.W. Estimation of life cycle components of selection in a experimental plant population. Genetics, 89: 765-92. 1978

COCKERHAM,C.C. Variance of gene frequencies. Evolution, 23: 72-84. 1969.

COCKERHAM, C.C. e WEIR,B.S. Correlations and descendent measures: drift with migration and mutation. Proc. Nat. Acad. Sci. USA, 84: 8512-4. 1987.

COCKERHAM, C.C. e WEIR,B.S. Estimation of gene flow from F-Statistics. Evolution, $47(3): 855-63.1993$

COMPS,B.; THIEBANT,B.; SUGAR,I; TRINAJSTIC,I.; PLAZIBAT, M. Genetic variation of croatian beech stands (Fagus sylvatica L.): spatial differentiation in connection with the enviroment. Ann. Sci. For., 48: 15-28. 1991.

CROW,J.F. e AOKI, K. Group selection for a polygenic behavioral trait: estimating the degree of population subdivision. Proc. Nat. Acad. Sci. USA, 81: 6073-7. 1984.

EGUIARTE， L.E.; BÚRQUEZ,A.; RODRIGUEZ， J.; MARTINEZ-RAMOS,M.; SARUKHÁN, J; PIÑERO,D. Direct and indirect estimates of neighborhood and 
effective population size in a tropical palm, Astrocarium mexicamum. Evolution, $f 7(1): 75-87.1993$.

EGUTARTE,L.E.; PEREZ-NASSER, N.; PIÑERO,D. Genetic structure, outcrossing rate and heterosis in Astricarium mexicanum (tropical palm): implications for evolution and conservation. Heredity, 69:217-28. 1992.

EHRLICH,P.R. e RAVEN, P.H. Differrentiation of populations. Gene flow seems to be less important in speciation then the neo-Darwinians trought. Science, 165: 1228-32. 1969.

FANTINI, A.C.; REIS,A.; REIS,M.S.; GUERRA,M.P. Sustained yield management in Tropical Forest: a proposal based on the autoecology of the species. Sellowia, 42/4t:25-33. 1992a.

FANTINI, A.C.; REIS,A.; REIS,M.S.; GUERRA,M.P. ;NODARI, R.O. Correlações entre parâmetros fenotípicos e a produtividade de palmito em Euterpe edulis Martius. In: $2^{\circ}$ Congresso Nacional sobre Essências Nativas, São Paulo - SP. Anais, 1992b. p. 534-6.

FANTINI, A.C.; REIS,A.; REIS,M.S.; GUERRA,M.P. Relatório de atividades do contrato entre a Fundação para a Conservação e a Produção Florestal do Estado de São Paulo e a Fundação de Ampara à Pesquisa e Extenção Universitária UFSC (referente abril/maio de 1992). 1992c. 17p.

FANTINI,A.C.; REIS,M.S.; SGROTT, E.Z.; REIS,A.; PORTILHO, W.G.; RIBEIRO,R.J. Demografia de Euterpe edulis no Vale do Rio Ribeira do Iguape - SP. In: $7^{\circ}$ Congresso Florestal Brasileiro, Curituba - PR. Anais, 1993. p.757.

FLORIANO,E.P.; NODARI, R.O.; REIS,A.; REIS,M.S.; GUERRA, M.P. Manejo do palmiteiro: uma proposta. In: I Encontro Nacional de Pesquisadores em Palmito, Curitiba - PR. Anais, 1987. p.189-92. 
FERRAZ,E.M; GANDARA, F.B; CUNHA, N.L.; REIS,M.S; KAGEYAMA, P.Y. Eletroforese de isoenzimas para espécies arbóreas - Mamal de Laboratório (versčo 1994). Piracicaba, ESALQ / Departamento de Ciências Florestais / Laboratório de Biologia Reprodutiva e Genética de Espécies Arbóreas. 1994. $23 p$.

FUTUYMA, D.J. Biologia Evolutiva (2 ed). Ribeirão Preto, SBG / CNPq. 1992. 646 p.

GANDARA, F.B. Diversidade genética, taxa de cruzamento e estrutura espacial dos genótipos em uma população natural de Cedrela fissilis Vell. (Meliaceae). Campinas - SP, 1996. 69 p. (Dissertação de Mestrado, UNICAMP)

GLOVER, D.E. e BARRET, S.C.H. Genetic variation in continental and island populations of Eichornia paniculata (Ponteriaceae). Heredity, 59: 7-17. 1987.

GOVINDARAJU,D.R. Relationship between dispersability and levels of ggene flow in plants. Oikos, 52(1): 31-5. 1988.

GOVINDARAJU, D.R. Estimates of gene flow in forest trees. Biological Journal of Limnean Society, 37: 345-57. 1989.

GOMES, F.P. Curso de estatistica experimental (13 ed.). Nobel, São Paulo-SP. 1990. $468 \mathrm{p}$.

GRANT, V. Gene flow and the homogeneity of specie populations. Biologisches Zentralblatt, 99: 157-69. 1980.

GUIX, J.C.; TABANEZ,A.A.J.; SILVA,A.N.; LOPEZ,C.; MARTINEZ,C.; MATHEU,E.; PISCIOTTA, K.R.; BRADBURY,N.; PORTILHO, W.G. Viagem de reconhecimento científico a algumas áreas desconhecidas da Fazenda intervales, Estado de São Paulo, durante o período de 04 a 16 de outubro de 1991. Grupo de Estudos Ecológicos - Série Documentos, f: 38-94. 1992. 
GUERRA, M.P.; NODARI, R.O.; REIS,A. Considerações sobre o palmiteiro no Sul do Brasil. Insula, It: 171-80. 1984.

GURIES, R.P. e LEDIG, F.T. Genetic diversity and population structure in pitch pine (Pinus regida Mill.) Evolution, 36(2): 387-42. 1982.

HALL,P.; ORREL,L.C.; BAWA,K. Genetic diversity and mating system in a tropical tree, Carapa guianensis (Meliaceae). Amer. J. Bot., 81(9): 1104-11. 1994.

HAMRICK, J.L. Plant population genetics and evolution. Amer. J. Bot., 69(10): 1685-93. 1982

HAMRICK, J.L. e ALLARD, R. W. Microgeographical variation in allozyme frequencies in Avena barbata. Proc. Nat. Acad. Sci. USA, 69(8): 2100-4. 1972.

HAMRICK, J.L. e GODT, M.J.W. Allozyme diversity in plant species. In: BROWN, A.D.H.; CLEG,M.T.; KAHLER, A.L.; WEIR,B.S. (eds.) Plant population genetics, breeding and genetic resources. Sinauer, Suderland - Massachusetts. 1990. p. 43-63.

HAMRICK,K.L.; LINHART, Y.B.; MITTON, J.B. Relationships between lefe history characteristics and electrophoretically detectable genetic variation in plants. Ann. Rev. Ecol. Syst., 10: 173-200. 1979

HAMRICK, J.L. e LOVELESS,M.D. Isozyme variation in tropical trees: procedures and preliminary results. Biotropica, 18: 201-7. 1986.

HAMRICK, JL. e MURAWSKI, D.A. Levels of allozyme diversity in populations of uncommon Neotropical tree species. Journal of Tropical Ecology, 7:395-9. 1991.

HERRITT, MM. Ecology and genetic variation of four hardwoods of Brazil's Atlantic Forest region. Raleigh (NC/USA), 1991. 204 p. (Tese de Doutorado, Department of Forestry / North Carolina State University) 
HEYWOOD, J.S. e FLEMING, T.H. Patterns of allozyme variation in three Costa Rican species of Piper. Biotropica, 18:208-13. 1986.

HILL, R.J; PRANCE,G.T.; MORI, S.A.; STEWARD,W.C.; SHIMANAKURU, D.; BERNARDI, J. Estudo eletroforérico da dinâmica da variação genética de três taxa ribeirinhos ao longo do rio Solimões, América do Sul. Acta Amazônica, 8(2): 183-99. 1978.

HUZINKER, J.H. e SCHAAL, B.A. Isozyme variation in diploid tropical and octaploid subtropical-temperate species of Bulnesia. The Journal of Heredity, 74: 358-60. 1983

IDE, B.Y; ALTHOFF, D.A.; THOME, V.M.R.; VIFOTTO, V.J. Zoneamento agroclimático do Estado de Santa Catarina, 2" etapa. Flonianópolis, EMPASC. 1980. $106 \mathrm{p}$.

JAIN,S.K. e MARTINS, P.S. Ecological genetics of the colonizing ability of rose clover (Trifolium hirtum All.). Amer. J. Bot., 66(4): 361-6. 1979.

KAGEYAMA, P.Y. e GANDARA, F.B. Dinâmica de populações de espécies arbóreas: implicações para o manejo e a conservação. In: III Simpósio de Ecossitemas da Costa Brasileira, Serra Negra-SP. Anais, 1993. p 115-25.

KEPHART,S.R. Starch gel electrophoresis of plant isozymes: a camparative analyses of techniques. Amer. J. Bot., 77(5): 693-712. 1990.

KIMURA, M. e CROW, J.F. The measurement of the effective population number. Evolution, 17: 279-88. 1963.

KITAMURA, K. e RAHMAN, M.Y.B.A. Genetic diversity among natural populations of Agathis borneensis (Araucariaceae), a tropical rain forest conifer from Brunei Darassalam, Borneo, Southest Asia. Can. J. Bot., 70: 1945-9. 1992 
KLEIN, R.M. Necessidade da pesquisa das florestas nativas para a exploração racional e manejo eficiente das mesmas. In: I Congresso Florestal Brasileiro. Anais, 1968. p. $125-8$.

KLEIN, R.M. Euterpe edulis Martius - Observações ecológicas. In: REITZ,R. Palmeiras. Flora Ilustrada Catarinense, PALM: 102-5. 1974.

KLEIN,R.M. Ecologia da flora e vegetação do Vale do Itajaí. Sellowia, 31-32: 9-389. 19791980.

KLEIN,R.M; PASTORE, U; COURA NETO, A.B. Vegetação. In : Atlas de Santa Catarina. Santa Catarina, Gabinete do Planejamento e Coordenação Geral. 1986. p. $35-6$.

LEÃO, M. e CARDOSO, M. Instruções para a cultura do palmiteiro (Euterpe edulis Mart.). Boletim Técnico do IAC. $1974.18 \mathrm{p}$.

LEGERCRANTZ, U e RYMAN,N. Genetic structure of Norway spruce (Picea abies): concordance of morphological and allozymic variation. Evolution, $44(1)$ : 38-53. 1990.

LEVIN, D.A. e KESTER, H.W. The dependence of bee-mediated pollen and gene dispersal upon plant density. Evolution, 23: 560-71. 1969

LEVIN, D.A. e KESTER, H.W. Neighbourhood structure in plants under diverse reproductive methods. The American Naturalist, 105:345-54. 1971.

LEVIN, D.A. e KESTER, H.W. Gene flow in seed plants. Evolutionary Biology, 7: 139220. 1974 .

LI, C.C. e HORWITZ, D.G. Some methods of estimating the inbreeding coefficient. The American Journal of Human Genetics, 5(2): 107-17. 1953. 
LOPES,C.R.; REIS, S.F.; FERREIRA, M.A.; MORETZSOHN, M.C. Genetics of the genus Acrocomia (Palmae) III. Microgeographical genetic variability in isozyme frequencies. $J$. Genet \& Breed., 46: 9-14. 1992

LOVELESS, M.D. e HAMRICK, J.L. Ecological determinants of genetic structure in plant populations Anm. Rev. Ecol. Syst., 15: 65-95. 1984.

LOVELESS, M.D. e HAMRICK, J.L. Distribuición de la variación en especies de árboles tropicales. Rev. Biol. Trop., 35(supl.1): 165-75, 1987.

LUDWIG, J.A. e REYNOLDS, J.F. Statistical ecology. John Wiley \& Sons, N.Y. 1988. $337 \mathrm{p}$.

MARCON, G. Estrutura genética de populações de Stylosantes humilis H.B.K. (Leguminosae) de três regiões ecogeográficas do Estado de Pernambuco. Piracicaba-SP, 1988. 178 p. (Tese de Doutorado, ESALQ/USP)

MARTINS, P.S. e JAIN,S.K. Role of genetic variation in colonizing ability of rose clover (Trifolium hirtum All.). The American Naturalist, 111: 591-5. 1977.

MORAES, M.L.T. Variabilidade gen;etica por isoenzimas e caracteres quantitativos em duas populações naturais de aroeira Myracrodruon urundeuva F.F. \& M.F. Allemão Anacardiaceae (Syn: Astronium urundeuva (Fr. Allemão) Engler. Piracicaba-SP, 1992.139 p. (Tese de Doutorado, ESALQ/USP)

MORAN,G.F.; MUONA, O.; BELL, C.J. Acacia mangium: a tropical forest tree of the coastal lowlands with low genetic diversity. Evolution, 43:231-5. 1989.

MOSER, J.M.; SHIMIZU,S.H.; SOMER, S.; VIEIRA, P.S. Pedologia. In : Atlas de Santa Catarina. Santa Catarina, Gabinete do Planejamento e Coordenação Geral 1986. p. 33-5.

MUONA, O. Population genetics in forest tree improvement. In: BROWN, A.D.H; CLEG,M.T.; KAHLER, A.L.; WEIR,B.S. (eds.) Plant population genetics, 
breeding and genetic resources. Sinauer, Suderland - Massachusetts. 1990. p.282-98.

MURAWSKI, D.A. e BAWA, K.S. Genetic structure and mating system of Stemonoporus oblongifolius (Dipterocarpaceae) in Sri Lanka. Amer. J. Bot., 81(2):155-60. 1994.

MURAWSKI, D. A. e HAMRICK, J. L. Local genetic and clonal structure in the tropical terrestrial bromeliad, Aechmea magdalenae. Amer. J. Bot., 77(9): 1201-8. 1990.

MURAWSKI, D. A. e HAMRICK, J. L. The effect of the density of flowering individuals on the mating systems of nine tropical tree species. Heredity, 67: 167-74. 1991.

MURAWSKI, D. A. e HAMRICK, J. L. Mating system and phenology of Ceiba pentandra (Bonbacaceae) in Central Panamá. Journal of Heredity, 83: 401-4. 1992a.

MURAWSKI, D. A. e HAMRICK, J. L. The mating system of Cavanillesia platanifolia under extremes of flowering tree density: a test of predictions. Biotropica, 24(1): 99-101. 1992b.

MURAWSKI, D. A.; HAMRICK, J. L.; HUBBELL, S.P.; FOSTER, R.B. Mating systems of two Bonbacaceous trees of a neotropical moist forest. Oecologia, 82: 501-6. 1990.

NEGREIROS, O.C. Características fitossociológicas de uma comunidade de Floresta Latifoliada Tropical visando ao manejo do palmito, Euterpe edulis Martius. Piracicaba-SP, 1982. 110p. (Dissertação de Mestrado, ESALQ/USP).

NODARI, R.O.; REIS,A.; GUERRA, M.P.; REIS,M.S.; FLORIANO, E. P. Análise preliminar do inventário do palmiteiro em Floresta Ombrófila Densa Montana. In: I Encontro Nacional de Pesquisadores em Palmito, Curitiba. Anais, 1987. p. $159-65$. 
NODARI, R.O.; REIS,M.S.; FANTINI,A.C.; REIS,A.; GUERRA, M.P.; MANTOVANI, A.; DIAS, M.P. Testes de procedencia e progênie de Euterpe edulis. I Procedências Saí-Guaçu e Itapocu, Vales do Mampituba e Araranguá e Médio Vale do Itajai-Açu. In: $7^{\circ}$ Congresso Florestal Brasileiro, Curitiba, 1993. Anais. 1993. p. 470-2.

NODARI, R.O. e REIS, M.S. Novas estratégias para coleta e implantação de testes de procedência e progênie para espécies arbóreas tropicais. Rev. Bras. de Genética, I8(3-suplemento): 262.1995

NEI, M. Genetic distance between populations. The American Naturalist, 106(949): 28392. 1972 .

NEI, M. Analysis of gene diversity in subdivided populations. Proc. Nat. Acad. Sci. USA, $70(12): 3321-3.1973$

NEI, M. F-statistics and analysis of gene diversity in subdivided populations. Ann. Human. Genet., +1: 225-33. 1977.

NEI, M. Estimation of average heterozygosity and genetic distance from a small number of individuals. Genetics, 89: 583-90. 1978.

NEI,M. Molecular evolutionary genetics. Columbia University Press, N.Y., USA. 1987.

O'MALLEY, D.M. e BAWA, K.S. Mating system of a tropical rain forest tree species. Amer. J. Bot., 74(8): 1143-9. 1987.

O'MALLEY,D.M.; BUCKLEY, D.P.; PRANCE, G.T.; BAWA, K.S. Genetics of Brazil nut (Bertholletia excelsa Humb.\& Bonpl.: Lecythidaceae). 2. Mating system. Theor. Appl. Genet.,76: 9292-32. 1988.

ORSELI, L. Climatologia. In: Atlas de Santa Catarina. Santa Catarina, Gabinete do Planejamento e Coordenação Geral. 1986. p. 38-9. 
OYAMA, K. Conservation Biology of Tropical Trees: Demographic and Genetic Considerations. Enviroment Update, 1: 17-32. 1993.

PAIVA, J.R. Variabilidade enzimática em populações naturais de seringueira (Hevea brasiliensis (Willd. ex Adr. de Juss) Muell. Arg.). Piracicaba, 1992. 144p. (Tese de doutorado, ESALQ/USP).

PAIVA,J.R.; KAGEYAMA, P.Y.; VENCOVSKY, R.; CONTEL, P.B. Genetics of rubber ttree (Hevea brasiliensis (Wild. ex Adr de Juss.) Müll. Arg.) 1. Genetic variation in natural populations. Silvae Genetica, 43(5/6): 307-12. 1994a.

PAIVA,J.R.; KAGEYAMA, P.Y.; VENCOVSKY, R. Genetic of rubber tree ((Hevea brasiliensis (Wild. ex Adr de Juss.) Müll. Arg.) 2. Mating system. Silvae Genetica, +3(5/6): 373-6. 1994b.

PEDROSA MACEDO, J.H.; RITTERSHOFER, F.O.; DESSENFFY, A. Silvicultura $e$ indistria do palmiteiro. IPRNR/SECRET, Porto Alegre-RS. (s.d.)

PEDROSA MACEDO, J.H. Palmito - uma grande fonte de divisas III. Floresta, 4(3): 57-9. 1973.

PEREIRA, L.B. Pamito: manejo sustentado e viabilidade econômica. Florestar Estatistico, 2(4): 13-15, 1994.

PÉREZ-NASSER,N.; EGUIARTE,L.E.; PIÑERO, D.; Mating system and genetic structure of the distylous tropical tree Psychotria faxlucens (Rubiaceae). Amer. J. Bot:; 80: 45-52. 1993.

RAUKER,T.A. Genetic diversity, mating system, and interpopulation gene flow in neotropical Hemionitis palmata L. (Adiantaceae). Heredity, 69: 192-201. 1992.

REIS, A. Manejo e conservação das florestas catarinenses. Florianópolis, 1993.137 p. 9tese Professor Titular, UFSC). 
REIS, A. Dispersão de sementes de Euterpe edulis Martius (Palmae) em uma Floresta Ombrófila Densa Montana da encosta Atântica em Blumenau - SC. Campinas, 1995. 154p. (tese de Doutorado, UNICAMP)

REIS,A.; NODARI, R.O.; REIS,M.S.; GUERRA,M.P. Rendimento comercial e relações entre carcterísticas associadas ao volume de palmito em Euterpe edulis. In: I Encontro Nacional de Pesquisadores em Palmito, Curitiba. Anais, 1987. p. $149-58$.

REIS, A.; REIS, A.S.; NODARI,R.O.; GUERRA, M.P.; QUEIROZ, M.H. O cultivo do palmiteiro (Euterpe edulis Martius) no Sul do Brasil. In: $6^{\circ}$ Congresso Florestal Estadual, Nova Prata. Anais, 1988. p. 633-42.

REIS,A.,; REIS,M.S.; FANTINI,A.C. O palmiteiro como um modelo de manejo de rendimento sustentado. Higiene Alimentar, 5(17): 27-31. 1991

REIS, A.; FANTINI, A.C.; REIS,M.S.; GUERRA, M.P.; DOEBELI, G. Aspectos da biodiversidade e o manejo da Floresta Tropical Atlântica. In: $2^{\circ}$ Congresso Nacional de Essências Nativas, São Paulo. Anais, 1992a. p. 169-73.

REIS,A.; REIS,M.S.; FANTINI,A.C. Manejo de rendimento sustentado de Futerpe edulis Martius. In: $7^{\circ}$ Congresso Florestal Estadual, Nova Prata. Anais, $1992 \mathrm{~b}$. p.1226-41.

REIS,A.; REIS,M.S.; FANTINI, A.C. Sustentabilidade das florestas tropicais: uma utopia? Ciência \& Ambiente, 9: 29-38. 1994

REIS,M.S.; FANTINI,A.C; REIS,A.; NODARI,R.O.; GUERRA, M.P. Sustainable yield management of Euterpe edulis Martius (Palmae), a tropical palm from the Atlantic Tropical Forest (Brazil). 1996. (submetido ao Journal of Ecology Management) 
REIS, M.S.; FANTINI, A.C.; REIS, A.; RIBEIRO, R.J.; PORTILHO, W.G. O desenvolvimento sustentável e o palmiteiro. In: LEONEL, C. (ed.) Intervales. Fundação Florestal, São Paulo. 1994 a (no prelo)

REIS, M.S.; FRANCHINI, R.G.; REIS,A.; FANTINI, A.C. Variação no periodo germinativo em sementes de Euterpe edulis Martius procedentes da região de Morretes-PR. In : $2^{\circ}$ Congresso Nacional de Essências Nativas, São Paulo, 1992. Anais. São Paulo, 1992. p. 1252-5.

REIS,M.S.; GUTMARÃES,E; OLIVEIRA, G. P. Estudos preliminares da biologia reprodutiva do palmiteiro (Euterpe edulis) em mata residual do Estado de São Paulo. In : $7^{\circ}$ Congresso Florestal Brasileiro, Curitiba, 1993. Anais. Curitiba, 1993. p. 358-60.

REIS, M.S.; NODARI, R.O; GUERRA, M. P.; FANTINI, A.C.; REIS, A. An alternative in situ conservation of the Tropical Atlantic Forest. In: FOREST $94-3^{\circ}$ Simpósio Internacional de Estudos ambientais sobre Ecossistemas Florestais, Posto Alegre. Anais, 1994b. p. 4-5

REIS, M.S.; REIS, A.; NODARI, R.O.; GUERRA, M.P.; ENDER, M. Caracterização preliminar da regeneração natural de Euterpe edulis em Floresta Ombrófila Densa Montana. In: $6^{\circ}$ Congresso Florestal Estadual, Nova Prata. Anais, 1988. p. $735-45$.

REIS, M.S.; REIS, A.; NODARI, R.O.; GUERRA, M.P.; FANTINI, A.C.; ENDER, M.; BASSANI, A. Incremento corrente anual do palmiteiro (Euterpe edulis) na Floresta Ombrófila Densa. Ínsula, 19:51-6. 1991.

REITZ,R. Palmeiras. Flora Ilustrada Catarinense, PALM : 102-5. 1974.

REITZ, R.; KLEIN, R.M.; REIS, A. Projeto madeira de Santa Catarina. SUDESULGoverno do Estado de Santa Catarina - IBDF, Itajaí. 1978. 320 p. 
RIBEIRO, R.J.; PORTILHO, W.G.; REIS, A.; FANTINI, A.C.; REIS, M.S. O manejo sustentado do palmiteiro no Vale do Ribeira. Florestar Estatístico, 1(3): 15-6. 1994.

RICHARDS, A.J. Plant breeding systems. George Allen and Unwin Pub. Ltd., London. 1986. $529 \mathrm{p}$.

RITLAND,K A series of FORTRAN computer programs for estimating plant mating systems. The Journal of Heredity, 81(3): 235-7. 1990.

RITLAND, K. e EL-KASSABAY, Y.A. The nature of inbreeding in a seed orchard of Douglas-fir as show by an efficient multilocus model. Theor. Appl. Genet., 71: 374-84. 1985.

RITLAND, K e JAIN, S. A model for estimation of outcrossing rate and gene frequencies using $n$ independent loci. Heredity, 47(1): 35-52, 1981

SANTOS, E. G. Ecologia da polinização, fluxo de pólen e taxa de cruzamento em Bauhinia forficata Link. (Caesalpiniaceae). Piracicaba, 1994. 114 p. (Dissertação de Mestrado, ESALQ/USP)

S.A.S. Institute. SAS STAT Guide for personal computers, Version 6.03. SAS Intitute Inc., Cary, NC. 1985.

SILVA,D. Estrutura de tamanho e padrão espacial de uma população de Euterpe edulis Mart. (Arecaceae) em Mata Mesófila smidecídua no Município de Campinas, SP. Campinas, 1991. 60 p. (Disssertação de Mestrado, UNICAMP)

SIMON,C. e ARCHIE,J. An empirical demonstration of the lability of heterozygosity estimates. Evolution, 39(2): 463-7. 1985.

SHAW, D.V; KAHLER, A.L.; ALLARD, R.W. A multilocus estimator of mating system parameters in plants population. Proc. Nat. Acad. Sci. USA, 78: 1298-302. 1980. 
SLATKIN, M. Gene flow in natural populations. Amm. Rev. Ecol. Syst., 16: 393-430. 1985.

SLATKIN, M. e BARTON, N.H. A comparison of three indirect methods for estimating average levels of gene flow. Evolution, $\$ 3(7)$ : 1349-68. 1989.

SNEATH, P.H.A. e SOKAL,R.R. Numeral taxonomy. W.H.Freeman, São Francisco. 1973.

SOLTIS,D.E.; GILMARTIN, A.J.; RIESEBERG,L.; GARDNER,S. Genetic variation in the epiphytes Tillandsia ionantha and T. recurvata (Bromeliaceae). Amer. J. Bot., 74(4): 531-7. 1987.

SWOFFORD, D.L. e SELANDER, R.B. A computer program for the analysis of allelic variation in population genetics and biochemical systematics. Release 1.7. Natural History Survey, Illinois. 1989. 43 p.

SYSTMA, K.J. e SCHAAL, B.A. Genetic variation, differentiation, and evolution in a species complex of tropical shrubs based on isozyme data. Evolution, 39: 58293. 1985.

TERBORGH, J. Keystone plant in a tropical forest. In: SOULE, M.E. (ed.) Conservation biology: the science of scarcity and diversity. Sinauer Associates Inc. Publishers, Suderlad, Maasachusetts. 1986.

TORGLER, M.G.F. Caracterização de variabilidade genética em plantas através da técnica de eletroforese de isoenzimas. Ribeirão Pretp, 1994. 193 p. (Monografia para exame de Qualificação, Fac. MEdicina Ribeirão Preto / USP)

VELOSO, H.P. e KLEIN, R.M. As comunidades e associações vegetais da mata pluvial atlântica do sul do Brasil. I. As associações do Município de Brusque, Estado de Santa Catarina. Sellowia, 8:81-235. 1957.

VELOSO, H.P. e KLEIN, R.M. As comunidades e associações vegetais da mata pluvial atlântica do sul do Brasil. II. Dinamismo e fidelidade das espécies em 
associações do Municipio de Brusque, Estado de Santa Catarina. Sellowia, I0: 9-124. 1959.

VELOSO, H.P.; RANGEL FILHO, A.L.R.R.; LIMA, J. C. A. Classificação da vegetação brasileira, adaptada a um sistema universal. IBGE, Departamento de Recursos Naturais e Estudos Ambientais, Rio de Janeiro. 1991. 124 p.

VENCOVSKY, $R$. Análise de variância de frequências alélicas. In : Congresso Latino Americano de Genética, $10^{\circ}$, Rio de Janeiro, 1992. Proceedings. Rio de Janeiro, 1992. p. 53-60.

WEIR, B.S. Genetic data analyses. Methods for discrete population genetic data. Sinauer Associates Inc. Publishers, Suderland Massachusetts. 1990a. 377p.

WEIR, B.S. Intraespecific differentiation. In: HILLIS, D.M. e MORITZ,C. Molecular systematics. Sinauer Associates Inc. Publishers, Suderland Massachusetts. 1990b. cap. 10. p.373-405.

WEIR, B.S. e COCKERHAM, C. C. Estimating F-statistics for the abalyses of population structure. Evolution, 38: 1358-70. 1984.

WOLF, P.G. e SOLTIS, P.S. Estimates of gene flow among populations, geografic races, and species in Ipomopsis aggregata complex. Genetics, 130:639-47. 1992.

WOLDA,H. Similarity indices, sample size and diversity. Oecologia, 50: 296-302. 1981.

WORKMAN, P.L. e NISWANDER,J.D. Population studies on Southwetern Indian tribes II. Local genetic differentiation in the Papago. Am. J. Human Genet., 22: 24-49. 1970.

WRIGHT, S. Systems of mating. Genetics, 6 : 111-78. 1921.

WRIGHT, S. Evolution in Mendelian populations. Genetics, 16:97-159. 1931

WRIGHT, S. Isolation by distance. Genetics, $28: 114-138.1943$. 
WRIGHT, S. Isolation by distance under diverse systems of mating. Genetics, $31: 39-59$ 1946.

WRIGHT, S. The genetical structure of populations. Ann. Eugenics, 15: 395-420. 1951.

WRIGHT, S. The interpretation of population structure by F-statistics with special regard to systems of mating. Evolution, 19:395-420. 1965.

YAMAZOE, G. Observações preliminares sobre a cultura de Euterpe edulis Mart. Boletin Técnico do Instituto Florestal, 6: 17-22. 1973. 
ANEXOS 


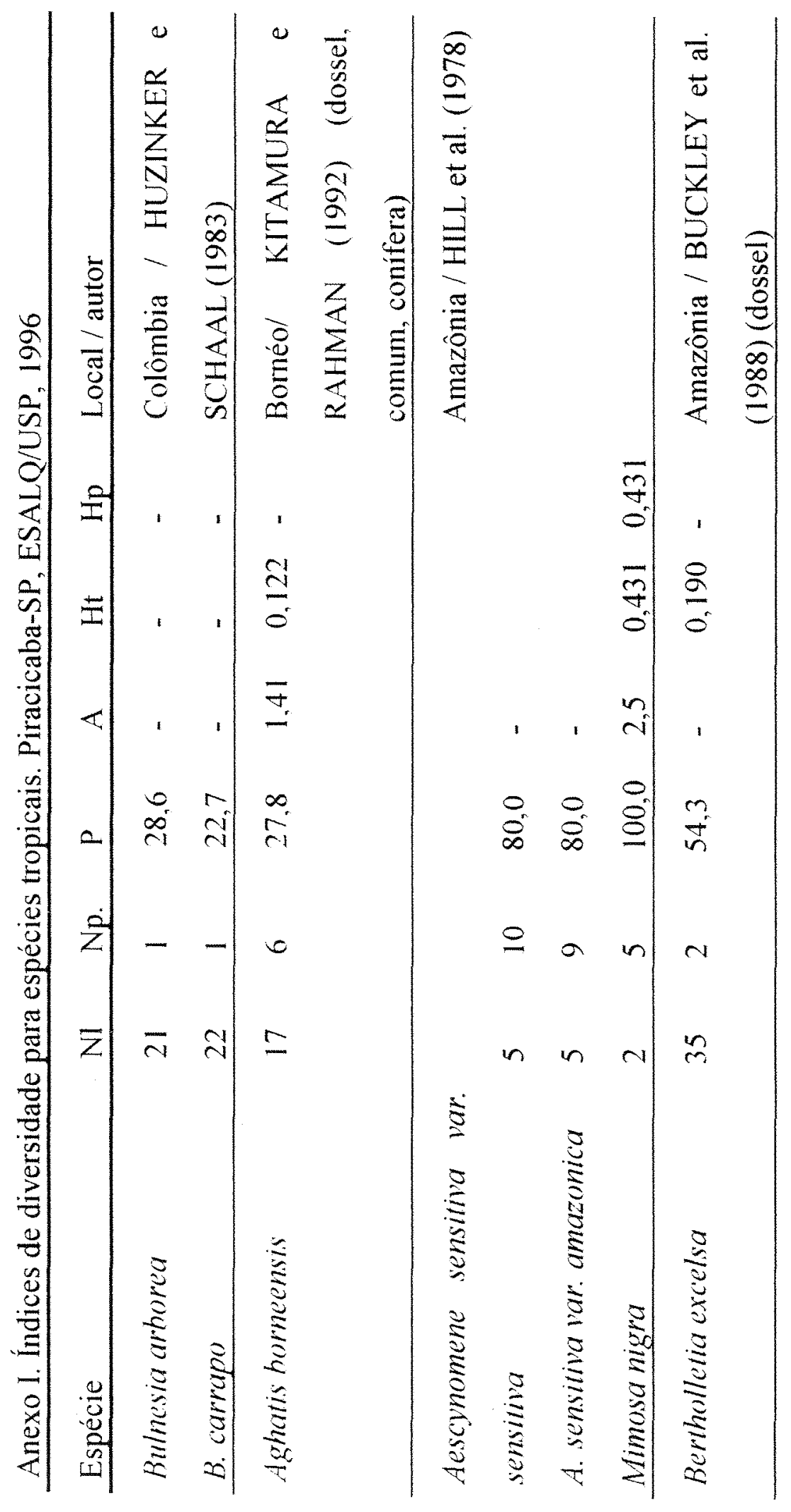




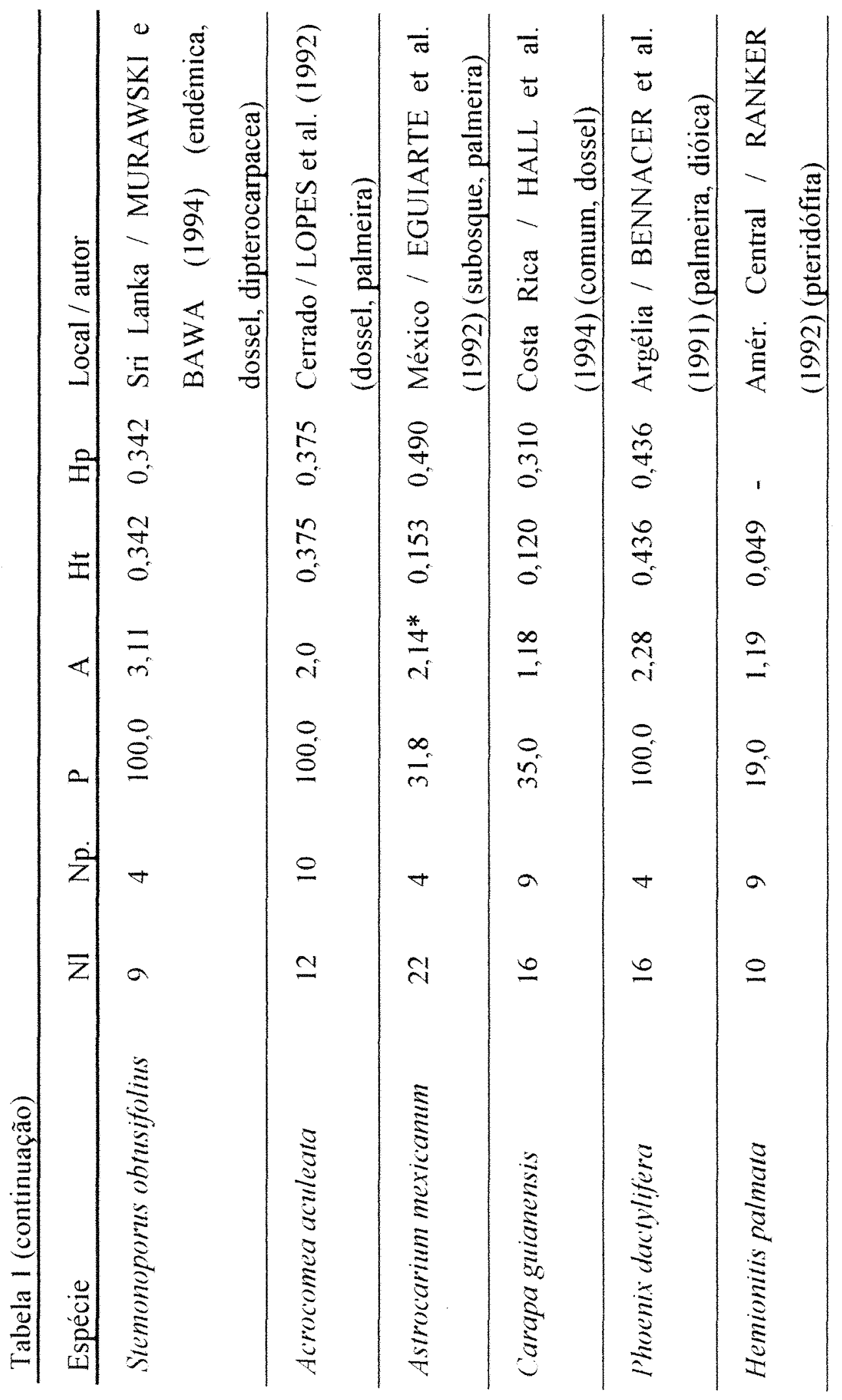




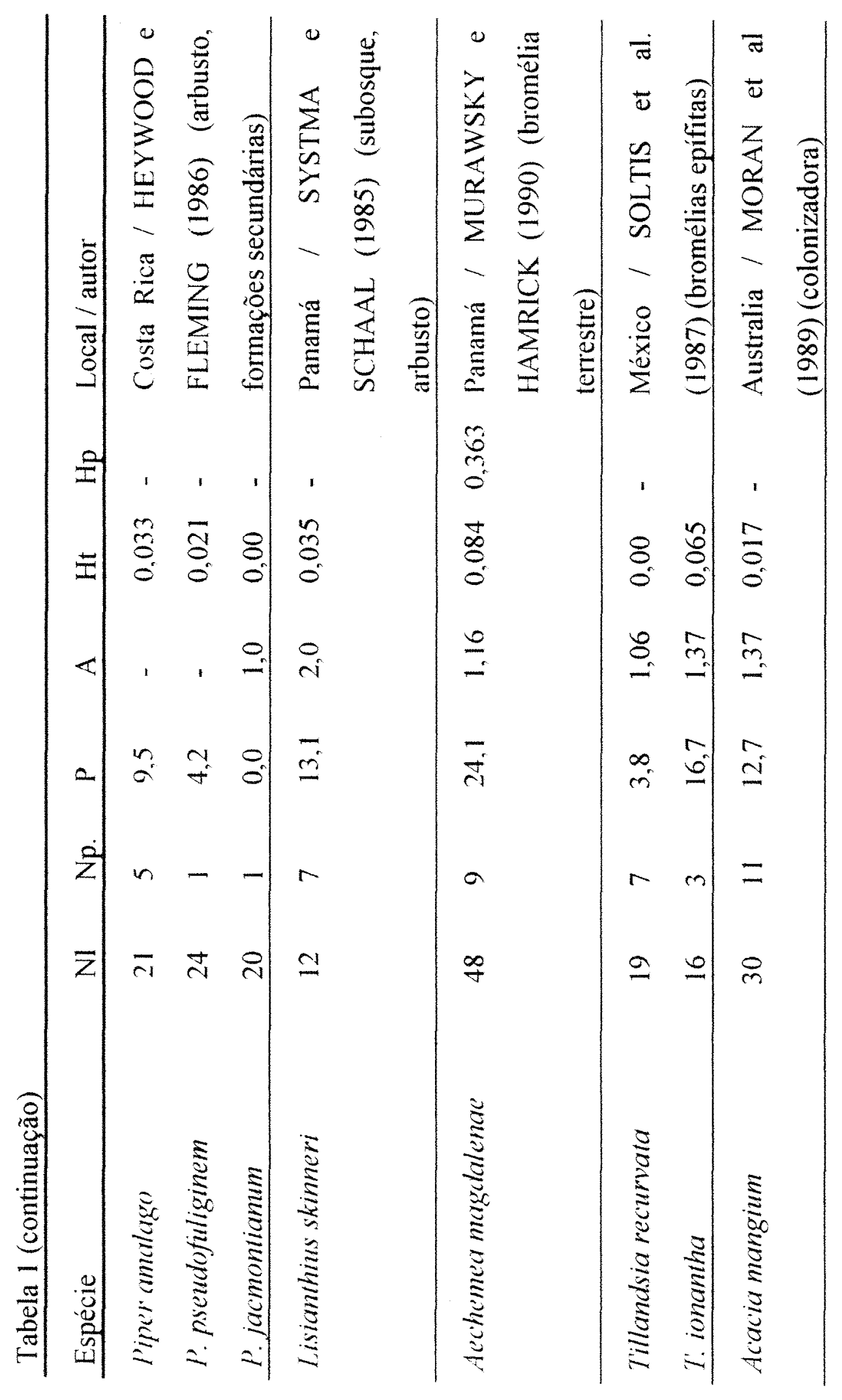




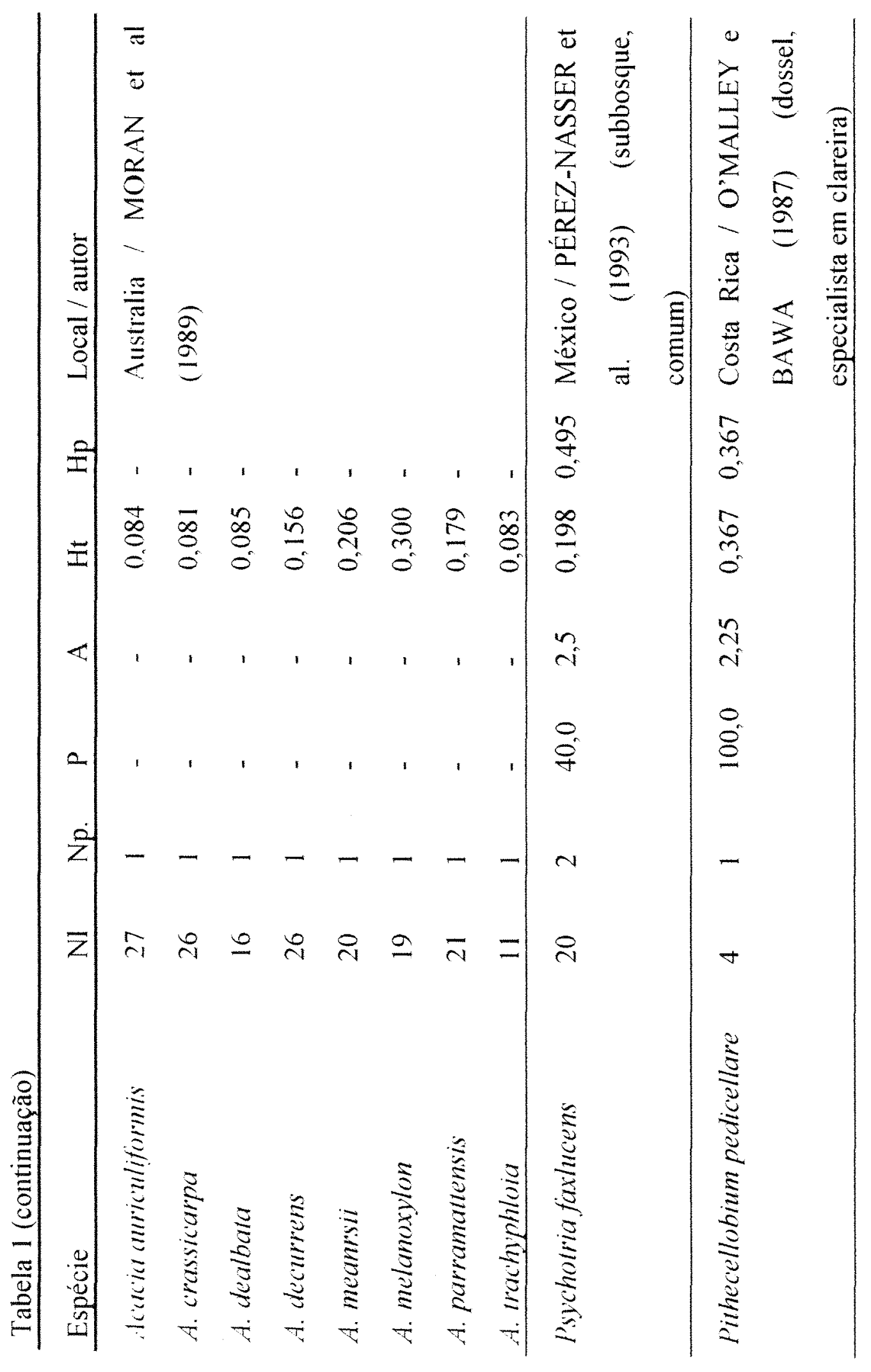




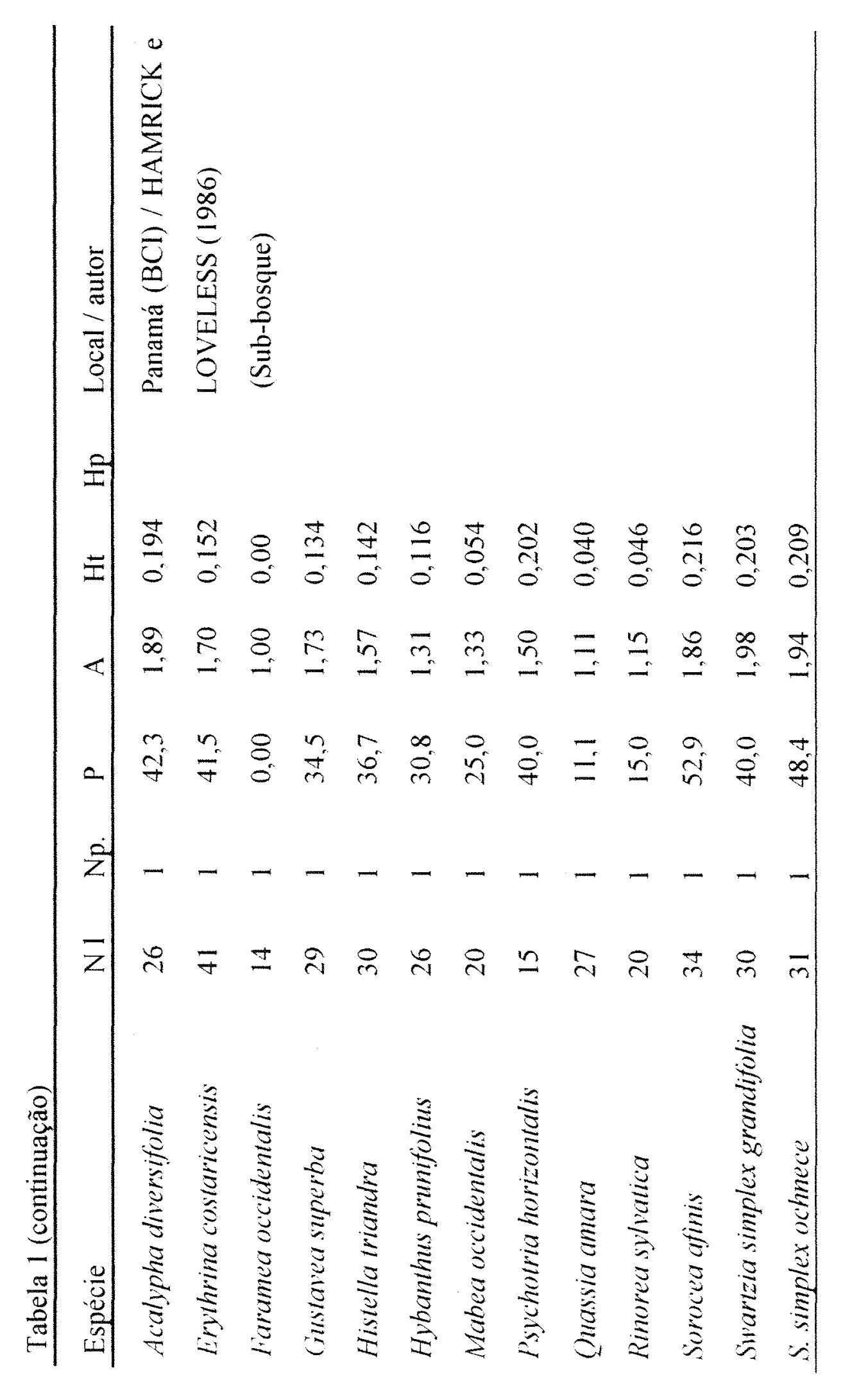




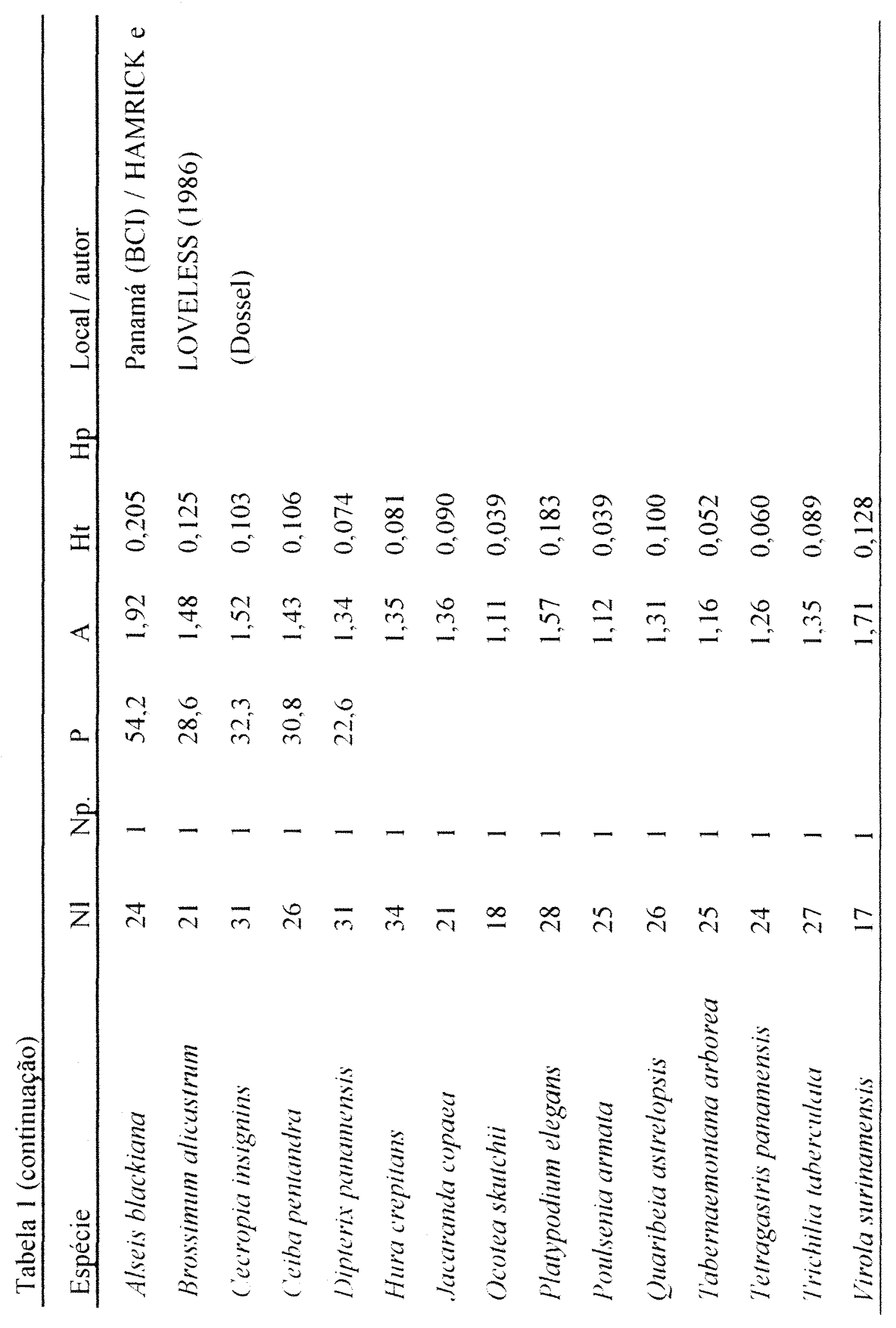




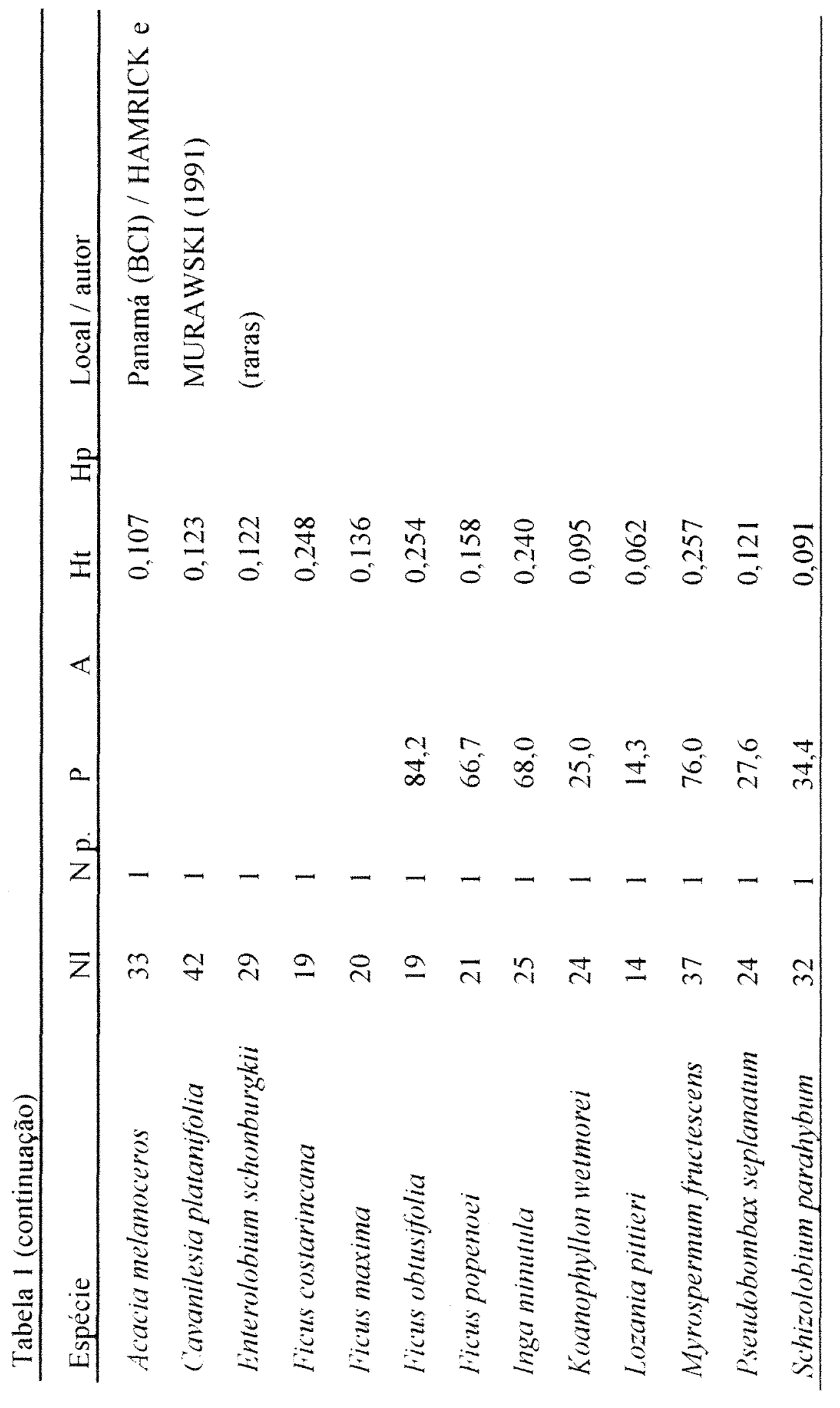




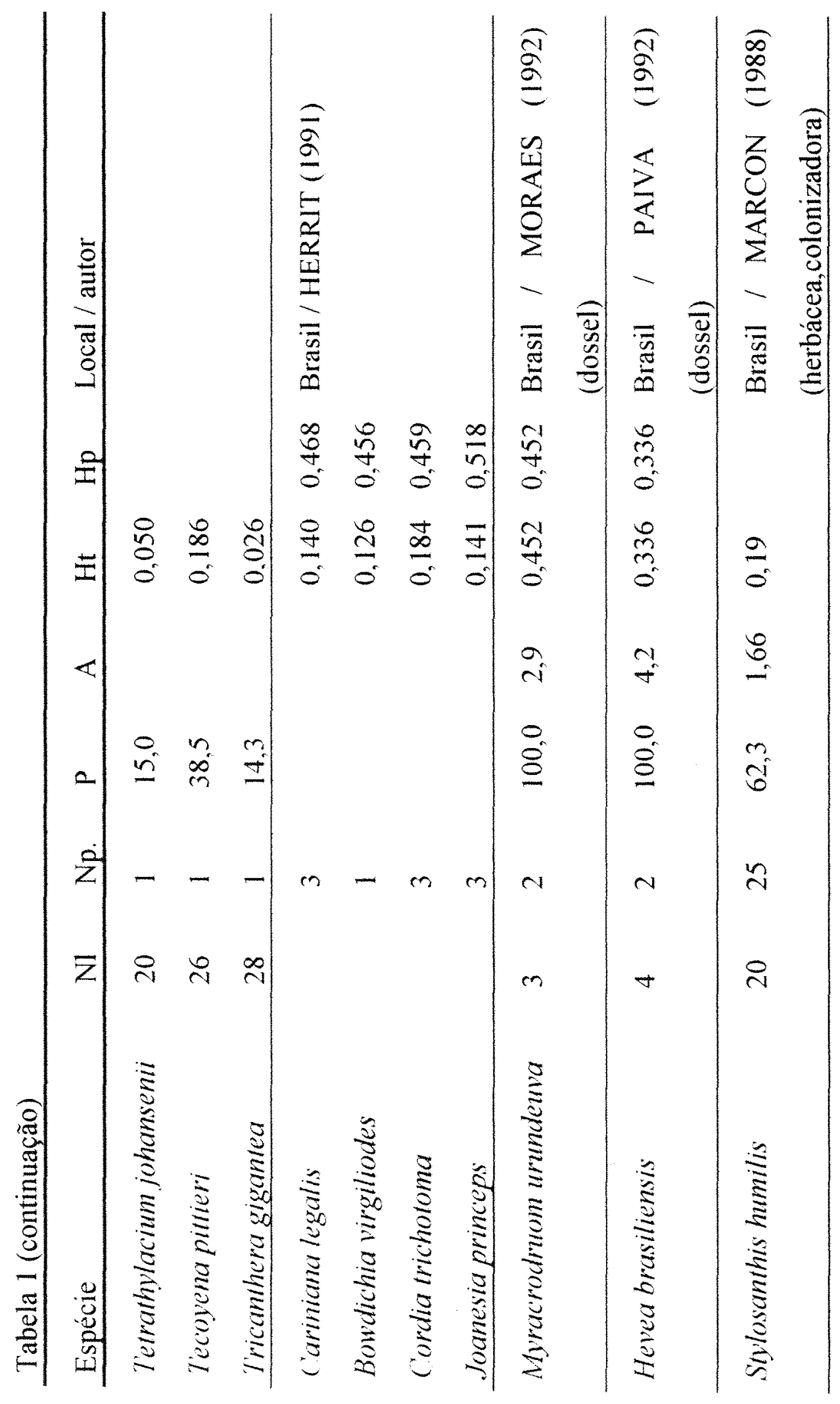




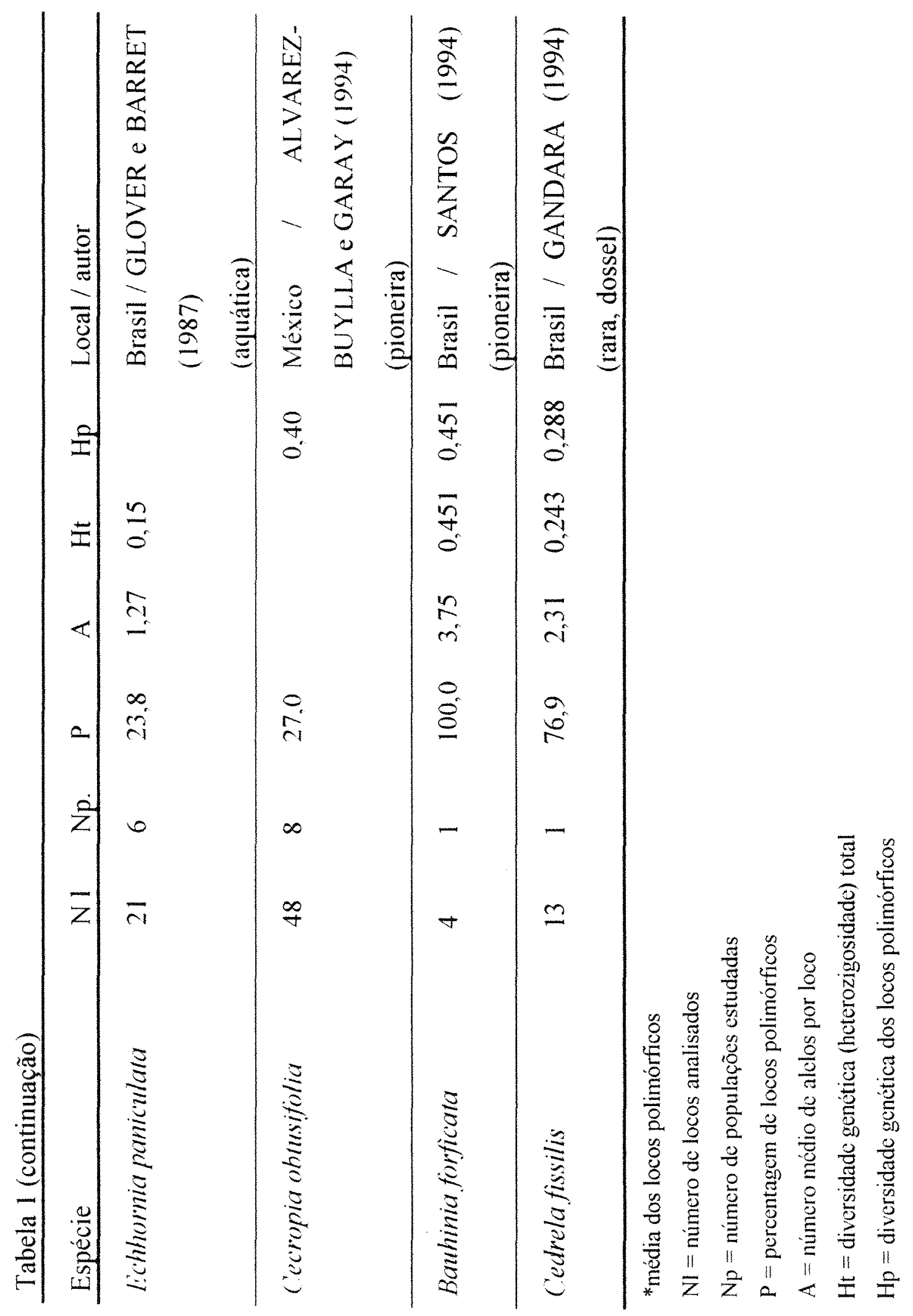


Anexo II. Solução extratora número 1 de ALFENAS et al. (1990, p. 41), modificada pela ausência do 2-Mercaptoetanol. Piracicaba-SP, ESALQ/USP, 1996

Produto

quantidade em $100 \mathrm{ml}$

Fosfato de sódio bibásico $(0,034 \mathrm{M})$

$0,6 \mathrm{~g}$

Sacarose $(0,2 \mathrm{M})$

$7,0 \mathrm{~g}$

PVP - $40(2,56 \%)$

$2,56 \mathrm{~g}$

DTT (3 nM)

$50 \mathrm{mg}$

L- Ácido ascórbico (5,7 mM)

$100 \mathrm{mg}$

$\operatorname{DIECA}(5,8 \mathrm{mM})$

$100 \mathrm{mg}$

Bissulfito de Sódio (2,6 mM)

$50 \mathrm{mg}$

Borato de Sódio (Bórax) (2,5 mM)

$50 \mathrm{mg}$

Polietilenoglicol - $6000(1 \%)$

$1,0 \mathrm{~g}$

Água deionizada (ou destilada) (q.s.p.)

$100 \mathrm{ml}$ 
Anexo III.1. Análise de contingência para freqüências alélicas em sete locos alozímicos para progênies entre sete populações naturais de Euterpe edulis. Piracicaba-SP. ESALQ/USP, 1996

\begin{tabular}{llllll}
\hline loco & $\begin{array}{c}\text { número de } \\
\text { alelos }\end{array}$ & $\begin{array}{c}\text { número de } \\
\text { indivíduos }\end{array}$ & $\chi^{2}$ & $\begin{array}{c}\text { graus de } \\
\text { liberdade }\end{array}$ & P (\%) \\
\hline PRX1 & 3 & 1898 & 156,46 & 12 & $<1$ \\
PRX2 & 4 & 1872 & 165,58 & 18 & $<1$ \\
PRX3 & 4 & 1867 & 415,59 & 18 & $<1$ \\
PRX4 & 3 & 1887 & 078,15 & 12 & $<1$ \\
PGI1 & 4 & 1886 & 124,00 & 18 & $<1$ \\
PGM1 & 5 & 1825 & 379,48 & 24 & $<1$ \\
G6P1 & 3 & 1855 & 061,79 & 12 & $<1$ \\
\hline Total & 26 & - & 1381,04 & 114 & $<1$ \\
\hline
\end{tabular}

Anexo III.2. Análise de contingência para freqüências alélicas em sete locos alozímicos para indivíduos adultos entre oito populações naturais de Euterpe edulis. Piracicaba-SP, ESALQ/USP, 1996

\begin{tabular}{llllll}
\hline loco & $\begin{array}{c}\text { número de } \\
\text { alelos }\end{array}$ & $\begin{array}{c}\text { número de } \\
\text { indivíduos }\end{array}$ & $\chi^{2}$ & $\begin{array}{c}\text { graus de } \\
\text { liberdade }\end{array}$ & P (\%) \\
\hline PRX1 & 3 & 197 & 16,81 & 14 & $50-25$ \\
PRX2 & 4 & 196 & 23,79 & 21 & $50-25$ \\
PRX3 & 4 & 196 & 38,87 & 21 & $<5$ \\
PRX4 & 2 & 195 & 19,02 & 07 & $<1$ \\
PGI1 & 2 & 195 & 6,02 & 07 & $25-10$ \\
PGM1 & 4 & 194 & 58,63 & 21 & $<1$ \\
G6P1 & 2 & 190 & 14,46 & 07 & $<5$ \\
\hline Total & 21 & - & 177,60 & 98 & $<1$ \\
\hline
\end{tabular}


Anexo III.3. Análise de contingência para freqüências alélicas em sete locos alozímicos para progênies e adultos de populações naturais de Euterpe edulis, procedentes de duas regiões. Piracicaba-SP, ESALQ/USP, 1996

\begin{tabular}{|c|c|c|c|}
\hline Locos & $\chi^{2}$ & Graus Liberdade & $\mathrm{P}(\%)$ \\
\hline \multicolumn{4}{|c|}{ Progênies } \\
\hline PRX1 & 9,813 & 2 & $<1$ \\
\hline PRX2 & 40,449 & 3 & $<1$ \\
\hline PRX3 & 239,940 & 3 & $<1$ \\
\hline PRX4 & 11,976 & 2 & $<1$ \\
\hline PGI1 & 49,209 & 3 & $<1$ \\
\hline PGM1 & 156,214 & 4 & $<1$ \\
\hline G6P1 & 28,980 & 2 & $<1$ \\
\hline Total & 536,581 & 19 & $<1$ \\
\hline \multicolumn{4}{|c|}{ Adultos } \\
\hline PRX1 & 1,562 & 2 & $50-25$ \\
\hline PRX2 & 0,365 & 3 & $95-90$ \\
\hline PRX3 & 14,370 & 3 & $<1$ \\
\hline PRX4 & 5,398 & 1 & $<5$ \\
\hline PGI1 & 0,003 & 1 & $25-10$ \\
\hline PGM1 & 31,087 & 3 & $<1$ \\
\hline G6P1 & 0,068 & 1 & $90-75$ \\
\hline Total & 52,854 & 14 & $<1$ \\
\hline
\end{tabular}


Anexo III.4. Análise de contingência para freqüências alélicas em sete locos alozímicos para progênies e adultos de populações naturais de Euterpe edulis, procedentes de três locais de coleta. Piracicaba-SP, ESALQ/USP, 1996 loco Graus Liberdade $\mathrm{P}(\%)$

Progènies

\begin{tabular}{lrrl}
\hline PRX1 & 76,174 & 4 & $<1$ \\
PRX2 & 111,605 & 6 & $<1$ \\
PRX3 & 330,301 & 6 & $<1$ \\
PRX4 & 15,593 & 4 & $<1$ \\
PGI1 & 100,914 & 6 & $<1$ \\
PGM1 & 210,644 & 8 & $<1$ \\
G6P1 & 32,385 & 4 & $<1$ \\
\hline Total & 877,617 & 38 & $<1$ \\
\hline & Adultos & & $<1$ \\
\hline PRX1 & 2,602 & 4 & $75-50$ \\
PRX2 & 13,927 & 6 & $<5$ \\
PRX3 & 24,327 & 6 & $<1$ \\
PRX4 & 5,706 & 2 & $10-5$ \\
PGI1 & 3,064 & 4 & $<5$ \\
PGM1 & 41,769 & 6 & $<1$ \\
G6P1 & 11,379 & 2 & $<1$ \\
\hline Total & 102,774 & 30 & $<1$ \\
\hline
\end{tabular}


Anexo IV. Estatísticas F para 7 locos alozimicos analisados em progênies e indivíduos adultos de 8 populações naturais de palmiteiro (Euterpe edulis). Piracicaba-SP, ESALQ/USP, 1996

\begin{tabular}{lllllll}
\hline locos $/$ & \multicolumn{3}{c}{ Adultos } & \multicolumn{3}{c}{ Progenies } \\
popul. & $\hat{F}_{I S}$ & $\hat{F}_{I T}$ & $\hat{F}_{S T}$ & $\hat{F}_{I S}$ & $\hat{F}_{I T}$ & $\hat{F}_{S T}$ \\
\hline PRX2 & 0,041 & 0,058 & 0,017 & $-0,177$ & $-0,149$ & 0,024 \\
PRX3 & $-0,071$ & $-0,056$ & 0,014 & $-0,055$ & $-0,036$ & 0,018 \\
PRX4 & 0,132 & 0,170 & 0,044 & 0,082 & 0,114 & 0,036 \\
PRX5 & $-0,054$ & $-0,036$ & 0,016 & $-0,097$ & $-0,042$ & 0,050 \\
PGI2 & $-0,015$ & 0,001 & 0,016 & $-0,161$ & $-0,145$ & 0,014 \\
PGM1 & 0,146 & 0,179 & 0,039 & $-0,064$ & $-0,009$ & 0,052 \\
G6P1 & $-0,040$ & $-0,028$ & 0,012 & $-0,107$ & $-0,065$ & 0,038
\end{tabular}

\begin{tabular}{lllllll} 
MÉDIA & 0,042 & 0,068 & 0,026 & $-0,067$ & $-0,033$ & 0,031 \\
\hline locos / & & & & & & \\
locais & & $(3)$ & & & & \\
\hline PRX2 & 0,076 & 0,085 & 0,010 & $-0,160$ & $-0,156$ & 0,003 \\
PRX3 & $-0,071$ & $-0,061$ & 0,010 & $-0,026$ & $-0,014$ & 0,012 \\
PRX4 & 0,109 & 0,140 & 0,035 & 0,089 & 0,115 & 0,028 \\
PRX5 & $-0,042$ & $-0,040$ & 0,002 & $-0,064$ & $-0,047$ & 0,016 \\
PGI2 & $-0,009$ & 0,006 & 0,015 & $-0,165$ & $-0,155$ & 0,009 \\
PGM1 & 0,181 & 0,204 & 0,028 & $-0,044$ & $-0,005$ & 0,037 \\
G6P1 & $-0,032$ & $-0,024$ & 0,008 & $-0,086$ & $-0,047$ & 0,036 \\
& & & & & & \\
MÉDIA & 0,053 & 0,072 & 0,019 & $-0,051$ & $-0,029$ & 0,021 \\
\hline
\end{tabular}


Anexo IV (continuação)

$\operatorname{locos} /$

regiōes

(2)

\begin{tabular}{lllllll} 
PRX2 & 0,061 & 0,062 & 0,001 & $-0,102$ & $-0,098$ & 0,003 \\
PRX3 & $-0,062$ & $-0,057$ & 0,005 & $-0,034$ & $-0,034$ & 0,000 \\
PRX4 & 0,151 & 0,175 & 0,028 & 0,104 & 0,116 & 0,013 \\
PRX5 & $-0,036$ & $-0,036$ & 0,001 & $-0,055$ & $-0,036$ & 0,018 \\
PG12 & $-0,017$ & $-0,013$ & 0,004 & $-0,166$ & $-0,165$ & 0,001 \\
PGM1 & 0,173 & 0,190 & 0,020 & $-0,031$ & 0,002 & 0,032 \\
G6P1 & $-0,026$ & $-0,019$ & 0,007 & $-0,047$ & $-0,047$ & 0,000 \\
& & & & & & \\
MÉDIA & 0,058 & 0,070 & 0,012 & $-0,036$ & $-0,025$ & $-0,011$ \\
& & & & & & \\
\hline
\end{tabular}


Anexo V.1. Somas de quadrados e graus de liberdade da análise de variância das frequências alélicas para progênies de Euterpe edulis, valores tomados para cada alelo. Piracicaba-SP, ESALQ/USP, 1996

\section{GLR* GLL GLP GLF GLI GLG SQR $\quad$ SQL $\quad$ SQP $\quad$ SQF $\quad$ SQI $\quad$ SQG}

\begin{tabular}{|c|c|}
\hline \multicolumn{2}{|l|}{ PRX2 } \\
\hline 11 & 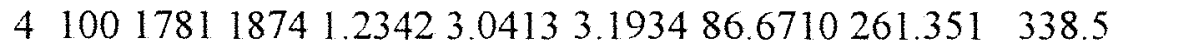 \\
\hline 11 & 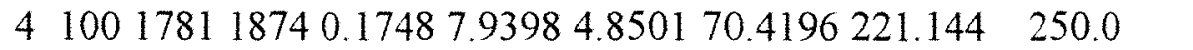 \\
\hline 1 & $4 \quad 100178118740.48001 .15313 .181431 .6495 \quad 98.469$ \\
\hline \multicolumn{2}{|r|}{ PRX3 } \\
\hline 11 & 4100177618692.70832 .55096 .8511124 .326274 .900505 .167 \\
\hline 1 & 4100177618690.18766 .85453 .978853 .241166 .290293 .000 \\
\hline 1 & $4100177618690.00652 .56790 .7060 \quad 40.621 \quad 125.517166 .500$ \\
\hline 1 & $4100177618694.57000 .30701 .6114 \quad 82.536190 .159216 .667$ \\
\hline 11 & $\begin{array}{llllllll}4 & 10017761869 & 0.0005 & 0.0008 & 0.0008 & 0.047 & 0.950 & 1.000\end{array}$ \\
\hline \multicolumn{2}{|r|}{ PRX4 } \\
\hline 11 & 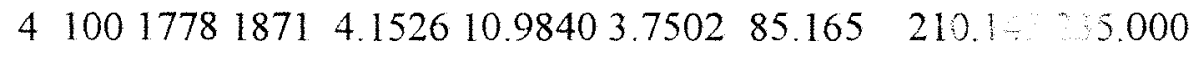 \\
\hline 11 & 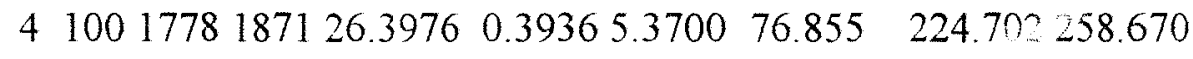 \\
\hline 11 & 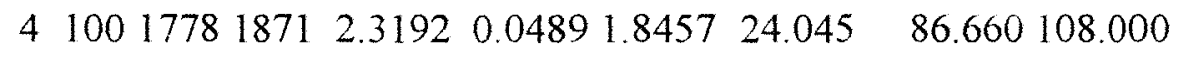 \\
\hline 11 & $4 \quad 1001778187121.372013 .84207 .5330152 .487 \quad 369.397359 .667$ \\
\hline \multicolumn{2}{|r|}{ PRX5 } \\
\hline 11 & $4 \quad 10017871880 \quad 0.1788 \quad 0.15322 .3467 \quad 17.884685 .4281 \quad 113.5$ \\
\hline 11 & 4100178718800.04810 .17652 .835018 .286079 .3299106 .5 \\
\hline 11 & 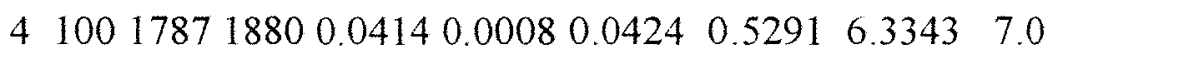 \\
\hline \multicolumn{2}{|r|}{ PGI2 } \\
\hline & $4 \quad 100178518804.661312 .05104 .6589127 .145328 .093 \quad 454.25$ \\
\hline 11 & $4100178518801.361310 .06902 .9581 \quad 124.067327 .620 \quad 448.75$ \\
\hline 11 & $4 \quad 100178518800.0306 \quad 0.00660 .0729 \quad 2.724 \quad 15.323 \quad 17.50$ \\
\hline 11 & 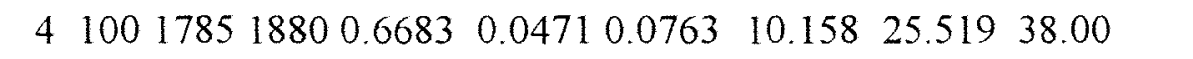 \\
\hline \multicolumn{2}{|r|}{ 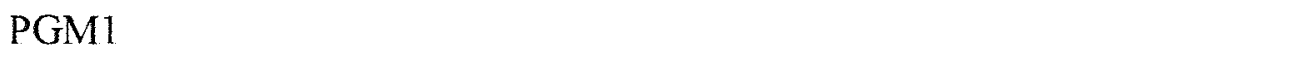 } \\
\hline 11 & 4991744183625.61406 .974016 .0980204 .157248 .558235 .0 \\
\hline 11 & $4 \quad 99174418360.04801 .1309 \quad 3.4610 \quad 110.029247 .092339 .5$ \\
\hline 11 & 4991744183615.67705 .278014 .4270229 .657288 .488345 .0 \\
\hline 11 & 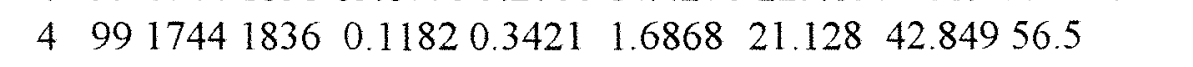 \\
\hline 11 & $\begin{array}{lllllllll}4 & 991744 & 1836 & 0.2904 & 0.0182 & 0.0306 & 6.325 & 18.711 & 22.0\end{array}$ \\
\hline \multicolumn{2}{|r|}{ G6P } \\
\hline 1 & $14 \quad 400175418491.55430 .11191 .410828 .600384 .8808123 .5$ \\
\hline 1 & 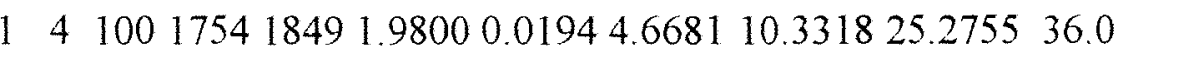 \\
\hline 1 & 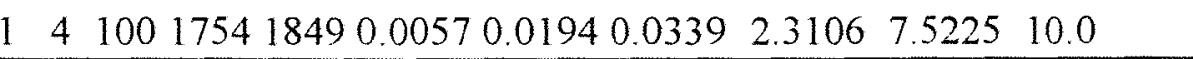 \\
\hline
\end{tabular}


Anexo V.2. Quadrados médios para regiōes (QMR), locais (QML), populaçōes (QMP), familias (QMF), indivíduos (QMI) e alelos (QMG), obtidos a partir da análise de variância das frequências alélicas para progênies de sete populações naturais de Euterpe edulis. Piracicaba-SP. ESALQ/USP. 1996

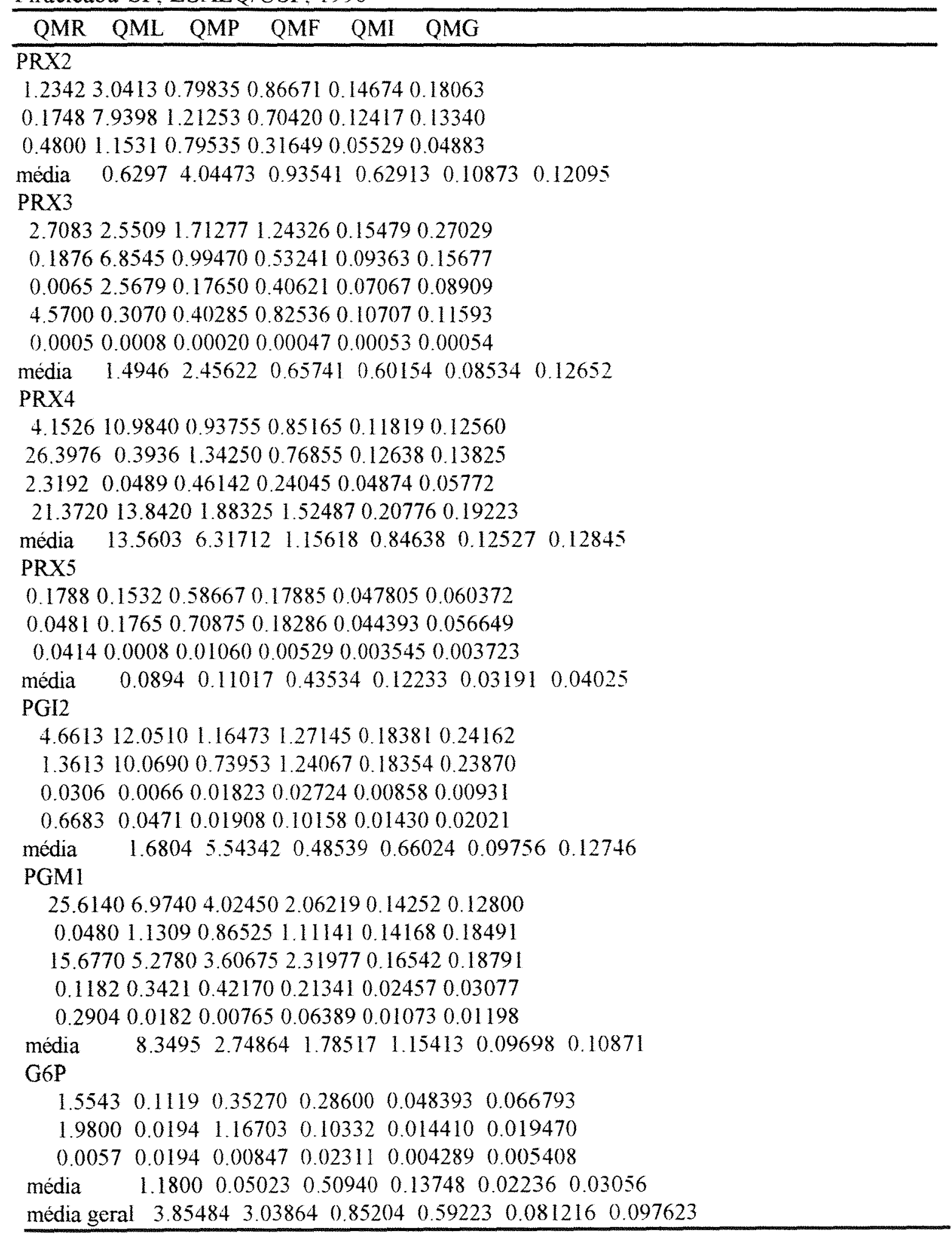


Anexo V.3. Variàncias total (VT), para regiões (VR), locais (VL), populações (VP), familias (VF), indivíduos (VI) e alelos (VG), obtidos a partir da decomposição dos quadrados médios da análise de variância das frequências alélicas para progènies de sete populações naturais de Euterpe edulis. Piracicaba-SP, ESALQ/USP, 1996

\begin{tabular}{cllllll}
\hline VG & VI & VF & VP & VL & VR & VT \\
\hline PRX2
\end{tabular}

$\begin{array}{lllllll}0.18063 & -0.016943 & 0.020506 & -.0001519 & 0019153 & -.0011979 & 0.18476\end{array}$

$\begin{array}{llllllll}0.13340 & -0.004618 & 0.016520 & 0.0010655 & 0054953 & -.0049289 & 0.14694\end{array}$

$\begin{array}{lllllllll}0.04883 & 0.003231 & 0.007440 & 0.0010068 & .0000215 & -.0002151 & 0.06031\end{array}$

$\begin{array}{llllllll}\text { média } & 0.12095 & -0.006110 & 0.014822 & 0.0006401 & 0.0024774 & -.0021140 & 0.13067\end{array}$

PRX3

$\begin{array}{llllllll}0.27029 & -0.057751 & 0.031082 & 0.00098125 & 0003669 & 0.0003609 & 0.24533\end{array}$

$\begin{array}{llllllll}0.15677 & -0.031568 & 0.012529 & 0.00097304 & 0047921 & -.0042383 & 0.13926\end{array}$

$\begin{array}{lllllll}0.08909 & -0.009206 & 0.009581 & -.00048953 .0021733 & -.0017871 & 0.08936\end{array}$

$\begin{array}{llllllll}0.11593 & -0.004427 & 0.020511 & -.00090149 & 00000848 & 0.0025813 & 0.13377\end{array}$

$0.00054-0.000000-0.000002-.00000057 .0000007-.0000003 \quad 0.00053$

$\begin{array}{llllllllll}\text { média } & 0.12652 & -0.020590 & 0.014740 & 0.0001125 & 0.0014835 & -.0006167 & 0.12165\end{array}$

PRX4

$\begin{array}{llllllll}0.12560 & -0037047 & 0.020920 & 0001739 & 0.008593 & -0.004653 & 0.14693\end{array}$

$\begin{array}{llllllll}0.13825 & -.0059367 & 0.018316 & 0012058 & -0.001201 & 0.016740 & 0.16738\end{array}$

$\begin{array}{lllllll}0.05772 & -0044915 & 0.005468 & 0004648 & -0.000498 & 0.001562 & 0.06023\end{array}$

$\begin{array}{lllllllll}0.19223 & 0.0077637 & 0.037567 & 0007435 & 0.010045 & 0.004486 & 0.25284\end{array}$

$\begin{array}{lllllllll}\text { média } & 0.12845 & -0.001592 & 0.020568 & 0.0006470 & 0.0042346 & 0.0045334 & 0.15684\end{array}$

PRX5

$\begin{array}{lllllll}0.060372 & -0062835 & 0037196 & 0008557 & -00061075 & 00021789 & 0.058271\end{array}$

$\begin{array}{lllllll}0.056649 & -0061281.0039304 & 0011037 & -00076168 & .00017552 & 0.054969\end{array}$

$0.003723-0000894.0000496 .0000111-00001155.000028270 .003711$

$\begin{array}{lllllllll}\text { média } & 0.04025 & -0.004167 & 0.002567 & 0.0006568 & -.0004613 & 0.0001406 & 0.03898\end{array}$

PGI2

$\begin{array}{lllllll}0.24162 & -0.028908 & 0.030890 & -0002319 & 0.0092963 & -.0050124 & 0.24766\end{array}$

$\begin{array}{llllllll}0.23870 & -0.027578 & 0.030024 & -.0010644 & 0.0081845 & -.0059415 & 0.24232\end{array}$

$\begin{array}{llllllll}0.00931 & -0.000362 & 0.000530 & -.0000191 & -.0000068 & 0.0000137 & 0.00946\end{array}$

$\begin{array}{lllllllll}0.02021 & -0.002958 & 0.002479 & -0001747 & 0.0000617 & 0.0003629 & 0.01998\end{array}$

$\begin{array}{llllllll}\text { média } & 0.12746 & -0.014952 & 0.015981 & -.0003725 & 0.0043839 & -.0026443 & 0.12986\end{array}$

PGM1

$\begin{array}{lllllll}0.12800 & 0.007263 & 0.055306 & 0.0041535 & 0.0014061 & 0.012610 & 0.20873\end{array}$

$\begin{array}{lllllll}0.18491 & -0.021616 & 0.027938 & -0005456 & 0.0002757 & -0.000704 & 0.19026\end{array}$

$\begin{array}{llllllll}0.18791 & -0.011246 & 0.062067 & 0.0027059 & 0.0005975 & 0.007222 & 0.24926\end{array}$

$\begin{array}{lllllll}0.03077 & -0.003102 & 0.005441 & 0.0004412 & -.0002022 & -0.000034 & 0.03332\end{array}$

$\begin{array}{llllllll}0.01198 & -0.000627 & 0.001531 & -0001212 & 0.0000345 & 0.000155 & 0.01296\end{array}$

$\begin{array}{lllllllll}\text { média } & 0.10871 & -0.005865 & 0.030457 & 0.0013268 & 0.0004223 & 0.0038497 & 0.13890\end{array}$

$\mathrm{G} 6 \mathrm{Pl}$

$\begin{array}{lllllll}0.066793 & -0092001.0068634 & 0.0001396 & -0002723 & 0.0009787 & 0.065302\end{array}$

$\begin{array}{llllllll}0.019470 & -.0025299 .0025681 & 0.0022822 & -.0016179 & 0.0017504 & 0.021923\end{array}$

$\begin{array}{lllllllll}0.005408 & -0005598 & 0005435 & -.0000317 & 0.0000160 & -0000134 & 0.005363\end{array}$

$\begin{array}{lllllllll}\text { média } & 0.03056 & -0.004097 & 0.003325 & 0.0007967 & -.0006247 & 0.0009053 & 0.03086\end{array}$

\begin{tabular}{llllllllllll}
\hline Média/loco & 0.097623 & -.0082037 & 0.014603 & .00054445 & .0017115 & .00056691 & 0.10684
\end{tabular}

$\begin{array}{lllllllll}\text { Média/alelo } & 0.10284 & -0089590 & 0.016042 & 0.00054057 & 0.0017951 & 0.00074568 & 0.1130\end{array}$ 
Anexo V.4. Valores de K empregados na decomposição das variâncias na análise variância das frequências alélicas de progênies em sete populações naturais de Euterpe edulis. Piracicaba-SP, ESALQ/USP, 1996

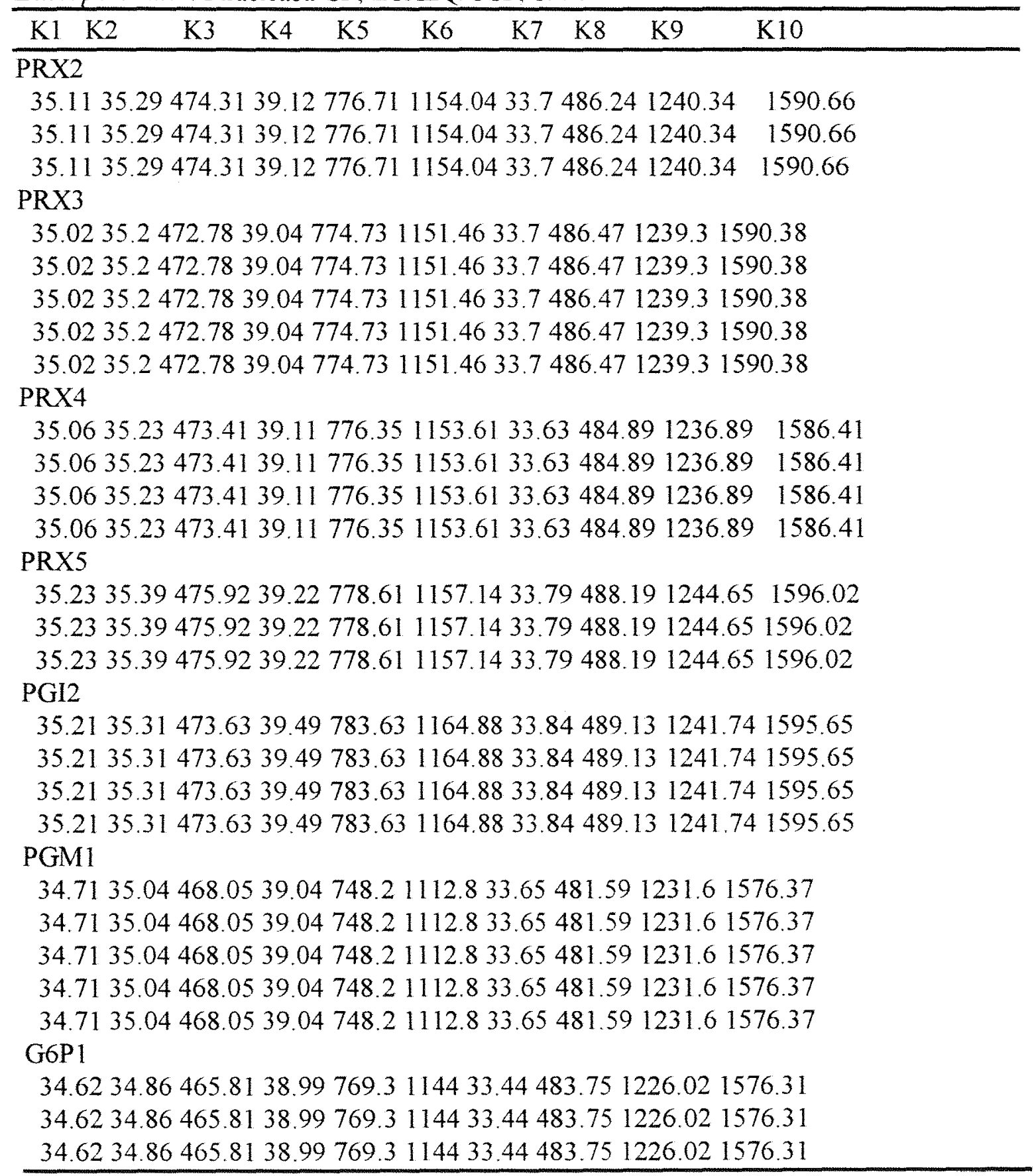


Anexo V.5. Somas de quadrado e quadrados médios da análise de variância das frequências alélicas para indivíduos adultos de Euterpe edulis, valores tomados para cada alelo. Piracicaba-SP, ESALQ/USP, 1996

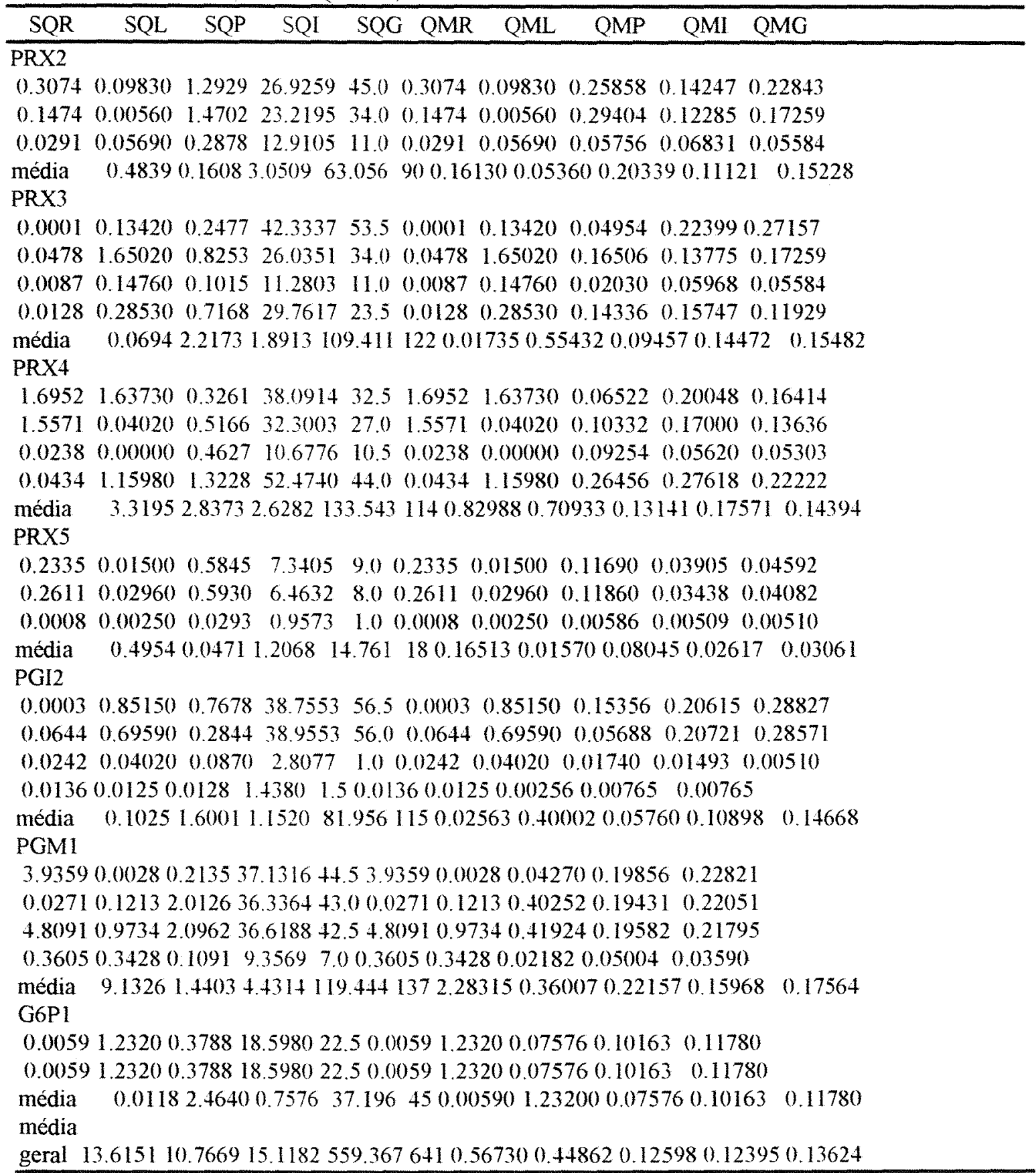

\footnotetext{
*SQR = soma de quadrados para regiōes: $\mathrm{SQL}=$ soma de quadrados para locais; $\mathrm{SQP}=$ soma de quadrados para populações: $S Q I=$ soma de quadrados para individuos: $S Q G=$ soma de quadrados para alelos: $\mathrm{QMR}=$ quadrado médio para região: $\mathrm{QML}=$ quadrado médio para locais: $\mathrm{QMP}=$ quadrado médio para populações; $\mathrm{QMI}=$ quadrado médio para indivíduos: $\mathrm{QMG}=$ quadrado médio para alelos.
} 
Anexo V.6. Graus de liberdade e valores de $\mathrm{K}$ empregados na decomposição das variâncias da análise de variância das frequências alélicas de indivíduos adultos de oito populações naturais de Euterpe edulis. Piracicaba-SP, ESALQ/USP, 1996

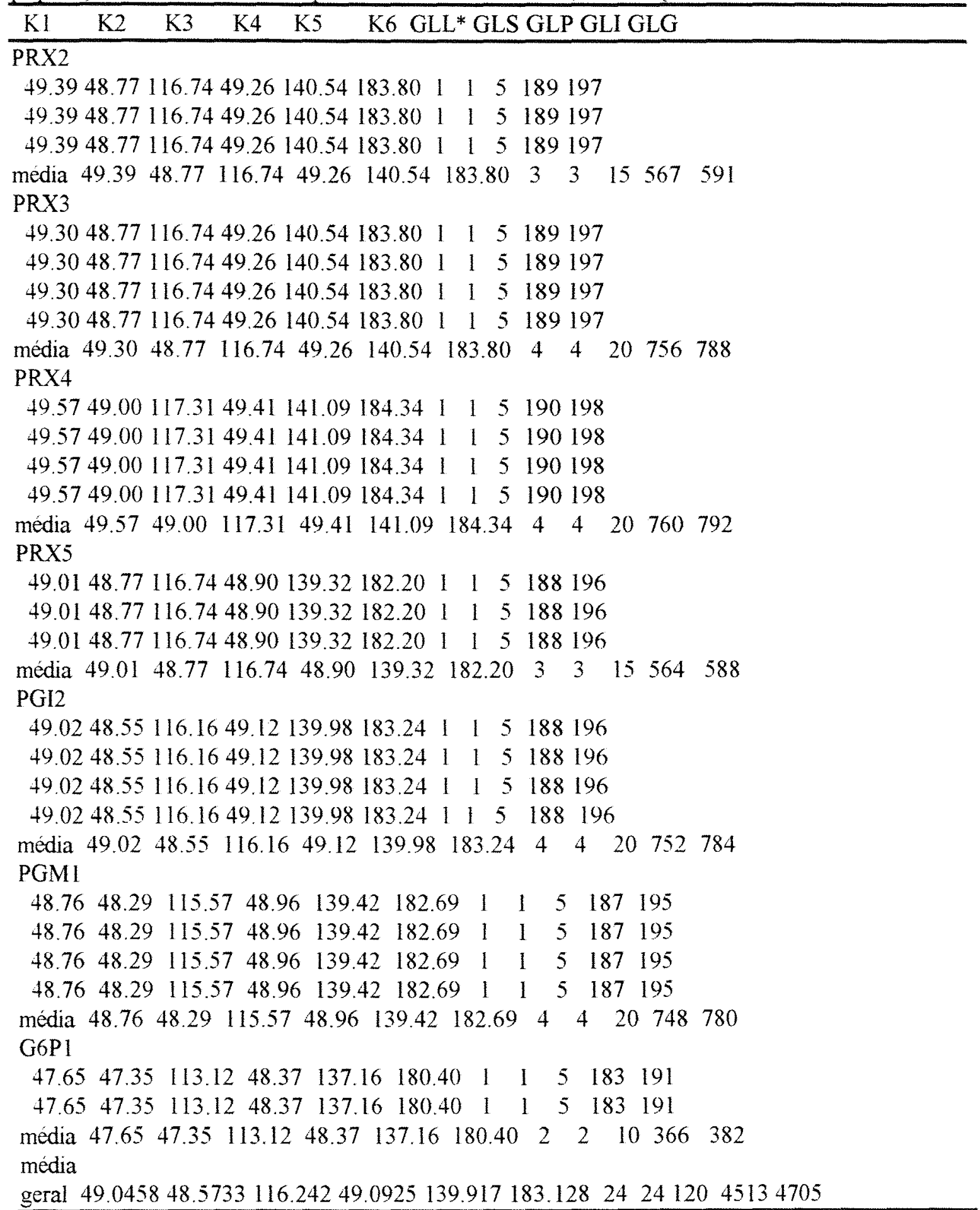

* GLR = graus de liberdade para regiōes: GLL = graus de liberdade para locais: GLP= graus de liberdade para populações: $\mathrm{GLI}=$ graus de liberdade para indivíduos; $\mathrm{GLG}=$ graus de liberdade para alelos 
Anexo V.7. Variâncias total (VT), para regiões (VR), locais (VL), populações (VP), individuos (VI) e alelos (VG), obtidos a partir da decomposição dos quadrados médios da análise de variância das frequências alélicas para indivíduos adultos de oito populações naturais de Euterpe edulis. Piracicaba-SP, ESALQ/USP, 1996

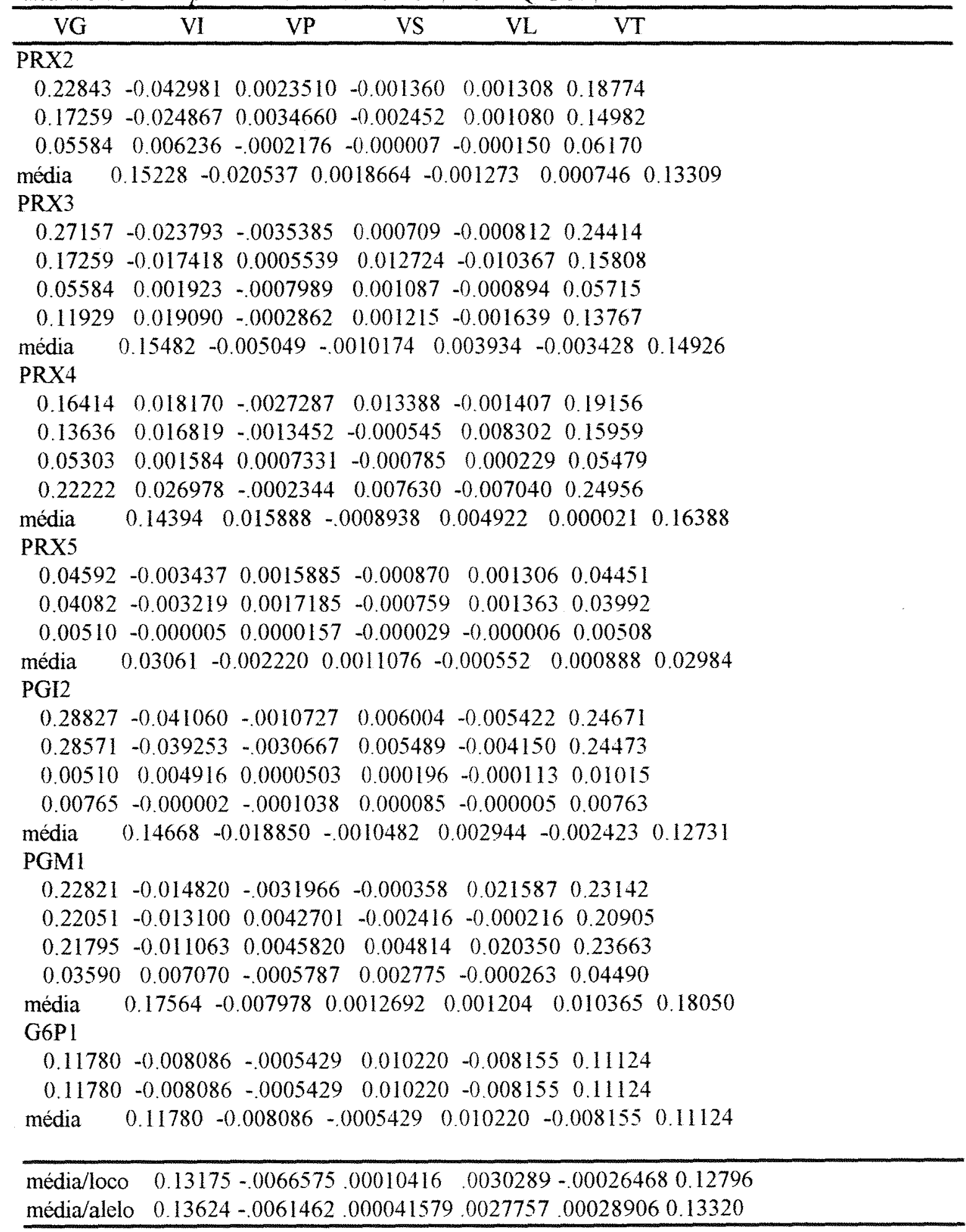


Anexo V.8. Estimativas dos coeficientes de coancestralidade para sete populações naturais de Euterpe edulis, com dados obtidos a partir de progênies maternais, empregando-se sete locos alozímicos. Piracicaba-SP, ESALQ/USP, 1996
$\hat{\theta}_{R}$
$\hat{\theta}_{L}$
$\hat{\theta}_{p}$
$\hat{\theta}_{F} \quad \hat{F}$
$\hat{f}$
$\hat{t}_{a 3}$
$\hat{\theta}_{F}$

$\begin{array}{ccccccccc}-0.006483 & 0.0038833 & 0.003061 & 0.11405 & 0.02235 & 0.01934 & 0.96205 & 0.11133 \\ -0.033544 & 0.0038547 & 0.011106 & 0.12354 & 0.09211 & 0.08191 & 0.84858 & 0.11369 \\ -0.003567 & -.0032106 & 0.013482 & 0.13684 & 0.19042 & 0.17935 & 0.69585 & 0.12504 \\ \mathbf{- 0 . 0 1 6 1 7 8} & \mathbf{0 . 0 0 2 7 8 1} & \mathbf{0 . 0 0 7 6 8 0} & \mathbf{0 . 1 2 1 1 1} & \mathbf{0 . 0 7 4 3 5} & \mathbf{0 . 0 6 7 1 9} & \mathbf{0 . 8 7 4 0 8} & \mathbf{0 . 1 1 4 3 1} \\ 0.001471 & 0.002967 & 0.006967 & 0.13366 & -0.10174 & -0.10947 & 1.2458 & 0.12758 \\ -0.030435 & 0.003977 & 0.010964 & 0.10094 & -0.12575 & -0.13823 & 1.32082 & 0.09097 \\ -0.020000 & 0.004321 & -0.001157 & 0.10607 & 0.00305 & 0.00420 & 0.99163 & 0.10710 \\ 0.019296 & 0.019929 & 0.013190 & 0.16651 & 0.13342 & 0.12183 & 0.78279 & 0.15537 \\ -0.000630 & 0.000640 & -0.000430 & -0.00391 & -0.00404 & -0.00360 & 1.00723 & -0.00348\end{array}$

$\begin{array}{lllllllll}-0.005070 & 0.007126 & 0.008051 & 0.12922 & \mathbf{- 0 . 0 4 0 0 4} & \mathbf{- 0 . 0 4 8 4 8} & 1.10190 & \mathbf{0 . 1 2 2 1 5}\end{array}$

$\begin{array}{lllllllll}-0.03167 & 0.026813 & 0.02800 & 0.17038 & 0.14516 & 0.12054 & 0.78485 & 0.14648\end{array}$

$\begin{array}{lllllllll}0.10001 & 0.092837 & 0.10004 & 0.20947 & 0.17400 & 0.08219 & 0.84811 & 0.12160\end{array}$

$\begin{array}{lllllllll}0.02593 & 0.017658 & 0.02537 & 0.11616 & 0.04159 & 0.01664 & 0.96727 & 0.09315\end{array}$

$\begin{array}{lllllllll}0.01774 & 0.057469 & 0.06041 & 0.20899 & 0.23970 & 0.19082 & 0.67952 & 0.15814\end{array}$

$\begin{array}{llllllll}\mathbf{0 . 0 2 8 9 0 4} & 0.055903 & 0.060029 & 0.19117 & 0.18101 & 0.12871 & 0.77193 & 0.13951\end{array}$

$\begin{array}{llllllll}.0037392 & -0.006742 .0079424 & 0.071774 & -0.036058 & -0.044352 & 1.09282 & 0.064343\end{array}$ $\begin{array}{lllllllll}.0031930 & -0.010664 & 0094146 & 0.080917 & -0.030566 & -0.040361 & 1.08412 & 0.072182\end{array}$ $\begin{array}{lllllll}.0076161 & 0.004505 .0075061 & 0.020862 & -0.003219 & -0.010806 & 1.02185 & 0.013457\end{array}$

$\begin{array}{llllllll}0.003606 & -0.008228 & 0.008620 & 0.07446 & -0.03244 & -0.04141 & 1.08640 & 0.06641\end{array}$

$\begin{array}{llllllll}-0.020239 & 0.017298 & 0.016362 & 0.14109 & 0.024364 & 0.008136 & 0.98386 & 0.12680\end{array}$

$\begin{array}{llllllll}-0.024519 & 0.009256 & 0.004864 & 0.12876 & 0.014955 & 0.010141 & 0.97992 & 0.12451\end{array}$

$\begin{array}{llllllll}0.001449 & 0.000732 & -0.001291 & 0.05469 & 0.016414 & 0.017682 & 0.96525 & 0.05591\end{array}$

$\begin{array}{llllllll}0.018159 & 0.021244 & 0.012501 & 0.13655 & -0.011482 & -0.024287 & 1.04978 & 2562\end{array}$

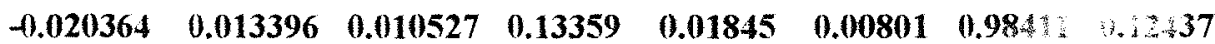

$\begin{array}{lllllllll}0.060413 & 0.067149 & 0.087048 & 0.35201 & 0.38680 & 0.32833 & 0.5056: & 0.29022\end{array}$

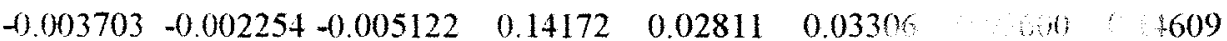

$\begin{array}{llllllll}0.028973 & 0.031370 & 0.042226 & 0.29124 & 0.24612 & 0.21286 & 0.048 \% & 5999\end{array}$

$\begin{array}{lllllllll}-0.001008 & -0.007075 & 0.006166 & 0.16946 & 0.07636 & 0.07062 & 0.86 \% & 0.16431\end{array}$

$\begin{array}{lllllllll}0.011950 & 0.014612 & 0.005255 & 0.12347 & 0.07508 & 0.07019 & 0.86882 & 0.11884\end{array}$

$\begin{array}{llllllllll}0.027715 & 0.030755 & 0.040307 & 0.25957 & 0.21734 & 0.18+47 & 0.68852 & 0.22847\end{array}$

$\begin{array}{llllllll}0.014987 & 0.010817 & 0.01296 & 0.11806 & -0.02283 & -0.036252 & 1.07523 & 0.10648\end{array}$

$\begin{array}{llllllll}0.079845 & 0.006046 & 0.11015 & 0.22729 & 0.11189 & 0.001959 & 0.99609 & 0.13164\end{array}$

$\begin{array}{llllllll}-0.002489 & 0.000493 & -0.00542 & 0.09593 & -0.00844 & -0.003013 & 1.00604 & 0.10080\end{array}$

$\begin{array}{llllllll}0.029332 & 0.009089 & 0.034905 & 0.14264 & 0.00991 & -0.02590 & 1.05319 & 0.11163\end{array}$

(Média por loco)

$\begin{array}{lllllllll}.0053059 & 0.021324 & 0.026420 & 0.16309 & 0.086311 & 0.061516 & 0.88410 & 0.14038\end{array}$

(Média por alelo)

$\begin{array}{lllllllll}.0065987 & 0.022484 & 0.027268 & 0.16923 & 0.089948 & 0.064437 & 0.87893 & 0.14594\end{array}$ 
Anexo V.9. Estimativas dos coeficientes de coancestralidade para oito populações naturais de Euterpe edulis, com dados obtidos a partir de indivíduos adultos, empregando-se sete locos alozimicos. Piracicaba-SP, ESALQ/USP, 1996

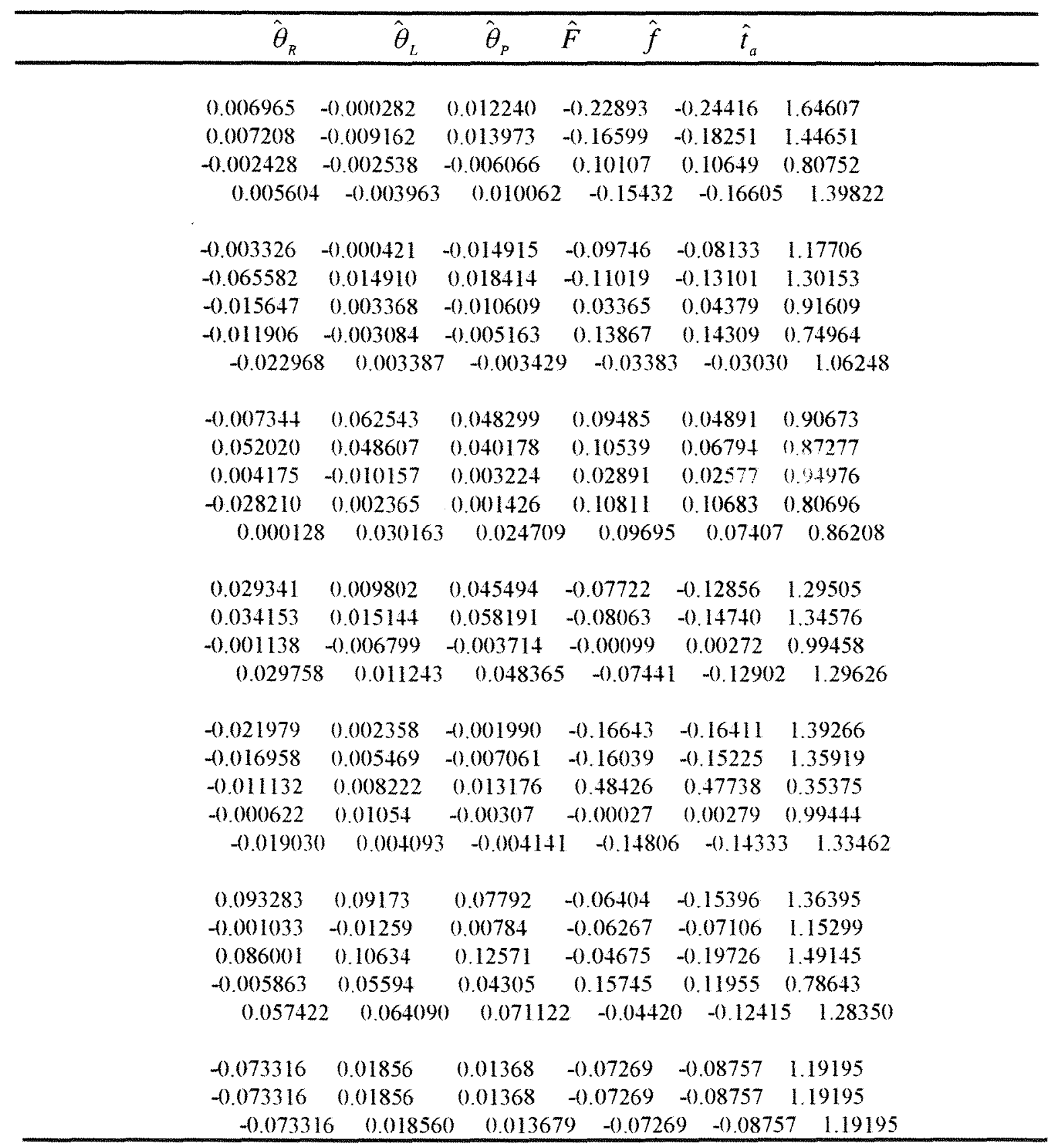

$\begin{array}{lllllll}\text { media loco } & -.0020684 & 0.021602 & 0.022416 & -0.052027 & -0.076150 & 1.16485\end{array}$ $\begin{array}{llllllll}\text { media alelo } & .0021702 & 0.023009 & 0.023321 & -0.046143 & -0.071123 & 1.15314\end{array}$ 
Anexo VI.1. Aderência aos equilíbrio de panmixia em sete locos alozímicos para progênies de sete populações naturais de Euterpe edulis. Piracicaba-SP, ESALQ/USP, 1996

\begin{tabular}{|c|c|c|c|c|c|c|c|}
\hline Populações & locos & GLhw & $y^{2} h w$ & Phw & GLp* & $x^{2} \mathrm{p}^{*}$ & $\mathrm{Pp}^{*}$ \\
\hline \multirow[t]{8}{*}{$\mathrm{SC}+50$} & PRX2 & 3 & 6.698 & $10-5$ & 1 & 6,260 & $<5$ \\
\hline & PRX3 & 6 & 6,392 & $50-25$ & 1 & 3.224 & $10-5$ \\
\hline & PRX4 & 3 & $4 \quad 17,413$ & $<1$ & 1 & 10,559 & $<1$ \\
\hline & PRX5 & 1 & $\quad 0.081$ & $>95$ & 1 & 0.081 & $90-75$ \\
\hline & PGI2 & 1 & 1.870 & $25-10$ & 1 & 1.869 & $25-10$ \\
\hline & PGM1 & 3 & 1,334 & $50-25$ & 1 & 0,899 & $50-25$ \\
\hline & G6Pl & 1 & 0.174 & $75-50$ & & & \\
\hline & & 18 & 33,96 & $<5$ & 6 & 22.89 & $<1$ \\
\hline \multirow[t]{8}{*}{ SC550 } & PRX2 & 3 & 35,395 & $<1$ & 1 & 0,007 & $95-90$ \\
\hline & PRX3 & 6 & 16,951 & $<1$ & 1 & 14,547 & $<1$ \\
\hline & PRX4 & 6 & 19,256 & $<1$ & 1 & 3,435 & $10-5$ \\
\hline & PRX5 & 1 & 0,008 & $>95$ & & & \\
\hline & PGI2 & 1 & 0.002 & $>95$ & & & \\
\hline & PGM1 & 6 & 61,219 & $<1$ & 1 & 1,495 & $25-10$ \\
\hline & G6Pl & 1 & 0,139 & $75-50$ & & & \\
\hline & & 24 & 132.97 & $<1$ & 4 & 19.48 & $<1$ \\
\hline \multirow[t]{8}{*}{ SC650 } & PRX2 & 1 & 0,022 & $>95$ & 1 & 0,042 & $90-75$ \\
\hline & PRX3 & 3 & 18,824 & $<1$ & 1 & 0,085 & $90-75$ \\
\hline & PRX4 & 6 & 27,633 & $<1$ & 1 & 9,853 & $<1$ \\
\hline & PRX5 & 1 & 0.020 & $>95$ & 1 & 0.011 & $95-90$ \\
\hline & PGI2 & 1 & 3,196 & $10-5$ & 1 & 3,198 & $10-5$ \\
\hline & PGMl & 6 & 47,945 & $<1$ & 1 & 17,776 & $<1$ \\
\hline & G6P1 & 1 & 0,018 & $>95$ & 1 & 0,017 & $90-75$ \\
\hline & & 19 & 97.66 & $<1$ & 7 & 30.98 & $<1$ \\
\hline \multirow{8}{*}{$\begin{array}{l}\text { Santa Catarina } \\
\text { (Blumenau - } \\
\text { altitudes) }\end{array}$} & PRX2 & 3 & 29,192 & $<1$ & 1 & 0,918 & $50-25$ \\
\hline & PRX3 & 6 & 34,269 & $<1$ & 1 & 11.040 & $<1$ \\
\hline & PRX4 & 3 & 69.047 & $<1$ & 1 & 29,367 & $<1$ \\
\hline & PRX5 & 1 & 0.125 & $75-50$ & l & 0.369 & $75-50$ \\
\hline & PGI2 & 1 & 3,594 & $10-5$ & 1 & 3.771 & $10-5$ \\
\hline & PGMI & 10 & 116.82 & $<1$ & 1 & 17,959 & $<1$ \\
\hline & G6P1 & 1 & 0,022 & $>95$ & 1 & 0.990 & $50-25$ \\
\hline & & 25 & 253.07 & $<1$ & 6 & 64.305 & $<1$ \\
\hline \multirow[t]{8}{*}{ SPS100 } & PRX2 & 3 & 6.037 & $10-5$ & 1 & 0,026 & $90-75$ \\
\hline & PRX3 & 6 & 15,031 & $<5$ & 1 & 1,399 & $25-10$ \\
\hline & PRX4 & 3 & 28,358 & $<1$ & 1 & 14,780 & $<1$ \\
\hline & PRX5 & 1 & 0,973 & $50-25$ & & & \\
\hline & PGI2 & 1 & 0,069 & $90-75$ & 1 & 0,070 & $90-75$ \\
\hline & PGMI & 3 & 5,045 & $25-10$ & 1 & 0,017 & $90-75$ \\
\hline & G6Pl & 1 & 0,603 & $75-50$ & 1 & 0,616 & $50-25$ \\
\hline & & 18 & 56.12 & $<1$ & 6 & 16.91 & $<1$ \\
\hline
\end{tabular}


Anexo VI.1. (continuação)

\begin{tabular}{|c|c|c|c|c|c|c|c|}
\hline \multirow[t]{8}{*}{ SPS250 } & PRX2 & 1 & 3.789 & $10-5$ & I & 3.786 & $10-5$ \\
\hline & PRX3 & 6 & 26,078 & $<1$ & 1 & 2,162 & $25-10$ \\
\hline & PRX4 & 3 & 7.580 & $<5$ & 1 & 2.824 & $10-5$ \\
\hline & PRX5 & 1 & 2,018 & $25-10$ & & & \\
\hline & PGI2 & 3 & 3,177 & $50-25$ & I & 0.000 & $>99$ \\
\hline & PGM1 & 3 & 39.583 & $0<1$ & 1 & 23.183 & $<1$ \\
\hline & G6P1 & 1 & 0,493 & $50-25$ & 1 & 0.490 & $50-25$ \\
\hline & & 18 & 82.72 & $<1$ & 6 & 32.45 & $<1$ \\
\hline \multirow[t]{8}{*}{ SPS350 } & $\mathrm{PRX} 2$ & 3 & 24,851 & $<1$ & 1 & 2,482 & $25-10$ \\
\hline & PRX3 & 6 & 39,073 & $<1$ & 1 & 2,508 & $25-10$ \\
\hline & PRX4 & 6 & 62,191 & $<1$ & 1 & 35,575 & $<1$ \\
\hline & PRX5 & 1 & 0,679 & $50-25$ & 1 & 0,713 & $50-25$ \\
\hline & PGI2 & 3 & 0,437 & $95-90$ & 1 & 0.007 & $95-90$ \\
\hline & PGM1 & 3 & 42,822 & $<1$ & 1 & 36,992 & $<1$ \\
\hline & G6P1 & 1 & 0,147 & $75-50$ & 1 & 0.103 & $75-50$ \\
\hline & & 23 & 170.20 & $<1$ & 7 & 78.38 & $<1$ \\
\hline \multirow{8}{*}{$\begin{array}{l}\text { Saibadela } \\
\text { ( } 3 \text { altitudes) }\end{array}$} & $\mathrm{PRX} 2$ & 3 & 34,689 & $<1$ & 1 & 0.004 & $>95$ \\
\hline & PRX3 & 6 & 63,110 & $<\mathrm{l}$ & 1 & 0,000 & $>99$ \\
\hline & PRX4 & 6 & 71,554 & $<1$ & 1 & 47,532 & $<1$ \\
\hline & PRX 5 & 1 & 3,064 & $10-5$ & I & 3.975 & $<5$ \\
\hline & PGI2 & 2 & 2,343 & $50-25$ & 1 & 1.133 & $50-25$ \\
\hline & PGMI & 5 & 112,47 & $<1$ & 1 & 33.055 & $<\mathrm{I}$ \\
\hline & G6Pl & 1 & 2,491 & $25-10$ & 1 & 3,432 & $10-5$ \\
\hline & & 24 & 289.72 & $<1$ & 7 & 89.131 & $<1$ \\
\hline \multirow[t]{8}{*}{ SPL700 } & PRX2 & I & 5,435 & $<5$ & 1 & 5.437 & $<5$ \\
\hline & PRX3 & 6 & 50,472 & $<1$ & 1 & 40.030 & $<1$ \\
\hline & PRX4 & 3 & 3,091 & $50-25$ & 1 & 0,303 & $75-50$ \\
\hline & PRX5 & 1 & 0,270 & $75-50$ & 1 & 0,248 & $75-50$ \\
\hline & PGI2 & 1 & 0.137 & $75-50$ & 1 & 0.137 & $75-50$ \\
\hline & PGMI & 6 & 74,552 & $<1$ & 1 & 45.180 & $<1$ \\
\hline & G6P1 & 1 & 0.278 & $74-50$ & 1 & 0.250 & $75-50$ \\
\hline & & 19 & 134.23 & $<1$ & 7 & 91.59 & $<1$ \\
\hline \multirow{8}{*}{$\begin{array}{l}\text { São Paulo } \\
\text { (Saibadela e } \\
\text { Limão) }\end{array}$} & PRX2 & 3 & 74.297 & $<1$ & I & 3.478 & $<5$ \\
\hline & PRX3 & 6 & 72,576 & $<1$ & 1 & 11.640 & $<1$ \\
\hline & PRX4 & 6 & 71,592 & $<1$ & 1 & 42.441 & $<1$ \\
\hline & PRX5 & 1 & 3,895 & $<5$ & 1 & 4.887 & $<5$ \\
\hline & PGI2 & 6 & 2.343 & $25-10$ & 1 & 3,312 & $10-5$ \\
\hline & PGMl & 6 & 212,41 & $<1$ & 1 & 64.293 & $<1$ \\
\hline & G6P1 & 1 & 3,376 & $10-5$ & 1 & 4.389 & $<5$ \\
\hline & & 29 & 440.49 & $<1$ & 7 & 134.440 & $<1$ \\
\hline
\end{tabular}

*agrupando todos os alelos exceto o mais frequiente 
Anexo VI.2. Aderência aos equilibrio de endogamia em sete locos alozímicos para progênies de sete populações naturais de Euterpe edulis. Piracicaba-SP, ESALQ/USP, 1996

\begin{tabular}{|c|c|c|c|c|c|}
\hline População & & loco & $\mathrm{GL}$ & $x^{2}$ & P \\
\hline \multirow{8}{*}{\multicolumn{2}{|c|}{$\mathrm{SC} 450$}} & PRX2 & 2 & 6,856 & $<5$ \\
\hline & & PRX3 & 5 & 6,673 & $25-10$ \\
\hline & & PRX4 & 2 & 16,612 & $<1$ \\
\hline & & PRX5 & & & \\
\hline & & PGI2 & & & \\
\hline & & PGM1 & 2 & 1,294 & $75-50$ \\
\hline & & $\mathrm{G} 6 \mathrm{Pl}$ & & & \\
\hline & & & 11 & 31.434 & $<1$ \\
\hline \multirow{8}{*}{\multicolumn{2}{|c|}{ SC550 }} & PRX2 & 2 & 30,424 & $<1$ \\
\hline & & PRX3 & 5 & 18,839 & $<1$ \\
\hline & & PRX4 & 5 & 18,346 & $<1$ \\
\hline & & PRX5 & & & \\
\hline & & PGI2 & & & \\
\hline & & PGMI & 5 & 56,348 & $<1$ \\
\hline & & G6P1 & & & \\
\hline & & & 17 & 123.957 & $<1$ \\
\hline \multirow{8}{*}{\multicolumn{2}{|c|}{ SC650 }} & PRX2 & & & \\
\hline & & PRX3 & 2 & 22,059 & $<1$ \\
\hline & & PRX4 & 5 & 15,367 & $<1$ \\
\hline & & PRX5 & & & \\
\hline & & PGI2 & & & \\
\hline & & PGMI & 5 & 31,637 & $<1$ \\
\hline & & G6P1 & & & \\
\hline & & & 12 & 69.063 & $<1$ \\
\hline \multirow{8}{*}{$\begin{array}{l}\text { Santa Catarina } \\
\text { (Blumenau } \\
\text { altitudes) }\end{array}$} & & PRX2 & 2 & 20,249 & $<1$ \\
\hline & todas & PRX3 & 5 & 43,909 & $<1$ \\
\hline & & PRX 4 & 2 & 45,765 & $<1$ \\
\hline & & PRX5 & & & \\
\hline & & PGI2 & & & \\
\hline & & PGMI & 9 & 93,834 & $<1$ \\
\hline & & G6Pl & & & \\
\hline & & & 18 & 203.757 & $<1$ \\
\hline \multirow{8}{*}{\multicolumn{2}{|c|}{ SPS100 }} & PRX2 & 2 & 5,183 & $10-5$ \\
\hline & & PRX3 & 5 & 15,955 & $<1$ \\
\hline & & PRX4 & 2 & 28,575 & $<1$ \\
\hline & & PRX5 & & & \\
\hline & & PGI2 & & & \\
\hline & & PGM1 & 2 & 4,609 & 10 \\
\hline & & G6P1 & & & \\
\hline & & & 11 & 54.32 & $<1$ \\
\hline
\end{tabular}


Anexo VI.2. (continuação)

\begin{tabular}{|c|c|c|c|c|c|}
\hline \multirow[t]{8}{*}{ SPS250 } & PRX2 & & & & \\
\hline & PRX3 & 5 & 26,740 & & $<1$ \\
\hline & PRXt & 2 & 3,837 & & $10-5$ \\
\hline & PRX5 & & & & \\
\hline & $\mathrm{PGI} 2$ & 2 & 3,498 & & $10-5$ \\
\hline & PGMI & 2 & 33,596 & & $<1$ \\
\hline & G6Pl & & & & \\
\hline & & 11 & 67.671 & & $<1$ \\
\hline \multirow[t]{8}{*}{ SPS350 } & PRX2 & 2 & 5,825 & $10-5$ & \\
\hline & PRX3 & 5 & 31,964 & $<1$ & \\
\hline & PRX4 & 5 & 33,375 & $<1$ & \\
\hline & PRX5 & & & & \\
\hline & PGI2 & 2 & 6,114 & $<5$ & \\
\hline & PGMI & 2 & 25,181 & $<1$ & \\
\hline & G6PI & & & & \\
\hline & & 16 & 102.459 & $<1$ & \\
\hline \multirow{8}{*}{$\begin{array}{l}\text { Saibadela } \\
\text { (todas as } \\
\text { altitudes) }\end{array}$} & PRX2 & 2 & 17.309 & $<1$ & \\
\hline & PRX3 & 5 & 64,631 & $<1$ & \\
\hline & PRXt & 5 & 52.811 & $<1$ & \\
\hline & PRX5 & & & & \\
\hline & PGI2 & 2 & 5,352 & $<5$ & \\
\hline & PGMI & 5 & 80,365 & $<1$ & \\
\hline & G6Pl & & & & \\
\hline & & 19 & 220,468 & $<1$ & \\
\hline \multirow[t]{8}{*}{ SPL700 } & PRX2 & & & & \\
\hline & PRX3 & 5 & 59,752 & $<1$ & \\
\hline & PRXt & 2 & 6,145 & $<5$ & \\
\hline & PRX5 & & & & \\
\hline & PGI2 & & & & \\
\hline & PGMI & 5 & 60.184 & $<1$ & \\
\hline & $\mathrm{G} 6 \mathrm{Pl}$ & & & & \\
\hline & & 12 & 126.08 & $<1$ & \\
\hline \multirow{8}{*}{$\begin{array}{l}\text { São Paulo } \\
\text { (Saibadela e } \\
\text { Limão) }\end{array}$} & PRX2 & 2 & 28.562 & $<1$ & \\
\hline & PRX3 & 5 & 87,613 & $<1$ & \\
\hline & PRXt & 5 & 59,894 & $<1$ & \\
\hline & PRX5 & & & & \\
\hline & PGI2 & 5 & 9.042 & $25-10$ & \\
\hline & PGM1 & 5 & 156,442 & $<1$ & \\
\hline & G6PI & & & & \\
\hline & & 22 & 341,553 & $<1$ & \\
\hline
\end{tabular}


Anexo VI.3. Aderência aos equilíbrio de panmixia em sete locos alozímicos para indivíduos adultos de oito populações naturais de Euterpe edulis. Piracicaba-SP, ESALQ/USP, 1996

\begin{tabular}{|c|c|c|c|c|c|c|c|}
\hline População & loco & GL & $y^{2}$ & $\mathrm{P}$ & GLp* & $\chi^{2} \mathrm{p}^{*}$ & $\mathrm{Pp} *$ \\
\hline \multirow[t]{8}{*}{$\mathrm{SC} 450$} & PRX2 & 1 & 0.019 & $90-75$ & 1 & 0,015 & $95-90$ \\
\hline & PRX3 & 3 & 0.885 & $90-75$ & 1 & 0.690 & $50-25$ \\
\hline & PRX4 & 1 & 0.371 & $75-50$ & 1 & 0,371 & $75-50$ \\
\hline & PRX5 & & & & & & \\
\hline & PGI2 & 1 & 0.020 & $>95$ & & & \\
\hline & PGM1 & 1 & 0.132 & $75-50$ & 1 & 0,134 & $75-50$ \\
\hline & G6P1 & & & & & & \\
\hline & & 7 & 1.428 & $>95$ & 4 & 1.210 & $90-75$ \\
\hline \multirow[t]{7}{*}{ SC550 } & PRX2 & 1 & 0.071 & $>95$ & 1 & 0,001 & $>99$ \\
\hline & PRX3 & 3 & 7.315 & $10-5$ & 1 & 0.835 & $50-25$ \\
\hline & PRX4 & 3 & 2.702 & $50-25$ & 1 & 0,001 & $>99$ \\
\hline & PRX5 & & & & & & \\
\hline & PGI2 & 1 & 2.337 & $25-10$ & & & \\
\hline & PGMI & 3 & 0.878 & $90-75$ & 1 & 0.111 & $75-50$ \\
\hline & G6P1 & 11 & 13,303 & $50-25$ & 4 & 0.948 & $90-95$ \\
\hline \multirow[t]{7}{*}{ SC650 } & PRX2 & & & & & & \\
\hline & PRX3 & 3 & 0,788 & $90-75$ & 1 & 0.690 & $50-25$ \\
\hline & PRX4 & 3 & 0.299 & $>95$ & 1 & 0,001 & $>99$ \\
\hline & PRX5 & & & & & & \\
\hline & $\mathrm{PGI} 2$ & 1 & 0,231 & $75-50$ & & & \\
\hline & PGM1 & 3 & 2.087 & $75-50$ & 1 & 0,103 & $75-50$ \\
\hline & & 10 & 3.585 & $>95$ & 3 & 0.794 & $90-75$ \\
\hline \multirow{8}{*}{$\begin{array}{l}\text { Santa Catarina } \\
\text { (Blumenau todas as } \\
\text { altitudes) }\end{array}$} & PRX2 & 1 & 0.053 & $90-75$ & 1 & 0,312 & $75-50$ \\
\hline & PRX3 & 3 & 1.687 & $75-50$ & 1 & 0.249 & $75-50$ \\
\hline & PRXt & 3 & 2.213 & $75-50$ & 1 & 0.761 & $50-25$ \\
\hline & PRX5 & & & & 1 & 0.007 & $>95$ \\
\hline & PGI2 & 1 & 2,152 & $25-10$ & & & \\
\hline & PGMI & 3 & 2.796 & $50-25$ & 1 & 0.026 & $95-90$ \\
\hline & $\mathrm{G} 6 \mathrm{Pl}$ & 1 & 0,148 & $75-50$ & & & \\
\hline & & 12 & 9.049 & $75-50$ & 5 & 1.365 & $95-90$ \\
\hline \multirow[t]{8}{*}{ SPS100 } & PRX2 & 1 & 1,172 & $50-25$ & 1 & 1.174 & $50-25$ \\
\hline & PRX3 & 3 & 7.836 & $<5$ & 1 & 8,710 & $<1$ \\
\hline & PRX4 & 3 & 0,498 & $95-90$ & 1 & 0.243 & $75-50$ \\
\hline & PRX5 & & & & & & \\
\hline & PGI2 & 1 & 0,157 & $90-75$ & & & \\
\hline & PGMI & 3 & 6,325 & $10-5$ & I & 0,001 & $>99$ \\
\hline & G6Pl & 1 & 0,453 & $75-50$ & & & \\
\hline & & 11 & 16.462 & $25-10$ & 4 & 10,128 & $<5$ \\
\hline
\end{tabular}


Anexo VI.3. (continuação)

\begin{tabular}{|c|c|c|c|c|c|c|c|}
\hline \multirow[t]{8}{*}{ SPS250 } & PRX2 & 1 & 2.868 & $10-5$ & 1 & 2.861 & $10-5$ \\
\hline & PRX3 & 3 & 2.845 & $25-10$ & 1 & 2.308 & $25-10$ \\
\hline & PRX4 & 3 & 1.308 & $75-50$ & 1 & 0.159 & $75-50$ \\
\hline & PRX5 & & & & & & \\
\hline & PGI2 & 1 & 4.293 & $<5$ & 1 & +.293 & $<5$ \\
\hline & PGMI & 3 & 6.674 & $10-5$ & 1 & 3.022 & $10-5$ \\
\hline & G6Pl & & & & & & \\
\hline & & 11 & 17.989 & $10-5$ & 5 & 12.643 & $<5$ \\
\hline \multirow[t]{8}{*}{ SPS350 } & PRX2 & 1 & 4.986 & $<5$ & 1 & 4,986 & $<5$ \\
\hline & PRX3 & 3 & 4.104 & $25-10$ & 1 & 0.490 & $50-25$ \\
\hline & PRX4 & 3 & 2.873 & $25-10$ & 1 & 2.719 & $10-5$ \\
\hline & PRX5 & 1 & 1,912 & $25-10$ & 1 & 0.001 & $>99$ \\
\hline & PGI2 & 1 & 1.865 & $25-10$ & 1 & 0,788 & $50-25$ \\
\hline & PGMI & 3 & 7.291 & $10-5$ & 1 & 6,938 & $<1$ \\
\hline & G6P1 & & & & & & \\
\hline & & 12 & 23.031 & $<5$ & 6 & 15.922 & $<5$ \\
\hline \multirow{8}{*}{$\begin{array}{l}\text { Saibadela } \\
\text { (todas altitudes) }\end{array}$} & PRX2 & 1 & 10,328 & $<1$ & 1 & 0.312 & $75-50$ \\
\hline & PRX3 & 3 & 8.236 & $<5$ & 1 & 0.249 & $75-50$ \\
\hline & PRX4 & 3 & 1.854 & $75-50$ & 1 & 0.761 & $50-25$ \\
\hline & PRX5 & 1 & 0,211 & $75-50$ & 1 & 0.007 & $>95$ \\
\hline & PGI2 & 3 & 5,009 & $25-10$ & & & \\
\hline & PGMI & 3 & 9.854 & $<5$ & 1 & 0,260 & $95-90$ \\
\hline & G6P1 & 1 & 0.829 & $50-25$ & & & \\
\hline & & 15 & 36.320 & $<1$ & 5 & 1.589 & $95-90$ \\
\hline \multirow[t]{7}{*}{ SPL350 } & PRX2 & 1 & 0,122 & $75-50$ & 1 & 0,780 & $50-25$ \\
\hline & PRX3 & 3 & 2.559 & $50-25$ & 1 & 1,986 & $25-10$ \\
\hline & PRX4 & 3 & 5.617 & $25-10$ & 1 & 4,082 & $<5$ \\
\hline & PRX5 & & & & & & \\
\hline & PGI2 & 1 & 0,563 & $50-25$ & 1 & 0.957 & $50-25$ \\
\hline & PGMI & 3 & 0.451 & $95-90$ & 1 & 0.010 & $95-90$ \\
\hline & GbPl & 11 & 9,313 & $75-50$ & 5 & 7.815 & $25-10$ \\
\hline \multirow[t]{7}{*}{ SPL 700 } & PRX2 & 1 & 4,268 & $<5$ & 1 & 4.250 & $<5$ \\
\hline & PRX3 & 3 & 0,640 & $90-75$ & 1 & 0.247 & $75-50$ \\
\hline & PRX4 & 3 & 2.791 & $50-25$ & 1 & 1.966 & $25-10$ \\
\hline & PRX5 & & & & & & \\
\hline & PGI2 & 1 & 0,018 & $>95$ & 1 & 0,001 & $>96$ \\
\hline & PGMI & 3 & 0,244 & $>95$ & 1 & 0.001 & $>95$ \\
\hline & G6Pl & 11 & 7.960 & $75-50$ & 5 & 6.465 & $50-25$ \\
\hline
\end{tabular}


Anexo VI.3. (continuação)

\begin{tabular}{lllllllll}
\hline Limão & PRX2 & 1 & 3,635 & $10-5$ & 1 & 11,506 & $<1$ \\
(todas altitudes) & PRX3 & 3 & 0,999 & $90-75$ & 1 & 4,669 & $<5$ \\
& PRX4 & 3 & 6,823 & $10-5$ & 1 & 1,511 & $25-10$ \\
& PRX5 & & & & 1 & 0,266 & $90-75$ \\
& PGI2 & 1 & 0,507 & $50-25$ & 1 & 2.827 & $10-5$ \\
& PGM1 & 3 & 0,139 & $>95$ & 1 & 10,263 & $<1$ \\
& G6P1 & & & & & & \\
& & 11 & 12.103 & $50-25$ & 6 & 31.042 & $<1$ \\
\hline São Paulo & PRX2 & 1 & 15,254 & $<1$ & 1 & 16,244 & $<1$ \\
(Saibadela c & PRX3 & 3 & 4,838 & $25-10$ & 1 & 2.036 & $25-10$ \\
Limão) & PRX4 & 3 & 3,246 & $50-25$ & 1 & 1,952 & $25-10$ \\
& PRX5 & 1 & 0,021 & $>95$ & 1 & 0.556 & $50-25$ \\
& PGI2 & 3 & 5,064 & $25-10$ & 1 & 3,075 & $10-5$ \\
& PGM1 & 3 & 7,098 & $10-5$ & 1 & 6,734 & $<1$ \\
& G6P1 & 1 & 0,254 & $75-50$ & & & & \\
& & 15 & 35,745 & $<1$ & 6 & 30.597 & $<1$ \\
\hline
\end{tabular}

*agrupando alelos exceto o mais frequiente 
Anexo VII. 1. Frequências genotípicas para sete locos alozímicos em oito populações naturais de indivíduos adultos de Euterpe edulis. Piracicaba-SP, ESALQ/USP, 1996

\section{LOCOS GENÓTIPOS}

G11 G12 G13 G14 G15 G22 G23 G24 G25 G33 G34 G35 G44 G45 G55

\begin{tabular}{|c|c|c|c|c|c|}
\hline \multirow[b]{2}{*}{ PRX2 } & \multicolumn{5}{|l|}{ População SC450 } \\
\hline & $\begin{array}{lllllllll}94 & 35 & 33 & 0 & 0 & 0 & 0 & 0 & 0\end{array}$ & 0 & 0 & $0 \quad 0$ & 0 \\
\hline PRX3 & $\begin{array}{lllll}62 & 39 & 25 & 22 & 0\end{array}$ & 5 & 0 & 0) 0 & 0 \\
\hline PRX4 & $\begin{array}{lllllllll}12 & 18 & 3 & 9 & 0 & 29 & 3 & 38 & 0\end{array}$ & $0 \quad 10$ & 0 & 380 & 0 \\
\hline PRX5 & 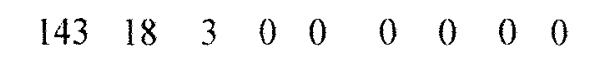 & 00 & 0 & 00 & 0 \\
\hline PGI2 & $\begin{array}{lllllllll}60 & 85 & 0 & 0 & 0 & 15 & 3 & 0 & 0\end{array}$ & 0 & 0 & $\begin{array}{ll}0 & 0\end{array}$ & 0 \\
\hline PGMl & $\begin{array}{lllllll}1 & 12 & 14 & 0 & 0 & 18 & 51\end{array}$ & 54 & 6 & $\begin{array}{ll}0 & 0\end{array}$ & 0 \\
\hline \multirow[t]{2}{*}{ G6P1 } & $\begin{array}{lllllll}139 & 22 & 0 & 0 & 0 & 1 & 0\end{array}$ & 0 & 0 & $\begin{array}{ll}0 & 0 \\
-1\end{array}$ & 0 \\
\hline & \multicolumn{5}{|l|}{$\begin{array}{l}\text { População SC550 } \\
\end{array}$} \\
\hline PRX2 & $\begin{array}{llllllllll}73 & 55 & 16 & 0 & 0 & 5 & 1 & 0 & 0 & 1\end{array}$ & 0 & 0 & $0 \quad 0$ & 0 \\
\hline PRX3 & $\begin{array}{lllllllll}48 & 61 & 19 & 19 & 0 & 1 & 3 & 7 & 0\end{array}$ & 0 & 0 & 10 & 0 \\
\hline $\mathrm{PRX}_{4}$ & $\begin{array}{lllllllll}1 & 3 & 1 & 16 & 0 & 15 & 15 & 23 & 0\end{array}$ & $0 \quad 25$ & 0 & 560 & 0 \\
\hline PRX5 & $\begin{array}{lllllllll}123 & 36 & 0 & 0 & 0 & 2 & 0 & 0 & 0\end{array}$ & $0 \quad 0$ & 0 & 00 & 0 \\
\hline PGI2 & $\begin{array}{lllllllll}60 & 76 & 0 & 0 & 0 & 25 & 0 & 0 & 0\end{array}$ & 0 & 0 & $\begin{array}{ll}0 & 0\end{array}$ & 0 \\
\hline PGMI & $\begin{array}{lllllll}16 & 5 & 12 & 7 & 2 & 13 & 58\end{array}$ & 42 & 1 & 00 & 0 \\
\hline \multirow[t]{2}{*}{ G6P1 } & $\begin{array}{lllllll}136 & 22 & 0 & 0 & 0 & 0 & 0\end{array}$ & 0 & 0 & $\begin{array}{ll}0 & 0\end{array}$ & 0 \\
\hline & \multicolumn{5}{|l|}{ População SC650 } \\
\hline PRX2 & $\begin{array}{lllllllll}132 & 77 & 18 & 0 & 0 & 18 & 1 & 0 & 0\end{array}$ & $0 \quad 0$ & 0 & 00 & 0 \\
\hline PRX3 & $\begin{array}{lllllllll}90 & 63 & 35 & 22 & 0 & 0 & 4 & 12 & 0\end{array}$ & $6 \quad 10$ & 0 & 40 & 0 \\
\hline PRX4 & $\begin{array}{lllllllll}11 & 18 & 1 & 22 & 0 & 40 & 26 & 53 & 0\end{array}$ & $5 \quad 17$ & 0 & $50 \quad 0$ & 0 \\
\hline PRX5 & $\begin{array}{lllllllll}226 & 15 & 7 & 0 & 0 & 0 & 0 & 0 & 0\end{array}$ & 00 & 0 & 000 & 0 \\
\hline PGI2 & $\begin{array}{lllllllll}82 & 132 & 2 & 0 & 0 & 32 & 1 & 0 & 0\end{array}$ & 0 & 0 & 00 & 0 \\
\hline PGMI & $\begin{array}{lllllllll}18 & 15 & 18 & 15 & 1 & 13 & 53 & 4 & 2\end{array}$ & 8211 & 8 & 44 & 0 \\
\hline \multirow[t]{2}{*}{ G6P1 } & $\begin{array}{lllllllll}184 & 56 & 4 & 0 & 0 & 4 & 0 & 0 & 0\end{array}$ & 0 & 0 & $0 \quad 0$ & 0 \\
\hline & \multicolumn{5}{|l|}{$\begin{array}{l}\text { População SPS100 } \\
\end{array}$} \\
\hline PRX2 & $\begin{array}{lllllllll}133 & 34 & 40 & 0 & 0 & 3 & 0 & 0 & 0\end{array}$ & 6 & 0 & $\begin{array}{ll}0 & 0\end{array}$ & 0 \\
\hline PRX3 & $\begin{array}{lllll}62 & 48 & 24 & 44 & 0\end{array}$ & 1. & 0 & 100 & 0 \\
\hline PRX4 & $\begin{array}{lllllllll}3 & 31 & 1 & 36 & 0 & 6 & 3 & 31 & 0\end{array}$ & 7 & 0 & 980 & 0 \\
\hline PRX5 & $\begin{array}{lllllllll}207 & 11 & 0 & 0 & 0 & 0 & 0 & 0 & 0\end{array}$ & 0 & 0 & 00 & 0 \\
\hline PGI2 & $\begin{array}{lllllllll}73 & 93 & 2 & 9 & 0 & 41 & 0 & 0 & 0\end{array}$ & 00 & 0 & 00 & 0 \\
\hline PGMl & $\begin{array}{lllllllll}8 & 14 & 22 & 1 & 0 & 13 & 74 & 3 & 2\end{array}$ & 697 & 0 & 00 & 0 \\
\hline \multirow[t]{2}{*}{ G6P1 } & $\begin{array}{lllllllll}180 & 31 & 2 & 0 & 0 & 0 & 0 & 0 & 0 \\
\end{array}$ & $0 \quad 0$ & 0 & $0 \quad 0$ & 0 \\
\hline & \multicolumn{5}{|c|}{$\begin{array}{l}\text { População SPS250 } \\
\end{array}$} \\
\hline PRX2 & $\begin{array}{lllllllll}208 & 76 & 24 & 0 & 0 & 3 & 0 & 0 & 0\end{array}$ & 1 & 0 & 00 & () \\
\hline PRX3 & $\begin{array}{lllllllll}106 & 75 & 40 & 46 & 0 & 0 & 8 & 15 & 1\end{array}$ & 22 & 0 & 140 & 0 \\
\hline PRX4 & $\begin{array}{lllllllll}19 & 12 & 3 & 65 & 0 & 2 & 5 & 46 & 0\end{array}$ & 114 & 01 & 1450 & 0 \\
\hline PRX5 & $\begin{array}{lllllllll}256 & 56 & 0 & 0 & 0 & 0 & 0 & 0 & 0\end{array}$ & $0 \quad 0$ & 0 & 00 & 0 \\
\hline PGI2 & $\begin{array}{lllllllll}68 & 131 & 0 & 11 & 0 & 75 & 12 & 10 & 0\end{array}$ & $0 \quad 0$ & 00 & 00 & 0 \\
\hline PGMI & $\begin{array}{lllllllll}50 & 55 & 37 & 5 & 0 & 15 & 62 & 0 & 1\end{array}$ & $67 \quad 1$ & $1 \mathrm{l}$ & 10 & 0 \\
\hline G6P1 & $\begin{array}{lllllllll}268 & 34 & 4 & 0 & 0 & 0 & 0 & 0 & 0\end{array}$ & & 0 & & 0 \\
\hline
\end{tabular}




\begin{tabular}{ccccccccccccccccc}
\hline PRX2 & 211 & 84 & 33 & 0 & 0 & 17 & 1 & 0 & 0 & 7 & 0 & 0 & 0 & 0 & 0 \\
PRX3 & 84 & 88 & 27 & 42 & 0 & 16 & 18 & 35 & 1 & 0 & 5 & 0 & 34 & 0 & 0 \\
PRX4 & 15 & 17 & 1 & 32 & 0 & 9 & 14 & 40 & 0 & 5 & 28 & 0 & 191 & 0 & 0 \\
PRX5 & 310 & 42 & 2 & 0 & 0 & 0 & 0 & 0 & 0 & 0 & 0 & 0 & 0 & 0 & 0 \\
PGI2 & 75 & 156 & 2 & 16 & 0 & 87 & 6 & 10 & 0 & 0 & 0 & 0 & 0 & 0 & 0 \\
PGM1 & 72 & 47 & 46 & 14 & 0 & 30 & 75 & 5 & 1 & 49 & 1 & 4 & 0 & 0 & 0 \\
G6P1 & 306 & 25 & 8 & 0 & 0 & 0 & 0 & 0 & 0 & 0 & 0 & 0 & 0 & 0 & 0 \\
\hline PRX2 & 232 & 136 & 17 & 0 & 0 & 41 & 0 & 0 & 0 & 3 & 0 & 0 & 0 & 0 & 0 \\
PRX3 & 124 & 71 & 92 & 106 & 0 & 0 & 4 & 2 & 0 & 10 & 7 & 0 & 13 & 0 & 0 \\
PRX4 & 36 & 53 & 6 & 120 & 0 & 7 & 5 & 64 & 0 & 0 & 24 & 0 & 114 & 0 & 0 \\
PRX5 & 390 & 38 & 2 & 0 & 0 & 0 & 0 & 0 & 0 & 0 & 0 & 0 & 0 & 0 & 0 \\
PGI2 & 175 & 180 & 8 & 11 & 0 & 53 & 0 & 9 & 0 & 0 & 0 & 0 & 0 & 0 & 0 \\
PGM1 & 102 & 54 & 51 & 25 & 1 & 22 & 72 & 7 & 2 & 64 & 3 & 2 & 2 & 0 & 1 \\
G6P1 & 389 & 38 & 2 & 0 & 0 & 0 & 0 & 0 & 0 & 0 & 0 & 0 & 0 & 0 & 0 \\
\hline
\end{tabular}


Anexo VII.2. Frequências genotípicas para sete locos alozímicos em oito populações naturais de indivíduos adultos de Euterpe edulis. Piracicaba-SP, ESALQ/USP, 1996

\begin{tabular}{|c|c|c|c|c|c|c|c|c|c|c|c|}
\hline \multirow[t]{2}{*}{ LOCOS } & \multicolumn{11}{|c|}{ GENOTIPOS } \\
\hline & G11 G12 & $2 \mathrm{G}$ & $13 \mathrm{G}$ & & & & 124 & $\mathrm{G} 33$ & G34 & $\mathrm{G} 4$ & \\
\hline & \multicolumn{11}{|c|}{ População SC450 } \\
\hline PRX2 & 13 & 7 & 1 & 0 & 0 & 0 & 0 & 2 & 0 & & 0 \\
\hline PRX3 & 6 & 7 & 3 & 4 & 1 & 0 & 1 & 0 & 0 & & 1 \\
\hline PRX4 & 2 & 1 & 0 & 3 & 2 & 0 & 6 & 0 & 0 & & 9 \\
\hline PRX5 & 22 & 1 & 0 & 0 & 0 & 0 & 0 & 0 & 0 & & 0 \\
\hline PGI2 & 6 & 12 & 0 & 0 & 5 & 0 & 0 & 0 & 0 & & 0 \\
\hline PGMl & 3 & 2 & 0 & 0 & 4 & 11 & 0 & 3 & 0 & & 0 \\
\hline \multirow[t]{2}{*}{ G6P1 } & 19 & 4 & 0 & 0 & 0 & 0 & 0 & 0 & 0 & & 0 \\
\hline & \multicolumn{11}{|c|}{ População SC550 } \\
\hline PRX2 & 19 & 4 & 3 & 0 & 1 & 0 & 0 & 0 & 0 & & 0 \\
\hline $\mathrm{PRX} 3$ & 11 & 9 & 0 & 1 & 0 & 0 & 3 & 0 & 2 & & 1 \\
\hline PRX4 & 1 & 2 & 0 & 6 & 3 & 1 & 4 & 0 & 3 & & 7 \\
\hline PRX5 & 27 & 0 & 0 & 0 & 0 & 0 & 0 & 0 & 0 & & 0 \\
\hline PGI2 & 6 & 18 & 0 & 0 & 3 & 0 & 0 & 0 & 0 & & 0 \\
\hline PGM1 & 0 & 3 & 8 & 0 & 2 & 7 & 0 & 7 & 0 & & 0 \\
\hline \multirow[t]{2}{*}{ G6P1 } & 23 & 3 & 0 & 0 & 1 & 0 & 0 & 0 & 0 & & 0 \\
\hline & \multicolumn{11}{|c|}{ População SC650 } \\
\hline PRX2 & 14 & 8 & 0 & 0 & 1 & 0 & 0 & 0 & 0 & & 0 \\
\hline PRX3 & 6 & 6 & 2 & 6 & 1 & 1 & 0 & 0 & 0 & & 1 \\
\hline PRX4 & 1 & 2 & 0 & 2 & 3 & 1 & 7 & 0 & 2 & & 5 \\
\hline PRX 5 & 21 & 0 & 1 & 0 & 0 & 0 & 0 & 0 & 0 & & 0 \\
\hline PGI2 & 7 & 13 & 0 & 0 & 3 & 0 & 0 & 0 & 0 & 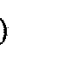 & 0 \\
\hline PGMl & 3 & 2 & 3 & 0 & 0 & 7 & 1 & 7 & 0 & & 0 \\
\hline \multirow[t]{2}{*}{ G6P1 } & 14 & 9 & 0 & 0 & 0 & 0 & 0 & 0 & 0 & 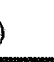 & 0 \\
\hline & \multicolumn{11}{|c|}{ População SPS100 } \\
\hline PRX2 & 14 & 8 & 4 & 0 & 0 & 0 & 0 & 0 & 0 & & 0 \\
\hline PRX3 & 4 & 16 & 3 & 2 & 0 & 0 & 1 & 0 & 0 & & 0 \\
\hline PRX4 & 2 & 3 & 2 & 6 & 0 & 1 & 4 & 0 & 1 & & 7 \\
\hline PRX5 & 26 & 0 & 0 & 0 & 0 & 0 & 0 & 0 & 0 & ) & 0 \\
\hline PGI2 & 9 & 10 & 0 & 0 & 5 & 0 & 0 & 0 & 0 & ) & 0 \\
\hline PGMI & 3 & 2 & 10 & 0 & 2 & 6 & 1 & 0 & 0 & ) & 1 \\
\hline G6P1 & 13 & 9 & 0 & 0 & 0 & 0 & 0 & 0 & 0 & ) & 0 \\
\hline
\end{tabular}




\begin{tabular}{|c|c|c|c|c|c|c|c|c|c|c|}
\hline \multirow[b]{2}{*}{ PRX2 } & \multicolumn{10}{|c|}{ População SPS250 } \\
\hline & 11 & 10 & 5 & 0 & 0 & 0 & 0 & 0 & 0 & 0 \\
\hline PRX3 & 7 & 8 & 3 & 6 & 1 & 0 & 0 & 0 & 0 & 1 \\
\hline PRX4 & 0 & 2 & 0 & 10 & 1 & 0 & 3 & 0 & 1 & 9 \\
\hline PRX5 & 20 & 6 & 0 & 0 & 0 & 0 & 0 & 0 & 0 & 0 \\
\hline PGI2 & 4 & 18 & 1 & 0 & 3 & 0 & 0 & 0 & 0 & 0 \\
\hline PGM1 & 1 & 9 & 6 & 1 & 0 & 3 & 0 & 4 & 0 & 0 \\
\hline \multirow[t]{2}{*}{ G6P1 } & 14 & 9 & 0 & 0 & 0 & 0 & 0 & 0 & 0 & 0 \\
\hline & \multicolumn{10}{|c|}{ População SPS350 } \\
\hline PRX2 & 8 & 13 & 4 & 0 & 0 & 0 & 0 & 0 & 0 & 0 \\
\hline PRX3 & 8 & 8 & 1 & 1 & 0 & 0 & 4 & 0 & 0 & 3 \\
\hline PRX4 & 2 & 3 & 1 & 2 & 1 & 1 & 3 & 0 & 3 & 10 \\
\hline PRX5 & 22 & 2 & 1 & 0 & 0 & 0 & 0 & 0 & 0 & 0 \\
\hline PGI2 & 3 & 15 & 0 & 1 & 5 & 1 & 0 & 1 & 0 & 0 \\
\hline PGM1 & 1 & 9 & 10 & 1 & 2 & 2 & 1 & 0 & 0 & 0 \\
\hline \multirow[t]{2}{*}{ G6P1 } & 18 & 7 & 0 & 0 & 1 & 0 & 0 & 0 & 0 & 0 \\
\hline & \multicolumn{10}{|c|}{ População SPL350 } \\
\hline PRX2 & 7 & 13 & 2 & 0 & 0 & 0 & 0 & 0 & 0 & 0 \\
\hline PRX3 & 8 & 1 & 3 & 8 & 0 & 0 & 0 & 0 & 2 & 0 \\
\hline PRX4 & 3 & 0 & 0 & 12 & 0 & 1 & 3 & 0 & 0 & 3 \\
\hline PRX5 & 21 & 1 & 0 & 0 & 1 & 0 & 0 & 0 & 0 & 0 \\
\hline PGI2 & 8 & 11 & 0 & 0 & 2 & 0 & 1 & 0 & 0 & 0 \\
\hline PGMI & 3 & 2 & 6 & 3 & 2 & 4 & 1 & 1 & 0 & 0 \\
\hline \multirow[t]{2}{*}{ G6P1 } & 20 & 2 & 0 & 0 & 0 & 0 & 0 & 0 & 0 & 0 \\
\hline & \multicolumn{10}{|c|}{ População SPL700 } \\
\hline $\mathrm{PRX} 2$ & 17 & 5 & 3 & 0 & 0 & 0 & 0 & 0 & 0 & 0 \\
\hline PRX3 & 10 & 2 & 2 & 5 & 2 & 0 & 1 & 1 & 0 & 2 \\
\hline PRX4 & 6 & 3 & 0 & 4 & 1 & 2 & 1 & 1 & 1 & 5 \\
\hline PRX5 & 19 & 6 & 0 & 0 & 0 & 0 & 0 & 0 & 0 & 0 \\
\hline PGI2 & 9 & 13 & 0 & 1 & 2 & 0 & 0 & 0 & 0 & 0 \\
\hline PGM1 & 4 & 9 & 0 & 3 & 3 & 2 & 2 & 1 & 0 & 1 \\
\hline G6P1 & 23 & 2 & 0 & 0 & 0 & 0 & 0 & 0 & 0 & 0 \\
\hline
\end{tabular}


Anexo VIII. Aderência ao modelo multilocos em sete locos alozímicos para progênies de sete populações naturais de Euterpe edulis. Piracicaba-SP, ESALQ/USP, 1996

\begin{tabular}{|c|c|c|c|c|}
\hline População & loco & $\mathrm{GL}$ & $y^{2}$ & $\mathrm{P}$ \\
\hline \multirow[t]{8}{*}{$\mathrm{SC} 450$} & PRX2 & 9 & 6,850 & $75-50$ \\
\hline & PRX3 & 9 & 14.617 & $25-10$ \\
\hline & PRXt & 9 & 22,270 & $<1$ \\
\hline & PRX5 & 9 & 1,985 & $>99$ \\
\hline & PGI2 & 9 & 1,713 & $>99$ \\
\hline & PGMI & 9 & 11,379 & $50-25$ \\
\hline & G6P1 & 1 & 3,033 & $10-5$ \\
\hline & & 55 & 61.847 & $<5$ \\
\hline \multirow[t]{8}{*}{$\mathrm{SC} 550$} & PRX2 & 9 & 12,526 & $25-10$ \\
\hline & PRX3 & 9 & 15,852 & $25-10$ \\
\hline & PRX4 & 9 & 8.943 & $50-25$ \\
\hline & PRX5 & 1 & 0,027 & $95-90$ \\
\hline & PGI2 & I & 2,904 & $10-5$ \\
\hline & PGMI & 9 & 9.014 & $50-25$ \\
\hline & G6P1 & 1 & 56,348 & $<1$ \\
\hline & & 30 & 105.614 & $<1$ \\
\hline \multirow[t]{8}{*}{ SC650 } & PRX2 & 9 & 11,976 & $50-25$ \\
\hline & PRX3 & 9 & 20,592 & $<5$ \\
\hline & PRX4 & 9 & 29,310 & $<1$ \\
\hline & PRX5 & 9 & 0,038 & $>99$ \\
\hline & PGI2 & 9 & 4,551 & $90-75$ \\
\hline & PGM1 & 9 & 59,691 & $<1$ \\
\hline & G6P1 & 9 & 2,059 & $>95$ \\
\hline & & 63 & 128.217 & $<1$ \\
\hline \multirow[t]{8}{*}{ SPS100 } & PRX2 & 9 & 10,230 & $50-25$ \\
\hline & PRX3 & 9 & 11,288 & $50-25$ \\
\hline & PRX4 & 9 & $16,00]$ & $10-5$ \\
\hline & PRX5 & 1 & 0.027 & $95-90$ \\
\hline & PGI2 & 9 & 2.387 & $>95$ \\
\hline & PGMI & 9 & 20,591 & $<5$ \\
\hline & G6P1 & 9 & 38,808 & $<1$ \\
\hline & & 55 & 89,332 & $<1$ \\
\hline \multirow[t]{8}{*}{ SPS250 } & PRX2 & 9 & 9.575 & $50-25$ \\
\hline & $\mathrm{PR} \times 3$ & 9 & 23,718 & $<1$ \\
\hline & PRX4 & 9 & 25,765 & $<1$ \\
\hline & PRX5 & 1 & 0,027 & $95-90$ \\
\hline & PGI2 & 9 & 23,333 & $<1$ \\
\hline & PGMI & 9 & 33,382 & $<1$ \\
\hline & G6P1 & 1 & 34,405 & $<1$ \\
\hline & & 42 & 150,205 & $<1$ \\
\hline
\end{tabular}


Anexo VIII. (continuação)

\begin{tabular}{lrrrl}
\hline SPS350 & PRX2 & 9 & 55,600 & $<1$ \\
PRX3 & 9 & 46.803 & $<1$ \\
PRX4 & 9 & 60,810 & $<1$ \\
PRX5 & 9 & 7,989 & $75-50$ \\
PGI2 & 9 & 4,187 & $90-75$ \\
PGM1 & 9 & 55,232 & $<1$ \\
G6P1 & 9 & 22,566 & $<1$ \\
& PRX2 & 9 & 253,187 & $<1$ \\
\hline SPL700 & 9 & 35,827 & $<1$ \\
& PRX3 & 9 & 105,583 & $<1$ \\
& PRX4 & 9 & 15,069 & $10-5$ \\
PRX5 & 9 & 2,838 & $>95$ \\
PGI2 & 9 & 2,208 & $>95$ \\
& PGM1 & 9 & 89,795 & $<1$ \\
G6P1 & 9 & 4,961 & $90-75$ \\
& 63 & 256.281 & $<1$ \\
\hline
\end{tabular}

